\title{
THALES SOUSA
}

\section{Valoração do fornecimento de serviços ancilares a partir de usinas hidroelétricas}

Tese apresentada à Escola Politécnica da Universidade de São Paulo para obtenção do título de Doutor em Engenharia Elétrica. 


\section{THALES SOUSA}

\section{Valoração do fornecimento de serviços ancilares a partir de usinas hidroelétricas}

Tese apresentada à Escola Politécnica da Universidade de São Paulo para obtenção do título de Doutor em Engenharia Elétrica.

Área de Concentração: Sistemas de Potência Orientador: Prof. Titular José Antônio Jardini 
Este exemplar foi revisado e alterado em relação à versão original, sob responsabilidade única do autor e com a anuência de seu orientador.

São Paulo, 09 de outubro de 2006.

Assinatura do autor

Assinatura do orientador

\section{FICHA CATALOGRÁFICA}

\section{Sousa, Thales}

Valoração do fornecimento de serviços ancilares a partir de usinas hidroelétricas / Thales Sousa. -- ed. rev. -- São Paulo, 2006.

$160 p$.

Tese (Doutorado) - Escola Politécnica da Universidade de São Paulo. Departamento de Engenharia de Energia e Automação Elétricas.

1. Reserva girante 2. Serviços ancilares 3 . Sistemas elétricos de potência 4. Suporte de potência reativa I. Universidade de São Paulo. Escola Politécnica. Departamento de Engenharia de Energia e Automação Elétricas II. t. 


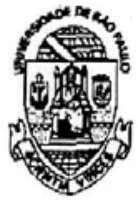

\section{UNIVERSIDADE DE SÃO PAULO}

\section{Relatório de Defesa}

Relatório de defesa pública de Tese do(a) Senhor(a) Thales Sousa no Programa: Engenharia Elétrica, do(a) Escola Politécnica da Universidade de São Paulo.

Aos 18 dias do mês de setembro de 2006, realizou-se a Defesa da Tese do(a) Senhor(a) Thales Sousa, apresentada para a obtenção do título de Doutor em Engenharia Elétrica - Área: Sistemas de Potência, intitulada:

"Valoração do fornecimento de serviços ancilares a partir de usinas hidroelétricas"

Após declarada aberta a sessão, o(a) Sr(a) Presidente passa a palavra aos examinadores para as devidas argüiçōes que se desenvolvem nos termos regimentais. Em seguida, a Comissão Julgadora proclama o resultado:

\begin{tabular}{|c|c|c|c|}
\hline Nome dos Participantes da Banca & Vínculo do Docente & Sigla da Unidade & Resultado \\
\hline Jose Antonio Jardini & Presidente & EP - USP & Aoundo' \\
\hline Dorel Soares Ramos & Titular & EP - USP & Apwindo \\
\hline Carlos Marcio Vieira Tahan & Titular & EP - USP & Apowate \\
\hline Gervasio Luiz de Castro Neto & Titular & SemVínculo - Externo & Agrovedo \\
\hline Hector Arango & Titular & UNIFEI - Externo & Aproved $x$ \\
\hline Resultado Final: & & & \\
\hline \multicolumn{4}{|c|}{ Parecer da Comissão Julgadora * } \\
\hline
\end{tabular}
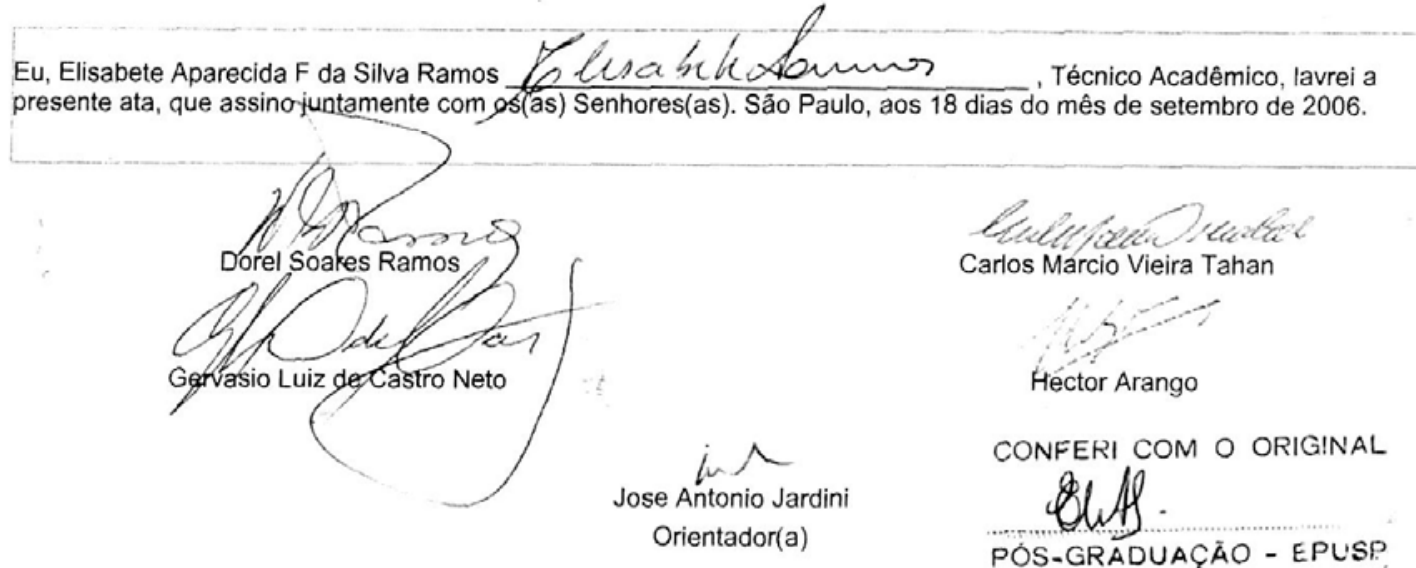

* Obs: Se o candidato for reprovado por algum dos membros, o preenchimento do parecer é obrigatório.

Nos termos do artigo 110, do RG-USP. encaminhe-se o presente relatório à CPG, para homologação. 
Aos meus Pais, responsáveis por todas as minhas conquistas e a minha Esposa, pela cumplicidade em todas as minhas decisões. 
"Seja quente ou seja frio, não seja morno que eu te vomito. É preferivel o erro à omissão. O fracasso, ao tédio. O escândalo, ao vazio. Porque já vi grandes livros e filmes sobre a tristeza, a tragédia, o fracasso. Mas ninguém narra o ócio, a acomodação, o não fazer, o remanso.

Colabore com seu biógrafo. Faça, erre, tente, falhe, lute. Mas, não jogue fora, se acomodando, a extraordinária oportunidade de ter vivido."

Nizan Guanaes 
Ao Prof. José Antônio Jardini pela compreensão, dedicação e paciência desprendida durante a elaboração deste trabalho.

À todos os companheiros do GAGTD pelo apoio e amizade.

Aos meus pais Vicente de Paulo e Geralda, ao meu irmão Júlio e a minha esposa Thaís Helena por todo apoio nos momentos de maiores dificuldades e confiança em todas as minhas ações.

A todos os colegas, professores e funcionários do Departamento de Engenharia de Energia e Automação Elétricas da EPUSP pela colaboração.

À AES Tietê S/A pelo apoio no desenvolvimento deste trabalho. 
LISTA DE FIGURAS.

vii

LISTA DE TABELAS

viii

LISTA DE ABREVEATURAS E SIGLAS.

LISTA DE SÍMBOLOS.

$\mathbf{x}$

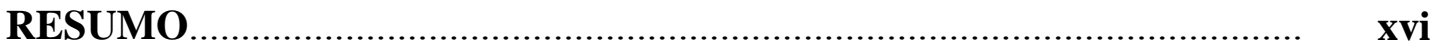

ABSTRACT

xvii

1 - PREÂMBULO.

1.1 - Introdução

1.2 - Objetivo.

1.3 - Organização do Trabalho.

2 - ESTADO DA ARTE.

2.1 - Introdução.

2.1.1 - Reserva de Potência Ativa.

2.1.2 - Reserva de Potência Reativa

2.2 - Custos de Fornecimento de Serviços Ancilares..

2.2.1 - Custos de fornecimento de reserva de potência ativa............................. 11

2.2.2 - Custos de fornecimento de suporte de potência reativa.......................... 14

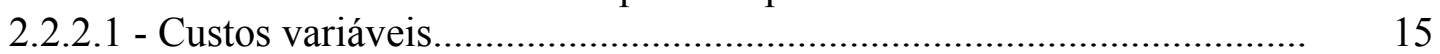

2.2.2.2 - Custos fixos.................................................................................. 19

2.3 - Serviços Ancilares na Austrália.................................................................. 19

2.4 - Serviços Ancilares na Alemanha........................................................... $\quad 20$

2.5 - Serviços Ancilares na Região Nórdica....................................................... 22

2.6 - Serviços Ancilares na Inglaterra............................................................. 24

2.7 - Serviços Ancilares nos Estados Unidos.................................................... 25

2.8 - Serviços Ancilares no Brasil....................................................................... 28

2.8.1 - Histórico ..................................................................................... 29

3 - RESERVA DE POTÊNCIA ATIVA................................................... 36

3.1 - Introdução.................................................................................... 36

3.2 - Função de Geração de Usinas Hidroelétricas............................................ 47

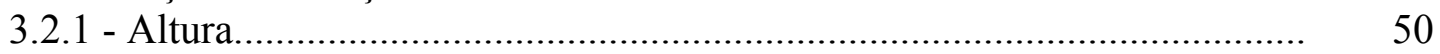

3.2.1.1 - Altura de queda bruta................................................................ $\quad 50$

3.2.1.2 - Altura de perdas hidráulicas.............................................................. $\quad 52$

3.2.1.3 - Altura de queda líquida.................................................................... 53

3.2.2 - Engolimento Máximo........................................................................... 54

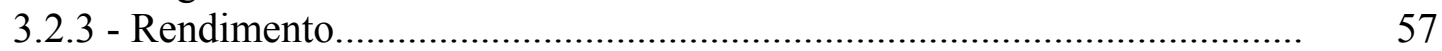

3.3 - O Problema de Despacho Econômico......................................................... 64 


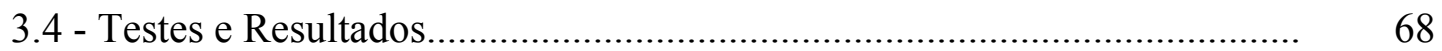

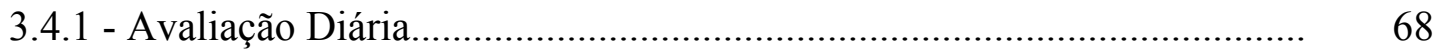

3.4.1.1 - Perdas elétricas................................................................. $\quad 72$

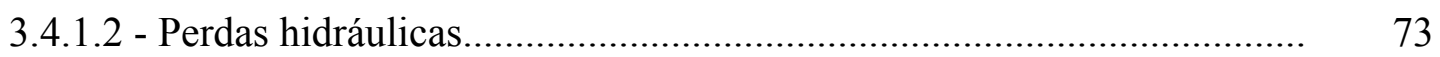

3.4.1.3 - Efeito de afogamento................................................................ $\quad 75$

3.4.2 - Avaliação Anual.......................................................................... $\quad 75$

3.5 - Conclusões Parciais.............................................................................. 80

4 - SUPORTE DE POTÊNCIA REATIVA ............................................. 82

4.1 - Introdução....................................................................................... 82

4.2 - Técnicas para Valoração do Suporte de Potência Reativa........................ 84

4.3 - Teoria de Fluxo de Potência e Fluxo de Potência Ótimo........................... 88

4.3.1 - Fluxo de Potência................................................................................. 8

4.3.2 - Fluxo de Potência Ótimo..................................................................... 92

4.4 - Formulação do Problema de Otimização do Suporte de Potência Reativa 97

4.4.1 - Obtenção da Matriz de Sensibilidade..................................................... 98

4.4.2 - Formulação do Problema de Programação Linear................................... 100

4.4.2.1 - Formulação do problema de Programação Linear para "Solução 103

Super Ótima".

4.4.2.2 - Formulação do problema de Programação Linear para "Solução Sub 104 Ótima".....

4.4.2.3 - Formulação do problema de Programação Linear para "Solução 105

Base"

4.5 - Metodologia Proposta....................................................................... 106

4.6 - Testes e Resultados........................................................................... 109

4.6.1 - Sistema de 8 Barras - Função Objetivo 1.............................................. 109

4.6.2 - Sistema de 30 Barras - Função Objetivo 1.............................................. 114

4.6.3 - Sistema de 53 Barras - Função Objetivo 1............................................. 119

4.7 - Otimização das Perdas Ativas do Sistema - Função Objetivo 2............... 126

4.7.1 - Sistema de 8 Barras - Função Objetivo 2 ............................................... 128

4.7.2 - Sistema de 30 Barras - Função Objetivo 2............................................ 130

4.7.3 - Sistema de 53 Barras - Função Objetivo 2............................................ 133

4.8 - Valoração do Suporte de Potência Reativa Fornecido............................... 137

4.9 - Alocação dos Custos Incrementais às Barras Responsáveis pelo Suporte de Potência Reativa.

4.10 - Função Objetivo..................................................................................... 143

4.11 - Conclusões Parciais................................................................................. 144

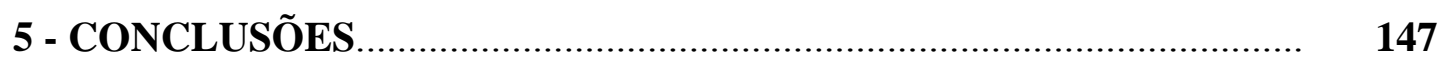

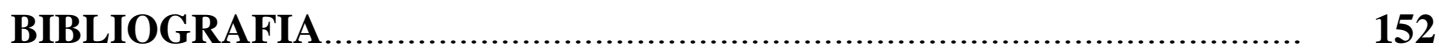

APÊNDICE 1 - Custo de Oportunidade

APÊNDICE 2 - Dados da Usina de Água Vermelha

APÊNDICE 3 - Programação Linear - Método do Simplex

APÊNDICE 4 - Programação Não Linear Aplicada ao Fluxo de Potência Ótimo 
Figura 3.1. Variáveis de uma usina hidroelétrica............................................... 48

Figura 3.2. Curvas de desempenho de uma turbina tipo Francis....................... 60

Figura 3.3. Potência gerada pela turbina para diferentes quedas líquidas........... 62

Figura 3.4. Rendimento da turbina para diferentes quedas líquidas................... 62

Figura 3.5. Rendimentos para diferentes níveis de altura de queda.................... $\quad 69$

Figura 3.6. Curva de Vazão (eixo y) com relação a Potência Ativa gerada (eixo $\mathrm{x})$.

Figura 3.7. Testes considerando que o rendimento das máquinas que operam com uma potência inferior a 90MW é igual ao rendimento das máquinas operando com 90MW.....

Figura 4.1. Fluxograma do problema de otimização do suporte de potência reativa......

Figura 4.2. Convenções de sinais adotados para os testes realizados.

Figura 4.3. Sistema de 8 barras................................................................. 110

Figura 4.4. Sistema AEP-30 barras...................................................... 115

Figura 4.5. Sistema 53 barras.................................................................... 120

Figura 4.6. Fluxograma da metodologia de valoração e alocação dos custos resultantes do suporte de potência reativa........................................................ 138

Figura 4.7. Equivalente utilizado na valoração do suporte de potência reativa... 139

Figura 4.8. Figura representativa das perdas no conjunto gerador/ transformador elevador............................................................................

Figura 4.9. Figura representativa das perdas no conjunto gerador/ Figura A1.1. Custo de oportunidade de uma unidade com preço da potência maior que o custo marginal de operação.

Figura A1.2. Custo de oportunidade de uma unidade com preço da potência menor que o custo marginal de operação. 
Tabela 3.1. Gerações da UHE de Água Vermelha no dia 21/11/2002.....

Tabela 3.2. Alternativa de Gerações da UHE de Água Vermelha para o dia 21/11/2002.

Tabela 3.3. Cálculo do aumento das perdas elétricas pela diminuição do número de máquinas.

Tabela 3.4. Vazões calculadas para a geração referente às $19 \mathrm{hs}$ na Tabela 3.1 e 3.2 .

Tabela 4.1. Dados iniciais do sistema de 8 barras.

Tabela 4.2. Ponto de operação do sistema de 8 barras, resultante do Fluxo de Potência convencional.

Tabela 4.3. Solução do PL para o caso definido por "Solução Base" - sistema de 8 barras - Função Objetivo 1

Tabela 4.4. Estado final resultante do Fluxo de Potência do teste "Solução Base" para o sistema de 8 barras - Função Objetivo 1

Tabela 4.5. Estado final resultante do Fluxo de Potência do teste "Solução Sub Ótima" para o sistema de 8 barras - Função Objetivo 1.

Tabela 4.6. Estado final resultante do fluxo de carga do teste "Solução Super Ótima" para o sistema de 8 barras - Função Objetivo 1 .

Tabela 4.7. Perdas e potência reativa gerada para os casos testados - sistema de 8 barras - Função Objetivo 1

Tabela 4.8. Ponto de operação do sistema de 30 barras, resultante do Fluxo de Potência convencional.

Tabela 4.9. Estado final resultante do Fluxo de Potência do teste "Solução Base" para o sistema de 30 barras - Função Objetivo 1

Tabela 4.10. Estado final resultante do Fluxo de Potência do teste "Solução Sub Ótima" para o sistema de 30 barras - Função Objetivo 1

Tabela 4.11. Estado final resultante do Fluxo de Potência do teste "Solução Super Ótima" para o sistema de 30 barras - Função Objetivo 1.

Tabela 4.12. Perdas e potência reativa gerada para os casos testados - sistema de 30 barras - Função Objetivo 1

Tabela 4.13. Ponto de operação do sistema de 53 barras, resultante do Fluxo de Potência convencional.

Tabela 4.14. Estado final resultante do Fluxo de Potência do caso "Solução Base" para o sistema de 53 barras - Função Objetivo 1 .

Tabela 4.15. Estado final resultante do Fluxo de Potência do caso "Solução Sub Ótima" para o sistema de 53 barras - Função Objetivo 1

Tabela 4.16. Estado final resultante do Fluxo de Potência do caso "Solução Super Ótima" para o sistema de 53 barras - Função Objetivo 1.

Tabela 4.17. Perdas e potência reativa gerada para os casos testados - sistema de 53 barras - Função Objetivo 1

Tabela 4.18. Estado final resultante do Fluxo de Potência do teste "Solução Base" para o sistema de 8 barras - Função Objetivo 2 
Tabela 4.19. Estado final resultante do Fluxo de Potência do teste "Solução Sub Ótima" para o sistema de 8 barras - Função Objetivo 2

Tabela 4.20. Estado final resultante do fluxo de carga do teste "Solução Super Ótima" para o sistema de 8 barras - Função Objetivo 2 ....

Tabela 4.21. Perdas e potência reativa gerada para os casos testados - sistema de 8 barras - Função Objetivo 2

Tabela 4.22. Estado final resultante do Fluxo de Potência do teste "Solução Base" para o sistema de 30 barras - Função Objetivo 2

Tabela 4.23. Estado final resultante do Fluxo de Potência do teste "Solução Sub Ótima" para o sistema de 30 barras - Função Objetivo 2

Tabela 4.24. Estado final resultante do Fluxo de Potência do teste "Solução Super Ótima" para o sistema de 30 barras - Função Objetivo 2.

Tabela 4.25. Perdas e potência reativa gerada para os casos testados - sistema de 30 barras - Função Objetivo 2

Tabela 4.26. Estado final resultante do Fluxo de Potência do caso "Solução Base" para o sistema de 53 barras - Função Objetivo 2.

Tabela 4.27. Estado final resultante do Fluxo de Potência do caso "Solução Sub Ótima" para o sistema de 53 barras - Função Objetivo 2

Tabela 4.28. Estado final resultante do Fluxo de Potência do caso "Solução Super Ótima" para o sistema de 53 barras - Função Objetivo 2.

Tabela 4.29. Perdas e potência reativa gerada para os casos testados - sistema de 53 barras - Função Objetivo 2

Tabela 4.30. Valores das perdas ativas no conjunto gerador/transformador elevador.

Tabela 4.31. Valores de $G_{R}$ calculados a partir da Equação 4.29

Tabela A2.1. Vazão (Q) em relação a altura de queda $(\mathrm{H})$ e a Potência gerada (P).

Tabela A2.2. Q/P em relação a Potência gerada $(\mathrm{P})$.

Tabela A2.3. Medições realizadas no dia 20/11/2002 na UHE de Água Vermelha.

Tabela A2.4. Medições realizadas no dia 21/11/2002 na UHE de Água Vermelha. 


\section{LISTA DE ABREVIATURAS E SIGLAS}

CAISO - California Independent System Operator

ANEEL - Agência Nacional de Energia Elétrica

ONS - Operador Nacional do Sistema

CIGRÉ - International Council on Large Electric Systems

CAG - Controle Automático de geração

NEM - National Electric Market

NEMMCO - National Electricity Market Management Company

NECA - National Electricity Code Administrator

NETA - New Electricity Trading Arrangements

DGV - German Interconnection Society

ISO - Independent System Operator

NGC - National Grid Company

ASB - Ancillary Services Business

FERC - Federal Energy Regulatory Commission

RTO - Regional Transmission Organizations

NE-ISO - New England Independent System Operator

NYISO - New York Independent System Operator

PJM - Pennsylvania-New Jersey-Maryland Interconnect

ERCOT - Electric Reliability Council of Texas

SIN - Sistema Interligado Nacional

MAE - Mercado Atacadista de Energia

ASMAE - Administradora de Serviços do Mercado Atacadista de Energia

ASA - Acordo de Serviço Ancilar

EES - Encargos de Serviços do Sistema

TSA - Tarifa de Serviços Ancilares

CPSA - Contrato de Prestação de Serviços Ancilares

SA - Serviços Ancilares

GSRSR - Generating System Response State Risk 
EPRI - Electric Power Research Institute

MRE - Mecanismo de Realocação de Energia

IEEE - Institute of Electrical and Electronics Engineers

UHE - Usina Hidroelétrica

SIPOT - Sistema de Informações do Potencial Hidrelétrico Brasileiro

EC - Efeito Cota

EA - Efeito de Afogamento

PLD - Preço de Liquidação de Diferenças

FPO - Fluxo de Potência Ótimo

LINDO - Linear Interactive Discrete Optimizer

PLS - Programação Linear Sucessiva

MPI - Métodos de Pontos Interiores

PDBL - Primal-Dual Barreira Logarítmica

PL - Programação Linear

FP - Fluxo de Potência

NB - Número de Barras do Sistema Elétrico

NBC - Número de Barras de Carga

NBCG - Número de Barras de Carga e Geração

NL - Número de Linhas

NG - Número de Geradores

NBCR - Número de Barras de Controle de Reativo

NBCCR - Número de Barras de Carga e de Controle de Reativos

UG - Unidade Geradora

Min - Minimizar

s.a. - Sujeito a

p.u. - por unidade 
$\mathrm{Hz}$ - hertz

MW - mega watts

MVA - mega volts ampere

$\mathrm{VAr}$ - volt ampere reativo

MVAr - mega volt ampere reativo

MVArh - mega volt ampere reativo hora

MWh - mega watts hora

$\mathrm{kWh}$ - quilo watts hora

$\mathrm{kV}$ - quilo volt

$\mathrm{m}^{3} / \mathrm{s}$ - metros cúbicos por segundo

$\mathrm{hm}^{3}$ - hecto metros cúbicos

$\mathrm{kg} / \mathrm{m}^{3}$ - quilogramas por metro cúbico

m - metros

$\mathrm{kg}$ - quilogramas

$\mathrm{m}^{2} / \mathrm{s}$ - metros quadrados por segundo

$\%$ - porcentagem

$\mathrm{N}^{\mathrm{o}}$ - número

$\mathrm{R} \$$ - reais

US\$ - dólares

$\mathrm{ZnO}$ - Zinco

$v$ - vazão vertida

$q$ - vazão turbinada

$u$ - vazão defluente

$x_{m o r}$ - volume morto do reservatório

$x_{\min }$ - volume mínimo operativo

$x_{\text {máx }}$ - volume máximo operativo

$x_{\text {máx,max }}$ - volume máximo maximorum

$x_{\text {seg }}$ - volume de segurança 
$e_{e}$ - energia elétrica

$e_{p}$ - energia potencial

$m$ - massa do volume de água $x$

$g$ - aceleração da gravidade

$h$ - altura de queda

$\rho$ - massa específica da água

$\eta$ - rendimento

$\Delta t$ - intervalo de tempo

$p$ - potência instantânea

$q_{\text {máx }}$ - vazão turbinada máxima

$h_{b}$ - altura de queda bruta

$h_{p}$ - altura de perdas hidráulicas

$h_{l}$ - altura de queda líquida

$u$ - vazão defluente total da usina

$c f_{\text {med }}$ - cota média do canal de fuga

$h_{j u s}(u)$ - função do nível jusante

$h_{m o n}(x)$ - função do nível montante

$q_{\text {máx }}$ - engolimento máximo

$n_{c o n j}$ - número de conjunto de máquinas

$n_{\text {máq }}$ - número de máquinas

$q_{\text {máx,máq }}$ - engolimento máximo de uma máquina

$p_{e f, m a ́ q}$ - potência efetiva ou potência nominal

pe - produtibilidade específica

$P_{i}$ - potência da máquina $i$

$P_{T}$ - potência total

$N$ - número de máquinas total

$\phi$ - função de restrição

$F$ - função objetivo

$\lambda$ - multiplicador de Lagrange

$L$ - função de Lagrange

$\mathrm{V}$ - vetor das magnitudes das tensões

$\theta$ - vetor dos ângulos das tensões 
G - condutância de linha na matriz Y barra

B - susceptância de linha na matriz Y barra

$\mathrm{P}$ - potência ativa

$\mathrm{Q}$ - potência reativa

$\mathrm{k}, \mathrm{m}$ - barras terminais de linha

$\mathrm{P}^{\mathrm{esp}}$ - potência ativa especificada

$\mathrm{Q}^{\text {esp }}$ - potência reativa especificada

$\mathrm{g}(\mathrm{x})$ - restrições de igualdade

$\mathrm{x}$ - variáveis de estado ou variáveis de dependentes

$\Delta$ - correção das variáveis;

$\mathrm{J}$ - Matriz Jacobiana

H, M, N, L - Blocos da Matriz Jacobiana

$\mathrm{g}_{\mathrm{x}}$ - matriz Jacobiana com relação ao vetor $\mathrm{x}$;

$\mathrm{g}_{\mathrm{u}}$ - matriz Jacobiana com relação ao vetor $\mathrm{u}$;

La - Matriz Lagrangiana

$\Delta \mathrm{V}$ - variação de magnitude de tensão;

$h(x)$ - restrições funcionais

$u$ - variáveis de controle ou independentes

$\Delta \mathrm{Q}$ - variação de potencia reativa

Barra PQ - Barra de Carga

Barra PV - Barra de Geração

Barra VӨ - Barra de Referência

S - Matriz de Sensibilidade

$F$ - função objetivo a ser minimizada

$Q_{j f}$ - potência reativa final da barra $j$

$Q_{j 0}$ - potência reativa inicial da barra $j$

$m$ - número de barras a serem alocados reativos;

$i$ - número de barras de carga do sistema;

$V_{i}^{\min }$ - limite mínimo da tensão da barra $i$

$V_{i}^{\max }$ - limite máximo da tensão da barra $i$

$V_{i 0}$ - tensão inicial da barra $i$ 
$-Q_{P V, V \vartheta_{\text {super }}}$ - limite mínimo de geração de reativos para as barras $P V$ e $V \theta$

$Q_{P V, V \vartheta \text { super }}$ - limite máximo de geração de reativos para as barras $P V$ e $V \theta$

- $Q_{P Q \text { super }}$ - limite mínimo de potência reativa nas barras $P Q$

$Q_{P Q \text { super }}$ - limite máximo de potência reativa nas barras $P Q$

$\triangle P 1$ - função de perdas do sistema

$\Delta V L^{\min }, \Delta V_{g}^{\min }$ e $\Delta V L^{\max }, \Delta V_{g}^{\max }$ - variação dos limites mínimos e máximos de tensões das barras de carga e de geração

$\Delta Q_{g}{ }^{m i n}, \Delta Q_{c}{ }^{m i n}$ e $\Delta Q_{g}{ }^{\max }, \Delta Q_{c}{ }^{\max } V_{g}{ }^{\max }$ - variação da potência reativa das barras de carga e de geração

$C_{S R}$ - custo incremental do suporte de reativos

$G_{R}(i)$ - grau de participação da barra de carga " $i$ "

$\mathrm{P}^{\mathrm{G}}$ - potência ativa gerada

$\mathrm{P}^{\mathrm{C}}$ - potência ativa consumida

$P_{i}$ - potência ativa no nó $i$

$Q^{\mathrm{G}}$ - potência reativa gerada

$Q^{C}$ - potência reativa consumida

$\mathrm{Q}_{\mathrm{j}}$ - potência reativa no nó $\mathrm{j}$

$\mathrm{s}$ - vetor das variáveis de folga ou excesso

$\lambda$ - multiplicadores de Lagrange para as restrições de igualdade

$\pi$ - multiplicadores de Lagrange para as restrições de desigualdade

$\nabla \mathrm{L}$ - gradiente da função

$f(x)$ - função objetivo

I - matriz identidade

$\alpha_{p}$ - passo primal

$\alpha_{d}$ - passo dual

$\mu$ - parâmetro de barreira;

$\beta$ - parâmetro utilizado na atualização de $\mu$; 


\section{RESUMO}

SOUSA, T. (2006). Valoração do Fornecimento de Serviços Ancilares a partir de Usinas Hidroelétricas, 2006. 160p. Tese (Doutorado) - Escola Politécnica, Universidade de São Paulo.

O presente trabalho propõe o desenvolvimento de uma metodologia de valoração da reserva de potência ativa e do suporte de potência reativa a partir de plantas hidroelétricas. Inicialmente foi apresentado um histórico que descreveu o que foi definido e regulamentado sobre estes serviços em diferentes mercados de energia. Em seguida, com o objetivo de valorar o serviço de reserva de potência ativa foi realizada a mensuração da perda de eficiência, resultante do fornecimento deste serviço, que após convertida em MWh foi relacionada à perda de oportunidade, caso essa energia fosse comercializada no mercado de energia. Para a valoração do suporte de potência reativa foi utilizada a teoria de Fluxo de Potência Ótimo com objetivo de minimizar as perdas do sistema e relacionar essa minimização à redução do suporte de potência reativa. Em seguida, foi apresentada uma metodologia de valoração e alocação dos custos do suporte de potência reativa entre as barras responsáveis pela necessidade adicional deste suporte. Foram realizados vários testes para validação e verificação das metodologias propostas.

Palavras-chave: Reserva Girante, Serviços Ancilares, Sistemas Elétricos de Potência, Suporte de Potência Reativa. 


\section{ABSTRACT}

SOUSA, T. (2006). Ancillary Services Supply Pricing from Hydroelectric Plants. São Paulo, 2006. 160p. Tese (Doutorado) - Escola Politécnica, Universidade de São Paulo.

The present study proposes valuation methodologies for the spinning reserve and for the reactive power support regarding hydroelectric plants. Initially, a revision describing what was defined and regulated on these services in different energy markets is presented. In order to valuate the spinning reserve service, the measurement of efficiency losses stemming from this service supply was done. Thereafter, the efficiency losses were converted into MWh and related to the opportunity loss, in case this energy was commercialized in the energy market. As for the reactive power support valuation, the Optimal Power Flow was used. The objective was to minimize the system losses and relate such a minimization to the reactive power support. Subsequently, methodologies for the reactive power support costs and for the cost allocation among the responsible buses for additional requirement of this support are also presented. Various tests to validate and verify the above mentioned methodologies were carried out.

Keywords: Ancillary Services, Power Systems, Reactive Power Support, Spinning Reserve. 


\section{Capítulo 1}

\section{Preâmbulo}

\subsection{Introdução}

As mudanças estruturais nas empresas de energia elétrica, decorrentes do processo de desverticalização, resultaram na separação das atividades de geração, transmissão e distribuição de energia elétrica.

Com o processo de desverticalização surge a necessidade de repartição dos custos de operação, de maneira que os agentes envolvidos sejam remunerados adequadamente e que as restrições do sistema sejam atendidas, viabilizando as operações de mercado.

Para que o processo de repartição dos custos ocorra com o máximo de eficiência possível, há a necessidade de definir os diferentes tipos de serviços prestados com o objetivo de conhecê-los, organizá-los por função e definir metodologias para identificação dos envolvidos no fornecimento e recebimento destes serviços.

Definidos os envolvidos no fornecimento e recebimento dos serviços prestados, o próximo passo é definir métodos de remuneração destes serviços, sem que haja subsídios cruzados e sem perder de vista os estímulos necessários à expansão do sistema. 
Uma classe de serviços melhor definida após o processo de reestruturação do setor elétrico é a dos Serviços Ancilares. Os Serviços Ancilares são definidos como os serviços que contribuem para segurança/ confiabilidade e qualidade do suprimento de energia elétrica, tornando-os imprescindíveis à operação eficiente do sistema elétrico em um ambiente de mercado.

Nos países onde o processo de reestruturação do mercado de energia elétrica está mais avançado, a remuneração pela prestação dos diferentes serviços definidos como Serviços Ancilares é bastante discutida. Em alguns mercados de energia, como por exemplo, o CAISO, na Califórnia - Estados Unidos, os Serviços Ancilares são adquiridos de forma independente à aquisição de energia.

No Brasil, os Serviços Ancilares de geração e transmissão foram definidos em 10 de junho de 2003, através da Resolução Nº 265 publicada pela Agência Nacional de Energia Elétrica - ANEEL. Embora tenha ocorrido tal definição, regras para remuneração da prestação destes serviços foram propostas apenas para o Serviço Ancilar prestado pelo gerador quando o mesmo trabalha como compensador síncrono.

Mediante a inexistência de regras oficiais para remuneração da maioria dos Serviços Ancilares definidos para o Sistema Elétrico Nacional, o presente trabalho propõe uma metodologia para valoração de alguns serviços definidos como Ancilares. São eles: o serviço de reserva de potência ativa e o serviço de suporte de potência reativa. 


\subsection{Objetivo}

O objetivo deste trabalho de pesquisa é apresentar uma metodologia para a valoração de Serviços Ancilares, mais especificamente, o serviço de reserva de potência ativa e o suporte de potência reativa. Para o tratamento do serviço de reserva de potência ativa será utilizado o princípio do custo de oportunidade e para do problema de alocação de reativos será utilizado o problema de Fluxo de Potência Ótimo com o objetivo de minimizar a geração de potência reativa a partir das barras de geração.

\subsection{Organização do Trabalho}

Este capítulo apresenta a justificativa, a motivação e o objetivo para o desenvolvimento deste trabalho e sua organização.

O capítulo 2 apresenta o estado da arte, onde serão apresentadas as definições de Serviços Ancilares, as parcelas de custos de provisão destes serviços e algumas formas de tratamentos destes serviços em diferentes mercados de energia elétrica.

O capítulo 3 apresenta a metodologia empregada para a valoração do serviço de reserva de potência ativa.

O capítulo 4 apresenta a metodologia empregada para a valoração do serviço de suporte de potência reativa.

O capítulo 5 apresenta as conclusões referentes à abordagem proposta. 


\subsection{Introdução}

Como descrito no Capítulo 1, os Serviços Ancilares são requeridos para assegurar aos Operadores do Sistema Elétrico (no Brasil, o Operador Nacional do Sistema - ONS) um sistema em estado de operação seguro. Para isso é necessário que o Operador Nacional do Sistema possa:

- Controlar a freqüência do sistema dentro de determinado limite;

- Controlar os níveis de tensão do sistema dentro de seus limites;

- Manter a estabilidade do sistema;

- Prevenir sobrecargas no sistema de transmissão e;

- Restaurar o sistema ou porção deste quando e se requerido.

Implícito a estas responsabilidades está à necessidade do Operador do Sistema manter a integridade do sistema na presença de eventos e distúrbios (contingências). Isso não requer apenas que o serviço seja fornecido, mas que tenha em reserva a capacidade de fornecer um serviço em um curto espaço de tempo. 
A necessidade de cada Serviço Ancilar é determinada pelos Operadores do Sistema, podendo ser ampla e diferir de um país para o outro, em função de suas características operativas, diferentes dimensões topológicas de seus sistemas, etc. Contudo, alguns serviços estão sempre na lista dos Serviços Ancilares.

Uma categoria específica dos Serviços Ancilares é a provisão de reservas. A necessidade por estas reservas surge de várias causas, mas as duas principais são: as interrupções da geração e a variação das cargas. As reservas podem ser separadas em reservas de potência ativa e reservas de potência reativa, CIGRÉ SC 38 (2001).

\subsubsection{Reserva de potência ativa}

Uma arbitrária, mas largamente aceita classificação, organiza os serviços de reservas de potência ativa em três blocos de tempo:

Reserva Rápida: disponibilizadas instantaneamente, podem estabilizar a freqüência do sistema devido à saída de serviço de um conjunto de unidades geradoras. Seu tempo de resposta é de alguns segundos até 5 minutos. Algumas unidades de partida rápida e alguns tipos de programas de gerenciamento da demanda podem, também, ser utilizados para função de reserva rápida.

Reserva Suplementar: essas reservas incidem no tempo entre alguns minutos e meia hora. Essas reservas são necessárias não apenas para estabilizar a freqüência do sistema, mas também tratar de um balanço de energia dentro de uma área de controle. Geralmente são utilizadas por um período de meia, uma hora ou mais e em seguida são substituídas pela Reserva de Reposição; 
Reserva de Reposição: são reservas que podem ficar em serviço por um considerável período de tempo depois que são requisitadas.

A necessidade de regulação, de controle de freqüência e de balanço/estabilidade do sistema estão relacionadas com os serviços de reservas de potência ativa.

Mudanças na freqüência são indicações do desequilíbrio de potência no sistema. Neste caso, a potência necessária para manter o equilíbrio entre geração e consumo será obtida da energia cinética das rotações das máquinas do sistema. Isso irá acelerar ou desacelerar as máquinas e influenciará a variação de freqüência.

Normalmente uma banda de freqüência aceitável para operação normal é definida em 49,9-50,1 Hz para um sistema de $50 \mathrm{~Hz}$ ou $59,9-60,1 \mathrm{~Hz}$ para um sistema de $60 \mathrm{~Hz}$. O objetivo dos operadores é manter a freqüência dentro da faixa especificada 100\% do tempo. Uma larga variação de freqüência, em operações sem distúrbio, pode ocorrer quando:

A potência ativa consumida pela carga difere da esperada. A razão para que isso ocorra pode ser, por exemplo, a mudança das condições climáticas.

Há transferência de geração entre geradores ou quando há erros no controle das capacidades das unidades.

A capacidade de controle primário de freqüência disponível para o sistema de potência não é suficiente para regular adequadamente as variações das cargas.

A regulação de freqüência pode ser dividida em duas diferentes funções, denominadas: 
Controle de freqüência primário: é o controle realizado por meio de reguladores automáticos de velocidade das unidades geradoras, objetivando limitar a variação da freqüência quando da ocorrência de desequilíbrio entre a carga e a geração. Esta ação controla a freqüência até próximo ao seu valor nominal.

Controle de freqüência secundário: é a provisão de reserva de potência ativa efetuada pelas unidades geradoras de forma automática ou manual. O objetivo do controle secundário de freqüência é restabelecer a freqüência ao seu valor nominal complementando a ação de controle primário. Balanço de carga pode também ser dito como parte da regulação de freqüência.

A qualidade da freqüência no sistema de potência é dependente da combinação do controle de freqüência primário e secundário.

O controle de freqüência pode ser obtido pelo Operador do Sistema pelas seguintes fontes:

(a) Controle Automático de Geração (CAG) a partir de unidades geradoras (controle secundário): neste caso os geradores fornecem ao sistema quantidades pré-especificadas, pelo centro de controle, baseado na curva de freqüências e mudam sua saída de acordo com as mudanças de freqüência do sistema dentro de uma faixa de freqüências.

(b) Obtendo a capacidade para exercitar o controle direto da saída de potência de um gerador específico;

(c) Obtendo a capacidade para controlar a demanda. Isto pode incluir o correto desligamento de cargas como parte da variação extrema de freqüência. 
Em princípio, o controle de freqüência pode ser atendido enviando um sinal apropriado aos geradores (e possivelmente às cargas) que devem voluntariamente ajustar suas produções e/ou consumo baseado nestes sinais.

\subsubsection{Reserva de potência reativa}

Outro serviço de interesse contido na maioria das definições de Serviços Ancilares é o controle de tensão nos sistemas de transmissão comumente realizado pelo ajuste de injeção de potência reativa. Fluxos de potência na rede criam aumentos e decréscimos de tensões que são resultantes da interação entre as correntes e a indutância ou capacitância de cada linha ou transformador. Em carga leve, efeitos capacitivos das linhas dominam e as tensões tendem a aumentar (Efeito Ferranti). Em carga pesada, efeitos indutivos dominam e as tensões tendem a diminuir. Assim, as razões pelas quais o controle de tensão é requerido nos sistemas incluem:

A necessidade das tensões estarem sempre dentro de um limite aceitável e projetado para cada componente. Tensões acima ou abaixo destes limites devem ser evitadas.

O fato das tensões afetarem o fluxo de potência reativa na rede. Mudanças nos fluxos de potência reativa têm uma forte influência nas perdas do sistema. Assim, o ajuste de tensão pode ter um significante efeito nas perdas. Em outras palavras, o controle de tensão é um eficiente método de redução das perdas. 
$>$ O fato das tensões e da injeção de potência reativa terem um impacto direto na capacidade de transferência do sistema. Falta de capacidade de distribuição de potência entre regiões pode criar congestionamento. Congestionamento geralmente resulta em preços diferenciados no sistema e restrições de intercâmbios, que por sua vez condicionam a otimização energética. Assim, a potência reativa pode ser uma ferramenta para aumentar a capacidade de transferência e assim aumentar a eficiência do sistema.

Desta forma, a geração ou absorção de potência reativa precisa variar com as condições do sistema. Mudanças rápidas nas condições do sistema podem levar à mudanças nas necessidades de potência reativa e/ou rápidas mudanças nas tensões. As características dinâmicas da potência reativa representam um importante papel no requerimento da mesma, isto porque, ajustes rápidos de fontes de potência reativa tendem a requerer um maior investimento.

Uma importante propriedade da potência reativa é que ela não deve ser transmitida em longas distâncias. Assim, fontes de potência reativa devem ser alocadas ao longo da rede. Os meios pelos quais a potência reativa pode ser obtida no sistema incluem:

Geradores: sua velocidade de resposta é rápida e sua habilidade de suportar tensões sobre condições extremas é muito boa. Os geradores síncronos possuem capacidade de ajustar sua injeção de potência reativa e podem ser especificados para ter uma alta ou baixa capacidade. Geradores com boas capacidades tendem a ser mais caros. A produção de potência reativa a partir de um gerador influencia a produção de potência ativa. 
Compensador Síncrono: estes geradores não produzem potência ativa, apenas potência reativa (capacitiva ou indutiva).

Capacitores: geralmente é a forma mais barata de fornecer potência reativa ao sistema. Contudo, a habilidade para suportar tensão sobre condições extremas de baixa tensão é pequena (a potência reativa cai com o quadrado da tensão). Sua velocidade de resposta é lenta e devem ser chaveados em quantidades discretas. Podem ser usados como compensação paralela ou série.

Reatores Shunt: com efeito oposto aos capacitores, eles são planejados para absorver potência reativa e tentar reduzir a sobretensão na rede.

Compensadores Estáticos: rápidos, porém mais caros. Sobre condições extremas a capacidade de potência reativa cai com o quadrado da tensão.

Fontes Geradoras Distribuídas: estes dispositivos são pequenos geradores, possuindo muito das características dos geradores de maiores dimensões.

Devido o fornecimento de potência reativa ser feito por meio de equipamentos, essa operação tende a ter um alto custo de investimento. Contudo, devido a natureza localizada da potência reativa, há um potencial de mercado de potência que surge dos Serviços Ancilares de potência reativa. Assim, métodos mais elaborados e técnicas para precificar o serviço de potência reativa são requeridos. Reservas de potência reativa são tão importantes quanto reservas de potência ativa.

Outros serviços que contribuem para segurança, confiabilidade e qualidade do suprimento de energia elétrica também podem ser classificados como Serviços Ancilares, como por exemplo, o auto-restabelecimento (black start). 
A seguir serão apresentados os custos envolvidos no fornecimento dos diferentes tipos de Serviços Ancilares.

\subsection{Custos de Fornecimento de Serviços Ancilares}

Uma etapa fundamental na remuneração dos agentes prestadores de Serviços Ancilares está na identificação e quantificação dos custos adicionais impostos pela prestação dos mesmos. A seguir é apresentado o custo de fornecimento de alguns tipos de Serviços Ancilares: reservas de potência ativa e reservas de potência reativa.

\subsubsection{Custos de fornecimento de reserva de potência ativa}

O custo de fornecimento de reservas ativas, incluindo controle de equipamentos, consiste dos seguintes componentes:

- Custos de investimento;

- Custos operacionais para manter a reserva em stand-by;

- Custos operacionais quando o serviço é ativado;

Estes custos são diferentes para sistemas térmicos e hidráulicos. Os custos para ambos os sistemas serão apresentados devido ao interesse em comparar sistemas térmicos e hidráulicos e também porque o fortalecimento da geração térmica no Brasil pode tornar o fornecimento de reserva ativa por parte das térmicas uma ação interessante. 
Os custos de fornecimento de reservas de potência ativa para os sistemas hidráulicos são:

Custos de Investimento: o custo de investimento consiste do custo de capacidade e o custo de controle de equipamentos. O custo de controle de equipamentos é muito pequeno comparado ao custo total de capacidade e o equipamento é usualmente instalado independente de se precisar participar na função de Serviços Ancilares ou não, isto porque muitos dos equipamentos são necessários para iniciar e sincronizar uma unidade. Uma estimativa grosseira indica que os equipamentos necessários para entregar reservas de potência ativa são aproximadamente $2 \%$ do investimento total, não considerando os investimentos de capacidade de potência.

Custos operacionais para manter a função de controle em stand-by: o custo de deter o controle das reservas rápidas no sistema de geração é afetado pelo grau de dependência entre a eficiência da unidade e a potência produzida (saída). Desta maneira há uma diferença em como os sistemas térmicos e os sistemas hidráulicos trabalham. Para unidades hidráulicas, as curvas de eficiência dependem do tipo de turbina, sendo comum ocorrer da máxima eficiência estar abaixo da máxima saída da máquina. Por exemplo, muitas turbinas Francis foram concebidas para ter sua maior eficiência ocorrendo a $80 \%$ da potência máxima de saída. O custo operacional para manter a reserva em stand-by inclui em muitas situações, o custo de funcionários e outros custos operacionais.

Custos operacionais de ativação da reserva: estes custos consistem de custos relacionados à eficiência dos geradores por desvios do nível mais eficiente, e pode incluir os custos de partida provenientes da necessidade de envolver unidades extras. 
O custo relacionado à eficiência pode ser alto. Isto ocorre, pois a queda em eficiência afeta a produção inteira de uma unidade específica e não apenas a produção adicional que é necessária para representar o controle.

A estes custos podem-se incluir os custos de partida quando a reserva não está em prontidão “quente” (reserva girante), que é o caso das reservas de controle secundário. Estes custos são causados por desgaste das turbinas (cavitação) e certa quantidade de água desperdiçada, que significa um componente de custo fixo (cavitação) e um componente de custo variado, isto é, kWh desperdiçado multiplicado pelo preço de mercado de energia, neste trabalho representado pelo Preço de Liquidação de Diferenças (PLD).

Os custos de fornecimento de reservas ativas para os sistemas térmicos estão relacionados à redução da eficiência e ao aumento dos custos de combustíveis. Podem também, ser considerados como custos adicionais, os investimentos extras e o aumento dos desgastes resultantes do aumento de produção.

O custo associado à reserva de controle secundário, a partir de unidades térmicas, pode ser também encontrado pela estimação da curva de carga para períodos diurnos e noturnos escolhidos. A diferença entre o custo acumulado, quando não há restrições de reservas e quando as operações de fornecimento de reserva são realizadas, dará uma estimação de como a reserva de controle secundário pode ser servida por um sistema térmico.

Para o valor do custo do controle secundário em plantas térmicas ou hidráulicas, devem ser consideradas as seguintes questões:

- Eficiência reduzida e aumento dos custos de combustíveis;

- Custos de desgastes como resultado da variação da saída; 
- Investimentos em novos equipamentos de controle;

- Custos de relocalização.

Os custos relativos aos três primeiros itens estão ligados ao controle da própria unidade, enquanto o último está relacionado aos custos que surgem devido às operações de controle.

\subsubsection{Custos de fornecimento de suporte de potência reativa}

Os custos incorridos no suporte de potência reativa serão classificados como: custos explícitos ou diretos, que correspondem aos custos fixos que incluem o custo do capital, da construção, da administração, da manutenção programada e os custos operacionais variáveis; e custos implícitos ou indiretos, que ocorrem somente no caso de um gerador, cujo diagrama de capacidade demonstre que, segundo um valor específico de potência reativa, a máquina teve sua capacidade de produzir potência ativa reduzida, SILVA (1998). Os custos indiretos correspondem à receita de potência ativa que não pôde ser obtida em razão da produção de potência reativa (Custo de Oportunidade).

A seguir serão apresentados os custos variáveis, diretos ou indiretos, e os custos fixos para diferentes componentes com capacidade de fornecer suporte de potência reativa. 


\subsubsection{Custos variáveis}

- Gerador

Geradores térmicos ou hidráulicos, além de gerar potência ativa, devem produzir ou consumir potência reativa, a fim de controlar o perfil da tensão, sob condições normais, assim como durante as contingências. O ideal seria que um gerador produzisse potência ativa segundo um fator de potência específico de forma que sua capacidade produtiva fosse completamente utilizada. No entanto, devido às necessidades do sistema, é possível que um gerador tenha de reduzir sua produção de potência ativa a fim de produzir potência reativa. Nessa situação, o custo da geração de potência reativa pode corresponder à receita de potência ativa que não pode ser obtida.

Portanto, os custos de oportunidade causados pela redução na geração deveriam ser tratados através de procedimentos semelhantes àqueles usados para tratar dos geradores operando com restrição devido à congestionamento no sistema de transmissão.

Os custos diretos associados com a provisão de suporte de potência reativa, quando o gerador está produzindo potência ativa, estão associados com as perdas nos enrolamentos de seu estator, enrolamentos de campo, na excitatriz e no transformador elevador de tensão. Daqui para frente este conjunto de perdas será denominado por perdas totais do grupo. A fim de identificar essas perdas, será importante observar a definição de fator de potência nominal do gerador. 
- Gerador operando como compensador síncrono

Às vezes, os geradores operam como compensadores síncronos e sob essa condição consomem potência ativa do sistema. No sistema brasileiro, esse tipo de operação acontece durante condições de carga mínima, quando há um excesso de potência reativa que deve ser absorvida como uma forma de controlar o perfil de tensão. Além disso, sob essas condições, o gerador permite uma operação mais confiável porque aumenta a inércia do sistema. Isso é muito importante caso o sistema sofra um colapso de tensão ou tenha necessidade de responder às oscilações rápidas desta.

Um gerador operando como compensador síncrono não tem custos de oportunidade porque o sistema está sob carga mínima. Entretanto, o gerador apresenta os seguintes custos explícitos: pelo fornecimento de potência aos motores responsáveis pela eliminação da água do interior do duto forçado da turbina; pela cobertura das perdas totais na unidade geradora.

Geralmente, para operar como compensador síncrono necessita da eliminação da água do duto da turbina. Por isso há necessidade de um sistema de bombeamento com um compressor trabalhando para eliminar a água do duto e então permitir que a turbina opere livremente.

Nas plantas térmicas, a operação como compensador síncrono é pouco comum, porém, possível. Por isso, é necessário que a unidade tenha um sistema de embreagem que permita transferir a unidade do modo do gerador para o modo síncrono e vice-versa. 
- Capacitores e reatores

Os custos variáveis dos capacitores e reatores estão limitados àqueles incorridos pela compensação da perda ativa e pela redução de vida útil resultante das operações de chaveamento. Geralmente, as perdas ativas nos reatores de derivação são inferiores àquelas dos geradores que operam como compensadores síncronos, porém, não são desprezáveis.

A operação de chaveamento dos reatores e dos capacitores pode influenciar não somente o período de vida útil do próprio equipamento, como dos seus disjuntores. Para evitar a redução de vida útil prematura dos reatores e capacitores é prática atual instalar-se um dispositivo de sincronização conectado aos disjuntores. Além disso, para os reatores, é instalado em paralelo um pára-raio de $\mathrm{ZnO}$ para controlar os níveis de tensões durante chaveamento. O dispositivo de sincronização tem a finalidade de abrir e fechar os disjuntores em um instante oportuno visando reduzir as solicitações excessivas. Portanto, existem meios técnicos disponíveis para minimizar a solicitação desse equipamento. Porém, para que isso ocorra, existe um custo fixo associado e um custo variável relativo ao aumento de manutenção.

- Reatores não chaveáveis

O reator não chaveável é útil na energização de uma linha de transmissão e para reduzir a sobretensão na condição de rejeição de carga. Levando-se em conta que esse equipamento está permanentemente ligado à linha de transmissão, deveria ser considerado como pertencente a ela. Assim, suas perdas seriam admitidas como inerentes ao sistema de transmissão. 
- Compensador síncrono

Um compensador síncrono é considerado uma fonte de reserva de potência reativa cuja função principal é controlar o perfil de tensão durante períodos a regime. Durante períodos transitórios, ele é capaz de oferecer potência reativa acima da sua capacidade nominal, ajudando nas oscilações de tensão. Para sua operação é necessária potência ativa para compensar as perdas causadas pela potência reativa que está sendo produzida ou consumida.

Considerando que os compensadores síncronos são fontes de reserva de potência reativa, estes deveriam estar continuamente em operação sendo desconectados apenas para fins de manutenção. Se forem sistematicamente desligados, os custos incorridos pelos procedimentos de partida deverão ser considerados.

- Compensador estático

Semelhante a um compensador síncrono, o compensador estático tem como principal função o controle do perfil de tensão durante períodos transitórios. Dessa forma, deveria ser considerado como uma fonte de reserva de potência reativa. As perdas são dependentes da potência reativa que está sendo produzida ou consumida. Estas perdas são relevantes e deverão ser consideradas como custos variáveis do fornecimento de suporte de potência reativa. 


\subsubsection{Custos fixos}

Refere-se ao custo de aquisição dos equipamentos e de suas instalações. Para geradores e síncronos pode-se aumentar sua capacidade de reativo aumentando o sistema de excitação. Este custo deveria ser remunerado como Serviço Ancilar.

O cálculo do custo da capacidade de potência reativa de um gerador não é comum, podendo ser desenvolvidas propostas baseadas nos custos da geração. Outra possibilidade seria utilizar o conceito do custo evitado, uma vez que ao se gerar potência reativa a partir de uma usina evita-se a instalação de reativos nas cargas, SILVA (1998).

A seguir será apresentada uma revisão bibliográfica que descreve como diversos países têm tratado o assunto de Serviços Ancilares em seus mercados de energia.

\subsection{Serviços Ancilares na Austrália}

Na Austrália existem mercados de energia operando em Queensland, New South Wales e Victoria. Estes mercados são definidos a partir de princípios similares, em que o despacho de geradores é baseado nas propostas de preços dos geradores e a energia é vendida e/ou comprada em um pool. Contudo, há diferenças significantes na estrutura exata e operacional de cada mercado, por exemplo, Serviços Ancilares são tratados diferentemente em cada mercado.

O principal mercado australiano é o Mercado Elétrico Nacional (NEM) que é um mercado de venda por atacado, para o fornecimento e compra de energia, combinado com um regime de livre acesso para o uso de redes de transmissão e distribuição nas jurisdições participantes do território da capital australiana, New South Wales, 
Queensland, South Australia e Victoria. As regras de mercado do NEM e o regime de acesso são definidos no Código Nacional de Energia. A National Electricity Market Management Company - NEMMCO gerencia o mercado de energia no varejo enquanto o National Electricity Code Administrator - NECA supervisiona, administra e faz cumprir o código.

No mercado de energia da Austrália foram definidos os seguintes Serviços Ancilares: o controle do regulador de velocidades. Para este serviço o código nacional de energia requer que todos os geradores acima de 100MW forneçam um nível mínimo de desempenho do regulador de velocidades; o alívio de carga; o carregamento rápido da unidade de geração, entregue quando uma unidade é capaz de iniciar ou mudar do modo de compensador síncrono para o modo de geração automaticamente em resposta a uma condição de aumento de freqüência; o descarregamento rápido da unidade de geração; a reserva de potência reativa; o restabelecimento do sistema, requerido para fornecer fontes de modo a restaurar a operação do sistema após uma interrupção parcial ou total.

Os serviços descritos podem receber pagamentos por disponibilidade, capacidade ou uso do serviço.

\subsection{Serviços Ancilares na Alemanha}

Após a proposta de reforma do setor elétrico alemão em abril de 1996, o interesse pelos Serviços Ancilares na Alemanha aumentou bastante. Nesta ocasião, a associação das nove companhias do setor elétrico interconectado alemão (DGV) intensificou seus trabalhos com o propósito de descrever e quantificar os seguintes 
Serviços Ancilares: controle de freqüência, controle de tensão, capacidade de restabelecimento, despacho, reservas de potência ativa e capacidade de curtocircuito, STASCHUS (1996).

O trabalho da DGV quantificou o investimento necessário e o custo operacional atribuído ao fornecimento dos Serviços Ancilares. Entre os importantes aspectos avaliados estão os custos de investimentos para capacidade extra das unidades de resposta rápida e os custos de novas unidades para o incremento da capacidade de reserva.

STASCHUS (1996) descreveu o nível de participação dos diferentes agentes envolvidos do setor elétrico alemão. O serviço de controle de freqüência e reserva girante seriam fornecidos por agentes geradores e um mercado para este serviço poderia ser desenvolvido tendo como coordenador o Operador do Sistema. O controle de tensão seria fornecido parte pelos agentes geradores e parte por componentes do sistema, como por exemplo, os compensadores estáticos. Um mercado seria esperado para estes tipos de serviço. Os custos associados ao aumento da capacidade de curto-circuito seriam cobertos pelos consumidores que requeressem tais investimentos, não esperando um mercado para este serviço. A capacidade de auto-restabelecimento consistiria parte pelos geradores e parte pelo sistema e processos de planejamento e um mercado para este serviço seria esperado. O serviço de despacho seria fornecido pelo Operador do Sistema. 


\subsection{Serviços Ancilares na Região Nórdica}

A região nórdica é formada pelos sistemas elétricos interconectados da Noruega, da Suécia, da Finlândia e da Dinamarca. Na Noruega 99\% do sistema de geração é hidráulico; na Suécia e Finlândia há uma mistura de térmico, hidráulico e nuclear; e na Dinamarca 95\% do sistema de geração é térmico (5\% eólico).

A reestruturação do sistema elétrico na região nórdica iniciou com a reestruturação do sistema elétrico da Noruega a partir da Lei Energética de junho de 1990 e com o início da operação do mercado em maio de 1992, com a introdução da tarifa ponto a ponto para transmissão. Na Suécia a legislação de desregulamentação iniciou em outubro de 1995 e juntou-se ao mercado norueguês em janeiro de 1996, GJENGEDAL et al. (1998). As principais mudanças nestes países foram a criação do Operador do Sistema, a criação de entidades responsáveis pela transmissão e a criação de um Operador de Mercado, o Nord Pool. A Lei de Mercado de Energia da Finlândia foi implantada em junho de 1995 e introduziu uma gradual abertura da competição do setor energético. Em 1998 o mercado de energia da Finlândia se juntou ao Nord Pool. Na Dinamarca uma nova Lei de Energia foi aprovada em maio de 1999.

Com o objetivo de assegurar um alto nível de segurança e qualidade do sistema, o Operador do Sistema, denominado na Noruega por Statnett, definiu um conjunto de Serviços Ancilares: o controle primário de freqüência; o controle secundário de freqüência; o controle de tensão/reserva de potência reativa; o alívio de carga; e o tripping de geradores. 
A capacidade de geração individual dos sistemas nórdicos, sendo separados em sistema hidráulico na Noruega, sistema hidráulico e térmico na Suécia e Finlândia, assim como puramente térmico na Dinamarca, faz com que os custos envolvidos no fornecimento dos Serviços Ancilares variem de um sistema para outro GJENGEDAL \& KVENNAS (2000). Os custos de fornecimento podem ser divididos em: custos de investimento, custos operacionais (combustível, por exemplo), custos de manutenção, custos de remuneração (remuneração da transmissão, por exemplo) e impostos.

O pagamento pela prestação destes serviços foi inicialmente definido em 1994 através de um contrato padrão. Em 1997 houve a edição de um novo contrato que foi atualizado em 1998, como resultado das novas negociações realizadas entre o Operador do Sistema, Statnett, e os fornecedores de Serviços Ancilares. Neste contrato a compensação pela prestação destes serviços é baseada nos seguintes fatores: capacidade instalada; reserva disponível; e reserva utilizada. No sistema nórdico o pagamento da reserva de potência é igual a 22\% do preço diário do mercado spot, multiplicado pela reserva de potência e pelo período de tempo utilizado. Caso a reserva de potência seja ativada, um pagamento adicional é dado à energia produzida, cujo valor é equivalente ao preço da potência no momento em que a energia é medida. A geração de potência reativa como conseqüência do controle de tensão é paga apenas quando o resultado desta geração produz $0,2<\operatorname{tg} \phi<0,4$. Tanto o serviço de reserva de potência ativa quanto o serviço reserva de potência reativa recebe a compensação pelos investimentos resultantes do fornecimento destes serviços. Os geradores participantes dos esquemas de proteção do sistema elétrico, 
tripping de geradores, recebem pagamento pela prestação destes serviços, GJENGEDAL \& KVENNAS (2000).

\subsection{Serviços Ancilares na Inglaterra}

Na Inglaterra o fornecimento de Serviços Ancilares é controlado por uma empresa licenciada separadamente dentro do National Grid Company - NGC, conhecida como Empresa de Serviços Ancilares (Ancillary Services Business - ASB). Esta empresa foi criada em março de 1990 como parte da nova estrutura do setor elétrico da Inglaterra. A regra básica da ASB é adquirir Serviços Ancilares em uma maneira econômica de modo que a freqüência e a tensão do sistema possam ser mantidas dentro de limites pré-definidos, PETTIGREW (2000).

Na Inglaterra há duas categorias de Serviços Ancilares. São estes: o conjunto de Serviços Ancilares que os geradores são obrigados a oferecer, como, por exemplo, controle de freqüência e a reserva de potência reativa; e o conjunto de serviços considerados comerciais, como por exemplo, a reserva de potência ativa, SALLÉ (1996). São considerados Serviços Ancilares pela ASB: o controle de freqüência, a reserva de potência reativa, a reserva de potência ativa e a capacidade de restabelecimento.

O serviço de controle de freqüência é obtido com base em contratos bilaterais entre a ASB e os fornecedores deste serviço. Este tipo de serviço é dividido entre fornecimento contínuo realizado pelas unidades de geração e o fornecimento ocasional realizado por equipamentos que tem uma rápida resposta a mudanças na freqüência. Em relação ao fornecimento de potência reativa, cada gerador é obrigado 
a oferecê-lo dentro de um limite. Pelo fornecimento deste serviço os geradores recebem um pagamento baseado no MVArh produzido. O serviço de reserva de potência ativa é pago a partir da disponibilidade e utilização. O serviço de restabelecimento é pago com base em contratos bilaterais de longo prazo, STRBAC (2001).

Em 1998, o diretor geral do fornecimento de energia apresentou um conjunto de reformas cujos objetivos foram melhorar a eficiência do mercado de energia e oferecer aos participantes do mercado boas oportunidades mantendo o sistema elétrico seguro e confiável. Estas reformas foram denominadas de NETA (New Electricity Trading Arrangements) e passaram a ter validade a partir de outubro de 2000. Após as mudanças propostas, a obtenção e o pagamento pelos Serviços Ancilares continuaram como eram realizados anteriormente, PETTIGREW (2000).

\subsection{Serviços Ancilares nos Estados Unidos}

A reestruturação do setor elétrico americano separou os serviços de geração, de transmissão, de distribuição de energia e os serviços que garantiam a confiabilidade dos sistemas e que eram fornecidos por empresas integradas verticalmente. Com a necessidade dos Operadores do Sistema manterem a confiabilidade do sistema e a habilidade dos geradores em responder as mudanças de cargas criou um mercado para diferentes serviços do setor. A criação deste mercado foi consolidada a partir das publicações das instruções $N^{0} 888$ e 889 realizadas pela Federal Energy Regulatory Comission (FERC) que capacitaram entidades, com capacidade de 
fornecer os serviços que compõem o sistema elétrico, para competirem pelo fornecimento destes serviços em mercados de energia.

Estes serviços foram separados em energia e Serviços Ancilares. Os Serviços Ancilares foram definidos como serviços necessários para satisfazer a variação de cargas sob intervalos pré-determinados, substituir geradores resultantes de paradas forçadas e satisfazer vários requisitos de forma a manter a operação do sistema dentro de tolerâncias permitidas. Foram definidos na instrução $\mathrm{N}^{0} 888$, seis Serviços Ancilares: serviço de regulação de freqüência; serviço de reserva de potência ativa; serviço de reserva de potência reativa; serviço de despacho e controle de energia. O serviço de capacidade de auto-restabelecimento (black start) é reconhecido como um Serviço Ancilar, mas deverá ser tratado separadamente.

Em 1999, a partir da instrução $\mathrm{N}^{0}$ 2000, foram criadas as organizações de transmissão regional (Regional Transmission Organizations - RTO) com a função de operar os sistemas de transmissão regionais e satisfazer oito funções mínimas, incluindo a provisão de Serviços Ancilares. Nos Estados Unidos as organizações de transmissão regional assumem o papel dos Operadores Independentes do Sistema e controlam cinco diferentes áreas: o New England ISO (NE-ISO), o New York ISO (NYISO) e o Pennsylvania-New Jersey-Maryland Interconnect (PJM) no leste; o ERCOT no Texas; e o California ISO (CAISO) no oeste.

O CAISO adquire os Serviços Ancilares e a energia necessária utilizando diferentes procedimentos. Os serviços de regulação ou reserva rápida, de reserva suplementar e de reserva de reposição são obtidos diariamente, baseados em mecanismos competitivos, SINGH \& PAPALEXOPOULOS (1999). Dois outros vitais Serviços Ancilares, o fornecimento de potência reativa para suporte de tensão e 
a capacidade de geração para o restabelecimento do sistema (black start), são adquiridos por contratos específicos. Para ajustar desequilíbrios entre o valor planejado e o valor real de fornecimento e demanda, o CAISO utiliza o mercado de energia de tempo real.

Os Serviços Ancilares fornecidos pelo mercado PJM são: reserva operativa e reserva de regulação. Desde 2000, o mercado de regulação do PJM tem permitido ofertas baseadas no mercado.

O NE-ISO administra o mercado de energia e os seguintes Serviços Ancilares: reserva girante (10 minutos), controle automático de geração, reserva não-girante, reserva suplementar. No mercado de energia, o participante do mercado pode vender a energia excedente produzida para atender a demanda de seus consumidores e outros participantes. No mercado de Serviços Ancilares, os geradores efetuam ofertas separadas, exceto para a reserva girante (10 minutos). Aos geradores hidráulicos são permitidos oferecer separadamente o serviço de reserva girante (10 minutos), enquanto outros geradores devem ofertá-lo em leilões combinados de energia e de reserva girante (10 minutos).

O NY-ISO opera mercados de dia a frente e mercados em tempo real para energia e Serviços Ancilares. Os Serviços Ancilares definidos no mercado do NYISO são: o serviço de regulação, a reserva girante, a reserva não-girante e a reserva suplementar. A reserva de potência reativa é organizada separadamente pelo NY-ISO e os custos são ressarcidos pelos usuários através de tarifas separadas, SCHULER (2001).

O ERCOT ISO representa um modelo completamente diferente dos outros Operadores Independentes do Sistema ligados ao FERC. O ERCOT opera através de 
contratos bilaterais, ou seja, não há um mercado de Serviços Ancilares ou de energia, exceto para o redespacho necessário para aliviar a sobrecarga na transmissão. Para um gerador participante do ERCOT ISO isso não significa que não há um mercado de Serviços Ancilares. Este mercado está implícito e é baseado em contratos bilaterais entre os agentes que atendem as cargas do sistema. Os geradores que operam como fornecedores de reservas realizam cálculos que determinarão se o valor pago pelo fornecimento de reservas irá compensar a perda da renda proveniente da venda de energia, LCG CONSULTING (2000a, 2000b).

\subsection{Serviços Ancilares no Brasil}

O Setor Elétrico Brasileiro passou por mudanças, tanto em relação à operação dos sistemas interligados, como em relação à comercialização de energia gerada. Neste novo contexto, obteve-se a separação das atividades de geração, transmissão e distribuição, de modo que a aquisição de energia deve envolver o pagamento de um produto, a energia, e o pagamento de um conjunto de serviços de maneira que os agentes envolvidos sejam remunerados adequadamente e os requisitos de operação sejam atendidos, viabilizando as transações de mercado e permitindo ao consumidor dispor de um produto com a qualidade desejada, SOARES et al. (2002).

Neste contexto surgem os Serviços Ancilares, necessários na operação segura e confiável do Sistema Interligado Nacional - SIN. O fornecimento dos Serviços Ancilares é uma questão técnica e econômica a ser considerada em todos os mercados competitivos de energia elétrica. Para garantir o suprimento adequado 
destes serviços, torna-se necessário estabelecer modelos econômicos que incluam remuneração explícita pelos Serviços Ancilares.

\subsubsection{Histórico}

A seguir é apresentado um breve histórico que descreve o que foi definido e regulamentado sobre Serviços Ancilares no SIN.

Em 02 de julho de 1998, foi estabelecido o Decreto $\mathrm{N}^{0} 2.655$ com o objetivo de regulamentar os aspectos relacionados com a reestruturação do setor elétrico brasileiro publicados na Lei $\mathrm{N}^{0}$ 9.648, de 27 de maio de 1998. Neste sentido, o Decreto $N^{0} 2.655$ regulamenta o antigo Mercado Atacadista de Energia Elétrica MAE, define as regras de organização do Operador Nacional do Sistema Elétrico ONS, além de outras providências.

No Decreto $\mathrm{N}^{0} 2.655$ é feita a primeira menção aos Serviços Ancilares na regulamentação do Setor Elétrico Brasileiro, proposta naquela ocasião. Com efeito, no Art. 18 foi estabelecido que as regras do antigo MAE poderiam prever pagamentos para a cobertura dos custos de prestação de Serviços Ancilares.

Analisando o texto do Artigo observa-se que seriam 5, os Serviços Ancilares definidos no mesmo: reserva de capacidade em MW; reserva de capacidade em MVAr; operação dos geradores com compensadores síncronos; regulação de tensão e esquemas de corte de geração e alívio de carga, ABREU \& VILELA (2001).

A segunda menção aos Serviços Ancilares foi feita no Estatuto do Operador Nacional do Sistema Elétrico - ONS. Neste Estatuto, o qual estabelece as atribuições 
do ONS, foi assinalado que cabe a este ente setorial a contratação e a administração dos Serviços Ancilares.

Cabe mencionar que o estatuto do ONS foi aprovado pela Agência Nacional de Energia Elétrica (ANEEL) através da Resolução Nº 307, de 30 de setembro de 1998. Neste sentido, pode ser entendido que o ente regulador atribui ao ONS a contratação e a administração dos Serviços Ancilares. É importante salientar que o Estatuto do ONS não define nenhum Serviço Ancilar e não dá destaque a qualquer um dos serviços anteriormente classificados.

Outra informação oficial sobre os Serviços Ancilares foi editada nas regras que regulamentaram o antigo MAE. No escopo das regras do antigo MAE foram consideradas proposições para modelagem de regras específicas para a comercialização de Serviços Ancilares, apesar de não existir uma formatação acordada entre os grupos técnicos da Administradora de Serviços do MAE ASMAE.

A primeira proposição, no âmbito do MAE, foi divulgada em Julho de 1999. Nesta ocasião foi estabelecida a orientação para o pagamento por Serviços Ancilares. As regras do MAE acrescentaram mais um serviço (capacidade de restauração black start) aos serviços anteriormente relacionados.

Em outubro de 1999, a ASMAE emitiu uma nova proposta, que continha um aprofundamento no tratamento comercial a ser dado aos pagamentos pela prestação de Serviços Ancilares. Nesta nova proposta é adicionada a idéia de um Acordo de Serviço Ancilar (ASA), o qual permitiria a criação de mecanismos para a inclusão dos encargos relacionados à prestação de Serviços Ancilares no Encargo de Serviço do Sistema. 
A quarta e última menção a Serviços Ancilares foi dada nos termos dos Contratos Iniciais, os quais foram idealizados com vistas a transição entre o antigo e o novo modelo, publicado Lei $\mathrm{N}^{0}$ 9.648, de 27 de maio de 1998. Nos termos deste contrato, a questão da remuneração dos Serviços Ancilares é tratada considerando que estes valores já estão inclusos no preço da energia elétrica. A flexibilização desta regra acompanharia o mesmo tratamento dado à energia, ou seja, a liberação dos montantes contratados para livre negociação é escalonada em incrementos de 25\%, começando em 2003 e se encerrando em 2006, ABREU \& VILELA (2001).

Paralelamente aos trabalhos realizados pelos agentes reguladores do Sistema Interligado Nacional (SIN), vários trabalhos foram publicados indicando propostas de classificação e precificação para os Serviços Ancilares.

GOMES et al. (1997) publicaram um trabalho abordando alguns tópicos relacionados ao problema de identificação de custos e atribuição de preços dos Serviços Ancilares à gestão da rede para fornecimento de energia elétrica em regime de prestação de serviços aos consumidores contratados.

ABREU \& VILELA (2001) apresentaram uma proposta de classificação e precificação dos Serviços Ancilares para o setor elétrico brasileiro. Esta proposta considerou duas ações principais: acompanhamento do que estava sendo definido e regulamentado na ocasião e absorção da experiência internacional.

SOARES et al. (2002) relacionaram os serviços que poderiam ser considerados como Serviços Ancilares no SIN, identificando os agentes que poderiam prover tais serviços e a forma de pagamento dos mesmos. Neste trabalho os autores classificaram a prestação dos Serviços Ancilares de forma mandatória, ou seja, provimento que pode ser exigido a todos os agentes, com ou sem remuneração; e 
voluntária, ou seja, a participação do agente só pode ser exigida quando haja consentimento por parte dele. Geralmente, o serviço prestado de forma voluntária é remunerado e submetido a um contrato específico.

Em 10 de junho de 2003, a ANEEL publicou a Resolução N $^{0} 265$ que estabelece os procedimentos para prestação de Serviços Ancilares de geração e transmissão. Para os fins e efeitos da Resolução $\mathrm{N}^{0} 265$ foram estabelecidas as seguintes definições relacionadas com Serviços Ancilares:

I - Controle Primário de Freqüência: é o controle realizado por meio de reguladores automáticos de velocidade das unidades geradoras, objetivando limitar a variação da freqüência quando da ocorrência de desequilíbrio entre a carga e a geração;

II - Controle Secundário de Freqüência: é o controle realizado pelas unidades geradoras participantes do Controle Automático de Geração (CAG), destinado a restabelecer a freqüência do sistema ao seu valor programado e manter e/ou restabelecer os intercâmbios de potência ativa aos valores programados;

III - Reserva de Potência Primária: é a provisão de reserva de potência ativa efetuada pelas unidades geradoras para realizar o controle primário de freqüência;

IV - Reserva de Potência Secundária: é a provisão de reserva de potência ativa efetuada pelas unidades geradoras participantes do CAG, para realizar o controle secundário de freqüência e/ou de intercâmbios líquidos de potência ativa entre áreas de controle;

V - Reserva de Prontidão: é a disponibilidade de unidades geradoras com o objetivo de recompor as reservas de potência primária ou secundária do sistema, em 
caso de indisponibilidade ou redeclaração de geração, se atingido o limite de provisão de reserva de potência ativa do sistema;

VI - Suporte de Reativos: é o fornecimento ou absorção de energia reativa, destinada ao controle de tensão da rede de operação, mantendo-a dentro dos limites de variação estabelecidos nos Procedimentos de Rede e;

VII - Auto-restabelecimento (black start): é a capacidade que tem uma unidade geradora ou usina geradora de sair de uma condição de parada total para uma condição de operação, independentemente de fonte externa para alimentar seus serviços auxiliares para colocar em operação suas unidades geradoras.

Com relação à provisão e ao encargo gerado pela prestação de Serviços Ancilares foi definido:

- O Controle Primário de Freqüência e a Reserva de Potência Primária deverão ser providos por todas as unidades geradoras integrantes do SIN, sem ônus para os demais agentes e consumidores.

- O Controle Secundário de Freqüência e a Reserva de Potência Secundário deverão ser providos por todas as usinas que atualmente participam do CAG, sempre que solicitado pelo Operador Nacional do Sistema Elétrico - ONS, sem ônus para os demais agentes e consumidores.

- A Reserva de Prontidão deverá ser provida por todas as unidades geradoras integrantes do SIN, que não tenham sido despachadas por razões sistêmicas, sempre que solicitado pelo ONS, sem ônus para os demais agentes e consumidores. Enquanto a unidade estiver como reserva de prontidão, o custo do consumo de combustível utilizado neste período, auditado e aprovado pela ANEEL, será ressarcido via Encargos de Serviços do Sistema (EES) e caso, após a sincronização 
ao SIN, a unidade geradora venha a fornecer energia ativa ao sistema, o ressarcimento passa a ser não mais pelo combustível utilizado, mas pelas regras de mercado vigentes.

- O Suporte de Reativos deverá ser provido por todas as unidades geradoras integrantes do SIN, que estejam fornecendo potência ativa, sempre que solicitado pelo ONS, sem ônus para os demais agentes e consumidores. Os casos de unidades geradoras que sejam solicitadas a operar como compensador síncrono, cujo serviço será provido de forma obrigatória e remunerado pela Tarifa de Serviços Ancilares (TSA), a ser estabelecida em resolução específica, visando recuperar os custos adicionais de operação e manutenção, pagos via Encargos de Serviços do Sistema (ESS), devendo ser celebrado Contrato de Prestação de Serviços Ancilares (CPSA) entre o ONS e os agentes.

A ANEEL, pela primeira vez, através da publicação da Resolução Normativa $\mathrm{N}^{0} 133$, de 23 de dezembro de 2004, estabeleceu o valor da Tarifa de Serviços Ancilares em R\$3,32/MVArh (três reais e trinta e dois centavos por megavar-hora), com vigência a partir de $1^{\circ}$ de janeiro de 2005 e atualizado ano a ano, para o pagamento do serviço de suporte de reativos, provido por unidade geradora quando operando na situação de compensador síncrono, de acordo com as ordens de despacho do ONS.

- O Auto-restabelecimento deverá ser provido por todas as unidades geradoras integrantes do SIN, que possuam equipamentos para esta finalidade, sempre que solicitado pelo ONS, sem ônus para os demais agentes e consumidores.

A Resolução $\mathrm{N}^{0} 265$ dispõe que para novas usinas ou usinas atualmente em operação, a ANEEL poderá determinar, respaldada em estudos do ONS, as unidades 
geradoras que tenham possibilidade de operar como compensador síncrono, bem como prover os serviços citados.

Os equipamentos dos concessionários de transmissão destinados ao controle de tensão e de fluxo de potência fazem parte de suas respectivas concessões e serão remunerados pelas mesmas regras e procedimentos aplicados às demais instalações de transmissão.

Os capítulos seguintes irão abordar os Serviços Ancilares de reserva de potência ativa e de suporte de potência reativa. Para estes Serviços Ancilares serão apresentadas metodologias de valoração dos mesmos. 


\subsection{Introdução}

Um aspecto compartilhado por várias estruturas do setor elétrico é a designação de um operador responsável pela operação segura do sistema elétrico. De forma a auxiliar o operador, os Serviços Ancilares são requeridos podendo corresponder em até $25 \%$ do custo da geração e transmissão, segundo uma pesquisa realizada entre as 12 maiores empresas do setor elétrico americano. Dentre os diferentes Serviços Ancilares (SA) definidos, o serviço de fornecimento de reserva de potência ativa é um dos mais importantes, correspondendo à $44 \%$ do custo total de SA, PRADA et al. (2002).

As reservas de potência ativa são necessárias para manter a integridade do sistema de transmissão na presença de eventos e distúrbios e podem ser providas a partir de geradores de retaguarda e/ou a partir da redução da carga.

Os tipos de reservas e suas definições podem variar de sistema para sistema. Os serviços de reservas de potência ativa podem ser classificados em: reserva de potência primária; reserva de potência secundária; e reserva de prontidão. Estes 
serviços são adquiridos geralmente na base de hora em hora em mercados do dia seguinte e mercados de hora seguinte CIGRÉ SC 38 (2001).

O mercado deve prover ao operador um sistema operável sob todas as circunstâncias previstas. Um mercado que não conduza propostas flexíveis de modo a manter o sistema operável é inadequado para operação. Assim um sistema poderá ser forçado a operar fora dos limites e das regras do mercado para manter a integridade do sistema. Um vigoroso mercado para reservas é extremamente importante nesta consideração.

O nível preciso de segurança e disposição que é requerido para atender o operador deve ser estabelecido previamente e de maneira economicamente positiva. As normas e critérios que um operador deverá seguir podem variar de sistema para sistema. As maneiras em que os Serviços Ancilares podem ser obtidos pelos operadores são: pelos proprietários do equipamento necessário para prover o serviço; pela contratação de fornecedores de Serviços Ancilares a partir de contratos de longo prazo, sob condições e termos específicos destes serviços; e pela criação de um mercado para estes serviços, onde as partes interessadas em fornecê-los o façam de forma direta.

Os custos de fornecimento dos Serviços Ancilares dependem das necessidades do sistema e devem ser em geral pagos pelos responsáveis pela necessidade dos serviços. Isto requer ferramentas para determinar os custos de provisão do serviço e ferramentas para alocar o custo entre as várias partes. Uma importante necessidade é a de desenvolver uma ferramenta para a classificação de reservas em uma maneira quantitativa ao invés de qualitativa. 
A seguir serão apresentados os diferentes custos envolvidos no fornecimento de reserva de potência ativa. São eles: o custo de manter a reserva a disposição e o custo pelo uso da reserva.

Os custos de manter a reserva à disposição são os custos de manter reservas mesmo que não sejam utilizadas no momento. Para os geradores o custo de fornecer reserva de potência ativa é diferente para sistemas térmicos e hidráulicos, mas em geral são compostos por: custos de investimento; custos operacionais para manter a reserva em stand-by; e custos operacionais quando o serviço é ativado.

Os custos pelo uso da reserva de potência ativa são os custos não energéticos das reservas usadas ou os custos do desequilíbrio de energia associado com o uso de reservas.

Para reservas fornecidas aos consumidores, os custos dependem do valor de consumo previsto, que varia largamente entre os consumidores. Os custos de reservas fornecidas aos geradores incluem: o combustível usado; os custos variáveis de manutenção e operação; e os custos relacionados à pressão que acompanha as mudanças dos níveis de saída, para o caso de unidades térmicas.

Um outro aspecto importante no fornecimento do serviço de reserva de potência ativa é a determinação de ferramentas para a precificação e a alocação dos custos entre os agentes envolvidos. Muitos trabalhos têm sido publicados com o objetivo de apresentar diferentes metodologias para precificação e alocação dos custos inerentes à prestação do serviço de fornecimento de potência ativa.

BILLINTON et al. (1996) apresentaram um trabalho cujo objetivo é alocar a capacidade de fornecimento de reserva de potência ativa considerando duas diferentes parcelas. A primeira parcela é o despacho ótimo do número de unidades, 
em que o operador decide quais unidades devem ser despachadas de forma a atender a demanda. A segunda parcela é associação das decisões de despacho das unidades e a avaliação da capacidade de resposta das unidades despachadas. Um índice definido como risco de resposta de um sistema de geração (Generating System Response State Risk - GSRSR) é utilizado como critério para o despacho ótimo das unidades disponíveis e assim maximizando a reserva girante do sistema, ou seja, reserva que está sincronizada ao sistema. A metodologia proposta foi aplicada a um sistema de geração térmica.

AGANAGIC et al. (1998) apresentaram um trabalho dedicado às questões de precificação e entrega do serviço de reserva de potência ativa. O trabalho apresentou uma nova formulação do problema de despacho econômico com restrição de segurança de forma a alocar a potência ativa, cuja função objetivo é minimizar os custos aos consumidores, atendendo a demanda de potência e a reserva de potência ativa. Os autores consideraram como restrições do problema: os limites de capacidade dos sistemas de transmissão, a capacidade de geração das unidades e as restrições de balanço de potência. Um exemplo ilustrativo foi usado para introduzir os conceitos e apresentar os resultados.

RAU (1999) utilizou um problema de programação linear inteira mista com o objetivo de solucionar o problema de despacho ótimo. O autor minimiza o custo da energia, da reserva de potência ativa e do controle automático de geração sujeito a um conjunto de restrições. A metodologia apresentada pode ser aplicada tanto para sistemas hidroelétricos como para sistemas termoelétricos.

SCHMITT \& VERSTEGE (2001) apresentaram uma metodologia com o objetivo de auxiliar o operador do sistema a gerenciar o fornecimento de Serviços Ancilares, 
em especial o fornecimento de reserva de regulação. São considerados como objetivo a otimização econômica, minimização dos custos ao consumidor, e a otimização técnica, maximização da capacidade de reserva de regulação. Devido a este fato, um método de otimização multi-critério com estratégias de evolução baseado em soluções Pareto é utilizado. Soluções Pareto são conjuntos de soluções que atendem a problemas multi-objetivos, onde a melhora de um objetivo é somente possível com a degradação de outro. Este método apresenta tanto soluções escalares como soluções espaciais.

CIGRÉ SC 38 (2001) apresentou um conjunto de ferramentas computacionais para precificação do serviço de reserva. As ferramentas computacionais apresentadas foram divididas no modelo proposto pelo EPRI (Electric Power Research Institute) e no modelo proposto pelo Operador do Sistema da Califórnia (CAISO).

O modelo apresentado pelo EPRI é baseado no Custo Marginal de Reserva e fornece estimativas do custo marginal variando com o período de tempo, o tipo de reserva e o tipo de consumidor. Este modelo consiste de dois sub-modelos que juntos determinam o custo marginal de reservas para níveis de fornecedores e consumidores. O primeiro sub-modelo é o modelo de despacho de potência ativa, com o objetivo de atender a demanda; e de despacho de reserva de potência ativa, que calcula, para cada período de tempo, a geração ótima e a capacidade de reserva. O segundo sub-modelo é o método de determinação do custo de diferentes índices de segurança e do preço mínimo da reserva disponível, a ser oferecido aos geradores, às cargas, aos transmissores e aos comercializadores.

Foram apresentados, também, os modelos propostos pelo CAISO. São eles: Método Seqüencial, que inclui as regras de múltiplas propostas, de ordem de 
qualidade, de propostas de preços inferiores, de seleção parcial, de restrição de capacidade e de restrição de tempo de resposta. Um segundo modelo apresentado foi o método dos compradores racionais (Rational Buyer's Method). Este método se baseia na busca exaustiva do menor preço de mercado para os serviços de reserva.

Os métodos apresentados em CIGRÉ SC 38 foram utilizados com objetivo de precificação do serviço de reserva em unidades térmicas.

XU et al. (2003) apresentaram uma metodologia de mercado integrando o suporte de energia e o serviço de reserva girante, com ênfase na coordenação do despacho de volumes de potência e do serviço de reserva girante. Um mecanismo de despacho em um novo mercado foi desenvolvido com o objetivo de minimizar os custos do serviço atendendo a segurança do sistema. Foi utilizada a metodologia de Algoritmos Genéticos na busca de soluções ótimas globais para o problema de despacho. Os autores consideraram as seguintes restrições: balanço de potência; restrições de segurança; restrições de mercado; e restrições de transmissão.

ONGSAKUL \& CHAYAKULKHEEREE (2003) apresentaram um algoritmo de despacho ótimo com restrições para leilões de energia e de Serviços Ancilares. O problema é decomposto em um subproblema de maximização do bem-estar social que é resolvido a partir de um problema de programação linear inteira mista e um subproblema de minimização das perdas ativas do sistema, que é resolvido a partir de métodos de programação quadrática. A abordagem proposta pode ser implementada tanto para unidades hidráulicas como para unidades térmicas.

VELASCO et al. (2003) apresentaram um trabalho com o objetivo de indicar possíveis conflitos contábeis e financeiros entre a remuneração pela prestação do serviço de reserva de potência ativa e os fluxos financeiros; e a contabilização final 
característicos do Mecanismo de Realocação de Energia (MRE), do mercado de energia do Brasil. Neste trabalho foram apresentadas as parcelas de remuneração dos geradores que em determinado instante geraram menos que sua energia assegurada, ou seja, apresentaram déficit de geração. Estas parcelas de remuneração foram apresentadas com o objetivo de mostrar os aspectos financeiros relacionados à participação no MRE.

WU et al. (2004) apresentaram a formulação de problema de Fluxo de Potência Ótimo CA com o objetivo de obter, precificar e alocar energia e Serviços Ancilares em leilões simultâneos realizados em sistemas de mercados integrados. O método proposto fornece claramente as definições de preços marginais locacionais de energia e preços marginais de Serviços Ancilares baseadas em multiplicadores de Lagrange. O trabalho avalia as condições sob as quais os custos de oportunidade são incorridos para as unidades que fornecem Serviços Ancilares. Esta avaliação mostra que a idéia de que o fornecimento de serviços de regulação não incorre em custos de oportunidade, em geral, não é verdade. A abordagem proposta foi implementada considerando a precificação e alocação de energia e de Serviços Ancilares a partir de unidades térmicas.

PAPADOGIANNIS \& HATZIARGYRIOU (2004) apresentaram um algoritmo de otimização que fornecia um despacho econômico minimizando o custo da prestação do serviço de reserva primária, assegurando a operação segura do sistema de potência na presença de contingências. $\mathrm{O}$ algoritmo leva em conta as restrições de segurança que são extraídas de uma série de regras provenientes de uma árvore de decisão. O algoritmo proposto foi implementado para o balanço de mercado de hora seguinte e de dia seguinte. Os autores formularam um problema de despacho 
econômico e utilizaram um método de programação quadrática seqüencial com o objetivo de determinar a solução do problema. A abordagem proposta foi implementada considerando a alocação de reserva primária a partir de unidades térmicas.

BOUFFARD \& GALIANA (2004) propuseram um método híbrido determinístico-probabilístico para o algoritmo de compensação do mercado de energia com restrição de reserva girante e incluindo o Unit Commmitment (despacho ótimo do número de unidades). O trabalho descreve que, em geral, o critério de confiabilidade que implicitamente adiciona os requisitos de reserva é definido pela probabilidade de perda de carga e pela carga não atendida. Como a formulação é complexa devido a sua não linearidade e a sua natureza combinatorial, para formulação do problema foi utilizada uma modelagem híbrida considerando as propriedades desejadas encontradas em critérios probabilísticos sem considerar a excessiva complexidade combinatorial normalmente encontrada nestes métodos. O método proposto utilizou programação linear inteira mista para solução do problema de compensação de mercado.

RIBEIRO et al. (2004) apresentaram uma metodologia para precificar os Serviços Ancilares de reserva de potência ativa quando providos por geradores. O trabalho propõe que a remuneração dos geradores seja baseada no benefício proporcionado ao sistema de potência. Para o serviço de reserva de geração este benefício será uma função da redução na potência esperada e não atendida multiplicada pelo custo de se atender uma demanda não contratada. A teoria de jogos corporativos foi utilizada com o objetivo de distribuir a remuneração do beneficio 
entre os agentes que forneceram o serviço. Foram escolhidos os métodos de Shapley e Aumman-Shapley como métodos de teoria de jogos coorporativos.

COSTA \& COSTA (2004) propuseram um método baseado no Fluxo de Potência Ótimo com o objetivo de fazer a compensação do mercado de dia seguinte para a energia e para a reserva girante. Os autores assumiram um ambiente competitivo onde as unidades geradoras podem ofertar potência ativa tanto para suprir a demanda como para prover Serviços Ancilares. Os agentes geradores podiam tomar sua própria decisão de despacho ótimo do número de unidades, escolhendo sua estratégia de oferta para o período de 24 horas. O Fluxo de Potência Ótimo proposto determina a solução ótima de despacho de energia e alocação de reserva girante levando em consideração: as restrições físicas do sistema; as perdas ativas; e o tempo de resposta das unidades geradoras. Para a solução do Fluxo de Potência Ótimo foi utilizado o método de pontos interiores primal-dual. A metodologia proposta foi testada a partir do sistema IEEE-30 barras.

VERBIC \& GUBINA (2004) apresentaram alguns métodos para precificação da reserva de potência para o controle de freqüência secundária e terciária. Os autores definiram o controle de reserva secundária como o restabelecimento da capacidade de reserva primária, retornando a freqüência para seu valor nominal e minimizando os fluxos de potência não programados entre controle de áreas vizinhas, realizado automaticamente e controlado centralmente; e controle de reserva terciária como o restabelecimento da capacidade de reserva primária ou secundária, realizada manualmente, ou seja, a partir da comunicação entre os centros de controle e os geradores. Os métodos propostos foram destinados para estimação do custo anual para a provisão de reservas de potência quando estas reservas são fornecidas com 
base em contratos bilaterais. Para o controle de freqüência secundária foram propostos três diferentes métodos. O primeiro é baseado na distribuição de probabilidade do preço da energia e dos custos incrementais da unidade de geração. O segundo é baseado na diferença entre os preços da energia durante a noite e durante o dia e o terceiro é baseado nos custos de oportunidade relacionado aos preços das bandas de potência. Para o controle de freqüência terciária foi apresentado apenas um método de precificação que leva em consideração os custos de investimentos, de partida e de operação. A estimação dos custos de operação é feita a partir de uma distribuição de probabilidades obtida heuristicamente com base na média de partidas e da duração das mesmas. Os testes realizados foram baseados em dados provenientes do sistema esloveno.

Os trabalhos apresentados anteriormente permitiram verificar que a maioria dos estudos realizados aborda uma otimização sistêmica. Outra característica importante presente nos trabalhos apresentados é que, na grande maioria, foi feita menção aos testes realizados e considerado o uso de unidades térmicas no fornecimento de reserva de potência ativa.

Com base nas características observadas nos trabalhos anteriormente apresentados, o presente trabalho propõe uma avaliação local do serviço de fornecimento de reserva de potência ativa e propõe esta aplicação considerando o provimento deste serviço a partir de unidades hidráulicas.

Em geral, uma unidade geradora pode estar desligada (e então prover o serviço de reserva de prontidão) ou permanecer ligada em mínima potência (neste caso, fornecendo uma máxima quantidade de reserva de potência primária ou secundária). 
Alternativamente, a mesma unidade pode estar operando e fornecer uma quantidade máxima de potência (e assim não oferecer o serviço de reserva).

Com o objetivo de valorar o serviço de reserva de potência ativa fornecido por uma unidade geradora, o presente trabalho utilizará o princípio do processo de otimização para medir e precificar o serviço de reserva de potência ativa e em seguida relacionará o resultado alcançado à definição de Custo de Oportunidade (Ver Apêndice 1).

Uma ferramenta fundamental para relacionar a valoração do fornecimento de reserva de potência ativa ao Custo de Oportunidade presente na atividade de geração é a determinação das parcelas que compõem os custos envolvidos no fornecimento de reserva.

Como descrito no Capítulo 2, para um sistema hidráulico, a maior parcela de custo de fornecimento de reserva de potência ativa está relacionada à eficiência do conjunto turbina/gerador. Assim, será utilizado, no presente trabalho, o rendimento (eficiência) do conjunto turbina/gerador para relacionar a valoração do fornecimento de reserva de potência ativa ao Custo de Oportunidade presente na atividade de geração.

A seguir é apresentada a função matemática que representa o rendimento do conjunto turbina/gerador e as variáveis a que este está relacionado. 


\subsection{Função de Geração de Usinas Hidroelétricas}

O modelo matemático de uma usina hidroelétrica será explicado com o auxílio da Figura 3.1. Para representar algumas limitações físicas do reservatório e os fluxos de água que passam pelas diferentes partes da usina, algumas variáveis são definidas:

- $\quad v$ : é a vazão vertida, em $\mathrm{m}^{3} / s$. É a vazão que flui diretamente do reservatório ao rio, através do vertedouro, sem gerar energia.

- $q$ : é a vazão turbinada, em $m^{3} / s$. É a vazão que efetivamente gera energia.

- $\quad u$ : é a vazão defluente, em $m^{3} / s$. É a soma das vazões turbinada e vertida.

- $x_{m o r}$ : é o volume morto do reservatório, em $h m^{3}$. É o volume de água armazenado e que não pode ser retirado do reservatório.

- $x_{\text {min }}$ : é o volume mínimo operativo, em $h m^{3}$. É o mínimo volume de água necessário para que a usina possa gerar energia.

- $x_{\text {máx }}$ é o volume máximo operativo, em $h m^{3}$. É o máximo volume de água que o reservatório armazena em condições normais de operação.

- $x_{\text {máx,max }}$ é o volume máximo maximorum, em $h m^{3}$. É o volume máximo que o reservatório pode armazenar sem que haja comprometimento da estrutura da barragem.

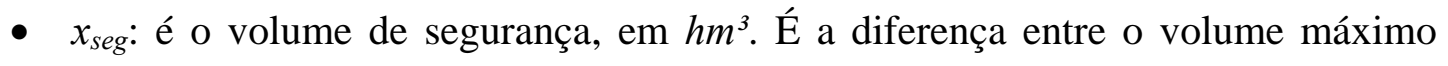
maximorum e o volume máximo operativo. 


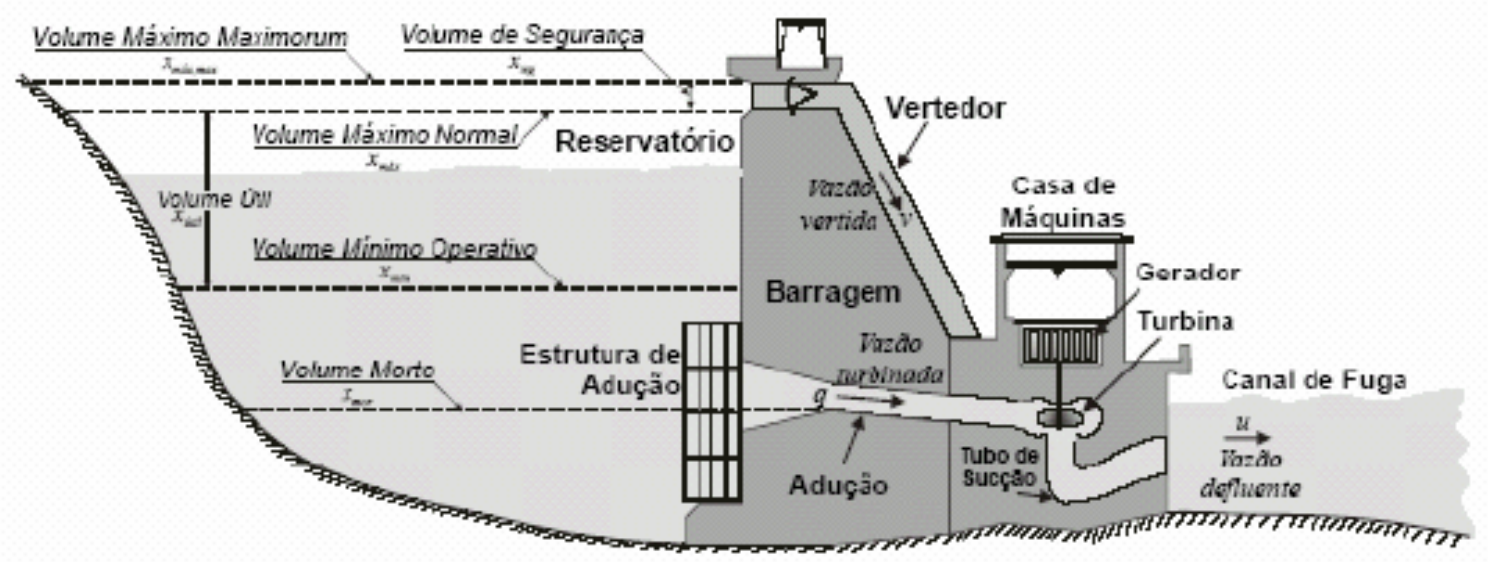

Figura 3.1. Variáveis de uma usina hidroelétrica. Fonte: SILVA FILHO (2003).

A quantidade de energia elétrica produzida por certo volume de água $x$ é o resultado da transformação da energia potencial desta massa de água em energia elétrica. As energias elétrica e potencial representadas por $e_{e}$ e $e_{p}$, respectivamente, são proporcionais. A energia potencial é expressa em Joule e calculada por:

$$
e_{p}=m \cdot g \cdot h
$$

sendo $m$ a massa do volume de água $x$, em $\mathrm{kg}, \mathrm{g}$ a aceleração da gravidade no local de implantação da turbina, tendo como valor de referência 9,81 $\mathrm{m} / \mathrm{s}^{2}$, e $h$ a altura da qual o volume de água cairá para produzir energia, em metros. A massa de água $m$ pode ser substituída pelo volume $x$ :

$$
\rho=\frac{m}{x} \rightarrow m=\rho \cdot x
$$

na qual $\rho$ é a massa específica da água, igual a $10^{3} \mathrm{~kg} / \mathrm{m}^{3}$ para temperatura de $4^{\circ} \mathrm{C}$ e altitude zero em relação ao nível do mar. Ou seja:

$$
e_{p}=\rho \cdot g \cdot h \cdot x
$$


Se um coeficiente de rendimento $\eta$, associado aos rendimentos da turbina e do gerador, é suposto estar envolvido no processo de transformação de energia potencial hidráulica em energia elétrica, pode-se escrever:

$$
e_{e}=\eta \cdot \rho \cdot g \cdot h \cdot x
$$

A Equação 3.4 especifica a energia elétrica que o volume $x$ de água gera ao passar pelas turbinas. Se o volume $x$ gasta um intervalo de tempo $\Delta t$ para produzir a quantidade de energia elétrica $e_{e}$, pode-se determinar a potência média dividindo-se a Equação 3.4 por $\Delta t$. De forma similar, volume dividido por tempo especifica o fluxo médio de água através das turbinas, denominado vazão turbinada. Fazendo o intervalo de tempo tender a zero e definindo a potência instantânea $p$, em Watts, e a vazão turbinada instantânea $q$, em $\mathrm{m}^{3} / \mathrm{s}$, tem-se:

$$
\begin{gathered}
\lim _{\Delta t \rightarrow 0} \frac{e_{e}}{\Delta t}=\eta \cdot \rho \cdot g \cdot h \cdot \lim _{\Delta t \rightarrow 0} \frac{x}{\Delta t} \\
p=\eta \cdot \rho \cdot g \cdot h \cdot q
\end{gathered}
$$

A potência instantânea $p$ é expressa em Watts, a altura $h$ em metros e a vazão turbinada $q$ em $\mathrm{m}^{3} / \mathrm{s}$; o rendimento $\eta$ é adimensional, a densidade da água $\rho$ é igual a $10^{3} \mathrm{~kg} / \mathrm{m}^{3}$ e a aceleração da gravidade $g$ é $9,81 \mathrm{~m} / \mathrm{s}^{2}$. Para se conseguir definir a função de geração de uma usina hidroelétrica, os valores de $\eta$ e $h$ devem ser determinados a partir das variáveis de entrada do modelo. A vazão turbinada $q$ deve possuir um limitante superior, $q_{\text {máx }}$, que reflita a máxima potência que pode ser gerada pela usina com base nas entradas do modelo e nas características das turbinas 
e dos geradores. Os desenvolvimentos das expressões de $h, \eta$ e $q_{\text {máx }}$ são realizados a seguir.

\subsubsection{Altura}

A altura $h$ representa à altura de queda efetiva na geração de energia e é conhecida como altura de queda líquida, $h_{l}$. O valor de $h_{l}$ é determinado pela diferença entre a altura de queda bruta $h_{b}$ e a altura de perdas hidráulicas $h_{p}$.

\subsubsection{Altura de queda bruta}

A altura de queda bruta de uma usina hidroelétrica é uma função dos níveis d’água de montante e de jusante. O nível de montante é uma função não-linear do volume total de água armazenado no reservatório, $x$, em $h m^{3}$. Esta função, denotada por $h_{m o n}(x)$, é normalmente côncava e sua forma depende basicamente do relevo da região na qual o reservatório foi construído. Similarmente ao nível de montante, o nível de jusante também é uma função não-linear côncava, mas que depende da vazão defluente total da usina, $u$, em $\mathrm{m}^{3} / s$. A forma desta função, chamada de $h_{j u s}(u)$, depende do canal de fuga da usina e das características do rio a jusante do reservatório. O nível médio a jusante do reservatório é chamado de cota média do canal de fuga, $c f_{\text {med, }}$ e é usualmente fornecido como um dado da usina hidroelétrica.

Ambas as funções $h_{m o n}(x)$ e $h_{j u s}(u)$ podem ser determinadas por medições realizadas no próprio local da barragem ou por modelos computacionais capazes de descrever as características da região e processar modelos de hidrodinâmica. No 
Brasil, adotam-se polinômios de até quarto grau para representar os níveis de montante e jusante das usinas, SILVA FILHO (2003). Assim, a altura de queda bruta passa a depender tanto do volume armazenado $x$ quanto da vazão defluente $u$ :

$$
h_{b}(x, u)=h_{m o n}(x)-h_{j u s}(u)
$$

Como descrito anteriormente, a altura de montante de uma usina é altamente dependente do volume de água armazenado no reservatório. Esta influência do volume d’água armazenado na queda disponível para geração é chamada de Efeito Cota, EC. A expressão que representa este efeito é dada por:

$$
E C=\frac{h_{\text {mon }}\left(x_{\text {máx }}\right)-h_{\text {mon }}\left(x_{\text {min }}\right)}{h_{\text {mon }}\left(x_{\text {máx }}\right)-c f_{\text {med }}} \cdot 100
$$

A forma do polinômio $h_{j u s}(u)$ retrata como a vazão defluente da usina pode influenciar de modo adverso sua operação. Quando a vazão defluente eleva-se, o nível de jusante também se eleva, reduzindo a queda d’água. Este efeito é conhecido como Efeito de Afogamento do canal de fuga, $E A$, definido por:

$$
E A=\frac{h_{\text {jus }}\left(u_{\text {máx }}\right)-h_{\text {jus }}\left(u_{\text {min }}\right)}{h_{\text {mon }}\left(x_{\text {máx }}\right)-c f_{\text {med }}} \cdot 100
$$

Em alguns casos o nível de jusante não depende somente da vazão defluente da usina, mas também da condição de reservatórios ou rios de jusante. São os chamados efeitos de remanso. O efeito de remanso caracteriza-se pela influência que o volume armazenado em uma usina hidroelétrica de jusante ou as águas de um rio de jusante podem ter sobre o nível do canal de fuga de uma usina hidroelétrica, como por exemplo, o efeito de remanso da Usina de Porto Primavera que causa o afogamento 
das turbinas da Usina de Jupiá, levando a um decréscimo na energia assegurada da mesma.

\subsubsection{Altura de perdas hidráulicas}

No processo de geração de uma usina hidroelétrica, há a perda de energia devido ao atrito contra algumas estruturas da usina, tais como: a estrutura de adução, a entrada do canal de adução, o canal de adução, o caracol da turbina, a turbina e o tubo de sucção. Apesar de todas as perdas deverem ser consideradas em benefício da precisão do modelo, apenas as três primeiras são consideradas diretamente no cálculo das perdas hidráulicas. As outras são consideradas de forma indireta no cálculo da eficiência da turbina.

As perdas devido à estrutura de adução, à entrada do canal de adução e ao próprio canal de adução podem ser calculadas utilizando a Equação de Bernoulli, MUNSON et al. (1998), que estabelece que a soma das alturas devido à elevação, à pressão e à velocidade deve permanecer constante para fluxos estacionários, nãoviscosos e incompressíveis.

Após algumas manipulações, a equação resultante para o cálculo das perdas não se tornam de uso prático nos modelos, principalmente porque as velocidades necessárias para o cálculo não são normalmente medidas. As variáveis que podem ser medidas são a altura de queda bruta e a vazão através das turbinas. Dependendo dos objetivos da operação e dos dados disponíveis, as perdas hidráulicas $h_{p}$, também conhecidas como perdas de carga, podem ser estimadas a partir dos seguintes modelos. 
- Perda hidráulica constante: Este é o modelo mais simples que pode ser adotado e também o menos preciso. A perda hidráulica é considerada constante e igual a algum valor médio. Este modelo é usado geralmente em estudos de expansão ou planejamento de longo prazo, onde outras fontes de incerteza são mais importantes para os estudos.

- Perda hidráulica proporcional à queda bruta: Este modelo considera que a altura de perdas $h_{p}$ depende da queda bruta disponível. As variações da altura de perdas em relação às velocidades de escoamento não são consideradas. O parâmetro $k$ é um número positivo que depende da usina hidroelétrica em estudo.

$$
h_{p}(x, u)=k \cdot h_{b}(x, u)
$$

- Perda hidráulica proporcional ao quadrado da vazão turbinada: Neste caso a altura de perdas $h_{p}$ depende do quadrado da vazão turbinada, mas não depende da queda bruta. Na realidade, a altura de perdas depende da velocidade e não da vazão; entretanto, velocidade e vazão são diretamente relacionadas, de forma que $h_{p}$ possa ser calculada utilizando a equação abaixo. O parâmetro $k$ é um número positivo que depende da usina em estudo, e a vazão $q$ é a vazão turbinada.

$$
h_{p}(q)=k \cdot q^{2}
$$

\subsubsection{Altura de queda líquida $h_{l}$}

A altura de queda líquida $h_{l}$, em $m$, é a altura $h$ procurada. A altura de queda líquida é calculada pela diferença entre a altura de queda bruta, $h_{b}$, e altura de perdas 
hidráulicas, $h_{p}$. A altura de queda bruta, $h_{b}$ depende do volume armazenado no reservatório, $x$, e da vazão defluente total, $u$. A altura de perdas hidráulicas, dependendo do modelo adotado, pode ser constante, dependente da altura de queda bruta ou da vazão turbinada. Assim, altura de queda líquida $h_{l}$ pode ser genericamente escrita como:

$$
h_{l}(x, q, v)=h_{\text {mon }}(x)-h_{j u s}(u)-h_{p}(x, q, v)
$$

\subsubsection{Engolimento máximo}

O engolimento máximo $q_{\text {máx }}$ é a maior vazão que pode ser turbinada pela máquina quando o distribuidor se encontra totalmente aberto. Juntamente com o cálculo de $q_{\text {máx }}$ também é realizado o cálculo de $p_{\text {máx }}$, a máxima potência que pode ser gerada pela usina. Como numa mesma usina pode haver máquinas (turbinas e/ou geradores) diferentes, divide-se a usina em $n_{\text {conj }}$ conjuntos de máquinas, cada um composto por $n_{\text {máq }}$ máquinas idênticas. Para cada conjunto $j, j=1, \ldots, n_{\text {conj }}$, primeiro calcula-se o engolimento máximo e a potência máxima de uma de suas máquinas, e depois multiplica-se o resultado pelo número de máquinas do conjunto. A soma do engolimento máximo de cada conjunto é o engolimento máximo total da usina. Para evitar confusões na interpretação das variáveis, os valores de potência e engolimento de uma única máquina (turbina e/ou gerador) conterão o subscrito “máq”, enquanto os valores totais de uma usina não conterão subscritos.

O engolimento máximo de uma turbina é definido pela vazão turbinada quando suas palhetas estão completamente abertas (abertura igual a 100\%). Como a vazão 
turbinada para uma determinada abertura das palhetas varia em função da altura de queda líquida, quanto maior a altura de queda, maior a vazão turbinada, o engolimento máximo de uma turbina é função da altura de queda líquida. No entanto, o engolimento máximo de uma máquina, $q_{\text {máx,máq, deve representar as }}$ limitações não somente da turbina, mas também do gerador. O gerador possui uma potência máxima que pode ser gerada, denominada potência efetiva ou potência nominal, em MW, denotada por $p_{e f, m a ́ q}$. Uma vez especificada a altura de queda, para assegurar a integridade do gerador deve-se garantir que a potência gerada pela turbina seja menor que a potência efetiva do gerador.

O engolimento máximo e a máxima potência do conjunto turbina/gerador podem ser expressos através do seguinte sistema de equações:

$$
\begin{aligned}
& q_{\text {máx,máq }}=\left\{\begin{array}{l}
q_{\text {máx }, \text { tur }}, \text { se } h_{l}<h_{e f, m a ́ q} \\
q_{\text {máx }, g e r}, \text { se } h_{l} \geq h_{e f, m a ́ q}
\end{array}\right. \\
& p_{\text {máx,máq }}=\left\{\begin{array}{l}
p_{\text {máx,tur }}, \text { se } h_{l}<h_{e f, m a ́ q} \\
p_{e f}, \quad \text { se } h_{l} \geq h_{e f, m a ́ q}
\end{array}\right.
\end{aligned}
$$

sendo:

- $q_{\text {máx,máq }}$ : engolimento máximo do conjunto turbina/gerador, em $\mathrm{m}^{3} / \mathrm{s}$;

- $q_{\text {máx,tur: }}$ engolimento máximo da turbina, em $\mathrm{m}^{3} / \mathrm{s}$;

- $q_{\text {máx,ger: }}$ engolimento máximo do gerador, em $\mathrm{m}^{3} / \mathrm{s}$;

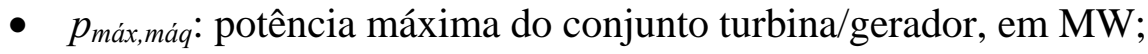

- $p_{\text {máx,tur: }}$ potência máxima da turbina, em MW;

- $\quad p_{\text {ef,máq }}$ : potência efetiva do gerador, em MW;

- $q_{e f, m a ́ q}$ : engolimento efetivo do conjunto gerador, em $\mathrm{m}^{3} / \mathrm{s}$;

- $h_{e f, m a ́ q}$ : altura de queda líquida efetiva da turbina, em m; 
- $h_{l}$ : altura de queda líquida, em m.

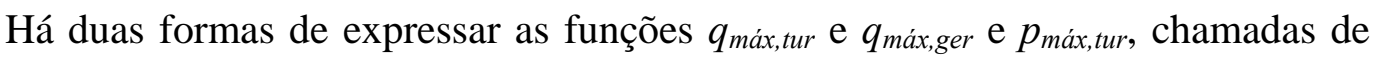
modelagem simplificada e modelagem detalhada. Para a modelagem simples é possível escrever as seguintes equações:

$$
\begin{aligned}
& q_{\text {máx,máq }}=\left\{\begin{array}{l}
q_{\text {máx }, \text { tur }}=\left(\frac{h_{l}}{h_{e f, m a ́ q}}\right)^{\alpha} \cdot q_{e f, m a ́ q}, \text { se } h_{l}<h_{e f, m a ́ q} \\
q_{\text {máx,ger }}=\left(\frac{h_{l}}{h_{e f, m a ́ q}}\right)^{-1} \cdot q_{e f, m a ́ q}, \text { se } h_{l} \geq h_{e f, m a ́ q}
\end{array}\right. \\
& p_{\text {máx }, \text { máq }}= \begin{cases}p_{\text {máx }, \text { tur }}=\left(\frac{h_{l}}{h_{e f, m a ́ q}}\right)^{\beta} \cdot p_{e f, m a ́ q}, & \text { se } h_{l}<h_{e f, m a \dot{q} q} \\
p_{e f, m a ́ q} & , \text { se } h_{l} \geq h_{e f, m a ́ q}\end{cases}
\end{aligned}
$$

Sendo que $\alpha$ e $\beta$ são coeficientes que dependem do tipo da turbina:

- $\alpha=0,5$ e $\beta=1,5$ para turbinas do tipo Francis e Pelton;

- $\alpha=0,2$ e $\beta=1,2$ para turbinas do tipo Kaplan.

Na modelagem detalhada são feitas várias medidas de pontos de operação do conjunto turbina/gerador da usina, e sobre estes pontos são ajustadas curvas, normalmente polinômios, para representar $q_{\text {máx,tur }}$ e $q_{\text {máx,ger }}$ e $p_{\text {máx,tur }}$.

Independente da modelagem adotada, a partir destas curvas pode-se determinar o engolimento máximo de uma usina desde que definidos o volume armazenado no reservatório e a vazão total a ser defluida. O cálculo do engolimento máximo é um processo iterativo, em função da interdependência das variáveis 
envolvidas, podendo ser determinado a partir do método apresentado em SILVA FILHO (2003).

\subsubsection{Rendimento}

Para a avaliação do custo de oportunidade relacionado ao fornecimento de reserva de potência ativa será utilizada a curva de rendimento (eficiência) do conjunto turbina/gerador. No desenvolvimento do trabalho o rendimento $\eta$ se referirá ao rendimento combinado da turbina e do gerador. O rendimento pode ser modelado de diferentes formas, dependendo dos dados disponíveis e da precisão desejada pelo modelo da usina hidroelétrica.

Para estudos de longo prazo, com intervalos de discretização mensais, usualmente adota-se $\eta$ constante e igual a um rendimento médio. No entanto, o catálogo de dados da Eletrobrás não apresenta o rendimento médio das usinas, mas sim um parâmetro chamado de produtibilidade específica, pe. Para explicar este parâmetro, rescreve-se a equação da potência gerada pela usina.

$$
p(t)=\eta \cdot \rho \cdot g \cdot h_{l} \cdot q(t)
$$

Se o rendimento $\eta$ é feito constante e igual a um valor médio $\eta_{\text {med }}$, a equação passa a ter três parâmetros constantes: $\rho$, $g$ e $\eta_{\text {med }}$ O produto destes parâmetros é que define a produtibilidade específica $p e$.

Para a Equação 3.16, se todos os parâmetros fossem expressos em unidades do Sistema Internacional de medidas, a potência $p(t)$ seria expressa em Watts, o que não é usual para uma usina hidroelétrica. Usualmente este valor é expresso em $10^{6} \mathrm{Watts}$, 
ou seja, em $M W$. Para manter essa coerência entre as unidades, deve-se dividir a equação por $10^{6}$, o que é feito no próprio parâmetro pe. Escrevendo pe tem-se:

$$
p e=\frac{\rho \cdot g}{10^{6}} \cdot \eta_{\text {med }} \quad \frac{M W}{\left(m^{3} / s\right) \cdot m}
$$

ou ainda, substituindo os valores de $\rho$ e $g$ :

$$
p e=9,81 \cdot 10^{-3} \cdot \eta_{\text {med }} \quad \frac{M W}{\left(m^{3} / s\right) \cdot m}
$$

A potência gerada pela usina pode ser reescrita utilizando-se a produtibilidade específica. Neste caso a potência $p(t)$ passa a ser expressa em $M W$, a altura líquida $h_{l}$ sendo expressa em $m$ e a vazão $q(t)$ expressa em $\mathrm{m}^{3} / \mathrm{s}$.

$$
p(t)=p e \cdot h_{l} \cdot q(t)
$$

Modelos que trabalham com a operação de uma usina hidroelétrica em intervalos de discretização menores, tais como dias, horas ou em tempo real, devem considerar as variações do rendimento $\eta$ em função das condições de operação da turbina. Por “condições de operação” entende-se a altura de queda líquida e a potência gerada; a relação entre as variáveis é complexa e usualmente modelada através de curvas de desempenho das turbinas.

A Figura 3.2 apresenta a curva de desempenho de uma turbina do tipo Francis. Nesta figura estão relacionadas quatro variáveis:

- Potência da turbina: também especificada em termos porcentuais. Adotou-se a potência na qual a turbina apresenta rendimento máximo, chamada de 
potência de projeto, como 100\%. O ponto de intersecção entre a queda de projeto e a potência de projeto é chamado de Ponto de Projeto. Pela figura observa-se que a turbina pode até mesmo gerar potências mais elevadas que a de projeto, porém o rendimento associado é sempre menor que o rendimento de ponto de projeto.

- Altura de queda líquida: esta variável foi especificada em termos porcentuais, onde para a queda de projeto definiu-se a queda liquida como 100\%. A área sombreada da figura especifica a faixa de operação da turbina, delimitada pelas alturas de queda mínima e máxima.

- Rendimento da turbina: representado pelas curvas contínuas; a cada curva está associado um valor constante de rendimento, indicado na parte superior do gráfico.

- Abertura das palhetas da turbina: representada pelas curvas pontilhadas. O ângulo de abertura das palhetas indica a vazão a ser turbinada; quanto maior o ângulo, maior o fluxo de água pela turbina. 


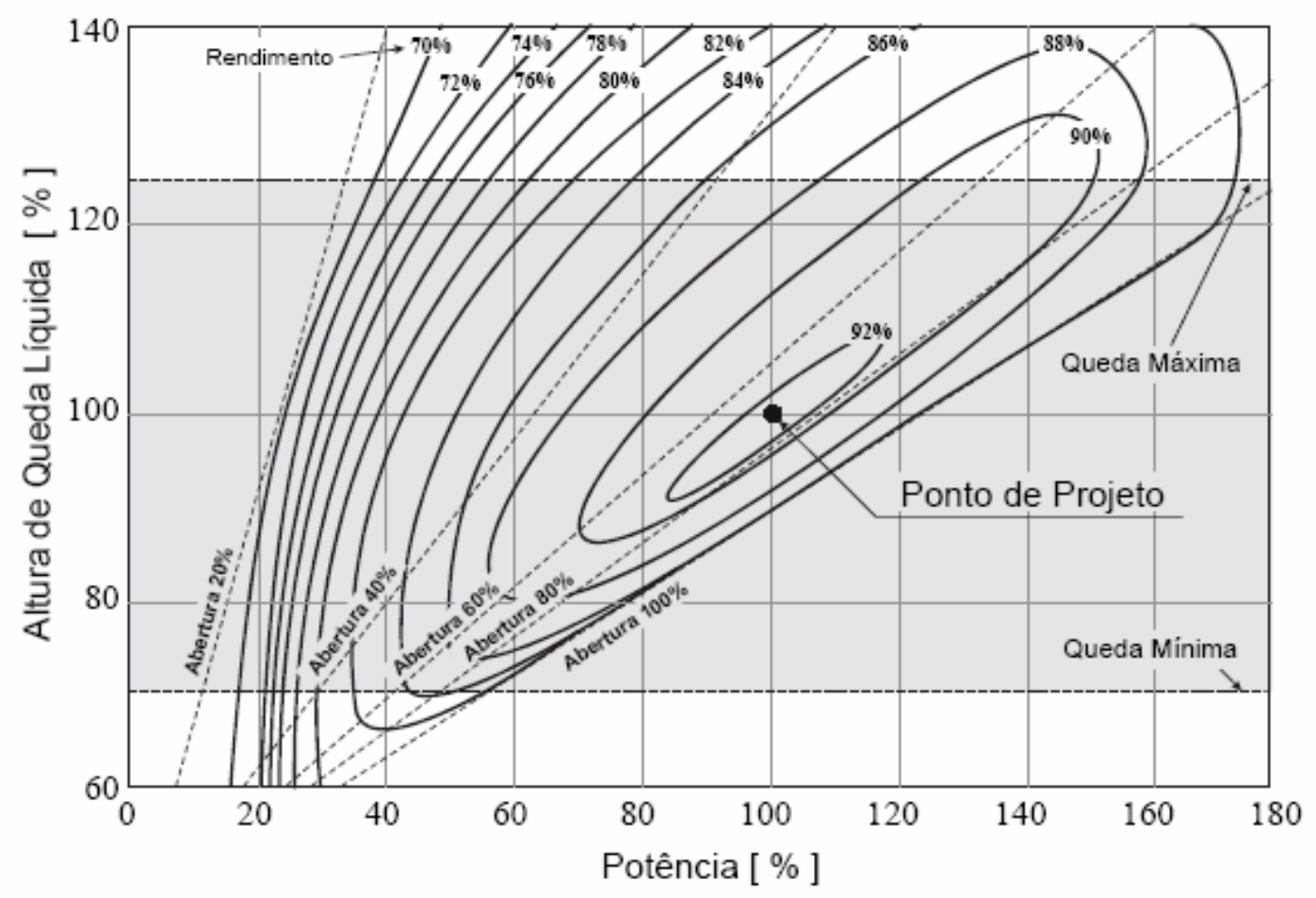

Figura 3.2. Curvas de desempenho de uma turbina tipo Francis. Fonte: SILVA FILHO (2003).

Algumas características da turbina podem ser explicadas através da Figura 3.2. Observa-se que há um ponto onde o rendimento é máximo, chamado de Ponto de Projeto. Devido às definições de valores de referência utilizados para expressão em porcentagem da potência e da altura de queda, o ponto de projeto é aquele no qual a potência e a altura de queda são ambas iguais a 100\%. Em todas as outras condições de operação da turbina, o rendimento será menor que aquele do Ponto de Projeto. Isto não significa que a potência gerada pela turbina no Ponto de Projeto seja máxima. Por exemplo, no Ponto de Projeto a abertura das palhetas é de 70\%; se a altura de queda for mantida constante e as palhetas continuarem a ser abertas até 100\%, a potência gerada pela turbina vai elevar-se e chegar a 123\%. Porém, o rendimento associado a este ponto será menor que o do Ponto de Projeto. Isto 
significa que com a queda de $100 \%$, a turbina gasta mais água por MW produzido quando ela gera $123 \%$ do que quando ela gera $100 \%$ da potência.

Pela Figura 3.2 também pode ser observado que para uma mesma abertura das palhetas da turbina, à medida que a altura de queda eleva-se, a potência gerada aumenta. Isso ocorre por causa de dois fatores. Primeiro, a potência gerada é proporcional à altura; logo, se a altura eleva-se, a potência gerada também se eleva. Segundo, quando a altura eleva-se e as palhetas são mantidas com a mesma abertura, devido ao aumento de pressão, o fluxo de água através da turbina aumenta. Como a potência gerada também é proporcional à vazão turbinada, a potência gerada aumenta.

O segundo efeito explica porque as taxas de incremento da potência gerada devido ao aumento da altura são diferentes para diferentes aberturas. Por exemplo, para abertura de $20 \%$, a potência gerada varia de $14 \%$ para $23 \%$ quando a queda varia de $80 \%$ para $100 \%$. Já para abertura de $100 \%$, admitindo-se a mesma variação de queda, a potência gerada varia de $77 \%$ para $123 \%$. Como as variações de altura de queda são as mesmas, conclui-se que o aumento nas variações de potência é causado pelo aumento da vazão turbinada.

As Figuras 3.3 e 3.4 também podem ser utilizadas para explicar algumas características da turbina. Considerando uma altura de queda fixa, ao progressivamente variar a abertura das palhetas de $20 \%$ a $100 \%$, o fluxo de água pela turbina sempre aumenta, aumentando também a potência gerada. Isso ocorre porque a potência é determinada basicamente através do produto entre a altura de queda e a vazão turbinada; como a altura de queda é considerada constante, conforme as palhetas são abertas, a vazão turbinada aumenta e a potência gerada eleva-se. 
O rendimento da turbina apresenta um comportamento diferente. No início, quando as palhetas começam a ser abertas, o rendimento vai progressivamente aumentando; atinge-se então o ponto com rendimento máximo para a altura de queda especificada. A partir daí o rendimento diminui com o aumento da abertura.

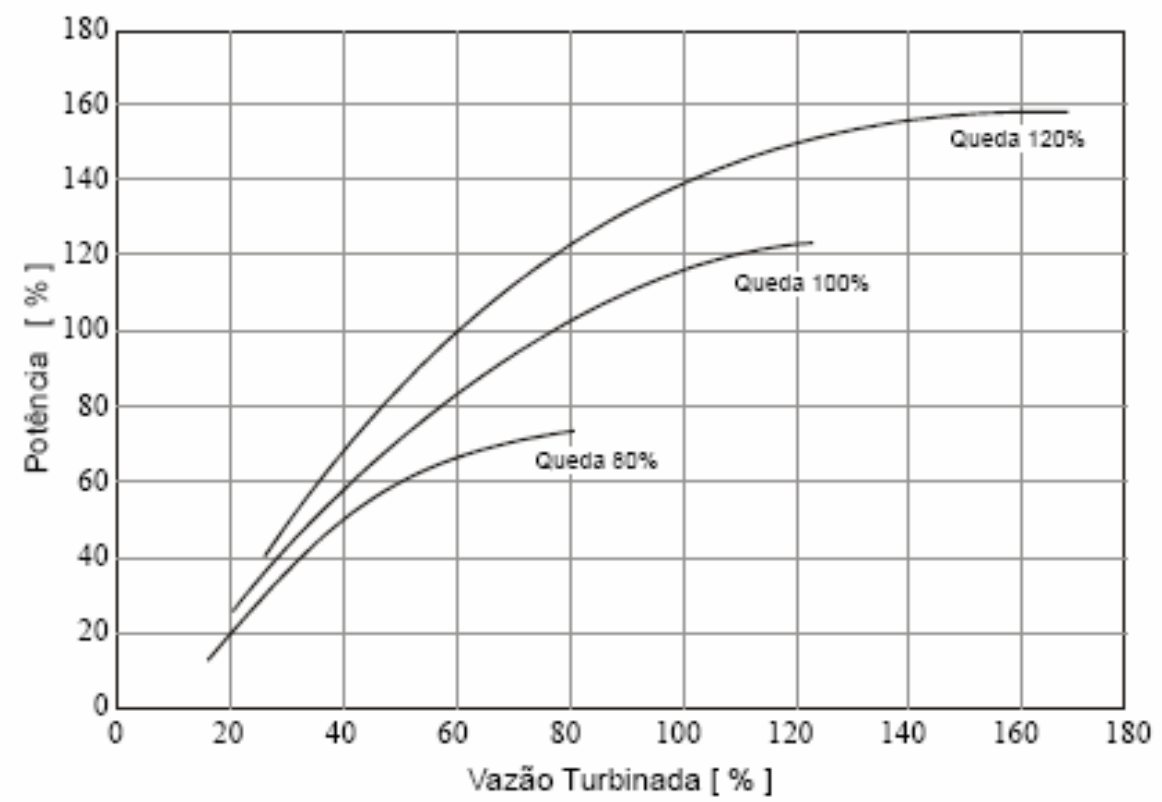

Figura 3.3. Potência gerada pela turbina para diferentes quedas líquidas. Fonte: SILVA FILHO (2003).

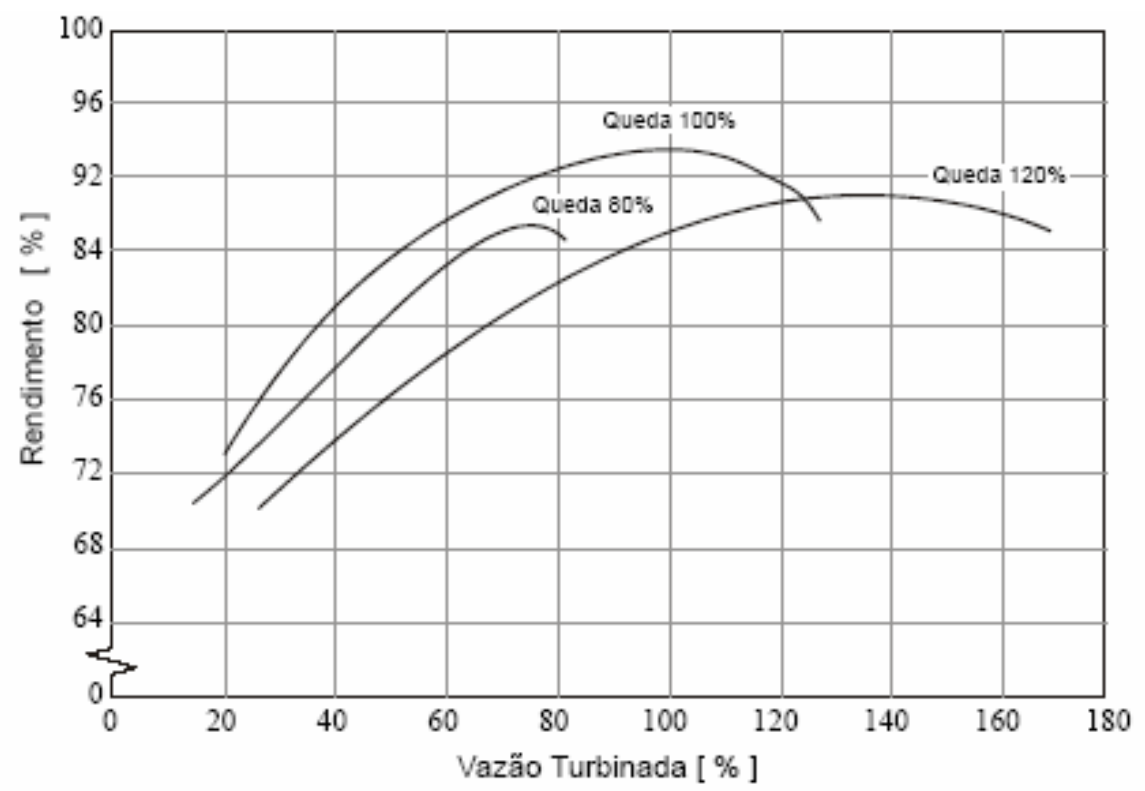

Figura 3.4. Rendimento da turbina para diferentes quedas líquidas.

Fonte: SILVA FILHO (2003). 
Muitos estudos foram realizados com o objetivo de otimizar a geração de energia com base no rendimento das unidades geradoras.

ARCE et al. (2002) apresentaram uma metodologia para o despacho ótimo de unidades hidroelétricas. Um modelo de programação dinâmica foi desenvolvido com o objetivo de otimizar o número de unidades geradoras em operação em cada hora de maneira a atender o planejamento de geração na forma mais econômica. A metodologia proposta destaca o intercâmbio entre a partida e a parada das unidades geradoras e o rendimento das mesmas, levando em consideração uma variação no rendimento das turbinas e dos geradores e na altura de queda efetiva da unidade. Testes para um planejamento típico têm sido realizados e os resultados têm mostrado que o número de grupos de turbinas e geradores a serem despachados tem maior influencia no rendimento global das unidades hidroelétricas.

RIBAS (2003) apresentou um protótipo de um sistema de avaliação e otimização da geração de energia em centrais hidroelétricas. O autor otimiza a geração determinando o rendimento e as perdas da unidade geradora. O trabalho aborda os ganhos decorrentes desta otimização.

ENCINA et al. (2004) apresentaram uma metodologia para a otimização do despacho de unidades geradoras hidráulicas. Foi adotado um critério que leva em conta a elevação do nível de canal de fuga, as perdas hidráulicas no sistema de adução e as variações no rendimento do conjunto turbina/gerador. Um procedimento heurístico baseado na técnica de relaxação lagrangena foi utilizado. Um método de programação dinâmica foi empregado para resolver o problema de despacho das unidades geradoras numa base horária considerando o custo de partida e parada de 
máquinas. Os resultados mostraram ganhos na ordem de 2,0\% em termos de rendimento das unidades de geração.

YAMIN (2003) apresentou uma revisão dos métodos de planejamento da geração utilizados desde 1951, tanto para ambientes verticalizados como para ambientes de mercado desverticalizados. O trabalho aborda uma grande extensão de metodologias determinísticas, meta-heuristicas e híbridas.

Para o presente trabalho, a metodologia proposta para a otimização do rendimento do conjunto turbina/gerador se baseia na teoria de despacho econômico apresentada a seguir.

\subsection{O Problema de Despacho Econômico}

A seguir é apresentada à formulação do problema de Despacho Econômico, proposto em WOOD \& WOLLENBERG (1983), e que será utilizada como base para a mensuração do fornecimento de reserva de potência ativa a partir da otimização do rendimento do conjunto turbina/gerador.

A formulação proposta pelos autores considera a função objetivo igual ao custo total para atender a carga indicada e como restrição é considerado que a soma da potência de saída das máquinas seja igual à demanda da carga. Assim, o problema é minimizar a função objetivo sujeito a restrição imposta.

Para este problema foram desprezadas as perdas na transmissão e nenhum limite de operação foi explicitado na formulação do mesmo. Assim temos o seguinte problema: 


$$
\begin{aligned}
& \text { Min } F=\sum_{i=1}^{N} F_{i}\left(P_{i}\right) \\
& \text { sujeito } a \quad \phi=0=P_{T}-\sum_{i=1}^{N} P_{i}
\end{aligned}
$$

Sendo $F$ a função matemática a ser minimizada, $P_{i}$ a potência da máquina $i, P_{T}$ a potência total e $N$ o número de máquinas total.

Este é um problema de otimização restrito que pode ser resolvido usando métodos que envolvem a função de Lagrange. Para estabelecer as condições necessárias para um valor extremo da função objetivo, adiciona-se a função de restrição $(\phi)$ à função objetivo $(F)$, depois da função restrição ter sido multiplicada por um multiplicador indeterminado $(\lambda)$. A função resultante é conhecida como função de Lagrange $(L)$ e pode ser apresentada como:

$$
L=F+\lambda \phi
$$

As condições necessárias para um valor extremo da função objetivo são obtidas quando a derivada primeira da função de Lagrange com respeito a cada uma das variáveis independentes for igualada a zero. Neste caso há $\mathrm{N}+1$ variáveis, os $\mathrm{N}$ valores de saída de potência, mais o multiplicador de Lagrange indefinido, $\lambda$. A derivada da função de Lagrange com respeito ao multiplicador de Lagrange resulta na equação de restrição. Enquanto isso, as $N$ equações resultantes da derivada parcial da função Lagrange em relação às potências de saída das máquinas são representadas pela equação a seguir:

$$
\frac{\partial L}{\partial P_{i}}=\frac{d F_{i}\left(P_{i}\right)}{\partial P_{i}}-\lambda=0
$$


ou,

$$
\frac{d F_{i}\left(P_{i}\right)}{\partial P_{i}}-\lambda=0
$$

Assim, a condição necessária para a existência de um mínimo custo de operação para o sistema de potência é que o custo incremental de todas as unidades seja igual ao valor de $\lambda$. A isto se deve adicionar a equação de restrição onde a soma das potências de saída deve ser igual à potência de demanda da carga. Em adição, há duas desigualdades que devem ser satisfeitas por cada uma das unidades. Ou seja, a potência de saída de cada unidade deve ser maior ou igual à potência mínima permitida e deve ser menor ou igual à potência máxima permitida para a unidade em questão.

Estas condições e desigualdades podem ser resumidas pelo conjunto de Equações a seguir:

$$
\begin{array}{ll}
\frac{d F_{i}\left(P_{i}\right)}{d P_{i}}=\lambda & N \text { equações } \\
P_{i, \min } \leq P_{i} \leq P_{i, \max } & 2 N \text { equações }
\end{array}
$$

A expansão das condições necessárias é mostrada pelo conjunto de Equações 3.26 . 


$$
\begin{array}{ll}
\frac{d F_{i}\left(P_{i}\right)}{d P_{i}}=\lambda & \text { para } P_{i, \min } \leq P_{i} \leq P_{i, \max } \\
\frac{d F_{i}\left(P_{i}\right)}{d P_{i}} \leq \lambda & \text { para } P_{i}=P_{i, \max } \\
\frac{d F_{i}\left(P_{i}\right)}{d P_{i}} \geq \lambda & \text { para } P_{i}=P_{i, \min }
\end{array}
$$

Como descrito anteriormente e formulado por WOOD \& WOLLENBERG (1983), o problema de despacho econômico aqui apresentado faz referência ao custo do combustível utilizado pelas unidades térmicas como sendo a função objetivo do problema e é representada por uma função do segundo grau.

No presente trabalho, a função custo será substituída por uma função do segundo grau que represente a eficiência do conjunto turbina/gerador. Isso porque, como descrito anteriormente, a maior parcela de custo associada à provisão de reserva de potência ativa está relacionada à eficiência do conjunto turbina/gerador. Assim, a metodologia de despacho econômico ora apresentada pode ser utilizada com o objetivo de mensurar o fornecimento de reserva de potência ativa.

O uso da função custo, como apresentado originalmente no problema de Despacho Econômico, não traria ganhos ao problema, pois, como no estágio atual as unidades são consideradas semelhantes, ter-se-ia um mesmo custo marginal, o que faria com que o processo de otimização resultasse em um despacho igual entre as unidades. O uso da função custo é interessante quando se trabalha com unidades diferentes, como ocorre na otimização de uma cascata de usinas, onde cada usina é representada por um custo marginal diferente.

A seguir serão apresentados os testes realizados a partir da metodologia proposta para mensuração do custo envolvido no fornecimento de reserva de potência ativa. 


\subsection{Testes e Resultados}

Para os testes realizados foram utilizados dados da UHE de Água Vermelha. A UHE de Água Vermelha é uma unidade pertencente ao grupo AES Tietê, localizada no Rio Grande, possui 6 unidades de geração do tipo Francis, cada uma com capacidade instalada de 232,7 MW por unidade e tem uma altura de queda útil nominal de 57,0 m. Os dados utilizados nos testes são referentes ao ano de 2002.

\subsubsection{Avaliação Diária}

Primeiramente foram analisados os dados que compõem a função de rendimento provenientes da UHE de Água Vermelha para um dia escolhido aleatoriamente. Os dados utilizados para traçar a curva do rendimento em relação à potência gerada estão apresentados no Apêndice 2.

De posse desta análise foram traçadas as curvas que representam a relação entre o Rendimento e a Potência Gerada. A Figura 3.5 apresenta as curvas do rendimento em relação à potência gerada para as alturas de queda de 48, 49 e 50 metros. 


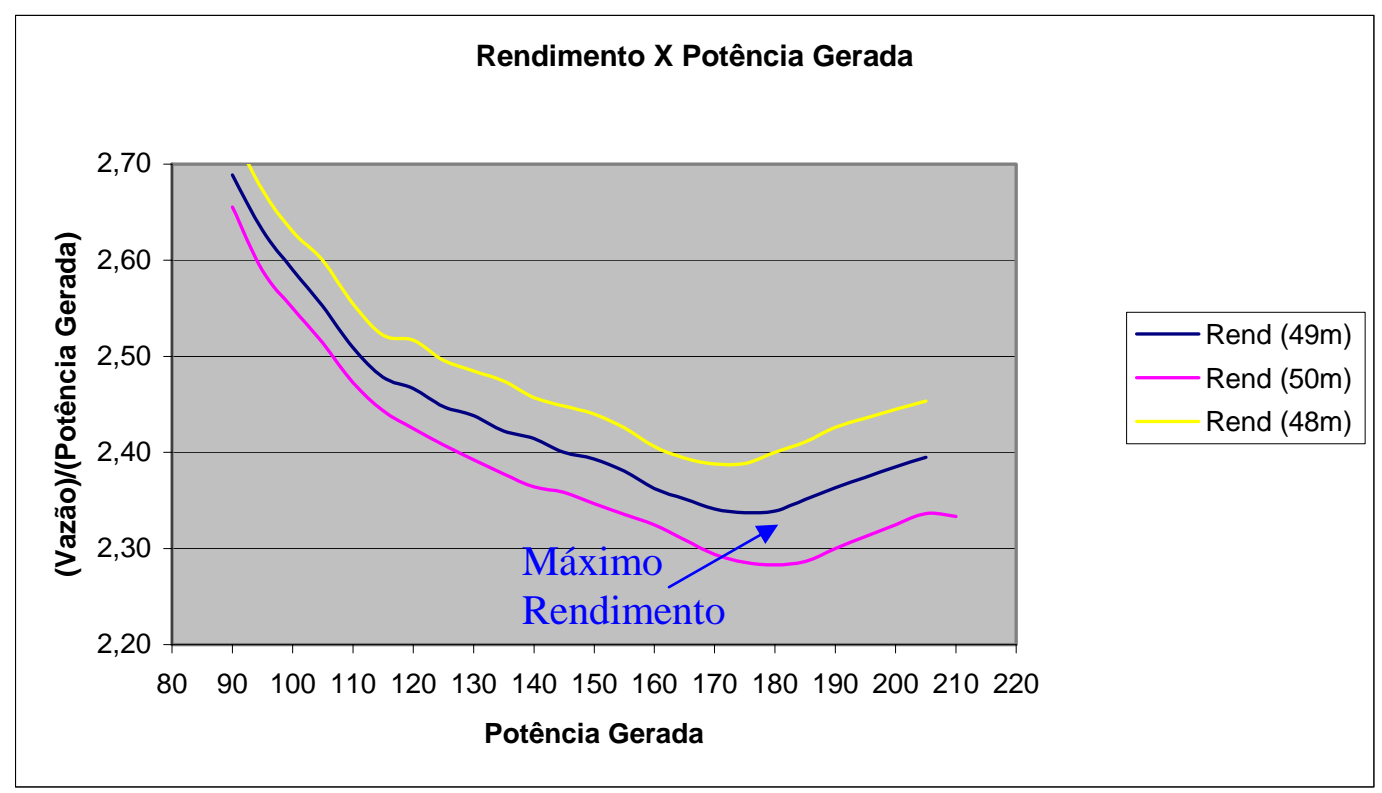

Figura 3.5. Rendimentos para diferentes níveis de altura de queda.

A partir da Figura 3.5 é possível observar o ponto de máxima geração de potência ativa para uma mínima vazão unitária. Esse ponto é definido como ponto de máximo rendimento e é representado pelo mínimo da função.

A Figura 3.5 permite observar que para uma mínima vazão unitária a geração máxima de potência ativa está em torno dos 175MW por unidade geradora. Assim, é possível observar que, para as medições realizadas junto a UHE de Água Vermelha (Tabela 3.1), em determinados períodos de tempo as unidades geradoras estavam operando longe de seu melhor rendimento. Essa distância com relação ao melhor rendimento, com o objetivo de prover reserva de potência ativa, afeta a eficiência global da usina, fazendo com que o custo de geração global da unidade aumente de forma significativa.

Desta forma, faz-se necessário a determinação de alternativas que melhorem o rendimento do processo de geração. A Tabela 3.1 representa o ponto de operação utilizado pelas unidades geradoras e a Tabela 3.2 representa uma opção que vêm a contribuir para a melhora do rendimento das mesmas. 
Tabela 3.1. Gerações da UHE de Água Vermelha no dia 21/11/2002*.

\begin{tabular}{|c|c|c|c|c|c|c|c|}
\hline \multirow{2}{*}{ Hora } & \multicolumn{6}{|c|}{ Controle de Geração (MWh) } & \multirow{2}{*}{$\begin{array}{c}\text { Geração } \\
\text { Total }\end{array}$} \\
\hline & UG1 & UG2 & UG3 & UG4 & UG5 & UG6 & \\
\hline 00 & 135 & 190 & 175 & 175 & 170 & 180 & 1025 \\
\hline 01 & 0 & 190 & 60 & 70 & 195 & 90 & 605 \\
\hline 02 & 0 & 195 & 0 & 0 & 200 & 0 & 395 \\
\hline 03 & 0 & 135 & 0 & 0 & 135 & 0 & 270 \\
\hline 04 & 0 & 125 & 0 & 0 & 130 & 0 & 255 \\
\hline 05 & 0 & 125 & 0 & 0 & 125 & 0 & 250 \\
\hline 06 & 0 & 180 & 0 & 0 & 175 & 0 & 355 \\
\hline 07 & 180 & 190 & 0 & 175 & 185 & 0 & 730 \\
\hline 08 & 185 & 200 & 170 & 180 & 200 & 50 & 985 \\
\hline 09 & 200 & 195 & 70 & 205 & 195 & 205 & 1070 \\
\hline 10 & 190 & 195 & 200 & 205 & 195 & 195 & 1180 \\
\hline 11 & 200 & 200 & 200 & 205 & 205 & 200 & 1210 \\
\hline 12 & 200 & 200 & 200 & 200 & 190 & 195 & 1185 \\
\hline 13 & 200 & 200 & 200 & 200 & 195 & 200 & 1195 \\
\hline 14 & 185 & 195 & 195 & 200 & 200 & 195 & 1170 \\
\hline 15 & 200 & 195 & 200 & 200 & 195 & 200 & 1190 \\
\hline 16 & 195 & 195 & 185 & 200 & 195 & 200 & 1170 \\
\hline 17 & 190 & 190 & 175 & 195 & 195 & 190 & 1135 \\
\hline 18 & 195 & 145 & 130 & 140 & 140 & 135 & 885 \\
\hline 19 & 135 & 130 & 130 & 130 & 130 & 135 & 790 \\
\hline 20 & 160 & 140 & 140 & 150 & 150 & 150 & 890 \\
\hline 21 & 195 & 195 & 190 & 195 & 190 & 195 & 1160 \\
\hline 22 & 195 & 200 & 195 & 200 & 195 & 195 & 1180 \\
\hline 23 & 195 & 200 & 190 & 195 & 200 & 195 & 1175 \\
\hline 24 & 130 & 165 & 175 & 165 & 170 & 175 & 980 \\
\hline
\end{tabular}

*Alguns exemplos de medições de potência ativa da UHE de Água Vermelha são apresentados no Apêndice 2.

Os despachos horários apresentados em vermelho na Tabela 3.1 deveriam ser otimizados a fim de alcançar o valor mais próximo ao máximo rendimento das máquinas, que está por volta de 175MW, conforme Figura 3.5. Caso não haja uma otimização no despacho das máquinas o custo de atendimento da demanda tende a ser maior, se comparado com o ponto de máximo rendimento. A Tabela 3.2 apresenta uma alternativa de despacho das máquinas de forma a proporcionar um melhor rendimento ao grupo turbina/gerador e como conseqüência uma economia no 
uso de água. Os valores apresentados em azul representam uma alternativa de redespacho das máquinas.

Tabela 3.2. Alternativa de gerações da UHE de Água Vermelha para o dia 21/11/2002.

\begin{tabular}{|c|c|c|c|c|c|c|c|}
\hline \multirow[t]{2}{*}{ Hora } & \multicolumn{6}{|c|}{ Controle de Geração (MWh) } & \multirow{2}{*}{$\begin{array}{c}\text { Geração } \\
\text { Total }\end{array}$} \\
\hline & UG1 & UG2 & UG3 & UG4 & UG5 & UG6 & \\
\hline 00 & 150 & 175 & 175 & 175 & 175 & 175 & 1025 \\
\hline 01 & 0 & 170 & 0 & 135 & 170 & 130 & 605 \\
\hline 02 & 0 & 195 & 0 & 0 & 200 & 0 & 395 \\
\hline 03 & 0 & 135 & 0 & 0 & 135 & 0 & 270 \\
\hline 04 & 0 & 125 & 0 & 0 & 130 & 0 & 255 \\
\hline 05 & 0 & 125 & 0 & 0 & 125 & 0 & 250 \\
\hline 06 & 0 & 180 & 0 & 0 & 175 & 0 & 355 \\
\hline 07 & 180 & 190 & 0 & 175 & 185 & 0 & 730 \\
\hline 08 & 170 & 170 & 170 & 170 & 170 & 135 & 985 \\
\hline 09 & 175 & 175 & 180 & 175 & 185 & 180 & 1070 \\
\hline 10 & 190 & 195 & 200 & 205 & 195 & 195 & 1180 \\
\hline 11 & 200 & 200 & 200 & 205 & 205 & 200 & 1210 \\
\hline 12 & 200 & 200 & 200 & 200 & 190 & 195 & 1185 \\
\hline 13 & 200 & 200 & 200 & 200 & 195 & 200 & 1195 \\
\hline 14 & 185 & 195 & 195 & 200 & 200 & 195 & 1170 \\
\hline 15 & 200 & 195 & 200 & 200 & 195 & 200 & 1190 \\
\hline 16 & 195 & 195 & 185 & 200 & 195 & 200 & 1170 \\
\hline 17 & 190 & 190 & 175 & 195 & 195 & 190 & 1135 \\
\hline 18 & 180 & 180 & 175 & 175 & 175 & 0 & 885 \\
\hline 19 & 158 & 158 & 158 & 158 & 158 & 0 & 790 \\
\hline 20 & 180 & 180 & 180 & 175 & 175 & 0 & 890 \\
\hline 21 & 195 & 195 & 190 & 195 & 190 & 195 & 1160 \\
\hline 22 & 195 & 200 & 195 & 200 & 195 & 195 & 1180 \\
\hline 23 & 195 & 200 & 190 & 195 & 200 & 195 & 1175 \\
\hline 24 & 130 & 170 & 170 & 170 & 170 & 170 & 980 \\
\hline
\end{tabular}

Realizada uma avaliação diária, algumas variáveis e efeitos foram analisados com o objetivo de definir se os mesmos deveriam ou não ser considerados na formulação da metodologia proposta e qual seria o impacto da não consideração dos mesmos. As variáveis e efeitos considerados foram: perdas elétricas, perdas hidráulicas e efeito de afogamento. 


\subsubsection{Perdas elétricas}

Com a opção de atender à demanda com um número menor de máquinas há um aumento das perdas elétricas na usina. Considerando-se que a perda nominal no gerador e transformador seja de $0,65 \%$, então a diferença de perdas para a geração total $P_{T}$ com diferentes números de máquinas (N1=6 e N2=5) será:

$$
\Delta P=0,0065 * 250 *\left(\frac{P_{T}}{250}\right)^{2} *\left(\frac{1}{N 2}-\frac{1}{N 1}\right)
$$

Considerando os dados das Tabelas 3.1 e 3.2, tem-se:

Tabela 3.3. Cálculo do aumento das perdas elétricas pela diminuição do número de máquinas.

\begin{tabular}{|c|c|c|c|c|}
\hline Hora & N1 & N2 & PT (MW) & $\begin{array}{c}\text { Diferença perdas } \\
\text { (MWh) }\end{array}$ \\
\hline 01 & 5 & 4 & 605 & 0,48 \\
\hline 18 & 6 & 5 & 885 & 0,68 \\
\hline 19 & 6 & 5 & 790 & 0,54 \\
\hline 20 & 6 & 5 & 890 & 0,68 \\
\hline Total & & & & 2,38 \\
\hline
\end{tabular}

Portanto o aumento de perdas elétricas é de 2,38 MWh em um dia.

Considerando que para o mesmo dia em análise o máximo rendimento é obtido para potência gerada em torno de 175 MW e que se, por exemplo, às 19hs fossem utilizadas 5 máquinas, gerando 158 MW (ponto mais favorável em eficiência), as vazões necessárias nas duas alternativas estão indicadas na Tabela 3.4: 
Tabela 3.4. Vazões calculadas para a geração referente às 19hs na Tabela 3.1 e 3.2 .

\begin{tabular}{|c|c|c|c|c|}
\hline $\mathrm{N}^{\mathrm{o}}$ de máq. & MW/máq & $\mathrm{m} 3 / \mathrm{s} / \mathrm{MW}$ & $\mathrm{m} 3 / \mathrm{s}$ (total) & $\%$ \\
\hline 6 & 131,7 & 2,43 & 1920 & 102,5 \\
\hline 5 & 158 & 2,37 & 1872 & 100 \\
\hline
\end{tabular}

A diferença de água equivale a $0,025 \times 790=19,8 \mathrm{MW}$ naquela hora, portanto 19,8 MWh, [0,025 = (1920/1872)-1].

Observa-se também na Tabela 3.1, que para os horários 01h, 18h, 20h dever-se-ia realizar o mesmo procedimento de se utilizar uma máquina a menos para se ter um melhor rendimento. Cálculo semelhante ao descrito leva a uma economia de água equivalente a 20,2 MWh, 20,8 MWh e 20,9 MWh respectivamente. A economia de energia naquele dia devido à operação próximo ao ponto de melhor rendimento foi de 81,7 MWh.

Considerando que o valor das perdas elétricas representa aproximadamente 3\% da energia perdida devido à operação fora do melhor rendimento, objetivo principal de nossa análise, optou-se por não considerar esta variável na formulação da metodologia proposta.

\subsubsection{Perdas hidráulicas}

Quando a água flui dentro de uma usina hidroelétrica, há uma perda de energia por causa do atrito contra algumas estruturas da usina, tais como: a estrutura de adução, a entrada do canal de adução, o canal de adução, o caracol da turbina, a turbina e o tubo de sucção.

Apesar de todas as perdas deverem ser consideradas em benefício da precisão do modelo, apenas as três primeiras são consideradas diretamente no cálculo das perdas 
hidráulicas. As outras são consideradas de forma indireta no cálculo da eficiência da turbina. A adoção desta metodologia simplifica a árdua tarefa de medir perdas em um ambiente turbulento, tal como o caracol da turbina ou o tubo de sucção.

Como descrito anteriormente, dependendo dos objetivos da operação e dos dados disponíveis, as perdas hidráulicas, também conhecidas como perdas de carga, podem ser estimadas a partir dos seguintes modelos: perdas hidráulicas constantes, perdas hidráulicas proporcionais à queda bruta e perdas hidráulicas proporcionais ao quadrado da vazão turbinada.

Considerando os dados disponibilizados no Sistema de Informações do Potencial Hidrelétrico Brasileiro - SIPOT, desenvolvido pela ELETROBRÁS (1994), o valor constante médio das perdas hidráulicas para a UHE de Água Vermelha, utilizado no cálculo da altura de queda líquida, é igual a 0,59 metros. Para a UHE de Água Vermelha, o valor das perdas hidráulicas representa 1,1\% da altura de queda de referência, 53,5 metros.

O valor das perdas hidráulicas sendo considerado uma constante, a diminuição do consumo de água obtido a partir da otimização da eficiência do conjunto turbina/gerador não irá influenciar no aumento ou na diminuição do valor das perdas hidráulicas. Essa característica permitiu a não consideração das perdas hidráulicas como uma variável na formulação da metodologia proposta. 


\subsubsection{Efeito de afogamento}

O efeito de afogamento do canal de fuga é definido como o efeito causado pelo aumento da vazão defluente e consequentemente pelo aumento do nível de jusante, reduzindo assim a queda d’água.

Tendo o presente trabalho o objetivo de atender uma mesma demanda de geração considerando a utilização de uma quantidade menor de combustível, a partir da otimização da eficiência do conjunto turbina/gerador, faz com que não se tenha que inserir este efeito à formulação da metodologia proposta. Isto porque, a utilização de uma quantidade menor de combustível reduz a vazão defluente, não havendo aumento do nível de afogamento do canal de fuga.

A partir da verificação da possibilidade de melhorar o rendimento das máquinas, otimizando o serviço de reserva de potência ativa e reduzindo o consumo de combustíveis, neste caso a água, o próximo passo foi a proposição de uma metodologia para determinar a economia gerada ao longo de um ano.

\subsubsection{Avaliação Anual}

Com o objetivo de verificar o benefício que o redespacho das máquinas, buscando um melhor rendimento, traria ao agente gerador, o próximo passo foi realizar o cálculo com base anual. O ano base utilizado para realização dos cálculos foi 2002. Os dados referentes ao ano de 2002 foram medidos de hora em hora.

Para esta avaliação foram realizados quatro testes. O primeiro teste realizado foi considerar que todas as máquinas em operação da UHE de Água Vermelha estariam 
trabalhando com a mesma geração. Esta hipótese é resultado da aplicação da teoria de Despacho Econômico apresentada anteriormente e tem como objetivo quantificar a economia de energia caso fosse adotado esta característica operacional. Para isso foi realizada uma aproximação da curva de Vazão X Potência Ativa gerada por uma função do segundo grau. Essa aproximação possibilita também a estimação da vazão necessária para gerar uma potência (MW) que estivesse fora do intervalo de valores contidos no banco de dados do Apêndice 2 (entre 90 e 240 MW).

A partir da Figura 3.6 é possível observar que para os intervalos de vazões contidos no banco de dados do Apêndice 2, essa aproximação para uma função do segundo grau resulta em uma curva bastante semelhante a original.

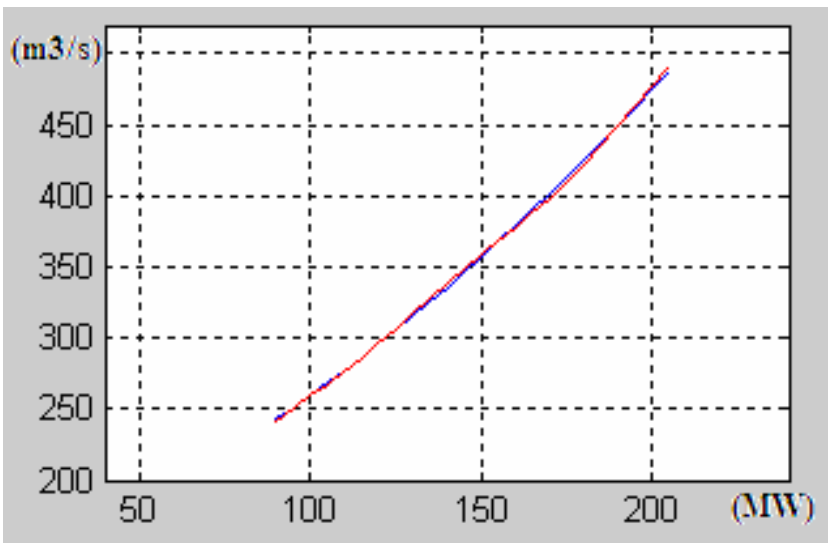

Figura 3.6. Curva de Vazão (eixo y) com relação a Potência Ativa gerada (eixo x).

A curva em vermelho apresentada na Figura 3.6 é referente à aproximação realizada e a curva em azul refere-se aos valores dados. Com a aproximação desta curva para uma função do segundo grau e com base na teoria de Despacho Econômico apresentada anteriormente conclui-se que para um mesmo número de máquinas (considerando todas iguais), a melhor regra operativa é que elas estejam gerando a mesma potência ativa. 
Determinada a função que representa a curva de rendimento das máquinas, o próximo passo foi determinar a vazão utilizada para gerar as potências medidas e determinar a vazão que seria utilizada caso as máquinas estivessem operando com igual valor de geração (de forma a atender toda a demanda). Determinadas estas vazões, foi então calculada a diferença entre estes valores e em seguida convertida esta diferença de vazão para MW, tendo como base a potência que cada máquina estaria gerando caso a política operativa fosse a de que todas estivesse gerando a mesma potência.

Esta diferença encontrada foi denominada de Economia de Energia. O valor encontrado de Economia de Energia para o teste descrito foi de 7.853 MWh no ano base.

Em seguida foi realizado um novo teste que mediu a Economia de Energia caso no despacho da UHE se optasse por atender a demanda com $\mathrm{N}-1$ máquinas (sendo $\mathrm{N}$ o número de máquinas originalmente despachadas), todas com a mesma geração. Para realização deste teste foram adotadas algumas condições:

1. Caso na hora analisada, a UHE estivesse operando com apenas 2 máquinas, a opção adotada foi continuar operando com 2 máquinas, ambas com igual geração;

2. Caso a potência gerada nas máquinas, no caso de estar sendo usado N-1 máquinas, ultrapasse seu valor de geração máxima, a opção adotada foi continuar operando com o número de máquinas inicial, todas com a mesma geração; 
3. Caso a opção de se usar N-1 máquinas não trouxesse um benefício, ou seja, uma Economia de Energia, a opção adotada foi continuar operando como inicialmente;

4. Caso contrário foi escolhido atender a demanda com N-1 máquinas, todas gerando igual potência.

Atendidas a estas condições, determinou-se a vazão utilizada para gerar as potências medidas nas máquinas para o ano de 2002 e também a vazão que seria utilizada para atender as condições impostas. Determinadas estas vazões foi então calculada a diferença entre estes valores e em seguida convertida esta diferença de vazão para MW, tendo como base a potência que cada máquina estaria gerando caso a política operativa fosse a de atender a demanda segundo as condições impostas.

Esta diferença encontrada foi denominada de Economia de Energia 2. O valor encontrado de Economia de Energia 2 foi de 43.625 MWh no ano base. Esse valor refere-se a 0,77\% da geração total da UHE de Água Vermelha, no ano de 2002.

Como dito anteriormente, a vazão necessária para gerar uma potência que estivesse fora do intervalo contido no banco de dados apresentado no Apêndice 2 (90 a 240 MW) foi estimada a partir de uma função do segundo grau. Essa estimação poderia trazer alguns erros aos valores de Economia de Energia obtidos. Com o objetivo de assegurar que estes erros não fossem cometidos, foi proposto um conjunto de testes denominados de “Testes Otimistas”.

Este conjunto de testes é o mesmo realizado anteriormente com a diferença de que as vazões que anteriormente eram estimadas pela equação do segundo grau, agora serão obtidas considerando que o rendimento das máquinas que operam com 
uma potência inferior a 90MW são iguais ao rendimento da máquina operando com 90MW.

Para este conjunto de testes, o valor encontrado de Economia de Energia foi de 3.548 MWh no ano base e o valor encontrado de Economia de Energia 2 foi de 35.555 MWh no ano base . Esse valor encontrado de Economia de Energia 2 referese a 0,62\% da geração total da UHE de Água Vermelha, no ano de 2002. A Figura 3.7 ilustra este conjunto de testes.
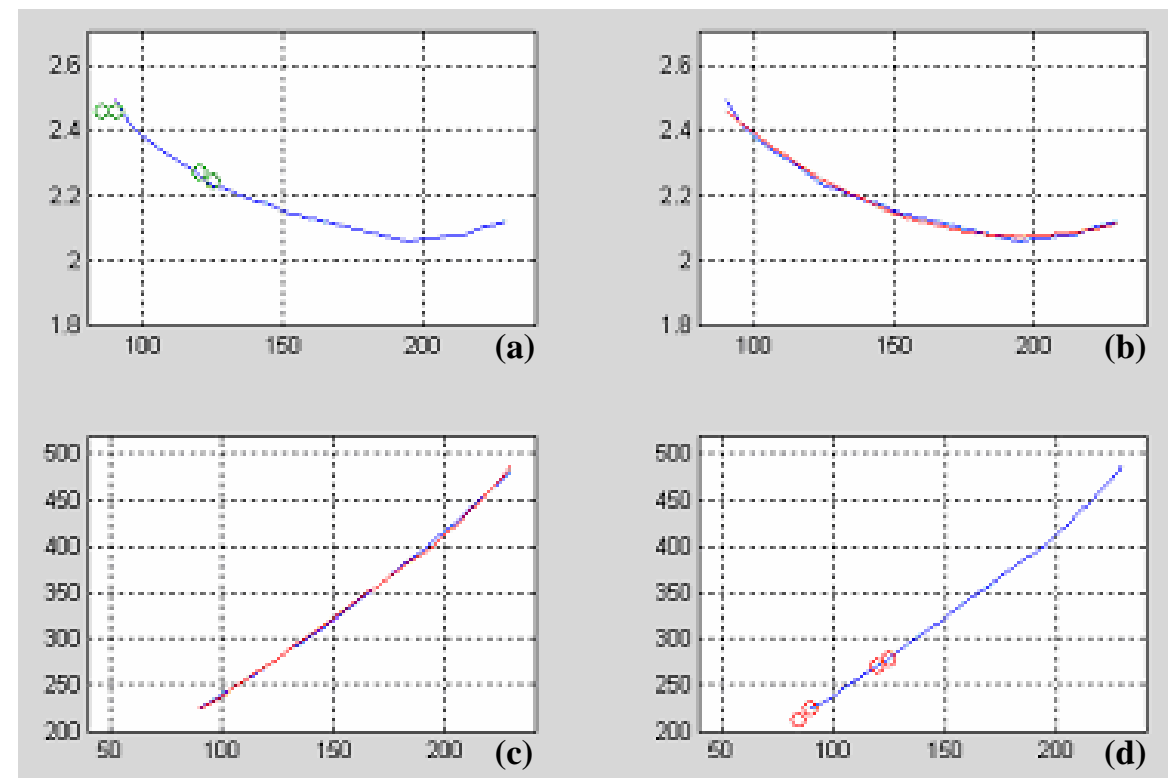

Figura 3.7. Testes considerando que o rendimento das máquinas que operam com uma potência inferior a 90MW é igual ao rendimento das máquinas operando com 90MW.

A Figura 3.7a ilustra a curva representativa do quociente entre (vazão/potência gerada) e potência gerada, (eixo y e x respectivamente). Os pontos em verde são gerações em um dado instante de tempo. Pode-se observar que neste instante de tempo existem gerações com valor inferior a 90MW. Para estes pontos foi assumido o mesmo quociente (vazão/potência gerada) utilizado para uma geração de 90MW. Este foi o diferencial do conjunto de testes denominado por “Otimistas”. 
A Figura 3.7b ilustra a curva obtida a partir do banco de dados do quociente vazão/potência gerada (eixo y) e potência gerada (eixo x) - curva em azul, e a curva obtida para uma função do segundo grau originada da regressão dos pontos contidos no banco de dados da relação vazão/potência gerada e potência gerada - curva em vermelho. A Figura 3.7b mostra a semelhança entre as duas curvas.

A Figura 3.7c ilustra a curva obtida a partir do banco de dados da vazão (eixo y) e potência gerada (eixo x) - curva em azul, e a curva obtida para uma função do segundo grau originada da regressão dos pontos contidos no banco de dados da vazão e potência gerada - curva em vermelho.

A Figura 3.7d ilustra a curva obtida a partir do banco de dados da relação vazão (eixo y) e potência gerada (eixo x). Os pontos ilustrados em vermelho são os dados de vazões para determinadas potências de geração em um dado instante de tempo. Pode-se observar que para as gerações abaixo de 90MW os valores de vazões são proporcionais aos valores apresentados para de geração igual à 90MW.

\subsection{Conclusões Parciais}

Com base nas alternativas propostas e suas soluções pode-se observar que a economia alcançada com a otimização da reserva de potência ativa pode chegar a ordem de US\$ 400.000,00 por ano no caso de se considerar o valor do MWh à US\$ 10,00 (Dez dólares). Esse valor do MWh baseia-se no Preço de Liquidação de Diferenças (PLD) para o período de agosto de 2005, preço este escolhido apenas para ilustrar o valor financeiro alcançado com a otimização da reserva de potência ativa.

Essa economia de energia apresentada nas soluções propostas está relacionada ao 
custo de oportunidade resultante da prestação do serviço de reserva de potência ativa.

No caso do Sistema Interligado Nacional onde existe o Mecanismo de Realocação de Energia elétrica $\left(\mathrm{MRE}^{1}\right)$ não há um estímulo à utilização mais eficiente por parte das usinas hidroelétricas uma vez que enquanto as usinas mantiverem sua eficiência em patamares iguais ou superiores àqueles empregados no cálculo de suas energias asseguradas, as mesmas terão sua participação na produção hidroelétrica total em proporção às respectivas energias asseguradas, não existindo nenhum ganho associado a um eventual aumento de eficiência.

Ao contrário do que ocorre nestes casos, há instantes em que as usinas são solicitadas pelo Operador do Sistema a proverem o serviço de reserva de potência ativa de maneira a operarem em uma configuração cuja eficiência é menor que a empregada no cálculo de suas energias asseguradas. Nestes instantes, as usinas prestadoras do serviço de reserva estão sujeitas a um consumo maior de combustível, resultando em um prejuízo sistêmico oriundo de um despacho distante da melhor eficiência.

Desta forma, caso o Operador do Sistema requeira que os agentes geradores trabalhem com uma configuração onde as unidades geradoras necessitem operar em pontos cuja eficiência é menor que a empregada no cálculo de suas energias asseguradas é interessante que se tenha uma compensação aos agentes pela prestação deste serviço. Isso porque os mesmos estariam consumindo uma quantidade de combustível maior que a que realmente consumiria para atender a demanda, não considerando os gastos com pessoal e manutenção.

\footnotetext{
${ }^{1} \mathrm{O}$ Mecanismo de Realocação de Energia é um mecanismo de compartilhamento do risco hidrológico entre as usinas hidroelétricas e baseia-se na atribuição de uma Energia Assegurada a cada usina hidroelétrica do Sistema Interligado, e na repartição de toda a geração hidroelétrica proporcionalmente a estas energias asseguradas.
} 


\section{Suporte de Potência Reativa}

\subsection{Introdução}

Este Capítulo abordará o serviço de suporte de potência reativa, responsável pela segurança operativa do suprimento de energia elétrica, de forma a melhorar os perfis de tensão do sistema, mantendo-os o mais próximo de seus valores nominais; e a minimizar as perdas do sistema, em condições normais e de contingência, SOUSA (2003).

Em determinadas situações, como por exemplo, variações de carga e perda de componentes (linhas de transmissão e ou geradores), podem ocorrer desvios de tensão que são indesejáveis para uma operação normal. Nestas situações, para a obtenção do perfil de tensão desejado, utiliza-se o suporte de potência reativa a partir da instalação de equipamentos de geração/absorção de potência reativa, como: capacitores; reatores; compensadores síncronos e estáticos; e através da utilização das unidades geradoras das usinas, PRADA et al. (2003).

O suporte de potência reativa ao sistema possui alguns requisitos que devem ser considerados. São eles: 
- Existem inúmeras variações regionais em relação à necessidade de suporte de potência reativa na rede de transmissão;

- Existem variações diárias em relação às necessidades de suporte de potência reativa, originadas da natureza da demanda e da forma de controle das tensões no sistema;

- Há necessidade de uma considerável flexibilidade nas fontes de potência reativa que permita tanto a produção como a absorção de VAr em diferentes momentos do dia e em quantidades variadas;

- Os problemas de controle de tensão são exacerbados pelas longas distâncias da transmissão no Brasil o que faz com que o controle local de VAr represente uma necessidade patente.

Esses pontos apresentam inúmeras implicações para o desenvolvimento do suporte de potência reativa, em todas as suas formas, como um Serviço Ancilar.

Assim, o nível preciso de segurança e disposição que é requerido do suporte de potência reativa para atender o Operador deve ser estabelecido previamente e de maneira economicamente positiva. Os critérios que um operador deverá seguir podem variar de sistema para sistema.

Independente da forma de obtenção do serviço de suporte de potência reativa, uma etapa importante no fornecimento deste é o conhecimento dos seus custos. Isto requer ferramentas que permitam determinar os custos de provisão do serviço e ferramentas que permitam alocar o custo entre as partes responsáveis pela necessidade dos serviços. 
Neste trabalho, será tratado apenas o custo de fornecimento a partir dos geradores. O custo de prover suporte de potência reativa a partir de geradores consiste de duas componentes:

- Uma variável (custo de produção) que consiste principalmente das perdas elétricas;

- E a outra representada pelo custo fixo da geração de potência reativa, que consiste do custo de capital, custo operacional fixo e custos fixos de manutenção. Estes custos agem diferentemente dependendo do tipo de equipamento usado no sistema.

Com base nos custos apresentados, vários trabalhos têm sido desenvolvidos com o objetivo de valorar o fornecimento de suporte de potência reativa a partir de unidades de geração.

\subsection{Técnicas para Valoração do Suporte de Potência Reativa}

Vários trabalhos têm sido publicados com o objetivo de definir ferramentas e/ou metodologias para a valoração e alocação dos custos de prover o suporte de potência reativa. A seguir serão apresentados alguns trabalhos que visam este objetivo.

DANDACHI et al. (1996) propuseram o uso da ferramenta Fluxo de Potência Ótimo (FPO), com restrição de segurança, para valorar o despacho de potência reativa. O algoritmo de FPO usado é baseado em programação linear seqüencial de maneira que a curva de custo de potência reativa utilizada como função objetivo seja representada por uma função linear ou uma função quadrática. A metodologia 
apresentada foi testada a partir de um típico modelo de sistema NGC (National Grid Company) - operador do sistema da Inglaterra e do país de Gales.

HAO \& PAPALEXOPOULOS (1997) abordam os aspectos técnicos e econômicos para determinação da estrutura de preços do suporte de potência reativa em um ambiente de acesso livre. Os autores apresentam vários métodos de alocação dos custos para remunerar o suporte de potência reativa e propõe duas estruturas para valoração da potência reativa. A primeira estrutura baseou-se nos padrões de desempenho do sistema e a segunda baseou-se no mercado de potência reativa local.

EL-KEIB \& MA (1997) publicaram uma formulação com o objetivo de valorar a potência ativa e a potência reativa. A abordagem proposta permite a valoração da potência ativa e reativa simultaneamente (ou independentemente) através da formulação do Fluxo de Potência Ótimo Desacoplado. A formulação consiste na separação do problema em dois subproblemas: P-subproblema, representado pela otimização da geração; e Q-subproblema. O Q-subproblema é formulado como um problema de minimização das perdas do sistema (minimização do custo de produção da barra de referência) atendendo as limitações físicas do sistema. A formulação proposta para cálculo do custo da potência ativa e reativa foi implementada a partir do pacote de programação linear LINDO 5.0.

LAMONT \& FU (1999) propuseram uma metodologia com o objetivo de analisar o custo do suporte de potência reativa. Os autores apresentam as parcelas que compõem o custo do suporte de potência reativa. Parcelas estas que foram separadas como custos explícitos e custos implícitos. Custos explícitos foram definidos como sendo os custos que devem ser pagos diretamente e os custos implícitos referem-se 
ao custo de oportunidade. A metodologia proposta utiliza programação linear com o objetivo de minimizar o custo total de despacho de potência reativa.

DOÑA \& PAREDES (2001) apresentaram uma metodologia para o cálculo de preços baseados na teoria de custos marginais de potência ativa e reativa a partir de técnicas de otimização desacoplada. Para o modelo de otimização desacoplado foram usadas como funções objetivos a minimização do custo de operação e a minimização das perdas de transmissão. A metodologia desenvolvida foi aplicada no sistema argentino, onde redes regionais, gerações térmicas e hidráulicas e cargas são consideradas como equivalentes em barras de $500 \mathrm{kV}$.

GROSS et al. (2002) apresentaram uma exposição sistemática do suporte de potência reativa, a partir de unidades geradoras, como um Serviço Ancilar independente em um sistema de transmissão de livre acesso. O trabalho apresentou: uma revisão das características físicas e naturais do serviço de suporte de potência reativa; uma análise do componente dominante da estrutura do custo do serviço; e as considerações chaves na aquisição e valoração do serviço em um ambiente de livre acesso. Os autores apresentaram como sendo o custo de oportunidade, o componente dominante do custo de fornecimento do suporte de potência reativa.

JARDINI et al. (2002) propuseram uma análise técnica e econômica determinando os incrementos de energia reativa de unidades geradoras e de perdas no sistema de transmissão, devido à variação do fator de potência das cargas supridas por elas. A análise econômica levou em consideração o custo incremental das perdas ativas ocorridas no conjunto gerador/transformador elevador e das perdas ativas na transmissão, resultantes da circulação adicional de potência reativa. Em seguida, foi realizada uma comparação com o custo referente à instalação capacitores diretamente 
nas barras de carga do sistema, diminuindo a geração adicional de potência reativa por parte das unidades geradoras. Essa comparação, entre os resultados alcançados, foi utilizada para definir o valor mínimo e máximo do MVAr a ser cobrado pela prestação do serviço de suporte de potência reativa.

PRADA et al. (2003) apresentaram dois métodos baseados em técnicas de otimização e confiabilidade para identificar os beneficiários, e alocar entre eles os custos de expansão do suporte de potência reativa. O primeiro método define um fator de sensibilidade proporcional ao benefício que a instalação do equipamento de compensação de potência reativa traz a cada barra do sistema, definindo assim os beneficiários pela provisão do suporte de potência reativa. O segundo método define um fator de sensibilidade capaz de alocar os custos de provisão do suporte de potência reativa proporcional à parcela de responsabilidade de cada barra do sistema.

DAI et al. (2003) apresentaram um método de alocação dos custos do serviço de suporte de potência reativa baseado em Fluxo de Potência Ótimo. O custo da potência reativa foi separado em duas partes: o custo de produção da potência reativa e o custo de transmissão da potência reativa. Os custos de produção de potência reativa foram analisados separadamente para os geradores, compensadores síncronos e capacitores.

Após uma análise aos trabalhos apresentados anteriormente é possível verificar que, em sua maioria, foram utilizadas as ferramentas de Fluxo de Potência e de Fluxo de Potência Ótimo com o objetivo de otimizar o suporte de potência reativa e a partir de suas soluções definir ferramentas e/ou metodologias para a valoração e alocação dos custos do fornecimento do mesmo. Essa constatação permitiu a criação de 
subsídios técnicos para utilização do Fluxo de Potência e do Fluxo de Potência Ótimo na realização do presente trabalho, cujas teorias serão apresentadas a seguir.

\subsection{Teoria de Fluxo de Potência e Fluxo de Potência Ótimo}

\subsubsection{Fluxo de Potência}

Considere-se a modelagem do sistema elétrico de potência representada por um conjunto de equações e inequações algébricas. Assim, a solução do problema de Fluxo de Potência tem como objetivo determinar o ponto de operação do sistema de energia elétrica. Estas equações são obtidas impondo-se o princípio da conservação das potências ativas e reativas em cada barra do sistema, enquanto que as inequações podem ser dadas pelas restrições das magnitudes de tensões e pelos limites das injeções de potência reativa nas barras de controle de reativo.

As equações básicas do Fluxo de Potência para um sistema elétrico são dadas por MONTICELLI (1983):

$$
\begin{aligned}
& P_{K}=V_{K} \sum_{m \in \Omega} V_{m}\left(G_{K m} \cos \theta_{K m}+B_{K m} \operatorname{sen} \theta_{K m}\right) \\
& Q_{K}=V_{K} \sum_{m \in \Omega} V_{m}\left(G_{K m} \operatorname{sen} \theta_{K m}-B_{K m} \cos \theta_{K m}\right)
\end{aligned}
$$

Sendo $k=1, \ldots, N B ; N B$ o número de barras da rede; $G_{k m}$ e $B_{k m}$ os valores de condutância e susceptância entre as barras $k$ e $m ; \mathrm{P}, \Theta$ e $\mathrm{V}$, os valores de potência ativa, ângulo e tensão das barras $k$ e $m$, respectivamente. 
Os métodos para o cálculo do Fluxo de Potência em geral são constituídos de duas partes: a primeira que trata da resolução dos métodos iterativos de um sistema de equações algébricas do tipo (4.1); e a segunda parte do processo de resolução do problema considera a atuação dos dispositivos de controle e representação dos limites de operação do sistema. Estas duas partes podem ser resolvidas alternadamente ou alterando-se as Equações 4.1 para incluir a representação dos dispositivos de controle.

Considere que um sistema elétrico é formado por três tipos de barras: Barra de Carga (PQ), Barra de Geração (PV) e Barra de Referência (VӨ); e que para a solução do problema de Fluxo de Potência são dados a potência ativa $(\mathrm{P})$ e a potência reativa (Q) para as barras $\mathrm{PQ}$, a potência ativa $(\mathrm{P})$ e a tensão $(\mathrm{V})$ para as barras $\mathrm{PV}$ e a tensão

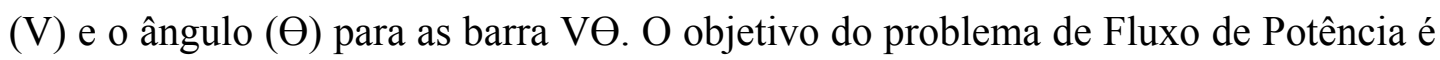
então calcular os valores de tensão e ângulo das barras PQ, ângulo e potência reativa das barras PV e, finalmente, potência ativa e reativa da barra VӨ. Desta forma, o problema anteriormente formulado pode ser apresentado da seguinte forma:

$$
\begin{aligned}
& \Delta P_{K}=P_{K}{ }^{e s p}-P_{K}(V, \theta)=0 \\
& \Delta Q_{K}=Q_{K}{ }^{e s p}-Q_{K}(V, \theta)=0
\end{aligned}
$$

Sendo $P_{k}^{e s p}$ e $Q_{k}^{e s p}$ os valores de potência ativa e reativa, especificados; $\mathrm{P}_{k}$ os valores das injeções de potência ativa nas barras $\mathrm{PQ}$ e $\mathrm{PV}$; e $\mathrm{Q}_{k}$ os valores das injeções de potência ativa nas barras PQ.

Um dos métodos utilizados para a solução do problema (Equação 4.2) é o método de Newton-Raphson, que consiste na expansão, em série de Taylor até $1^{\text {a }}$ ordem, das equações. O sistema linearizado (4.3) é resolvido iterativamente, até que o critério de convergência estabelecido seja atingido, MONTICELLI (1983). 


$$
g(x)=J(x) \Delta x
$$

Onde $g(x)$ representa o conjunto de equações:

$$
g(x)=\left[\begin{array}{l}
\Delta P(x) \\
\Delta Q(x)
\end{array}\right]=0
$$

e:

$x=$ vetor das variáveis dependentes, $x=\left[\begin{array}{l}\theta \\ V\end{array}\right]$;

$\Delta x=$ vetor das correções;

$J(x)=$ matriz Jacobiana.

A matriz Jacobiana é dada por:

$$
J=\left[\begin{array}{ll}
H & N \\
M & L
\end{array}\right]
$$

Sendo as componentes das submatrizes jacobianas $H, N, M, L$ dadas por:

$\mathrm{H}\left\{\begin{array}{l}H_{k m}=\partial P_{k} / \partial \theta_{m}=V_{k} V_{m}\left(G_{k m} \operatorname{sen} \theta_{k m}-B_{k m} \cos \theta_{k m}\right) \\ H_{k k}=\partial P_{k} / \partial \theta_{k}=-V_{k}^{2} B_{k k}-V_{k} \sum_{m \in K} V_{m}\left(G_{k m} \operatorname{sen} \theta_{k m}-B_{k m} \cos \theta_{k m}\right)\end{array}\right.$

$N\left\{\begin{array}{l}N_{k m}=\partial P_{k} / \partial V_{m}=V_{k}\left(G_{k m} \cos \theta_{k m}+B_{k m} \operatorname{sen} \theta_{k m}\right) \\ N_{k k}=\partial P_{k} / \partial V_{k}=V_{k} G_{k k}+\sum_{m \in K} V_{m}\left(G_{k m} \cos \theta_{k m}+B_{k m} \operatorname{sen} \theta_{k m}\right)\end{array}\right.$

$M\left\{\begin{array}{l}M_{k m}=\partial Q_{k} / \partial \theta_{m}=-V_{k} V_{m}\left(G_{k m} \cos \theta_{k m}+B_{k m} \operatorname{sen} \theta_{k m}\right) \\ M_{k k}=\partial Q_{k} / \partial \theta_{k}=-V_{k}^{2} G_{k k}+V_{k} \sum_{m \in K} V_{m}\left(G_{k m} \cos \theta_{k m}+B_{k m} \operatorname{sen} \theta_{k m}\right)\end{array}\right.$ 


$$
L\left\{\begin{array}{l}
L_{k m}=\partial Q_{k} / \partial V_{m}=V_{k}\left(G_{k m} \operatorname{sen} \theta_{k m}-B_{k m} \cos \theta_{k m}\right) \\
L_{k k}=\partial Q_{k} / \partial V_{k}=-V_{k} B_{k k}+\sum_{m \in K} V_{m}\left(G_{k m} \operatorname{sen} \theta_{k m}-B_{k m} \cos \theta_{k m}\right)
\end{array}\right.
$$

Outra forma de solução para o problema de Fluxo de Potência é o emprego dos Métodos Desacoplados. Estes métodos baseiam-se no fato das sensibilidades $\partial P / \partial \theta$ e $\partial Q / \partial V$ serem mais intensas que as sensibilidades $\partial P / \partial V$ e $\partial Q / \partial \theta$. Esse tipo de relação é geralmente verificado para redes de transmissão em extra-alta tensão e ultra-alta tensão.

Os Métodos Desacoplados podem ser apresentados em duas versões. A primeira conhecida como Método de Newton Desacoplado, as submatrizes $N$ e $M$ são feitas iguais a zero e as matrizes $H$ e $L$ são calculadas a cada iteração. Na segunda versão, chamada de Método Desacoplado Rápido, além de ignorar o efeito das submatrizes $N$ e $M$, as submatrizes $H$ e L são mantidas constantes durante o processo iterativo. Às submatrizes $H$ e $L$ do Método Desacoplado Rápido são introduzidas as seguintes aproximações: $\cos \Theta_{k m}$ é muito próximo de $1 ; B_{k m}$ é muito maior que $G_{k m} \operatorname{sen} \Theta_{k m}$; $B_{k k} V_{k}^{2}$ é muito maior que $Q_{k}$. Estas aproximações são válidas se considerarmos sistemas de transmissão (em particular extra-alta tensão e ultra-alta tensão) e que as reatâncias shunt, de uma rede de transmissão, são muito maiores que as reatâncias séries.

Considerando que as tensões das barras estão próximas aos seus valores unitários, as matrizes $H$ e $L$ podem ser aproximadas por $H^{\prime}$ e $L$ ', o que resulta em: 


$$
\begin{aligned}
& \Delta P / V=B^{\prime} \Delta \theta \\
& \Delta Q / V=B^{\prime \prime} \Delta V
\end{aligned}
$$

Sendo $B$ ' e $B$ "' a representação da matriz admitância da rede, com a diferença que $B$ ' não aparecem as linhas e colunas referentes às barras $V \Theta$ e em $B$ '” não aparecem as linhas e colunas referentes às barras $P V$ e as barras $V \Theta$.

Os métodos Desacoplados na forma como são apresentados aproximam o cálculo das derivadas do problema, mas mantêm a integridade da rede e, por isso, não afetam a solução final do Fluxo de Potência.

Quando as variáveis do problema de Fluxo de Potência são alteradas, resultantes de modificações na configuração da rede, como por exemplo, alterações na geração ou na carga, um ajuste nos equipamentos (variáveis de controle) é realizado para situações localizadas. À medida que há um aumento no número de variáveis de controle a serem ajustadas, para satisfazer as condições de operação do sistema, estes ajustes tornam-se um exaustivo processo de tentativas e erros. Neste caso o Fluxo de Potência Ótimo é o instrumento ideal, ajustando simultaneamente, de maneira ótima, todas as variáveis de controle do sistema satisfazendo, critérios pré-estabelecidos.

A seguir é apresentada uma introdução ao problema de Fluxo de Potência Ótimo.

\subsubsection{Fluxo de Potência Ótimo}

O problema de Fluxo de Potência Ótimo proposto no início da década de 60 por CARPENTIER (1962) foi elaborado com base no problema de despacho econômico, que compreende o quanto cada gerador tem de produzir de potência ativa para atender a demanda do sistema. 
Entre as técnicas de programação matemática, utilizadas em algoritmos para solução do Fluxo de Potência Ótimo, pode-se citar: programação linear sucessiva (PLS), programação quadrática e métodos de programação não linear baseados em métodos do tipo Newton, como por exemplo, a aplicação dos Métodos de Pontos Interiores (MPI).

GRANVILLE (1994) apresentou uma técnica que utiliza Métodos de Pontos Interiores na solução de problemas de despacho ótimo de reativos. O autor classificou o despacho ótimo de reativos como um caso particular do problema de Fluxo de Potência Ótimo. Na formulação do método de pontos interiores, o autor baseou-se no método de barreira logarítmica primal-dual, descrita para problemas de Programação Linear e Quadrática. O autor utilizou o sistema de geração/transmissão da região Sul/Sudeste brasileira para o ano de 1995 com o objetivo de ilustrar a metodologia proposta.

A partir da solução do problema de Fluxo de Potência Ótimo, é possível determinar o melhor ponto de operação do sistema através da otimização de uma função objetivo que representa um dado desempenho do sistema, como exemplo, a minimização das perdas ativas na transmissão, a minimização dos custos de geração, etc. O Fluxo de Potência Ótimo pode ser representado matematicamente através de um problema geral de otimização com restrições de igualdade e desigualdade como:

$$
\begin{array}{ll}
\text { Min } & f(x) \\
\text { s.a.: } & g(x)=0 \\
& \underline{h} \leq h(x) \leq \bar{h} \\
& \underline{x} \leq x \leq \bar{x}
\end{array}
$$


O vetor das variáveis de estado $x$ pode ser representado pela magnitude de tensão $(V)$ e pelo ângulo $(\theta)$. A função $f(x)$ é a função objetivo a ser minimizada e pode ser representada pelas perdas ativas na transmissão.

As restrições de igualdade $g(x)$ são as equações do Fluxo de Potência obtidas quando se impõe o princípio da conservação de potência em cada barra da rede. As restrições de desigualdade $h(x)$ representam as restrições funcionais, como a potência reativa nas barras de controle de reativos, os fluxos ativos e reativos nas linhas de transmissão, fluxo de intercâmbio, etc.

Ao rescrever (4.10) utilizando as equações de Fluxo de Potência, temos o seguinte problema de Fluxo de Potência Ótimo:

$$
\begin{aligned}
& \operatorname{Min} \sum_{i=1}^{N L} G_{i}\left[V_{k}^{2}+V_{m}^{2}-2 V_{k} V_{m} \cos \theta_{k m}\right] \\
& \text { s.a.: } \Delta P_{k}=0 \\
& k=1, \ldots, N B C G \\
& \Delta Q_{k}=0 \\
& k=1, \ldots, N B C \\
& \underline{Q}_{j} \leq Q_{j} \leq \bar{Q}_{j} \\
& j=1, \ldots, N B G \\
& \underline{F}_{m} \leq F_{m} \leq \bar{F}_{m} \\
& m=1, \ldots, N L \\
& \underline{V}_{k} \leq V_{k} \leq \bar{V}_{K} \\
& k=1, \ldots, N B
\end{aligned}
$$

Sendo NBCG o número de barras de carga e geração, NBC o número de barras de carga, NBG o número de barras de geração, NL o número de linhas e NB o número de barras do sistema. As restrições de desigualdades estão sendo representadas pelos limites de potência reativa das barras de geração, limite de fluxo nas linhas e limites de tensão das barras do sistema.

O problema de Fluxo de Potência Ótimo com a função objetivo representada pelas perdas ativas no sistema, Equação (4.11), é conhecido como Fluxo de Potência Ótimo Reativo. Essa definição se dá pelo fato de todas as variáveis associadas às 
potências ativas estarem fixas, com exceção da potência gerada na barra de referência.

Muitas técnicas de solução do problema de Fluxo de Potência Ótimo têm sido estudadas. A seguir são utilizados alguns trabalhos a fim de apresentar o que tem sido feito nos últimos anos relacionado a esta linha de pesquisa.

SOUSA (2001) apresentou o método primal-dual barreira logarítmica (PDBL) para a solução do problema de Fluxo de Potência Ótimo. A técnica de solução utiliza Pontos Interiores e tem se mostrado uma alternativa na solução de problemas de otimização de sistemas de potência. Com objetivo de descrever didaticamente a solução do problema de Fluxo de Potência Ótimo a partir de técnicas não lineares, o método primal-dual barreira logarítmica é apresentado no Apêndice 4.

BHATTACHARYA \& ZHONG (2001) apresentaram uma metodologia para a otimização do suporte de potência reativa. Os autores avaliaram o benefício marginal ao sistema a partir da otimização do Problema de Fluxo de Potência Ótimo, cuja função objetivo é representada pela minimização das perdas do sistema. Em seguida, a partir da otimização dos custos relacionados à potência reativa provida pelos geradores, os autores avaliaram o compromisso entre a melhor solução técnica e a solução mais segura financeiramente para o Operador do Sistema. Os autores utilizaram o método de simulação Monte Carlo para a obtenção da solução do problema.

PUDJIANTO et al. (2002) apresentaram algoritmos de Programação Linear e Programação Não-Linear com o objetivo de solucionar o problema de alocação ótima de potência reativa a partir de fontes geradoras em um ambiente desverticalizado. Os autores apresentaram as diferenças entre as características dos algoritmos, 
destacando o desempenho confiável dos algoritmos de programação linear; e a velocidade e precisão dos algoritmos de programação não-linear. Os autores apontaram à necessidade que os algoritmos de programação linear têm de utilizar técnicas que garantam a convergência do problema de alocação ótima de potência reativa. Os autores apresentaram uma seqüência de testes que mostrou que o algoritmo de programação não-linear foi mais rápido no processamento e apesar do algoritmo de programação linear apresentar um comportamento mais instável considerando as barras individualmente, ambos algoritmos apresentaram um comportamento global semelhante para o problema de suporte de potência reativa.

KHIAT et al. (2003) descreveram uma metodologia com o objetivo de apresentar uma solução para o problema de despacho de potência reativa e controle de tensão. Foi utilizado um modelo híbrido combinando técnicas de solução heurística e de solução numérica, para solução deste problema. A metodologia apresentada buscou impedir a violação da tensão das barras do sistema e caso não houvesse violação de tensão a resposta do despacho de potência reativa indicava para uma redução das perdas ativas do sistema.

ZHU \& XIONG (2003) propuseram a aplicação de Métodos de Pontos Interiores para a solução do problema de controle ótimo de potência reativa. Na metodologia proposta foram empregados dois passos para a obtenção da solução ótima. São eles: a classificação dos locais ótimos a serem alocadas fontes reativas e a determinação dos valores a serem alocados. Os autores utilizaram o problema de controle de potência reativa não-linear na sua forma linearizada, ficando o problema representado pelas matrizes de sensibilidade pertinentes ao problema. 
LIU et al. (2004) apresentaram um problema de Programação Linear aplicado à otimização da capacidade e da aquisição da potência reativa necessária para o bom funcionamento do sistema elétrico. O problema propõe a minimização do custo do fornecimento de potência reativa sujeito a um conjunto de restrições, representadas pelos limites operativos das barras de carga e das barras de geração.

Apresentada a formulação do problema de Fluxo de Potência Ótimo, bem como alguns trabalhos desenvolvidos para solução do mesmo, a seguir será apresentada a metodologia de solução do problema, a ser empregada no presente trabalho, para valoração do custo de fornecimento do suporte de potência reativa.

\subsection{Formulação do Problema de Otimização do Suporte de Potência Reativa}

O presente trabalho propõe uma metodologia com objetivo de minimizar o fornecimento do suporte de potência reativa prestado pelos agentes geradores e identificar quem oferece e quem utiliza esse serviço. Essa metodologia permitirá que os agentes tenham condições de indicar o grau de responsabilidade de cada um na necessidade de prestação do serviço de suporte de potência reativa.

Alternativamente à solução do problema de Fluxo de Potência Ótimo, apresentado no Apêndice 4, a metodologia proposta no presente trabalho utiliza uma solução linearizada do problema de Fluxo de Potência Ótimo podendo ter em sua função objetivo a minimização da potência reativa das barras do sistema ou a minimização das perdas ativas na transmissão. A este problema será imposto um 
conjunto de restrições, tais como: níveis de tensão do sistema, limites de reativos dos geradores e limites de potência reativa das cargas.

Essa alternativa foi escolhida inicialmente devido à dificuldade em se trabalhar com os parâmetros de controle impostos pelos algoritmos de Programação Não Linear propostos para solução do problema de Fluxo de Potência Ótimo, como apresentado pelo método descrito no Apêndice 4 .

Outro fator que contribuiu para a escolha desta alternativa foram os testes apresentados em PUDJIANTO et al. (2002), onde foi mostrado que os algoritmos de Programação Não Linear e de Programação Linear apresentaram um comportamento global semelhante para o problema de suporte de potência reativa.

Mais do que isso, como apresentado em WOOD \& WOLLENBERG (1983), o desvio entre a solução do problema de Programação Linear e a solução do problema de Fluxo de Potência Ótimo, resultante da não linearidade do sistema elétrico, pode ser superado, com o auxílio do programa de Fluxo de Potência, após duas ou três iterações, garantindo a convergência do problema de alocação ótima de potência reativa.

Desta forma, a seguir será apresentada a formulação da matriz sensibilidade $S$ utilizada no Fluxo de Potência Ótimo empregado no presente trabalho.

\subsubsection{Obtenção da Matriz de Sensibilidade}

A matriz sensibilidade entre tensão e potência reativa será utilizada na construção do problema de Programação Linear. 
Considere um vetor $u$, formado pelas variáveis de controle do sistema, que, neste problema, corresponde às injeções de reativos $(\Delta Q)$ nas barras do sistema. Caso $x=x_{0}$ seja solução do problema de Fluxo de Potência para um dado vetor $u=u_{0}$ especificado, tem-se que:

$$
g\left(x_{0}, u_{0}\right)=0
$$

Sendo $g(x, u)$ as equações do Fluxo de Potência. Suponha que uma pequena variação $\Delta u$ no vetor $u$ cause uma mudança $\Delta x$ no vetor $x$, então a expansão em série de Taylor da equação (4.12) até $1^{\mathrm{a}}$ ordem é dada por:

$$
g\left(x_{0}+\Delta x, u_{0}+\Delta u\right)=g\left(x_{0}, u_{0}\right)+g_{x} \Delta x+g_{u} \Delta u=0
$$

Sendo $g_{x}$ a matriz Jacobiana de $g(x, u)$ com relação ao vetor $x$. A matriz $g_{x}$ é quadrada e não singular, sendo definida por:

$$
g_{x}=\frac{\partial\left(g_{1}, g_{2}, \ldots, g_{2 n b}\right)}{\partial\left(x_{1}, x_{2}, \ldots, x_{2 n b}\right)}
$$

Sendo $g_{u}$ a matriz Jacobiana de $g(x, u)$ com relação ao vetor $u$. A matriz $g_{u}$ não é necessariamente quadrada, sendo definida por:

$$
g_{u}=\frac{\partial\left(g_{1}, g_{2}, \ldots, g_{2 n b}\right)}{\partial\left(u_{1}, u_{2}, \ldots, u_{m}\right)}
$$

Sendo $\Delta x$ e $\Delta u$ os vetores de correções de $x$ e $u$, respectivamente. Combinando as equações (4.12) e (4.13) tem-se que:

$$
g_{x} \Delta x+g_{u} \Delta_{u}=0
$$


Rescrevendo a equação acima, pode-se definir a matriz de sensibilidade $[S]$ como sendo:

$$
[S]=\frac{\Delta x}{\Delta u}=-g_{x}^{-1} * g_{u}
$$

Para um caso geral, a dimensão da matriz de sensibilidade [S] é igual a $2 n b \times m$, sendo $m$ o número de variáveis independentes e $n b$ o número de barras do sistema.

\subsubsection{Formulação do Problema de Programação Linear}

O vetor $x$, como mencionado anteriormente, é formado pelas variáveis dependentes do sistema, ou seja, pelas tensões e seus respectivos ângulos. Com o intuito de estudar o suporte de potência reativa no sistema, apenas parte deste vetor será utilizada, isto é, as magnitudes das tensões nas barras do sistema. Assim, considerando que uma mudança na injeção de reativo $\Delta Q_{j}$ na barra $j$ cause uma variação $\Delta V_{i}$ na tensão da barra $i$, a equação (4.17) na forma matricial, em função das variáveis do problema, KISHORE (1971), pode ser rescrito por:

$$
\left[\begin{array}{c}
\Delta V_{1} \\
\Delta V_{2} \\
\vdots \\
\Delta V_{k}
\end{array}\right]=\left[\begin{array}{cccc}
S_{11} & S_{12} & \cdots & S_{1 m} \\
S_{21} & S_{22} & \cdots & S_{2 m} \\
\vdots & \vdots & \ddots & \vdots \\
S_{k 1} & S_{k 2} & \cdots & S_{k m}
\end{array}\right]\left[\begin{array}{c}
\Delta Q_{1} \\
\Delta Q_{2} \\
\vdots \\
\Delta Q_{m}
\end{array}\right]
$$

Sendo $k$ o número de barras do sistema e $m$ o número de barras onde serão alocados reativos.

Devido à alocação de reativos no sistema, uma variação $\Delta V_{i}$ na tensão $V_{i}$ da barra $i$ fará com que a tensão fique dentro de seus limites, ou seja: 


$$
V_{i}^{\min } \leq V_{i 0}+\Delta V_{i} \leq V_{i}^{\max }
$$

Sendo $V_{i}^{\min }$ e $V_{i}^{\max }$ os valores mínimos e máximos desejados na barra $i$.

Sabendo-se que $\Delta Q_{j}=Q_{j f}-Q_{j 0}$, a formulação do problema de otimização do suporte de potência reativa utilizando programação linear pode ser representada por:

$$
\begin{array}{ll}
\text { Min } & F \\
\text { s.a. } & {[S]\left[Q_{j f}-Q_{j 0}\right] \geq\left[V_{i}^{\min }-V_{i 0}\right]} \\
& {[S]\left[Q_{j f}-Q_{j 0}\right] \leq\left[V_{i}^{\max }-V_{i 0}\right]} \\
& Q_{j f} \geq 0 \\
& j=1, \ldots, m \\
& i=1, \ldots, k
\end{array}
$$

Sendo:

$F$ a função objetivo a ser minimizada;

$Q_{j f}$ a potência reativa final da barra $j$;

$Q_{j 0}$ a potência reativa inicial da barra $j$;

$m$ o número de barras a serem alocados reativos;

$k$ o número de barras do sistema;

$[S]$ a matriz de sensibilidade;

$V_{i}^{\min }$ e $V_{i}^{\max }$ os limites mínimo e máximo da tensão da barra $i$, respectivamente;

$V_{i 0}$ a tensão inicial da barra $i$.

A função objetivo $(F)$ do problema de programação linear apresentado no sistema de equações (4.20) pode ser representada pelas perdas do sistema ou pela potência 
reativa final nas barras de geração. A matriz de sensibilidade, para o problema proposto, será calculada a partir da equação (4.8).

A seguir serão apresentadas as formulações dos problemas de Programação Linear (PL) propostas para o presente trabalho, onde a função objetivo está representada pela minimização da geração de potência reativa nas barras de geração.

A formulação de diferentes problemas de otimização permitirá a relaxação dos limites de potência reativa das barras de carga com o objetivo de determinar o valor da potência reativa nas mesmas, definindo a solução de menor dependência em relação à potência reativa provida pelos geradores. Essa variação de potência reativa das barras de carga alcançada, pré e pós-otimização, não deverá ser fornecida por nenhuma fonte de potência reativa, servindo apenas como referência para a medição da dependência em relação à potência reativa provida pelos geradores. Essa medição será utilizada como ferramenta para valoração do suporte de potência reativa provida pelos geradores. Para estes diferentes pontos de operação foram definidos os seguintes estados do sistema:

- "Solução Base";

- "Solução Sub Ótima" e;

- "Solução Super Ótima".

A "Solução Base" é o ponto de operação do sistema, resultante do problema de Programação Linear, onde considera que os valores de potência reativa nas barras de carga do sistema estejam com um fator de potência menor ou igual a 0,95 (indutivo).

A "Solução Sub Ótima" é um caso otimizado em relação ao ponto de operação denominado por "Solução Base". A "Solução Sub Ótima" é obtida a partir do 
problema de Programação Linear que considera que os valores de potência reativa nas barras de carga do sistema estejam com um fator de potência menor ou igual a 0,98 (indutivo).

E por fim é apresentada "Solução Super Ótima", caso mais otimista do sistema. Este caso apresenta o menor valor de reativo suprido pelos geradores e eventualmente pode não ser praticado por exigir em algumas barras de carga fator de potência unitário ou capacitivo. A seguir são apresentadas as formulações dos problemas de Programação Linear que definem os pontos de operações descritos anteriormente.

\subsubsection{Formulação do problema de Programação Linear para "Solução Super} Ótima”

O problema de Programação Linear para a "Solução Super Ótima" pode ser representado matematicamente através de um problema de otimização com restrições de igualdade e desigualdade como:

$$
\begin{array}{ll}
\text { Min } & F(x)=\sum_{g=1}^{N G}\left(Q_{g f}\right) \\
\text { s.a. } & {[-S]\left[Q_{j f}-Q_{j 0}\right] \leq\left[V_{j 0}-V_{\text {Min }}\right]} \\
& {[S]\left[Q_{j f}-Q_{j 0}\right] \leq\left[V_{\text {Max }}-V_{j 0}\right]} \\
& -\underline{Q} \leq Q(j) \leq \bar{Q} \\
& j=1, \ldots, m
\end{array}
$$

A equação (4.21) indica a função objetivo que se pretende minimizar. Para este problema a função objetivo é representada pela soma das potências reativas finais nas barras de geração do sistema. Também serão examinadas as formulações 
propostas do Problema de Programação Linear contemplando na função objetivo as perdas no sistema de transmissão. A minimização da potência reativa nos geradores, aqui apresentada, é uma forma indireta de minimização das perdas na transmissão.

As equações (4.22) e (4.23) indicam que as tensões de todas as barras deverão ficar entre os limites mínimos e máximos, respectivamente;

A equação (4.24) indica os limites mínimo e máximo de potência reativa nas barras do sistema. Para o caso denominado "Solução Super Ótima” estes limites podem assumir valores nulos, capacitivos ou indutivos;

[S] é a matriz de sensibilidade que relaciona a variação de tensão com a variação de potência reativa resultante do problema de Fluxo de Potência. A matriz de sensibilidade [S] será calculada a cada iteração da metodologia proposta, com base no ponto de operação $J-1$ em relação à iteração $J ; N G$ é o número total de geradores do sistema; $\mathrm{V}_{\mathrm{j} 0}$ é a magnitude de tensão do ponto de operação inicial; e $\mathrm{Q}_{\mathrm{j} 0}$ e $\mathrm{Q}_{\mathrm{jf}}$ são os valores iniciais e finais da potência reativa nas barras.

\subsubsection{Formulação do problema de Programação Linear para "Solução Sub Ótima”}

O problema de Programação Linear para a "Solução Sub Ótima" pode ser representado matematicamente através de um problema de otimização com restrições de igualdade e desigualdade como: 


$$
\begin{array}{ll}
\text { Min } & F(x)=\sum_{g=1}^{N G}\left(Q_{g f}\right) \\
\text { s.a. } & {[-S]\left[Q_{j f}-Q_{j 0}\right] \leq\left[V_{j 0}-V_{\text {Min }}\right]} \\
& {[S]\left[Q_{j f}-Q_{j 0}\right] \leq\left[V_{M a x}-V_{j 0}\right]} \\
& -Q \leq Q(j) \leq \bar{Q} \\
& j=1, \ldots, m
\end{array}
$$

Na formulação apresentada para a "Solução Sub Ótima", a última equação indica os limites de potência reativa das barras do sistema. No sistema de equações (4.25), para as potências reativas das barras $\mathrm{PQ}$, os limites mínimo e máximo podem assumir um fator de potência menor ou igual a 0,98 (indutivo).

\subsubsection{Formulação do problema de Programação Linear para "Solução Base"}

O problema de Programação Linear para a "Solução Base" pode ser representado matematicamente através de um problema de otimização com restrições de igualdade e desigualdade como:

$$
\begin{array}{ll}
\text { Min } & F(x)=\sum_{g=1}^{N G}\left(Q_{g f}\right) \\
\text { s.a. } & {[-S]\left[Q_{j f}-Q_{j 0}\right] \leq\left[V_{j 0}-V_{\text {Min }}\right]} \\
& {[S]\left[Q_{j f}-Q_{j 0}\right] \leq\left[V_{M a x}-V_{j 0}\right]} \\
& -Q \underline{Q} \leq Q(j) \leq \bar{Q} \\
& j=1, \ldots, m
\end{array}
$$

Na formulação apresentada para a "Solução Base", a última equação indica os limites de potência reativa das barras do sistema. No sistema de equações (4.26), para as potências reativas das barras $P Q$, os limites mínimo e máximo podem assumir um fator de potência menor ou igual a 0,95 (indutivo). 
É importante salientar que, como apresentado anteriormente pelas formulações dos problemas de otimização, as potências reativas e as tensões das barras do sistema sofreram uma relaxação com objetivo de permitir a otimização da potência reativa provida pelos geradores; e permitir a determinação do valor de potência reativa nas barras de carga de forma a resultar na menor dependência em relação à potência reativa provida pelos geradores, sempre atendendo os níveis de tensão e demais restrições impostas ao sistema.

\subsection{Metodologia Proposta}

Para o desenvolvimento da metodologia utilizada para quantificar o excedente de potência reativa fornecida pelas barras geradoras foi empregado o processo descrito a seguir.

A partir dos dados de carregamento e de configuração física de um sistema elétrico é realizada a simulação do Fluxo de Potência do mesmo. A solução resultante do programa de Fluxo de Potência é então empregada na formulação da matriz sensibilidade utilizada no problema de Programação Linear (PL).

Determinada a matriz de sensibilidade utilizada como matriz dos coeficientes das restrições de desigualdade do problema, o próximo passo é a formulação do problema de PL que represente o estado operacional que se queira alcançar em termos de tensões e potência reativa, definidos anteriormente.

Formulado o problema de PL, o próximo passo é a execução do mesmo. A metodologia utilizada na solução deste problema, Método Simplex, é apresentada no Apêndice 3 . 
Após este passo, caso o problema convirja, os resultados do mesmo devem ser ajustados no arquivo de dados do cálculo de Fluxo de Potência. Caso contrário devese fazer uma nova formulação para o problema de PL.

Após o ajuste dos dados de entrada do Fluxo de Potência, o mesmo é executado e caso convirja para uma solução melhor que a solução anterior, o problema é finalizado. Caso contrário, essa nova solução do Fluxo de Potência será um novo conjunto de dados para uma nova formulação do problema de PL. Inicia-se então uma nova iteração.

Esse processo iterativo ocorre, pois junto ao Fluxo de Potência está representada a não linearidade do sistema elétrico, o que não acontece no PL. Esse desvio entre a resposta do problema do PL e a solução do Fluxo de Potência é superado após duas ou três iterações do Fluxo de Potência, WOOD \& WOLLENBERG (1983). Esse processo iterativo é representado pela Figura 4.1. 


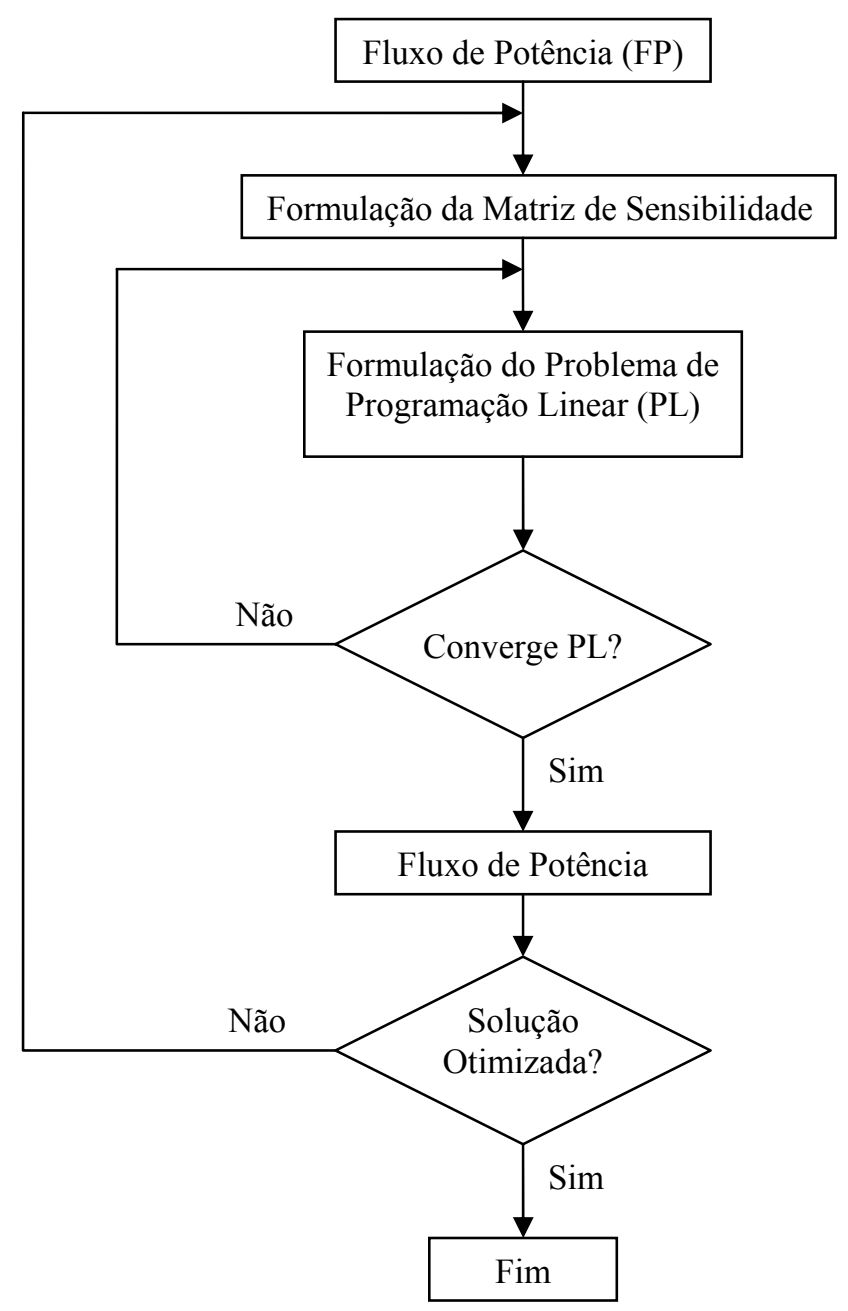

Figura 4.1. Fluxograma do problema de otimização do suporte de potência reativa.

Obtida as soluções finais dos estados operacionais definidos, são realizadas análises em relação à potência reativa gerada e às perdas ativas resultantes do Fluxo de Potência. A partir destas soluções é determinada à variação de potência reativa. Em seguida, é realizada a valoração do suporte de potência reativa provido pelas barras geradoras, conforme Item 4.8 . 


\subsection{Testes e Resultados}

A seguir, serão apresentados os resultados obtidos utilizando a metodologia proposta para o problema de otimização do suporte de potência reativa.

Inicialmente serão apresentados os resultados do problema de otimização que contemplou em sua função objetivo a minimização da potência reativa das barras de geração, denominada de função objetivo 1. Em seguida, será apresentada a formulação e as soluções obtidas para o problema de otimização que contemplou em sua função objetivo a minimização das perdas do sistema, denominada de função objetivo 2 .

Os testes foram realizados a partir dos sistemas: 8; 30 barras (AEP); e 53 barras (Equivalente São Paulo). Os limites de tensões utilizados para os sistemas foram 0,95 p.u. e 1,05 p.u.. As convenções de sinais adotadas para os valores de potência estão representadas na Figura 4.2.

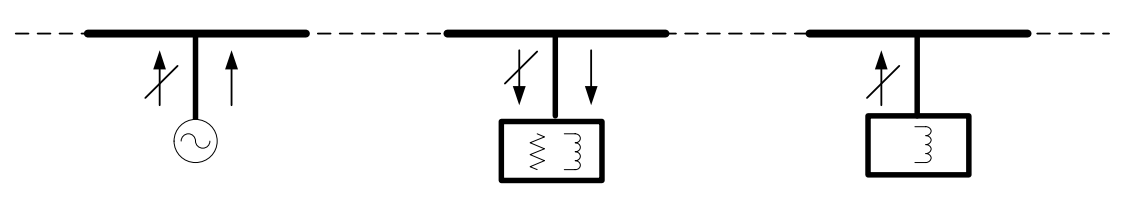

Figura 4.2. Convenções de sinais adotados para os testes realizados.

\subsubsection{Sistema de 8 Barras - Função Objetivo 1}

O sistema de 8 barras (Figura 4.3), utilizado para realização dos testes, possui as seguintes características: 
- 1 barra de referência;

- 1 barra de geração;

- 6 barras de carga;

- 9 linhas de transmissão.

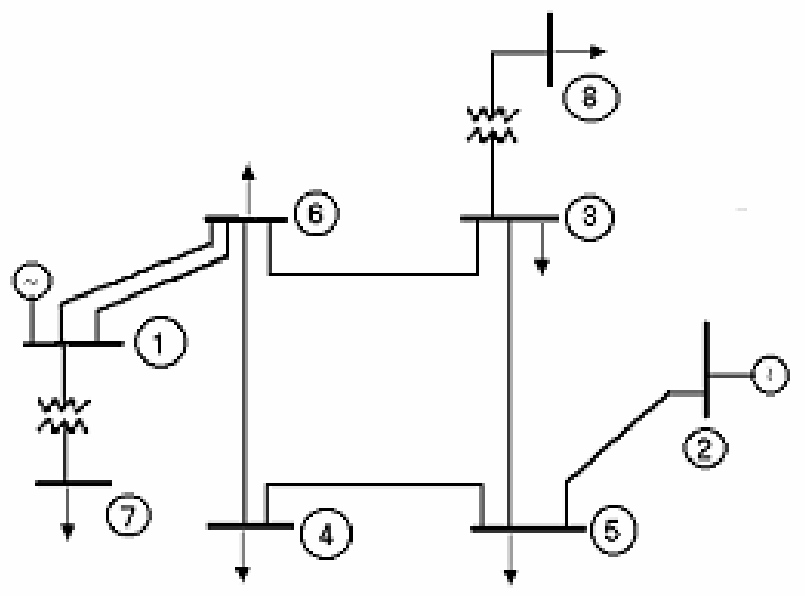

Figura 4.3. Sistema de 8 barras.

Os dados de partida de tensões, gerações e cargas para sistema de 8 barras são apresentados na Tabela 4.1.

Tabela 4.1. Dados iniciais do sistema de 8 barras.

\begin{tabular}{|c|c|c|c|c|c|c|c|c|}
\hline Barra & \multirow{2}{*}{ Tipo } & \multicolumn{2}{|c|}{ Tensão } & \multicolumn{2}{c|}{ Geração } & \multicolumn{3}{c|}{ Carga } \\
\cline { 3 - 8 } & & $\begin{array}{c}\text { V } \\
\text { (p.u.) }\end{array}$ & $\theta$ (graus) & $\begin{array}{c}\text { P } \\
\text { (MW) }\end{array}$ & Q (MVAr) & $\begin{array}{c}\text { P } \\
(\mathrm{MW})\end{array}$ & Q (MVAr) & Q $_{\text {sh }}$ (MVAr) \\
\hline 1 & Referência & 1,050 & 0,0 & - & - & 0,0 & 0,0 & - \\
\hline 2 & Geração & 1,000 & $-34,0$ & 240,0 & - & 0,0 & 0,0 & \\
\hline 3 & Carga & 1,000 & $-26,0$ & - & - & 0,0 & 0,0 & $-75,0$ \\
\hline 4 & Carga & 1,000 & $-26,0$ & - & - & 134,0 & $-32,0$ & $-140,0$ \\
\hline 5 & Carga & 1,019 & $-35,0$ & - & - & 1300,0 & 50,0 & $-140,0$ \\
\hline 6 & Carga & 1,020 & $-15,0$ & - & - & 0,0 & 0,0 & $-300,0$ \\
\hline 7 & Carga & 1,031 & $-6,0$ & - & - & 180,0 & 86,0 & - \\
\hline 8 & Carga & 1,007 & $-30,0$ & - & - & 290,0 & 48,0 & - \\
\hline
\end{tabular}

A Tabela 4.2 apresenta para o sistema representado pela Figura 4.3, os seguintes valores resultantes do Fluxo de Potência convencional. 
Tabela 4.2. Ponto de operação do sistema de 8 barras, resultante do Fluxo de Potência convencional.

\begin{tabular}{|c|c|c|c|c|c|c|c|c|c|}
\hline \multirow[t]{2}{*}{ Barra } & \multirow[t]{2}{*}{ Tipo } & \multicolumn{2}{|c|}{ Tensão } & \multicolumn{2}{|c|}{ Geração } & \multicolumn{4}{|c|}{ Carga } \\
\hline & & $\begin{array}{c}\mathrm{V} \\
\text { (p.u.) }\end{array}$ & $\theta$ (graus) & $\begin{array}{c}\mathrm{P} \\
(\mathrm{MW})\end{array}$ & $\begin{array}{c}\mathrm{Q} \\
\text { (MVAr) }\end{array}$ & $\begin{array}{c}\mathrm{P} \\
(\mathrm{MW})\end{array}$ & $\begin{array}{c}\mathrm{Q} \\
\text { (MVAr) }\end{array}$ & $\operatorname{Cos} \varphi$ & $\begin{array}{c}\mathrm{Q}_{\mathrm{sh}} \\
\text { (MVAr) }\end{array}$ \\
\hline 1 & $\mathrm{~V} \theta$ & 1,050 & 0,0 & 1711,2 & 217,0 & 0,0 & 0,0 & - & - \\
\hline 2 & PV & 1,000 & $-32,0$ & 240,0 & $-54,2$ & 0,0 & 0,0 & - & - \\
\hline 3 & PQ & 0,996 & $-23,5$ & - & - & 0,0 & 0,0 & - & $-74,3$ \\
\hline 4 & PQ & 1,000 & $-23,0$ & - & - & 134,0 & $-32,0$ & 0,97 & $-139,9$ \\
\hline 5 & $\mathrm{PQ}$ & 0,998 & $-32,6$ & - & - & 1300,0 & 50,0 & 0,99 & $-139,4$ \\
\hline 6 & PQ & 1,009 & $-12,0$ & - & - & 0,0 & 0,0 & - & $-305,6$ \\
\hline 7 & $\begin{array}{l}\mathrm{PQ} \\
\end{array}$ & 1,029 & $-2,3$ & - & - & 180,0 & 86,0 & 0,90 & - \\
\hline 8 & PQ & 0,981 & $-27,6$ & - & - & 290,0 & 48,0 & 0,98 & - \\
\hline
\end{tabular}

A partir dos dados apresentados nas Tabelas 4.1 e 4.2 foram realizados os testes com o objetivo de determinar os três estados operacionais definidos para minimização da potência reativa dos geradores.

O primeiro teste realizado trata da solução definida como "Base" (solução cujas barras de carga ficaram limitadas a um fator de potência menor ou igual 0,95 indutivo). A Tabela 4.3 apresenta os resultados obtidos a partir da otimização feita via problema de Programação Linear.

Tabela 4.3. Solução do PL para o caso definido por "Solução Base" - sistema de 8 barras - Função Objetivo 1.

\begin{tabular}{|c|c|c|c|}
\hline \multirow{2}{*}{ Barra } & \multirow{2}{*}{ Tipo } & \multicolumn{2}{|c|}{ Solução PL } \\
\cline { 3 - 4 } & & V (p.u.) & Q (MVAr) \\
\hline 1 & VӨ & 1,050 & 170,2 \\
\hline 2 & PV & 1,050 & 456,7 \\
\hline 3 & PQ & 1,001 & 0,0 \\
\hline 4 & PQ & 1,002 & 44,0 \\
\hline 5 & PQ & 1,022 & 427,0 \\
\hline 6 & PQ & 1,011 & 0,0 \\
\hline 7 & PQ & 1,036 & 59,0 \\
\hline 8 & PQ & 0,974 & 95,0 \\
\hline
\end{tabular}

Notar que a solução do PL alocou todas as barras de carga no limite de reativos (fator de potência igual a 0,95 ). Os valores das tensões ficaram dentro dos valores limites especificados.

A Tabela 4.4 apresenta o resultado do cálculo do Fluxo de Potência alterando os valores das tensões das barras de geração e referência; e as potências reativas das 
cargas conforme determinado pelo PL. Para esta nova solução pode-se observar que os limites de tensões continuam sendo obedecidos.

Tabela 4.4. Estado final resultante do Fluxo de Potência do teste "Solução Base" para o sistema de 8

\begin{tabular}{|c|c|c|c|c|c|c|c|c|c|}
\hline \multirow[t]{2}{*}{ Barra } & \multirow[t]{2}{*}{ Tipo } & \multicolumn{2}{|c|}{ Tensão } & \multicolumn{2}{|c|}{ Geração } & \multicolumn{4}{|c|}{ Carga } \\
\hline & & $\begin{array}{c}\mathrm{V} \\
\text { (p.u.) }\end{array}$ & $\theta$ (graus) & $\begin{array}{c}\mathrm{P} \\
(\mathrm{MW})\end{array}$ & Q (MVAr) & $\begin{array}{c}\mathrm{P} \\
(\mathrm{MW})\end{array}$ & Q (MVAr) & $\cos \varphi$ & $\begin{array}{c}\mathrm{Q}_{\mathrm{sh}} \\
\text { (MVAr) }\end{array}$ \\
\hline 1 & $\mathrm{~V} \Theta$ & 1,050 & 0,0 & 1711,8 & 170,2 & 0,0 & 0,0 & - & - \\
\hline 2 & PV & 1,050 & $\begin{array}{l}-31,8 \\
\end{array}$ & 240,0 & 456,7 & 0,0 & 0,0 & - & - \\
\hline 3 & PQ & 1,002 & $-23,4$ & - & - & 0,0 & 0,0 & - & $-75,2$ \\
\hline 4 & $\begin{array}{l}\mathrm{PQ} \\
\end{array}$ & 1,003 & $-22,9$ & - & - & 134,0 & 44,0 & 0,95 & $-140,8$ \\
\hline 5 & $\begin{array}{l}\mathrm{PQ} \\
\end{array}$ & 1,023 & $-32,4$ & - & - & 1300,0 & 427,0 & 0,95 & $-146,6$ \\
\hline 6 & PQ & 1,012 & $-12,0$ & - & - & 0,0 & 0,0 & - & $-307,2$ \\
\hline 7 & PQ & 1,035 & $-2,3$ & - & - & 180,0 & 59,0 & 0,95 & - \\
\hline 8 & $\begin{array}{l}\mathrm{PQ} \\
\end{array}$ & 0,976 & $-27,5$ & - & - & 290,0 & 95,0 & 0,95 & - \\
\hline
\end{tabular}

Como descrito anteriormente, a formulação do problema de otimização permitiu a relaxação da potência reativa das barras de carga, e por conseqüência, a variação do fator de potência relacionado às mesmas, com o objetivo de permitir a determinação do valor de potência reativa nas barras de carga de maneira a resultar na menor dependência em relação à potência reativa provida pelos geradores, atendendo as restrições impostas ao sistema. $\mathrm{Na}$ realidade, essa variação dos valores de potência reativa das barras de carga, pré e pós-otimização, não deverá ser fornecida por nenhuma fonte de potência reativa, servindo apenas para medir a dependência das barras de carga em relação à potência reativa provida pelos geradores.

O teste seguinte realizado trata do ponto operacional definido como "Solução Sub Ótima”, Item 4.4.3.2. Neste caso as barras de carga foram limitadas a um fator de potência menor ou igual a 0,98 (indutivo). 
A Tabela 4.5 apresenta os resultados do processo de otimização para este teste realizado. Estes valores são aqueles calculados pelo Fluxo de Potência com os resultados obtidos a partir do problema de Programação Linear, similarmente ao processo realizado para obtenção da Tabela 4.4.

Tabela 4.5. Estado final resultante do Fluxo de Potência do teste "Solução Sub Ótima" para o sistema de 8 barras - Função Objetivo 1 .

\begin{tabular}{|c|c|c|c|c|c|c|c|c|c|}
\hline \multirow[t]{2}{*}{ Barra } & \multirow[t]{2}{*}{ Tipo } & \multicolumn{2}{|c|}{ Tensão } & \multicolumn{2}{|c|}{ Geração } & \multicolumn{4}{|c|}{ Carga } \\
\hline & & $\begin{array}{c}\mathrm{V} \\
\text { (p.u.) }\end{array}$ & $\theta$ (graus) & $\begin{array}{c}\mathrm{P} \\
(\mathrm{MW})\end{array}$ & Q (MVAr) & $\begin{array}{c}\mathrm{P} \\
(\mathrm{MW})\end{array}$ & Q (MVAr) & $\cos \varphi$ & $\begin{array}{c}\mathrm{Q}_{\mathrm{sh}} \\
\text { (MVAr) }\end{array}$ \\
\hline 1 & $\mathrm{VO}$ & 1,050 & 0,0 & 1710,3 & 93,4 & 0,0 & 0,0 & - & - \\
\hline 2 & PV & 1,050 & $-31,3$ & 240,0 & 256,8 & 0,0 & 0,0 & - & - \\
\hline 3 & PQ & 1,017 & $-23,1$ & - & - & 0,0 & 0,0 & - & $-77,5$ \\
\hline 4 & PQ & 1,014 & $-22,6$ & - & - & 134,0 & 27,0 & 0,98 & $-144,1$ \\
\hline 5 & PQ & 1,033 & $-31,8$ & - & - & 1300,0 & 264,0 & 0,98 & $-149,3$ \\
\hline 6 & PQ & 1,019 & $-11,9$ & - & - & 0,0 & 0,0 & - & $-311,8$ \\
\hline 7 & PQ & 1,041 & $-2,3$ & - & - & 180,0 & 37,0 & 0,98 & - \\
\hline 8 & PQ & 1,000 & $-27,1$ & - & - & 290,0 & 59,0 & 0,98 & - \\
\hline
\end{tabular}

Observe que os fatores de potência $(\cos \varphi)$ das barras de carga ficaram todos em 0,98 (indutivo). Os reativos nas barras de geração apresentados na Tabela 4.5 foram evidentemente menores visto que os reativos das cargas também foram menores.

O terceiro teste realizado trata do ponto operacional definido como "Solução Super Ótima”, Item 4.4.3.1. A Tabela 4.6 apresenta os resultados deste processo de otimização.

Tabela 4.6. Estado final resultante do fluxo de carga do teste "Solução Super Ótima" para o sistema de 8 barras - Função Objetivo 1.

\begin{tabular}{|c|c|c|c|c|c|c|c|c|c|}
\hline Barra & Tipo & \multicolumn{2}{|c|}{ Tensão } & \multicolumn{2}{|c|}{ Geração } & \multicolumn{4}{|c|}{ Carga } \\
\cline { 3 - 10 } & & $\begin{array}{c}\text { V } \\
\text { (p.u.) }\end{array}$ & $\theta$ (graus) & $\begin{array}{c}\mathrm{P} \\
(\mathrm{MW})\end{array}$ & Q (MVAr) & $\begin{array}{c}\mathrm{P} \\
(\mathrm{MW})\end{array}$ & Q (MVAr) & $\cos \varphi$ & $\begin{array}{c}\mathrm{Q}_{\text {sh }} \\
\text { (MVAr) }\end{array}$ \\
\hline 1 & $\mathrm{~V}$ & 1,050 & 0,0 & 1708,1 & $-81,2$ & 0,0 & 0,0 & - & - \\
\hline 2 & $\mathrm{PV}$ & 1,050 & $-30,0$ & 240,0 & $-108,9$ & 0,0 & 0,0 & - & - \\
\hline 3 & $\mathrm{PQ}$ & 1,048 & $-22,4$ & - & - & 0,0 & 0,0 & - & $-82,4$ \\
\hline 4 & $\mathrm{PQ}$ & 1,050 & $-21,9$ & - & - & 134,0 & $-94,0$ & 0,82 & $-154,4$ \\
\hline
\end{tabular}




\begin{tabular}{|c|c|c|c|c|c|c|c|c|c|}
\hline 5 & PQ & 1,050 & $-30,7$ & - & - & 1300,0 & 25,0 & 0,99 & $-154,4$ \\
\hline 6 & PQ & 1,038 & $-11,7$ & - & - & 0,0 & 0,0 & - & $-323,3$ \\
\hline 7 & PQ & 1,049 & $-2,2$ & - & - & 180,0 & $-1,0$ & 0,99 & - \\
\hline 8 & PQ & 1,050 & $-26,1$ & - & - & 290,0 & $-17,0$ & 0,99 & - \\
\hline \multicolumn{7}{|l}{ Perdas $=44,10 \mathrm{MW}$ Pota Reativa Gerada $=-190,1 \mathrm{MVAr}$} \\
\hline
\end{tabular}

Na Tabela 4.7 estão apresentados os valores de perdas do sistema e os valores de potência reativa gerados pelas barras de geração para os três testes realizados.

Tabela 4.7. Perdas e potência reativa gerada para os casos testados - sistema de 8 barras - Função Objetivo 1.

\begin{tabular}{|c|c|c|}
\hline Caso & Perdas sistêmicas (MW) & Q total gerado (MVAr) \\
\hline Base & 47,80 & 626,9 \\
\hline Sub Ótimo & 46,30 & 350,2 \\
\hline Super Ótimo & 44,10 & $-190,1$ \\
\hline
\end{tabular}

A partir da Tabela 4.7 é possível observar que:

- As perdas e os reativos gerados no sistema foram menores no caso "Sub Ótimo" em relação ao caso "Base";

- Para o caso "Super Ótimo" as perdas e os reativos gerados foram menores em relação ao caso "Sub Ótimo".

Para o teste anteriormente realizado, a função objetivo reduziu as perdas no sistema a partir da minimização da potência reativa gerada. As perdas apresentadas para o caso "Super Ótimo" são menores quando comparadas aos outros casos.

\subsubsection{Sistema de 30 Barras - Função Objetivo 1}

O sistema de 30 barras, utilizado para realização dos testes, é apresentado na Figura 4.4. O sistema apresentado possui as seguintes características:

- 1 barra de referência; 
- 5 barras de geração;

- 24 barras de carga;

- 37 linhas de transmissão;

- 4 transformadores.

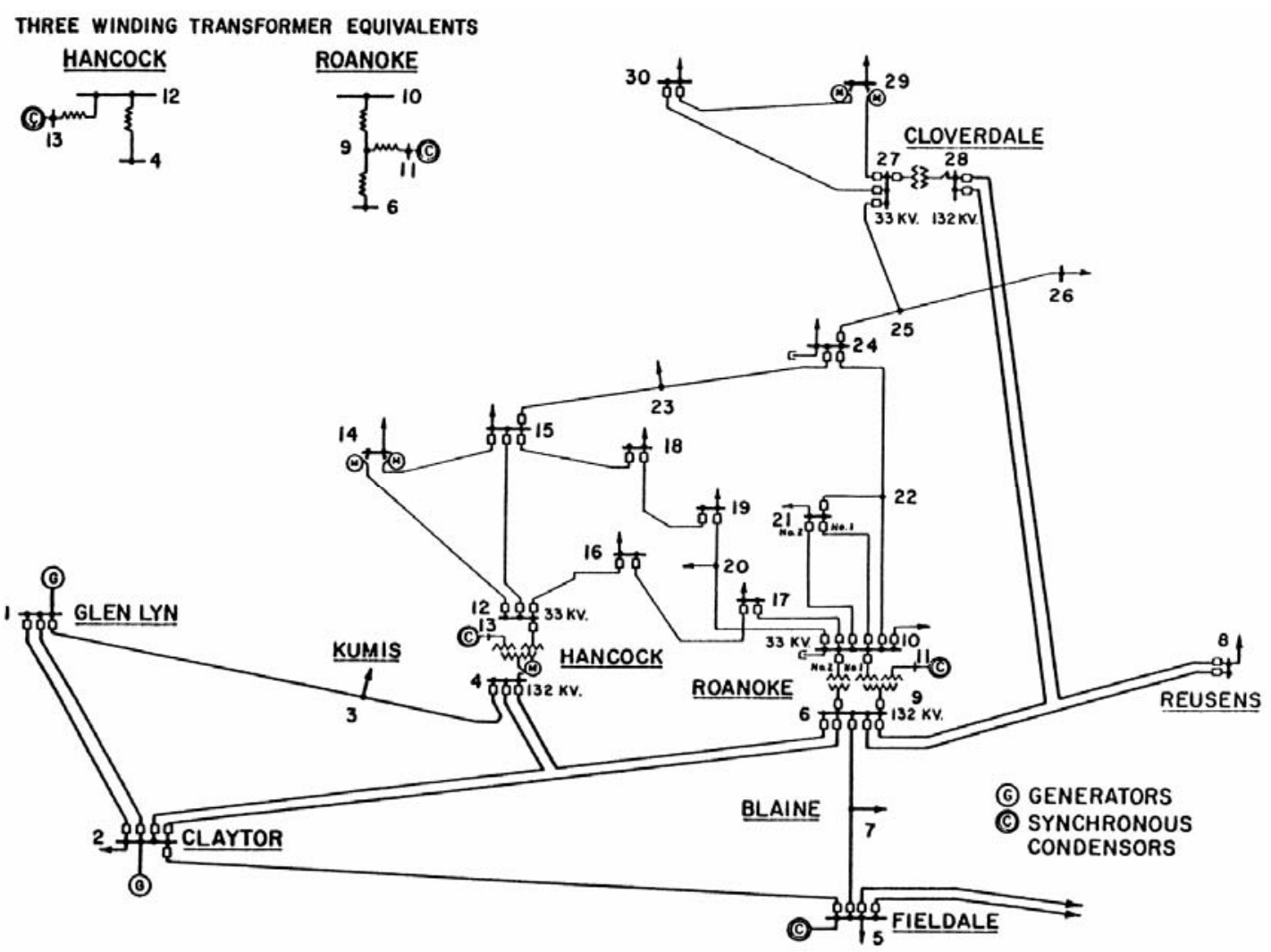

Figura 4.4. Sistema AEP-30 barras.

Para o sistema representado pela Figura 4.3 têm-se como resultado do Fluxo de Potência convencional, os valores apresentados na Tabela 4.8.

Tabela 4.8. Ponto de operação do sistema de 30 barras, resultante do Fluxo de Potência convencional.

\begin{tabular}{|c|c|c|c|c|c|c|c|c|c|}
\hline Barra & \multirow{2}{*}{ Tipo } & \multicolumn{2}{|c|}{ Tensão } & \multicolumn{2}{c|}{ Geração } & \multicolumn{4}{c|}{ Carga } \\
\cline { 3 - 9 } & & $\begin{array}{c}\mathrm{V} \\
\text { (p.u.) }\end{array}$ & $\begin{array}{c}\Theta \\
\text { (graus) }\end{array}$ & $\begin{array}{c}\mathrm{P} \\
\text { (MW) }\end{array}$ & $\begin{array}{c}\mathrm{Q} \\
\text { (MVAr) }\end{array}$ & $\begin{array}{c}\mathrm{P} \\
(\mathrm{MW})\end{array}$ & $\begin{array}{c}\mathrm{Q} \\
\text { (MVAr) }\end{array}$ & $\cos \varphi$ & $\mathrm{Q}_{\text {sh }}(\mathrm{MVAr})$ \\
\hline 1 & $\mathrm{~V}$ & 1,050 & 0,0 & 261,3 & $-16,7$ & 0,0 & 0,0 & - & - \\
\hline 2 & $\mathrm{PV}$ & 1,032 & $-5,6$ & 0,0 & 36,5 & $-18,3$ & 12,7 & 0,82 & - \\
\hline 3 & $\mathrm{PV}$ & 1,010 & $-12,5$ & 0,0 & 45,9 & 30,0 & 30,0 & 0,71 & - \\
\hline 4 & $\mathrm{PV}$ & 1,050 & $-15,0$ & 0,0 & 20,2 & 0,0 & 0,0 & - & - \\
\hline
\end{tabular}




\begin{tabular}{|c|c|c|c|c|c|c|c|c|c|}
\hline 5 & PV & 1,010 & $-14,8$ & 0,0 & 45,9 & 94,2 & 19.0 & 0,98 & - \\
\hline 6 & PV & 1,050 & $-16,0$ & 0,0 & 26,4 & 0,0 & 0,0 & - & - \\
\hline 7 & PQ & 1,001 & $-13,5$ & - & - & 22,8 & 10,9 & 0,90 & - \\
\hline 8 & PQ & 1,018 & $-8,2$ & - & - & 2,4 & 1,2 & 0,89 & - \\
\hline 9 & PQ & 1,010 & $-15,0$ & - & - & 0,0 & 0,0 & - & - \\
\hline 10 & PQ & 1,011 & $-16,7$ & - & - & 5,8 & 2,0 & 0,95 & 19,4 \\
\hline 11 & $\mathrm{PQ}$ & 1,012 & $-9,9$ & - & - & 7,6 & 1,6 & 0,98 & - \\
\hline 12 & PQ & 1,015 & $-16,0$ & - & - & 11,2 & 7,5 & 0,83 & - \\
\hline 13 & PQ & 1,008 & $-11,7$ & - & - & 0,0 & 0,0 & - & - \\
\hline 14 & PQ & 1,001 & $-16,8$ & - & - & 6,2 & 1,6 & 0,97 & - \\
\hline 15 & PQ & 0,998 & $-17,1$ & - & - & 8,2 & 2,5 & 0,96 & - \\
\hline 16 & $\begin{array}{l}\mathrm{PQ} \\
\end{array}$ & 1,006 & $-16,6$ & - & - & 3,5 & 1,8 & $\begin{array}{l}0,89 \\
\end{array}$ & - \\
\hline 17 & PQ & 1,004 & $-16,9$ & - & - & 9,0 & 5,8 & 0,84 & - \\
\hline 18 & PQ & 0,990 & $-17,7$ & - & - & 3,2 & 0,9 & 0,96 & - \\
\hline 19 & PQ & 0,988 & $-17,9$ & - & - & 9,5 & 3,4 & 0,94 & - \\
\hline 20 & PQ & 0,993 & $-17,6$ & - & - & 2,2 & 0,7 & 0,95 & - \\
\hline 21 & PQ & 0,999 & $-17,2$ & - & - & 17,5 & 11,2 & 0,84 & - \\
\hline 22 & PQ & 1,000 & $-17,2$ & - & - & 0,0 & 0,0 & - & - \\
\hline 23 & PQ & 0,991 & $-17,4$ & - & - & 3,2 & 1,6 & 0,89 & - \\
\hline 24 & PQ & 0,991 & $-17,6$ & - & - & 8,7 & 6,7 & 0,79 & 4,2 \\
\hline 25 & PQ & 1,001 & $-17,2$ & - & - & 0,0 & 0,0 & - & - \\
\hline 26 & PQ & 0,983 & $-17,6$ & - & - & 3,5 & 2,3 & 0,84 & - \\
\hline 27 & PQ & 1,016 & $-16,6$ & - & - & 0,0 & 0,0 & - & - \\
\hline 28 & PQ & 1,002 & $-12,4$ & - & - & 0,0 & 0,0 & - & - \\
\hline 29 & PQ & 0,996 & $-17,9$ & - & - & 2,4 & 0,9 & 0,94 & - \\
\hline 30 & PQ & 0,984 & $-18,8$ & - & - & 10,6 & 1,9 & 0,98 & - \\
\hline
\end{tabular}

A seguir serão apresentados os testes com o objetivo de determinar os três estados operacionais definidos para minimização da potência reativa dos geradores.

O resultado para o caso definido como "Solução Base" é apresentado na Tabela 4.9. Para este caso, as barras de carga ficaram limitadas a um fator de potência menor ou igual 0,95 (indutivo).

Tabela 4.9. Estado final resultante do Fluxo de Potência do teste "Solução Base" para o sistema de 30 barras - Função Objetivo 1.

\begin{tabular}{|c|c|c|c|c|c|c|c|c|c|}
\hline \multirow[t]{2}{*}{ Barra } & \multirow[t]{2}{*}{ Tipo } & \multicolumn{2}{|c|}{ Tensão } & \multicolumn{2}{|c|}{ Geração } & \multicolumn{4}{|c|}{ Carga } \\
\hline & & $\begin{array}{c}\mathrm{V} \\
\text { (p.u.) }\end{array}$ & $\begin{array}{c}\Theta \\
\text { (graus) }\end{array}$ & $\begin{array}{c}\mathrm{P} \\
(\mathrm{MW})\end{array}$ & $\begin{array}{c}\mathrm{Q} \\
\text { (MVAr) }\end{array}$ & $\begin{array}{c}\mathrm{P} \\
(\mathrm{MW})\end{array}$ & $\begin{array}{c}\mathrm{Q} \\
\text { (MVAr) }\end{array}$ & $\cos \varphi$ & $\mathrm{Q}_{\text {sh }}(\mathrm{MVAr})$ \\
\hline 1 & $\mathrm{V \theta}$ & 1,050 & 0,0 & 261,8 & $-60,1$ & 0,0 & 0,0 & - & - \\
\hline 2 & $\mathrm{PV}$ & 1,050 & $-5,8$ & 0,0 & 46,6 & $-18,3$ & 12,7 & 0,82 & - \\
\hline 3 & PV & 1,050 & $-12,7$ & 0,0 & 70,1 & 30,0 & 30,0 & 0,71 & - \\
\hline 4 & $\mathrm{PV}$ & 1,045 & $-15,1$ & 0,0 & 6,9 & 0,0 & 0,0 & - & - \\
\hline 5 & PV & 1,050 & $-14,8$ & 0,0 & 60,1 & 94,2 & 19.0 & 0,98 & - \\
\hline 6 & $\mathrm{PV}$ & 1,050 & $-15,8$ & 0,0 & 12,5 & 0,0 & 0,0 & - & - \\
\hline 7 & PQ & 1,038 & $-13,6$ & - & - & 22,8 & 7,5 & 0,95 & - \\
\hline 8 & PQ & 1,039 & $-8,4$ & - & - & 2,4 & 0,8 & 0,95 & - \\
\hline 9 & PQ & 1,031 & $-15,1$ & - & - & 0,0 & 0,0 & - & - \\
\hline 10 & PQ & 1,041 & $-16,7$ & - & - & 5,8 & 1,9 & 0,95 & 20,6 \\
\hline 11 & PQ & 1,037 & $-10,1$ & - & - & 7,6 & 2,5 & 0,95 & - \\
\hline 12 & PQ & 1,033 & $-15,8$ & - & - & 11,2 & 3,7 & 0,95 & - \\
\hline 13 & PQ & 1,040 & $-11,9$ & - & - & 0,0 & 0,0 & - & - \\
\hline 14 & PQ & 1,021 & $-16,7$ & - & - & 6,2 & 2,0 & 0,95 & - \\
\hline 15 & PQ & 1,021 & $-16,9$ & - & - & 8,2 & 2,7 & 0,95 & - \\
\hline
\end{tabular}




\begin{tabular}{|l|c|c|c|c|c|c|c|c|c|}
\hline 16 & PQ & 1,031 & $-16,5$ & - & - & 3,5 & 1,2 & 0,95 & - \\
\hline 17 & PQ & 1,034 & $-16,9$ & - & - & 9,0 & 3,0 & 0,95 & - \\
\hline 18 & PQ & 1,016 & $-17,5$ & - & - & 3,2 & 1,0 & 0,95 & - \\
\hline 19 & PQ & 1,016 & $-17,7$ & - & - & 9,5 & 3,1 & 0,95 & - \\
\hline 20 & PQ & 1,021 & $-17,5$ & - & - & 2,2 & 0,7 & 0,95 & - \\
\hline 21 & PQ & 1,033 & $-17,2$ & - & - & 17,5 & 5,8 & 0,95 & - \\
\hline 22 & PQ & 1,033 & $-17,2$ & - & - & 0,0 & 0,0 & - & - \\
\hline 23 & PQ & 1,021 & $-17,4$ & - & - & 3,2 & 1,0 & 0,95 & - \\
\hline 24 & PQ & 1,028 & $-17,7$ & - & - & 8,7 & 2,9 & 0,95 & 4,5 \\
\hline 25 & PQ & 1,038 & $-17,2$ & - & - & 0,0 & 0,0 & - & - \\
\hline 26 & PQ & 1,025 & $-17,7$ & - & - & 3,5 & 1,1 & 0,95 & - \\
\hline 27 & PQ & 1,050 & $-16,6$ & - & - & 0,0 & 0,0 & - & - \\
\hline 28 & PQ & 1,036 & $-12,5$ & - & - & 0,0 & 0,0 & - & - \\
\hline 29 & PQ & 1,029 & $-17,7$ & - & - & 2,4 & 0,8 & 0,95 & - \\
\hline 30 & PQ & 1,015 & $-18,4$ & - & - & 10,6 & 3,5 & 0,95 & - \\
\hline \multicolumn{7}{|l|}{ Potência Reativa Gerada $=136,1$ MVAr } \\
\hline
\end{tabular}

A Tabela 4.10 apresenta os resultados do processo de otimização para a "Solução Sub Ótima”. Para este teste as barras de carga foram limitadas a um fator de potência menor ou igual a 0,98 (indutivo).

Tabela 4.10. Estado final resultante do Fluxo de Potência do teste "Solução Sub Ótima" para o

\begin{tabular}{|c|c|c|c|c|c|c|c|c|c|}
\hline \multirow[t]{2}{*}{ Barra } & \multirow[t]{2}{*}{ Tipo } & \multicolumn{2}{|c|}{ Tensão } & \multicolumn{2}{|c|}{ Geração } & \multicolumn{4}{|c|}{ Carga } \\
\hline & & $\begin{array}{c}\mathrm{V} \\
\text { (p.u.) }\end{array}$ & $\begin{array}{c}\Theta \\
\text { (graus) }\end{array}$ & $\begin{array}{c}\mathrm{P} \\
(\mathrm{MW})\end{array}$ & $\begin{array}{c}\mathrm{Q} \\
\text { (MVAr) }\end{array}$ & $\begin{array}{c} \\
(\mathrm{MW}) \\
\end{array}$ & $\begin{array}{c}\mathrm{Q} \\
\text { (MVAr) }\end{array}$ & $\cos \varphi$ & $\mathrm{Q}_{\mathrm{sh}}(\mathrm{MVAr})$ \\
\hline 1 & $\mathrm{V \Theta}$ & 1,050 & 0,0 & 261,7 & $-61,0$ & 0,0 & 0,0 & - & - \\
\hline 2 & PV & 1,050 & $-5,8$ & 0,0 & 44,6 & $\begin{array}{l}-18,3 \\
\end{array}$ & 12,7 & 0,82 & - \\
\hline 3 & PV & 1,050 & $-12,7$ & 0,0 & 65,7 & 30,0 & 30,0 & 0,71 & - \\
\hline 4 & PV & 1,050 & $-15,1$ & 0,0 & 6,4 & 0,0 & 0,0 & - & - \\
\hline 5 & PV & 1,050 & $-14,8$ & 0,0 & 58,0 & 94,2 & 19.0 & 0,98 & - \\
\hline 6 & PV & 1,050 & $-15,7$ & 0,0 & 8,3 & 0,0 & 0,0 & - & - \\
\hline 7 & PQ & 1,040 & $\begin{array}{l}-13,6 \\
\end{array}$ & - & - & 22,8 & 4,6 & 0,98 & - \\
\hline 8 & PQ & 1,041 & $-8,4$ & - & - & 2,4 & 0,5 & 0,98 & - \\
\hline 9 & PQ & 1,037 & $-15,1$ & - & - & 0,0 & 0,0 & - & - \\
\hline 10 & PQ & 1,050 & $-16,7$ & - & - & 5,8 & 1,4 & 0,98 & 20,9 \\
\hline 11 & PQ & 1,038 & $-10,1$ & - & - & 7,6 & 1,5 & 0,98 & - \\
\hline 12 & PQ & 1,039 & $-15,7$ & - & - & 11,2 & 2,3 & 0,98 & - \\
\hline 13 & PQ & 1,041 & $-11,9$ & - & - & 0,0 & 0,0 & - & - \\
\hline 14 & PQ & 1,029 & $-16,7$ & - & - & 6,2 & 1,3 & 0,98 & - \\
\hline 15 & $\begin{array}{l}\text { PQ } \\
\end{array}$ & 1,029 & $-16,9$ & - & - & 8,2 & 1,7 & 0,98 & - \\
\hline 16 & PQ & 1,039 & $-16,5$ & - & - & 3,5 & 0,7 & 0,98 & - \\
\hline 17 & PQ & 1,043 & $\begin{array}{l}-16,9 \\
\end{array}$ & - & - & 9,0 & 1,8 & 0,98 & - \\
\hline 18 & PQ & 1,026 & $-17,6$ & - & - & 3,2 & 0,7 & 0,98 & - \\
\hline 19 & PQ & 1,027 & $-17,8$ & - & - & 9,5 & 1,9 & 0,98 & - \\
\hline 20 & PQ & 1,032 & $-17,6$ & - & - & 2,2 & 0,5 & 0,98 & - \\
\hline 21 & PQ & 1,043 & $-17,2$ & - & - & 17,5 & 3,6 & 0,98 & - \\
\hline 22 & PQ & 1,043 & $-17,2$ & - & - & 0,0 & 0,0 & - & - \\
\hline 23 & PQ & 1,030 & $-17,4$ & - & - & 3,2 & 0,7 & 0,98 & - \\
\hline 24 & PQ & 1,037 & $-17,7$ & - & - & 8,7 & 1,8 & 0,98 & 4,6 \\
\hline 25 & PQ & 1,043 & $-17,2$ & - & - & 0,0 & 0,0 & - & - \\
\hline 26 & PQ & 1,032 & \begin{tabular}{|l|}
$-17,8$ \\
\end{tabular} & - & - & 3,5 & 0,7 & 0,98 & - \\
\hline 27 & PQ & 1,051 & $-16,5$ & - & - & 0,0 & 0,0 & - & - \\
\hline 28 & PQ & 1,037 & $-12,5$ & - & - & 0,0 & 0,0 & - & - \\
\hline 29 & PQ & 1,025 & $-17,4$ & - & - & 2,4 & 2,3 & 0,72 & - \\
\hline 30 & $\begin{array}{l}\text { PQ } \\
\end{array}$ & 1,011 & $-18,2$ & - & - & 10,6 & 3,9 & 0,94 & - \\
\hline
\end{tabular}


A Tabela 4.11 apresenta os resultados do processo de otimização para o caso denominado por "Super Ótimo".

Tabela 4.11. Estado final resultante do Fluxo de Potência do teste "Solução Super Ótima" para o

\begin{tabular}{|c|c|c|c|c|c|c|c|c|c|}
\hline \multirow[t]{2}{*}{ Barra } & \multirow[t]{2}{*}{ Tipo } & \multicolumn{2}{|c|}{ Tensão } & \multicolumn{2}{|c|}{ Geração } & \multicolumn{4}{|c|}{ Carga } \\
\hline & & $\begin{array}{c}\mathrm{V} \\
\text { (p.u.) }\end{array}$ & $\begin{array}{c}\Theta \\
\text { (graus) }\end{array}$ & $\begin{array}{c}\mathrm{P} \\
(\mathrm{MW})\end{array}$ & $\begin{array}{c}\mathrm{Q} \\
\text { (MVAr) }\end{array}$ & $\begin{array}{c}\mathrm{P} \\
(\mathrm{MW})\end{array}$ & $\begin{array}{c}\mathrm{Q} \\
\text { (MVAr) }\end{array}$ & $\cos \varphi$ & $\mathrm{Q}_{\mathrm{sh}}(\mathrm{MVAr})$ \\
\hline 1 & $\mathrm{VO}$ & 1,050 & 0,0 & 261,6 & $-64,1$ & 0,0 & 0,0 & - & - \\
\hline 2 & PV & 1,050 & $-5,8$ & 0,0 & 38,9 & $-18,3$ & 12,7 & 0,82 & - \\
\hline 3 & $\mathrm{PV}$ & 1,050 & $-12,7$ & 0,0 & 56,1 & 30,0 & 30,0 & 0,71 & - \\
\hline 4 & $\mathrm{PV}$ & 1,050 & $-15,0$ & 0,0 & 5,8 & 0,0 & 0,0 & - & - \\
\hline 5 & PV & 1,050 & $-14,7$ & 0,0 & 50,3 & 94,2 & 19.0 & 0,98 & - \\
\hline 6 & $\mathrm{PV}$ & 1,050 & $-15,8$ & 0,0 & 0,1 & 0,0 & 0,0 & - & - \\
\hline 7 & PQ & 1,048 & $-13,7$ & - & - & 22,8 & $-9,4$ & 0,92 & - \\
\hline 8 & PQ & 1,046 & $-8,5$ & - & - & 2,4 & $-2,4$ & 0,71 & - \\
\hline 9 & PQ & 1,038 & $-15,0$ & - & - & 0,0 & 0,0 & - & - \\
\hline 10 & PQ & 1,050 & $-16,6$ & - & - & 5,8 & $-1,1$ & 0,98 & 21,0 \\
\hline 11 & PQ & 1,044 & $-10,2$ & - & - & 7,6 & $-7,6$ & 0,71 & - \\
\hline 12 & PQ & 1,050 & $-15,8$ & - & - & 11,2 & $-8,8$ & 0,79 & - \\
\hline 13 & PQ & 1,045 & $-11,9$ & - & - & 0,0 & 0,0 & - & - \\
\hline 14 & PQ & 1,044 & $-16,9$ & - & - & 6,2 & $-1,6$ & 0,97 & - \\
\hline 15 & PQ & 1,040 & $-17,0$ & - & - & 8,2 & $-2,2$ & 0,97 & - \\
\hline 16 & PQ & 1,045 & $-16,5$ & - & - & 3,5 & 0,6 & 0,99 & - \\
\hline 17 & PQ & 1,045 & $-16,8$ & - & - & 9,0 & 3,2 & 0,94 & - \\
\hline 18 & PQ & 1,032 & $-17,5$ & - & - & 3,2 & 0,6 & 0,98 & - \\
\hline 19 & PQ & 1,029 & $-17,7$ & - & - & 9,5 & 4,1 & 0,92 & - \\
\hline 20 & PQ & 1,034 & $-17,5$ & - & - & 2,2 & 0,3 & 0,99 & - \\
\hline 21 & PQ & 1,041 & $-17,1$ & - & - & 17,5 & 8,3 & 0,90 & - \\
\hline 22 & PQ & 1,041 & $-17,1$ & - & - & 0,0 & 0,0 & - & - \\
\hline 23 & PQ & 1,035 & $-17,4$ & - & - & 3,2 & 0,8 & 0,97 & - \\
\hline 24 & PQ & 1,035 & $-17,5$ & - & - & 8,7 & 5,1 & 0,86 & 4,6 \\
\hline 25 & PQ & 1,040 & $-17,0$ & - & - & 0,0 & 0,0 & - & - \\
\hline 26 & PQ & 1,024 & $-17,4$ & - & - & 3,5 & 2,0 & 0,87 & - \\
\hline 27 & PQ & 1,051 & $-16,4$ & - & - & 0,0 & 0,0 & - & - \\
\hline 28 & PQ & 1,040 & $-12,5$ & - & - & 0,0 & 0,0 & - & - \\
\hline 29 & $\mathrm{PQ}$ & 1,028 & $-17,5$ & - & - & 2,4 & 0,6 & 0,97 & - \\
\hline 30 & PQ & 1,011 & $-18,2$ & - & - & 10,6 & 4,9 & 0,91 & - \\
\hline
\end{tabular}

Na Tabela 4.12 estão apresentados os valores de perdas do sistema e os valores de potência reativa gerados para o sistema de 30 barras.

Tabela 4.12. Perdas e potência reativa gerada para os casos testados - sistema de 30 barras - Função Objetivo 1.

\begin{tabular}{|c|c|c|}
\hline Caso & Perdas sistêmicas (MW) & Q total gerado (MVAr) \\
\hline Base & 18,4 & 136,1 \\
\hline Sub Ótimo & 18,4 & 122,0 \\
\hline Super Ótimo & 18,3 & 87,1 \\
\hline
\end{tabular}

A partir da Tabela 4.12 é possível observar que: 
- As perdas do sistema para o caso "Sub Ótimo" foram iguais às perdas do sistema para o caso "Base" e os reativos gerados no caso "Sub Ótimo" foram menores em relação ao caso "Base". Com o objetivo de se alcançar uma solução otimizada do caso "Sub Ótimo" em relação ao caso "Base", uma formulação do problema de otimização que contemple em sua função objetivo a minimização das perdas do sistema será apresentada;

- Para o caso "Super Ótimo”, as perdas no sistema e os reativos gerados foram menores em relação ao caso "Sub Ótimo".

\subsubsection{Sistema de 53 Barras - Função Objetivo 1}

O sistema de 53 barras, utilizado para realização dos testes, é apresentado na Figura 4.5. Este sistema é um equivalente do sistema elétrico do Estado de São Paulo, carga pesada, sob influência das usinas pertencentes à AES Tietê S/A. O sistema apresentado possui as seguintes características:

- 1 barra de referência;

- 15 barras de geração;

- 37 barras de carga;

- 89 linhas de transmissão;

- 26 transformadores. 


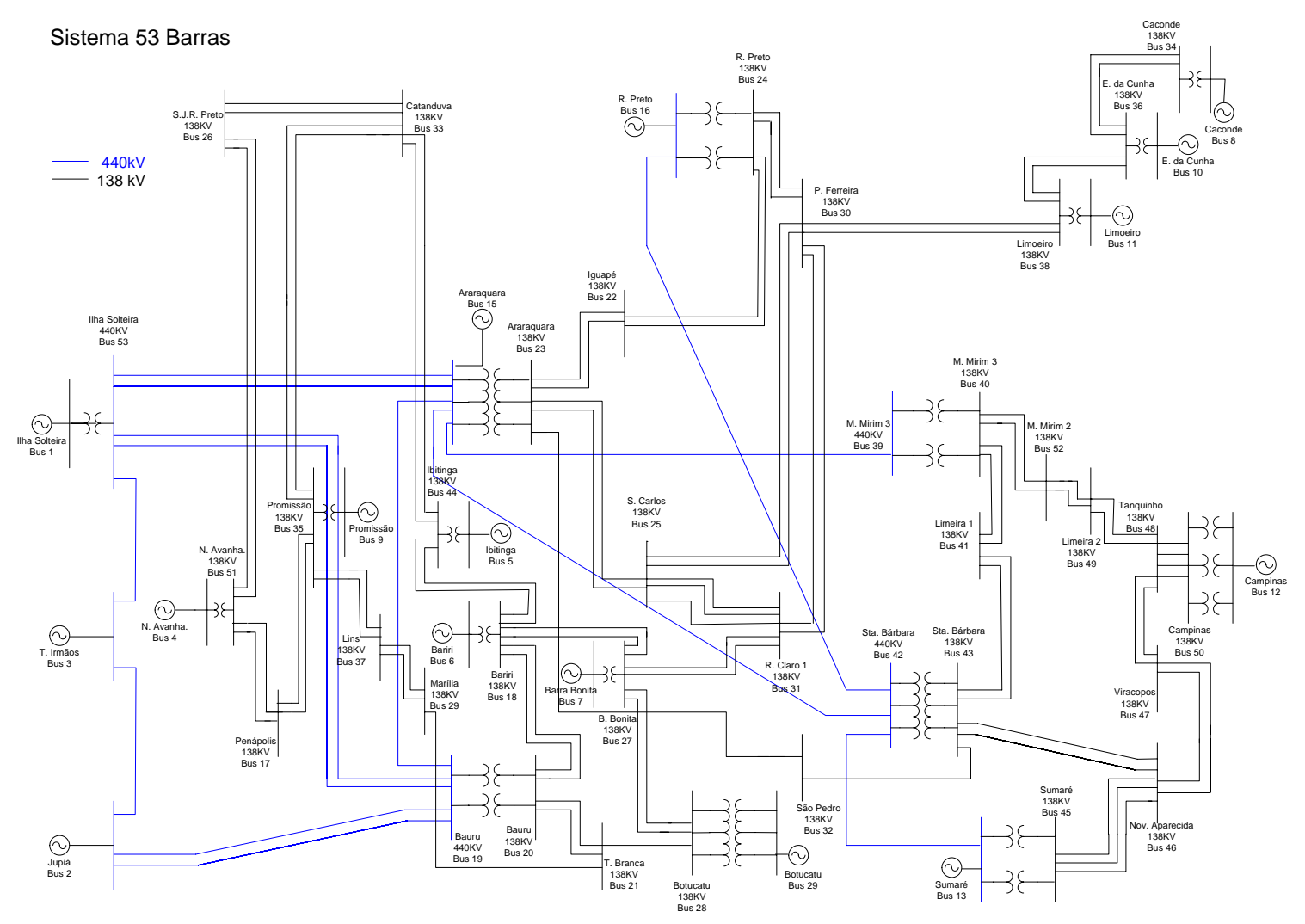

Figura 4.5. Sistema 53 barras.

Os resultados do Fluxo de Potência para o Sistema de 53 barras estão apresentados na Tabela 4.13 .

Tabela 4.13. Ponto de operação do sistema de 53 barras, resultante do Fluxo de Potência

\begin{tabular}{|c|c|c|c|c|c|c|c|c|c|}
\hline \multirow[t]{2}{*}{ Barra } & \multirow[t]{2}{*}{ Tipo } & \multicolumn{2}{|c|}{ Tensão } & \multicolumn{2}{|c|}{ Geração } & \multicolumn{4}{|c|}{ Carga } \\
\hline & & $\begin{array}{c}\mathrm{V} \\
\text { (p.u.) }\end{array}$ & $\begin{array}{c}\Theta \\
\text { (graus) }\end{array}$ & $\begin{array}{c}\mathrm{P} \\
(\mathrm{MW})\end{array}$ & $\begin{array}{c}\mathrm{Q} \\
\text { (MVAr) }\end{array}$ & $\begin{array}{c}\mathrm{P} \\
(\mathrm{MW})\end{array}$ & $\begin{array}{c}\mathrm{Q} \\
\text { (MVAr) }\end{array}$ & $\cos \varphi$ & $\begin{array}{c}\mathrm{Q}_{\mathrm{sh}} \\
\text { (MVAr) }\end{array}$ \\
\hline 1 & $\mathrm{~V} \Theta$ & 1,020 & 12,00 & 2391,9 & $-288,7$ & - & - & - & - \\
\hline 2 & PV & 1,040 & 7,80 & 1068,0 & $-189,6$ & - & - & - & - \\
\hline 3 & PV & 1,040 & 8,60 & 513,0 & $-6,7$ & - & - & - & - \\
\hline 4 & PV & 1,000 & 3,60 & 254,0 & 45,6 & - & - & - & - \\
\hline 5 & $\mathrm{PV}$ & 1,010 & $-5,80$ & 101,0 & 14,9 & - & - & - & - \\
\hline 6 & PV & 1,050 & $-9,40$ & 105,0 & 65,0 & - & - & - & - \\
\hline 7 & PV & 1,005 & $-14,50$ & 114,0 & 11,1 & - & - & - & - \\
\hline 8 & PV & 1,025 & $-20,70$ & 46,0 & 19,4 & - & - & - & - \\
\hline 9 & PV & 1,010 & $\begin{array}{l}-0,10 \\
\end{array}$ & 216,0 & 57,9 & - & - & - & - \\
\hline 10 & PV & 1,035 & $-20,20$ & 78,0 & 22,0 & - & - & - & - \\
\hline 11 & PV & 1,036 & $-22,10$ & 23,0 & 11,7 & - & - & - & - \\
\hline 12 & PV & 1,030 & $-22,70$ & 614,0 & 236,9 & - & - & - & - \\
\hline 13 & PV & 1,004 & $-22,30$ & 235,0 & 239,4 & - & - & - & - \\
\hline 14 & PV & 1,010 & $-14,50$ & 239,0 & 138,2 & - & - & - & - \\
\hline
\end{tabular}




\begin{tabular}{|c|c|c|c|c|c|c|c|c|c|}
\hline 15 & PV & 1,033 & $-13,10$ & 232,0 & 457,0 & - & - & - & $-192,1$ \\
\hline 16 & PV & 1,009 & $-17,50$ & 629,0 & 93,6 & - & - & - & - \\
\hline 17 & PQ & 1,037 & $\begin{array}{l}-3,90 \\
\end{array}$ & - & - & 41,9 & 11,2 & 0,97 & - \\
\hline 18 & $\mathrm{PQ}$ & 1,036 & $-13,20$ & - & - & - & - & - & - \\
\hline 19 & PQ & 1,022 & $\begin{array}{l}-9,20 \\
\end{array}$ & - & - & 1795,0 & 365,0 & 0,98 & - \\
\hline 20 & $\begin{array}{l}\mathrm{PQ} \\
\end{array}$ & 1,019 & $-13,40$ & - & - & 85,2 & 25,0 & 0,96 & - \\
\hline 21 & PQ & 1,014 & $-14,40$ & - & - & 82,5 & 22,4 & 0,96 & - \\
\hline 22 & PQ & 0,982 & $-24,10$ & - & - & 198,1 & 69,4 & 0,94 & - \\
\hline 23 & $\begin{array}{l}\mathrm{PQ} \\
\end{array}$ & 1,016 & $-18,80$ & - & - & 295,9 & 85,0 & 0,96 & - \\
\hline 24 & PQ & 1,008 & $-22,60$ & - & - & 191,3 & 56,0 & 0,96 & - \\
\hline 25 & PQ & 0,970 & $-26,10$ & - & - & 119,8 & 30,3 & 0,97 & - \\
\hline 26 & PQ & 0,983 & $-11,00$ & - & - & 123,3 & 41,6 & 0,95 & 19,3 \\
\hline 27 & PQ & 1,000 & $-18,90$ & - & - & 114,8 & 44,0 & 0,93 & - \\
\hline 28 & PQ & 1,014 & $-19,80$ & - & - & 287,2 & 75,0 & 0,97 & - \\
\hline 29 & PQ & 0,996 & $-13,00$ & - & - & 78,4 & 23,5 & 0,96 & 19,9 \\
\hline 30 & PQ & 0,980 & $-26,70$ & - & - & 91,3 & 19,3 & 0,98 & - \\
\hline 31 & PQ & 0,963 & $-29,00$ & - & - & 210,8 & 33,4 & 0,99 & 55,7 \\
\hline 32 & PQ & 1,001 & $-26,00$ & - & - & 17,3 & 3,3 & 0,98 & - \\
\hline 33 & PQ & 0,986 & $-11,30$ & - & - & 126,3 & 43,5 & 0,95 & - \\
\hline 34 & $\mathrm{PQ}$ & 1,031 & $-23,80$ & - & - & 16,3 & 6,5 & 0,93 & - \\
\hline 35 & PQ & 1,042 & $-4,5$ & - & - & - & - & - & - \\
\hline 36 & PQ & 1,021 & $-24,50$ & - & - & 74,5 & 19,5 & 0,97 & - \\
\hline 37 & PQ & 1,015 & $-8,80$ & - & - & 50,5 & 20,5 & 0,93 & - \\
\hline 38 & PQ & 1,018 & $-24,60$ & - & - & - & - & - & - \\
\hline 39 & $\mathrm{PQ}$ & 0,984 & $-21,10$ & - & - & 44,7 & 25,0 & 0,87 & - \\
\hline 40 & PQ & 0,986 & $-28,20$ & - & - & 162,9 & 47,5 & 0,96 & - \\
\hline 41 & PQ & 0,978 & $-30,70$ & - & - & 174,4 & 38,6 & 0,98 & 17,2 \\
\hline 42 & PQ & 1,002 & $-22,00$ & - & - & - & - & - & - \\
\hline 43 & PQ & 1,005 & $-28,60$ & - & - & 612,0 & 124,3 & 0,98 & - \\
\hline 44 & $\mathrm{PQ}$ & 1,026 & $-10,8$ & - & - & 29,1 & 10,2 & 0,94 & - \\
\hline 45 & PQ & 1,013 & $-28,10$ & - & - & 136,0 & 41,0 & 0,96 & - \\
\hline 46 & PQ & 0,999 & $-29,90$ & - & - & 276,2 & 105,0 & 0,93 & 30,0 \\
\hline 47 & $\mathrm{PQ}$ & 0,992 & $-31,00$ & - & - & 80,3 & 33,7 & 0,92 & 29,5 \\
\hline 48 & $\mathrm{PQ}$ & 0,996 & $-30,50$ & - & - & 541,3 & 110,0 & 0,98 & - \\
\hline 49 & $\mathrm{PQ}$ & 0,968 & $-31,60$ & - & - & 85,1 & 28,7 & 0,95 & - \\
\hline 50 & PQ & 0,997 & $-30,40$ & - & - & - & - & - & - \\
\hline 51 & PQ & 1,037 & $-1,80$ & - & - & 49,9 & 19,6 & 0,93 & - \\
\hline 52 & $\mathrm{PQ}$ & 0,967 & $-30,40$ & - & - & 224,0 & 66,0 & 0,96 & - \\
\hline 53 & $\mathrm{PQ}$ & 1,034 & 7,20 & - & - & 269,9 & 98,0 & 0,94 & - \\
\hline \multicolumn{4}{|c|}{ Perdas $=172,50 \mathrm{MW}$} & \multicolumn{6}{|c|}{ Potência Reativa Gerada $=1670,5 \mathrm{MVAr}$} \\
\hline
\end{tabular}

\section{A Tabela 4.14 apresenta os resultados do caso definido por "Solução Base" para}

o sistema de 53 barras.

Tabela 4.14. Estado final resultante do Fluxo de Potência do caso "Solução Base" para o sistema de 53 barras - Função Objetivo 1 .

\begin{tabular}{|c|c|c|c|c|c|c|c|c|c|}
\hline \multirow[t]{2}{*}{ Barra } & \multirow[t]{2}{*}{ Tipo } & \multicolumn{2}{|c|}{ Tensão } & \multicolumn{2}{|c|}{ Geração } & \multicolumn{4}{|c|}{ Carga } \\
\hline & & $\begin{array}{c}\mathrm{V} \\
\text { (p.u.) }\end{array}$ & $\begin{array}{c}\Theta \\
\text { (graus) }\end{array}$ & $\begin{array}{c}\mathrm{P} \\
(\mathrm{MW})\end{array}$ & $\begin{array}{c}\mathrm{Q} \\
\text { (MVAr) }\end{array}$ & $\begin{array}{c}\mathrm{P} \\
(\mathrm{MW})\end{array}$ & $\begin{array}{c}\mathrm{Q} \\
\text { (MVAr) }\end{array}$ & $\cos \varphi$ & $\begin{array}{c}\mathrm{Q}_{\mathrm{sh}} \\
\text { (MVAr) }\end{array}$ \\
\hline 1 & VE & 1,050 & 12,0 & 2393,8 & 75,6 & - & - & - & - \\
\hline 2 & $\mathrm{PV}$ & 1,050 & 8,1 & 1068,0 & $-155,4$ & - & - & - & - \\
\hline 3 & $\mathrm{PV}$ & 1,050 & 8,8 & 513,0 & $-94,3$ & - & - & - & - \\
\hline 4 & $\mathrm{PV}$ & 1,050 & 3,9 & 254,0 & 159,7 & - & - & - & - \\
\hline 5 & PV & 1,050 & $-5,8$ & 101,0 & 54,4 & - & - & - & - \\
\hline 6 & $\mathrm{PV}$ & 1,050 & $-9,0$ & 105,0 & 54,1 & - & - & - & - \\
\hline 7 & PV & 1,050 & $-14,5$ & 114,0 & 39,5 & - & - & - & - \\
\hline
\end{tabular}




\begin{tabular}{|c|c|c|c|c|c|c|c|c|c|}
\hline 8 & PV & 1,050 & $-19,8$ & 46,0 & 26,0 & - & - & - & - \\
\hline 9 & PV & 1,050 & 0,4 & 216,0 & 169,9 & - & - & - & - \\
\hline 10 & PV & 1,050 & $\begin{array}{l}-19,2 \\
\end{array}$ & 78,0 & 22,3 & - & - & - & - \\
\hline 11 & PV & 1,050 & $-21,0$ & 23,0 & 11,5 & - & - & - & - \\
\hline 12 & PV & 1,050 & $-21,2$ & 614,0 & 268,2 & - & - & - & - \\
\hline 13 & PV & 1,050 & $-21,4$ & 235,0 & 443,0 & - & - & - & - \\
\hline 14 & PV & 1,050 & $-14,7$ & 239,0 & 177,3 & - & - & - & - \\
\hline 15 & PV & 1,050 & $-12,4$ & 232,0 & 440,5 & - & - & - & $-198,5$ \\
\hline 16 & PV & 1,050 & $-17,0$ & 629,0 & 126,8 & - & - & - & - \\
\hline 17 & PQ & 1,035 & $-3,2$ & - & - & 41,9 & 54,5 & 0,61 & - \\
\hline 18 & PQ & 1,043 & $\begin{array}{l}-12,8 \\
\end{array}$ & - & - & - & - & - & - \\
\hline 19 & PQ & 1,021 & $-8,6$ & - & - & 1795,0 & 597,0 & 0,95 & - \\
\hline 20 & PQ & 1,019 & $-12,9$ & - & - & 85,2 & 28,0 & 0,95 & - \\
\hline 21 & $\begin{array}{l}\mathrm{PQ} \\
\end{array}$ & 1,012 & $\begin{array}{l}-13,8 \\
\end{array}$ & - & - & 82,5 & 27,1 & 0,95 & - \\
\hline 22 & PQ & 1,016 & $-23,2$ & - & - & $\begin{array}{l}198,1 \\
\end{array}$ & 65,1 & 0,95 & - \\
\hline 23 & PQ & 1,032 & $-17,9$ & - & - & 295,9 & 97,3 & 0,95 & - \\
\hline 24 & PQ & 1,042 & $-21,8$ & - & - & 191,3 & 62,9 & 0,95 & - \\
\hline 25 & PQ & 0,980 & $\begin{array}{l}-24,8 \\
\end{array}$ & - & - & 119,8 & 39,4 & 0,95 & - \\
\hline 26 & PQ & 0,949 & $-9,9$ & - & - & 123,3 & 88,2 & 0,81 & 18,0 \\
\hline 27 & PQ & 1,027 & $-18,6$ & - & - & 114,8 & 37,7 & 0,95 & - \\
\hline 28 & PQ & 1,043 & $\begin{array}{l}-19,6 \\
\end{array}$ & - & - & 287,2 & 94,4 & 0,95 & - \\
\hline 29 & PQ & 0,951 & $-11,8$ & - & - & 78,4 & 53,5 & 0,83 & 18,1 \\
\hline 30 & PQ & 0,993 & $-25,5$ & - & - & 91,3 & 30,0 & 0,95 & - \\
\hline 31 & PQ & 0,967 & $-27,6$ & - & - & 210,8 & 69,3 & 0,95 & 56,1 \\
\hline 32 & PQ & 1,025 & $-24,8$ & - & - & 17,3 & 5,7 & 0,95 & - \\
\hline 33 & PQ & 0,961 & $-10,4$ & - & - & 126,3 & 83,5 & 0,83 & - \\
\hline 34 & PQ & 1,050 & $-22,8$ & - & - & 16,3 & 5,4 & 0,95 & - \\
\hline 35 & PQ & 1,045 & $-3,8$ & - & - & - & - & - & - \\
\hline 36 & PQ & 1,036 & $-23,3$ & - & - & 74,5 & 24,5 & 0,95 & - \\
\hline 37 & PQ & 0,983 & $-7,4$ & - & - & 50,5 & 65,5 & 0,61 & - \\
\hline 38 & PQ & 1,033 & $-23,5$ & - & - & - & - & - & - \\
\hline 39 & $\mathrm{PQ}$ & 1,004 & $\begin{array}{l}-20,1 \\
\end{array}$ & - & - & 44,7 & 14,7 & 0,95 & - \\
\hline 40 & PQ & 1,005 & $-26,8$ & - & - & 162,9 & 53,5 & 0,95 & - \\
\hline 41 & PQ & 1,000 & $-29,1$ & - & - & 174,4 & 57,3 & 0,95 & 18,0 \\
\hline 42 & $\mathrm{PQ}$ & 1,043 & $-21,0$ & - & - & - & - & - & - \\
\hline 43 & PQ & 1,035 & $-27,3$ & - & - & 612,0 & 201,2 & 0,95 & - \\
\hline 44 & PQ & 1,033 & $-10,5$ & - & - & 29,10 & 9,6 & 0,95 & - \\
\hline 45 & PQ & 1,051 & $-26,9$ & - & - & 136,0 & 51,7 & 0,93 & - \\
\hline 46 & PQ & 1,038 & $-28,5$ & - & - & 276,2 & 90,8 & 0,95 & 32,3 \\
\hline 47 & $\mathrm{PQ}$ & 1,024 & $-29,5$ & - & - & 80,3 & 26,4 & 0,95 & 31,5 \\
\hline 48 & PQ & 1,010 & $-28,7$ & - & - & 541,3 & 178,0 & 0,95 & - \\
\hline 49 & $\mathrm{PQ}$ & 0,984 & $-29,9$ & - & - & 85,1 & 28,0 & 0,95 & - \\
\hline 50 & PQ & 1,011 & $-28,6$ & - & - & - & - & - & - \\
\hline 51 & PQ & 1,048 & $-1,2$ & - & - & 49,9 & 64,9 & 0,61 & - \\
\hline 52 & $\mathrm{PQ}$ & 0,984 & $-28,8$ & - & - & 224,0 & 73,6 & 0,95 & - \\
\hline 53 & PQ & 1,051 & 7,4 & - & - & 269,9 & 351,0 & 0,61 & - \\
\hline
\end{tabular}

\section{A Tabela 4.15 apresenta os resultados do caso definido por "Solução Sub Ótima"}

para o sistema de 53 barras.

Tabela 4.15. Estado final resultante do Fluxo de Potência do caso "Solução Sub Ótima" para o sistema de 53 barras - Função Objetivo 1.

\begin{tabular}{|c|c|c|c|c|c|c|c|c|c|}
\hline \multirow{2}{*}{ Barra } & \multirow{2}{*}{ Tipo } & \multicolumn{2}{|c|}{ Tensão } & \multicolumn{2}{c|}{ Geração } & \multicolumn{4}{c|}{ Carga } \\
\cline { 3 - 9 } & & $\begin{array}{c}\mathrm{V} \\
\text { (p.u.) }\end{array}$ & $\begin{array}{c}\Theta \\
\text { (graus) }\end{array}$ & $\begin{array}{c}\mathrm{P} \\
\text { (MW) }\end{array}$ & $\begin{array}{c}\mathrm{Q} \\
\text { (MVAr) }\end{array}$ & $\begin{array}{c}\mathrm{P} \\
\text { (MW) }\end{array}$ & $\begin{array}{c}\mathrm{Q} \\
\text { (MVAr) }\end{array}$ & $\cos \varphi$ & $\begin{array}{c}\mathrm{Q}_{\text {sh }} \\
\text { (MVAr) }\end{array}$ \\
\hline 1 & $\mathrm{~V}$ & 1,050 & 12,0 & 2390,8 & 74,6 & - & - & - & - \\
\hline 2 & $\mathrm{PV}$ & 1,050 & 8,1 & 1068,0 & $-156,0$ & - & - & - & - \\
\hline 3 & $\mathrm{PV}$ & 1,050 & 8,8 & 513,0 & $-94,6$ & - & - & - & - \\
\hline
\end{tabular}




\begin{tabular}{|c|c|c|c|c|c|c|c|c|c|}
\hline 4 & PV & 1,050 & 4,1 & 254,0 & 159,6 & - & - & - & - \\
\hline 5 & PV & 1,050 & $-5,7$ & 101,0 & 50,8 & - & - & - & - \\
\hline 6 & PV & 1,050 & $\begin{array}{l}-8,9 \\
\end{array}$ & 105,0 & 46,1 & - & - & - & - \\
\hline 7 & PV & 1,050 & $-14,5$ & 114,0 & 22,0 & - & - & - & - \\
\hline 8 & PV & 1,050 & $\begin{array}{l}-19,3 \\
\end{array}$ & 46,0 & 23,3 & - & - & - & - \\
\hline 9 & PV & 1,050 & 0,6 & 216,0 & 169,8 & - & - & - & - \\
\hline 10 & PV & 1,050 & $-18,9$ & 78,0 & 13,3 & - & - & - & - \\
\hline 11 & PV & 1,050 & $-20,7$ & 23,0 & 6,5 & - & - & - & - \\
\hline 12 & PV & 1,050 & $-21,0$ & 614,0 & 180,5 & - & - & - & - \\
\hline 13 & PV & 1,050 & $-21,3$ & 235,0 & 359,1 & - & - & - & - \\
\hline 14 & PV & 1,050 & $-14,6$ & 239,0 & 154,4 & - & - & - & - \\
\hline 15 & PV & 1,050 & $-12,4$ & 232,0 & 298,1 & - & - & - & $-198,5$ \\
\hline 16 & PV & 1,050 & $-16,9$ & 629,0 & 68,8 & - & - & - & - \\
\hline 17 & $\begin{array}{l}\mathrm{PQ} \\
\end{array}$ & 1,035 & $-3,0$ & - & - & 41,9 & 54,5 & 0,61 & - \\
\hline 18 & PQ & 1,048 & $-12,7$ & - & - & - & - & - & - \\
\hline 19 & PQ & 1,021 & $-8,6$ & - & - & 1795,0 & 612,0 & 0,95 & - \\
\hline 20 & PQ & 1,026 & $-12,8$ & - & - & 85,2 & 17,3 & 0,98 & - \\
\hline 21 & PQ & 1,019 & $\begin{array}{c}-13,8 \\
\end{array}$ & - & - & 82,5 & 16,8 & 0,98 & - \\
\hline 22 & PQ & 1,033 & $-23,1$ & - & - & 198,1 & 40,2 & 0,98 & - \\
\hline 23 & PQ & 1,043 & $-17,8$ & - & - & 295,9 & 60,1 & 0,98 & - \\
\hline 24 & $\begin{array}{l}\mathrm{PQ} \\
\end{array}$ & 1,051 & $-21,6$ & - & - & 191,3 & 48,0 & 0,97 & - \\
\hline 25 & PQ & 1,005 & $\begin{array}{l}-24,8 \\
\end{array}$ & - & - & 119,8 & 24,3 & 0,98 & - \\
\hline 26 & PQ & 0,949 & $-9,7$ & - & - & 123,3 & 88,2 & 0,81 & 18,0 \\
\hline 27 & $\begin{array}{l}\mathrm{PQ} \\
\end{array}$ & 1,038 & $-18,5$ & - & - & 114,8 & 23,3 & 0,98 & - \\
\hline 28 & PQ & 1,051 & $-19,4$ & - & - & 287,2 & 78,0 & 0,97 & - \\
\hline 29 & PQ & 0,950 & $-11,6$ & - & - & 78,4 & 56,8 & 0,81 & 18,1 \\
\hline 30 & PQ & 1,016 & $-25,3$ & - & - & 91,3 & 18,5 & 0,98 & - \\
\hline 31 & $\mathrm{PQ}$ & 0,999 & $-27,6$ & - & - & 210,8 & 42,8 & 0,98 & 59,9 \\
\hline 32 & $\mathrm{PQ}$ & 1,042 & $-24,6$ & - & - & 17,3 & 3,5 & 0,98 & - \\
\hline 33 & $\mathrm{PQ}$ & 0,961 & $-10,2$ & - & - & 126,3 & 86,3 & 0,83 & - \\
\hline 34 & PQ & 1,051 & $-22,3$ & - & - & 16,3 & 14,9 & 0,74 & - \\
\hline 35 & PQ & 1,045 & $-3,6$ & - & - & - & - & - & - \\
\hline 36 & PQ & 1,044 & $-23,0$ & - & - & 74,5 & 15,1 & 0,98 & - \\
\hline 37 & PQ & 0,983 & $-7,2$ & - & - & 50,5 & 65,5 & 0,61 & - \\
\hline 38 & PQ & 1,043 & $-23,1$ & - & - & - & - & - & - \\
\hline 39 & PQ & 1,019 & $-20,1$ & - & - & 44,70 & 9,1 & 0,98 & - \\
\hline 40 & PQ & 1,032 & $-26,6$ & - & - & 162,9 & 33,1 & 0,98 & - \\
\hline 41 & $\mathrm{PQ}$ & 1,026 & $-28,9$ & - & - & 174,4 & 35,4 & 0,98 & 19,0 \\
\hline 42 & PQ & 1,045 & $-20,9$ & - & - & - & - & - & - \\
\hline 43 & PQ & 1,051 & $-27,1$ & - & - & 612,0 & 124,3 & 0,98 & - \\
\hline 44 & PQ & 1,036 & $-10,4$ & - & - & 29,1 & 5,9 & 0,98 & - \\
\hline 45 & PQ & 1,052 & $-26,6$ & - & - & 136,0 & 118,0 & 0,76 & - \\
\hline 46 & PQ & 1,047 & $-28,2$ & - & - & 276,2 & 56,1 & 0,98 & 32,9 \\
\hline 47 & PQ & 1,039 & $-29,2$ & - & - & 80,3 & 16,3 & 0,98 & 32,4 \\
\hline 48 & PQ & 1,029 & $-28,4$ & - & - & 541,3 & 110,0 & 0,98 & - \\
\hline 49 & PQ & 1,012 & $-29,6$ & - & - & 85,1 & 17,3 & 0,98 & - \\
\hline 50 & PQ & 1,029 & $-28,4$ & - & - & - & - & - & - \\
\hline 51 & $\mathrm{PQ}$ & 1,048 & $-1,0$ & - & - & 49,9 & 64,9 & 0,61 & - \\
\hline 52 & PQ & 1,015 & $-28,6$ & - & - & 224,0 & 45,5 & 0,98 & - \\
\hline 53 & PQ & 1,051 & 7,4 & - & - & 269,9 & 351,0 & 0,61 & - \\
\hline \multicolumn{10}{|c|}{ Perdas $=171,40 \mathrm{MW}$} \\
\hline
\end{tabular}

\section{A Tabela 4.16 apresenta os resultados do caso definido por "Solução Super} Ótima" para o sistema de 53 barras. 
Tabela 4.16. Estado final resultante do Fluxo de Potência do caso "Solução Super Ótima" para o sistema de 53 barras - Função Objetivo 1.

\begin{tabular}{|c|c|c|c|c|c|c|c|c|c|}
\hline \multirow[t]{2}{*}{ Barra } & \multirow[t]{2}{*}{ Tipo } & \multicolumn{2}{|c|}{ Tensão } & \multicolumn{2}{|c|}{ Geração } & \multicolumn{4}{|c|}{ Carga } \\
\hline & & $\begin{array}{c}\mathrm{V} \\
\text { (p.u.) }\end{array}$ & $\begin{array}{c}\Theta \\
\text { (graus) }\end{array}$ & $\begin{array}{c}\mathrm{P} \\
(\mathrm{MW})\end{array}$ & $\begin{array}{c}\mathrm{Q} \\
\text { (MVAr) }\end{array}$ & $\begin{array}{c}\mathrm{P} \\
(\mathrm{MW})\end{array}$ & $\begin{array}{c}\mathrm{Q} \\
\text { (MVAr) }\end{array}$ & $\cos \varphi$ & $\begin{array}{c}\mathrm{Q}_{\mathrm{sh}} \\
\text { (MVAr) }\end{array}$ \\
\hline 1 & VO & 1,030 & 12,0 & 2390,5 & 6,1 & - & - & - & - \\
\hline 2 & $\mathrm{PV}$ & 1,030 & 8,0 & 1068,0 & $-168,5$ & - & - & - & - \\
\hline 3 & PV & 1,030 & 8,7 & 513,0 & $-125,0$ & - & - & - & - \\
\hline 4 & $\mathrm{PV}$ & 1,030 & 3,3 & 254,0 & 94,1 & - & - & - & - \\
\hline 5 & $\mathrm{PV}$ & 1,030 & $-6,4$ & 101,0 & 11,1 & - & - & - & - \\
\hline 6 & PV & 1,030 & $-9,5$ & 105,0 & 10,2 & - & - & - & - \\
\hline 7 & $\mathrm{PV}$ & 1,030 & $-15,2$ & 114,0 & $-25,6$ & - & - & - & - \\
\hline 8 & PV & 1,030 & $-19,9$ & 46,0 & 6,1 & - & - & - & - \\
\hline 9 & $\mathrm{PV}$ & 1,030 & $-0,2$ & 216,0 & 93,7 & - & - & - & - \\
\hline 10 & PV & 1,030 & $-19,6$ & 78,0 & $-14,5$ & - & - & - & - \\
\hline 11 & $\mathrm{PV}$ & 1,030 & $-21,4$ & 23,0 & $-8,1$ & - & - & - & - \\
\hline 12 & $\mathrm{PV}$ & 1,030 & $-22,2$ & 614,0 & $-27,9$ & - & - & - & - \\
\hline 13 & $\mathrm{PV}$ & 1,030 & $-22,2$ & 235,0 & 145,3 & - & - & - & - \\
\hline 14 & $\mathrm{PV}$ & 1,030 & $-14,9$ & 239,0 & 100,6 & - & - & - & - \\
\hline 15 & $\mathrm{PV}$ & 1,030 & $-13,3$ & 232,0 & $-48,0$ & - & - & - & $-191,0$ \\
\hline 16 & PV & 1,030 & $-17,6$ & 629,0 & $-30,4$ & - & - & - & - \\
\hline 17 & PQ & 1,044 & $-3,9$ & - & - & 41,9 & 29,9 & 0,81 & - \\
\hline 18 & PQ & 1,051 & $-13,3$ & - & - & - & - & - & - \\
\hline 19 & PQ & 1,009 & $-9,3$ & - & - & 1795,0 & 527,0 & 0,96 & - \\
\hline 20 & PQ & 1,033 & $-13,5$ & - & - & 85,2 & $-24,0$ & 0,96 & - \\
\hline 21 & PQ & 1,029 & $-14,5$ & - & - & 82,5 & 3,2 & 0,99 & - \\
\hline 22 & PQ & 1,031 & $-23,8$ & - & - & 198,1 & 54,7 & 0,96 & - \\
\hline 23 & PQ & 1,050 & $-18,7$ & - & - & 295,9 & $-90,0$ & 0,96 & - \\
\hline 24 & PQ & 1,052 & $-22,4$ & - & - & 191,3 & $-11,0$ & 0,99 & - \\
\hline 25 & PQ & 1,037 & $-25,9$ & - & - & 119,8 & 0,0 & 1,0 & - \\
\hline 26 & PQ & 0,975 & $-10,7$ & - & - & 123,3 & 88,7 & 0,81 & 19,0 \\
\hline 27 & PQ & 1,050 & $-19,3$ & - & - & 114,8 & $-40,0$ & 0,94 & - \\
\hline 28 & PQ & 1,050 & $-19,9$ & - & - & 287,2 & 55,0 & 0,98 & - \\
\hline 29 & PQ & 0,974 & $-12,5$ & - & - & 78,4 & 54,0 & 0,82 & 19,0 \\
\hline 30 & PQ & 1,050 & $-26,6$ & - & - & 91,3 & $-49,0$ & 0,88 & - \\
\hline 31 & PQ & 1,036 & $-28,6$ & - & - & 210,8 & 19,2 & 0,99 & 64,4 \\
\hline 32 & PQ & 1,045 & $-25,5$ & - & - & 17,3 & 6,4 & 0,94 & - \\
\hline 33 & PQ & 0,998 & $-11,4$ & - & - & 126,3 & 24,3 & 0,98 & - \\
\hline 34 & PQ & 1,052 & $-22,9$ & - & - & 16,3 & 13,2 & 0,78 & - \\
\hline 35 & PQ & 1,051 & $-4,5$ & - & - & - & - & - & - \\
\hline 36 & PQ & 1,051 & $-23,7$ & - & - & 74,5 & $-10,0$ & 0,99 & - \\
\hline 37 & PQ & 1,006 & $-8,3$ & - & - & 50,5 & 35,0 & 0,82 & - \\
\hline 38 & PQ & 1,051 & $-23,9$ & - & - & - & - & - & - \\
\hline 39 & PQ & 1,030 & $-21,3$ & - & - & 44,7 & $-36,0$ & 0,78 & - \\
\hline 40 & PQ & 1,052 & $-27,7$ & - & - & 162,9 & $-65,0$ & 0,93 & - \\
\hline 41 & PQ & 1,040 & $-29,8$ & - & - & 174,4 & 46,0 & 0,97 & 19,5 \\
\hline 42 & PQ & 1,029 & $-21,9$ & - & - & - & - & - & - \\
\hline 43 & PQ & 1,051 & $-28,0$ & - & - & 612,0 & $-22,0$ & 0,99 & - \\
\hline 44 & PQ & 1,050 & $-11,2$ & - & - & 29,1 & $-20,0$ & 0,82 & - \\
\hline 45 & PQ & 1,054 & $-27,5$ & - & - & 136,0 & $-5,0$ & 0,99 & - \\
\hline 46 & PQ & 1,045 & $-29,1$ & - & - & 276,2 & 129,0 & 0,91 & 32,8 \\
\hline 47 & PQ & 1,044 & $-30,1$ & - & - & 80,3 & 31,4 & 0,93 & 32,7 \\
\hline 48 & $\mathrm{PQ}$ & 1,052 & $-29,6$ & - & - & 541,3 & $-129,0$ & 0,97 & - \\
\hline 49 & $\mathrm{PQ}$ & 1,039 & $-30,7$ & - & - & 85,1 & 22,0 & 0,97 & - \\
\hline 50 & $\mathrm{PQ}$ & 1,051 & $-29,6$ & - & - & - & - & - & - \\
\hline 51 & PQ & 1,051 & $-1,9$ & - & - & 49,9 & 36,5 & 0,81 & - \\
\hline 52 & PQ & 1,046 & $-29,6$ & - & - & 224,0 & 33,8 & 0,99 & - \\
\hline 53 & PQ & 1,033 & 7,3 & - & - & 269,9 & 216,0 & 0,78 & - \\
\hline \multicolumn{4}{|c|}{ Perdas $=171,20 \mathrm{MW}$} & otênci & $\mathrm{a} \mathrm{Ger}$ & $19,2 \mathrm{MV}$ & & & \\
\hline
\end{tabular}


Na Tabela 4.17 estão apresentados os valores de perdas do sistema e os valores de potência reativa gerados para o sistema de 53 barras.

Tabela 4.17. Perdas e potência reativa gerada para os casos testados - sistema de 53 barras - Função Objetivo 1.

\begin{tabular}{|c|c|c|}
\hline Caso & Perdas sistêmicas (MW) & Q total gerado (MVAr) \\
\hline Base & 174,4 & 1819,1 \\
\hline Sub Ótimo & 171,4 & 1376,2 \\
\hline Super Ótimo & 171,2 & 19,2 \\
\hline
\end{tabular}

A partir da Tabela 4.17 é possível observar que:

- As perdas no sistema e os reativos gerados foram menores no caso "Sub Ótimo" em relação ao caso "Base";

- Para o caso "Super Ótimo", as perdas no sistema e os reativos gerados foram menores em relação ao caso "Sub Ótimo".

Os resultados apresentados anteriormente mostraram a necessidade de se investigar uma formulação do processo de otimização que contemple em sua função objetivo a minimização das perdas ativas do sistema. Desta forma, a seguir será apresentada à formulação do problema de minimização das perdas ativas do sistema, sujeito a um conjunto de restrições; e a solução obtida para os testes realizados a partir dos sistemas apresentados anteriormente, 8; 30 barras (AEP); e 53 barras (Equivalente São Paulo). 


\subsection{Otimização das Perdas Ativas do Sistema - Função Objetivo 2}

Apresentados os resultados do problema otimização formulado a partir da minimização das potências reativas das barras de geração, Função Objetivo 1, a seguir será apresentada a formulação do problema de otimização com base na minimização das perdas ativas do sistema, Função Objetivo 2. Essa formulação permitirá uma maior sensibilidade em relação à variação da geração/absorção de potência reativa e das perdas ativas no sistema. Essas duas variáveis são fundamentais para aplicação da metodologia de valoração do suporte de potência reativa provido pelos agentes geradores.

Considere a formulação geral do problema de otimização, sistema de equações 4.27, onde a função objetivo é representada pela minimização das perdas ativas, e as restrições são representadas pelos limites operativos do sistema, IBA et al. (1988).

$$
\begin{aligned}
& \text { Min } F=\Delta P 1=[L] *\left[\begin{array}{l}
\Delta Q_{c} \\
\Delta V_{g}
\end{array}\right] \\
& \text { s.a. }
\end{aligned}
$$

$$
\left[\begin{array}{c}
\Delta V L^{\min } \\
\frac{\Delta Q_{g}^{\min }}{\Delta Q_{c}^{\min }} \\
\Delta V_{g}^{\min }
\end{array}\right] \leq\left[\frac{S}{1}\right]\left[\begin{array}{c}
\Delta Q_{c} \\
\Delta V_{g}
\end{array}\right] \leq\left[\begin{array}{c}
\Delta V L^{\max } \\
\frac{\Delta Q_{g}^{\max }}{\Delta Q_{c}^{\max }} \\
\Delta V_{g}^{\max }
\end{array}\right]
$$

Para o sistema de equações (4.27) $\Delta P 1$ representa a função de perdas do sistema; [L] o vetor de sensibilidade com relação à barra swing, derivado da matriz Jacobiana

- Equação 4.4; $\Delta Q_{c}$ e $\Delta V_{g}$ as variáveis do problema, representadas pelas variações de 
potência reativa das barras de carga e de tensão das barras de geração, respectivamente; [S] a matriz de sensibilidade com relação às barras de geração e de carga, derivada da matriz Jacobiana - Equação 4.8; $\Delta \mathrm{VL}^{\min }, \Delta \mathrm{V}_{\mathrm{g}}^{\min } \mathrm{e} \Delta \mathrm{VL}^{\max }$, $\Delta \mathrm{V}_{\mathrm{g}}{ }^{\max }$ a variação entre os valores presentes e os limites mínimos e máximos de tensões das barras de carga e das barras de geração, respectivamente; $\Delta \mathrm{Q}_{\mathrm{g}}{ }^{\mathrm{min}}, \Delta \mathrm{Q}_{\mathrm{c}}{ }^{\mathrm{min}}$ e $\Delta \mathrm{Q}_{\mathrm{g}}{ }^{\max }, \Delta \mathrm{Q}_{\mathrm{c}}{ }^{\max } \mathrm{V}_{\mathrm{g}}{ }^{\max }$ a variação entre os valores presentes e os limites mínimos e máximos de potência reativa das barras de carga e das barras de geração, respectivamente.

A partir do problema geral de otimização proposto no sistema de equações 4.27 , serão realizadas as formulações dos problemas de Programação Linear com base nos diferentes pontos de operação definidos no Item 4.4.2. São eles: Solução Base; Solução Sub Ótima; e Solução Super Ótima. Essas soluções se diferenciam pelos níveis de restrições impostos ao problema de otimização.

Recordando, a "Solução Base" considera que os valores de potência reativa nas barras de carga do sistema estejam com um fator de potência menor ou igual a 0,95 (indutivo). A "Solução Sub Ótima” considera que os valores de potência reativa nas barras de carga do sistema estejam com um fator de potência menor ou igual a 0,98 (indutivo). E a "Solução Super Ótima" considera que as barras de carga do sistema podem assumir qualquer valor de potência reativa.

A partir da formulação dos problemas de Programação Linear é aplicada a metodologia proposta no Item 4.5.

Com base na formulação e na metodologia proposta para minimização das perdas ativas do sistema, serão apresentadas as soluções dos testes realizados a partir dos sistemas de 8 barras, 30 barras (AEP) e 53 barras (Equivalente São Paulo). Os 
limites de tensões utilizados para os sistemas foram 0,95 p.u. e 1,05 p.u..

\subsubsection{Sistema de 8 Barras - Função Objetivo 2}

A seguir serão apresentadas as soluções obtidas a partir do sistema de 8 Barras. $\mathrm{O}$ primeiro teste realizado trata da solução definida como "Base".

A Tabela 4.18 apresenta os resultados do processo de otimização para este teste. Estes valores são resultantes do cálculo do Fluxo de Potência a partir da solução do problema de Programação Linear.

Tabela 4.18. Estado final resultante do Fluxo de Potência do teste "Solução Base" para o sistema de 8 barras - Função Objetivo 2.

\begin{tabular}{|c|c|c|c|c|c|c|c|c|c|}
\hline \multirow{2}{*}{ Barra } & \multirow{2}{*}{ Tipo } & \multicolumn{2}{|c|}{ Tensão } & \multicolumn{2}{|c|}{ Geração } & \multicolumn{4}{|c|}{ Carga } \\
\hline & & $\begin{array}{c}\mathrm{V} \\
\text { (p.u.) }\end{array}$ & $\theta$ (graus) & $\begin{array}{c}\mathrm{P} \\
(\mathrm{MW})\end{array}$ & Q (MVAr) & $\begin{array}{c}\mathrm{P} \\
(\mathrm{MW})\end{array}$ & Q (MVAr) & $\cos \varphi$ & $\begin{array}{c}\mathrm{Q}_{\mathrm{sh}} \\
\text { (MVAr) }\end{array}$ \\
\hline 1 & $\mathrm{V \Theta}$ & 1,050 & 0,0 & 1711,8 & 170,2 & - & - & - & - \\
\hline 2 & PV & 1,050 & $-31,8$ & 240,0 & 456,7 & - & - & - & - \\
\hline 3 & PQ & 1,002 & $-23,4$ & - & $\begin{array}{lll}- & -\end{array}$ & 0,0 & 0,0 & - & $-75,2$ \\
\hline 4 & PQ & 1,003 & \begin{tabular}{|c|}
$-22,9$ \\
\end{tabular} & - & - & 134,0 & 44,0 & 0,95 & $-140,8$ \\
\hline 5 & PQ & 1,023 & $-32,4$ & - & - & 1300,0 & 427,0 & 0,95 & $-146,6$ \\
\hline 6 & PQ & 1,012 & $-12,0$ & - & - & 0,0 & 0,0 & - & $-307,2$ \\
\hline 7 & PQ & 1,035 & $\begin{array}{l}-2,3 \\
\end{array}$ & - & - & $\begin{array}{l}180,0 \\
\end{array}$ & 59,0 & 0,95 & - \\
\hline 8 & PQ & 0,976 & $\begin{array}{l}-27,5 \\
\end{array}$ & - & - & 290,0 & 95,0 & 0,95 & - \\
\hline
\end{tabular}

O teste seguinte realizado trata do ponto operacional definido como "Solução Sub Ótima", onde as potências reativas das barras de carga são limitadas a um fator de potência menor ou igual a 0,98 (indutivo).

A Tabela 4.19 apresenta os resultados calculados pelo Fluxo de Potência a partir da solução obtida via problema de PL. 
Tabela 4.19. Estado final resultante do Fluxo de Potência do teste "Solução Sub Ótima" para o sistema de 8 barras - Função Objetivo 2.

\begin{tabular}{|c|c|c|c|c|c|c|c|c|c|}
\hline \multirow[t]{2}{*}{ Barra } & \multirow[t]{2}{*}{ Tipo } & \multicolumn{2}{|c|}{ Tensão } & \multicolumn{2}{|c|}{ Geração } & \multicolumn{4}{|c|}{ Carga } \\
\hline & & $\begin{array}{c}\mathrm{V} \\
\text { (p.u.) }\end{array}$ & $\theta$ (graus) & $\begin{array}{c}\mathrm{P} \\
(\mathrm{MW})\end{array}$ & Q (MVAr) & $\begin{array}{c}\mathrm{P} \\
(\mathrm{MW})\end{array}$ & Q (MVAr) & $\cos \varphi$ & $\begin{array}{c}\mathrm{Q}_{\mathrm{sh}} \\
\text { (MVAr) }\end{array}$ \\
\hline 1 & Vब & 1,050 & 0,0 & 1710,3 & 93,4 & - & - & - & - \\
\hline 2 & PV & 1,050 & $-31,3$ & 240,0 & 256,8 & - & - & - & - \\
\hline 3 & PQ & 1,017 & $-23,1$ & - & - & 0,0 & 0,0 & - & $-77,5$ \\
\hline 4 & PQ & 1,014 & $-22,6$ & - & - & 134,0 & 27,0 & 0,98 & $-144,1$ \\
\hline 5 & PQ & 1,033 & $-31,8$ & - & - & 1300,0 & 264,0 & 0,98 & $-149,3$ \\
\hline 6 & PQ & 1,019 & $-11,9$ & - & - & 0,0 & 0,0 & - & $-311,8$ \\
\hline 7 & PQ & 1,041 & $-2,3$ & - & - & 180,0 & 37,0 & 0,98 & - \\
\hline 8 & PQ & 1,000 & $-27,1$ & - & - & 290,0 & 59,0 & 0,98 & - \\
\hline
\end{tabular}

O terceiro teste realizado trata do ponto operacional definido como "Solução Super Ótima”. A Tabela 4.20 apresenta os resultados deste processo de otimização.

Tabela 4.20. Estado final resultante do fluxo de carga do teste "Solução Super Ótima" para o sistema

\begin{tabular}{|c|c|c|c|c|c|c|c|c|c|}
\hline \multirow[t]{2}{*}{ Barra } & \multirow[t]{2}{*}{ Tipo } & \multicolumn{2}{|c|}{ Tensão } & \multicolumn{2}{|c|}{ Geração } & \multicolumn{4}{|c|}{ Carga } \\
\hline & & $\begin{array}{c}\mathrm{V} \\
\text { (p.u.) }\end{array}$ & $\theta$ (graus) & $\begin{array}{c}\mathrm{P} \\
(\mathrm{MW})\end{array}$ & Q (MVAr) & $\begin{array}{c}\mathrm{P} \\
(\mathrm{MW})\end{array}$ & Q (MVAr) & $\cos \varphi$ & $\begin{array}{c}\mathrm{Q}_{\mathrm{sh}} \\
\text { (MVAr) }\end{array}$ \\
\hline 1 & $\mathrm{~V} \Theta$ & 1,030 & 0,0 & 1710,0 & 40,0 & - & - & - & - \\
\hline 2 & PV & 1,030 & $-31,3$ & 240,0 & $-35,4$ & - & - & - & - \\
\hline 3 & PQ & 1,034 & $-23,4$ & - & - & 0,0 & 0,0 & - & $-80,2$ \\
\hline 4 & PQ & 1,023 & $-22,8$ & - & - & 134,0 & $-64,0$ & 0,90 & $-146,4$ \\
\hline 5 & PQ & 1,027 & $-32,0$ & - & - & 1300,0 & 100,0 & 0,99 & $-147,6$ \\
\hline 6 & PQ & 1,016 & $-12,2$ & - & - & 0,0 & 0,0 & - & $-310,0$ \\
\hline 7 & PQ & 1,007 & $-2,4$ & - & - & 180,0 & 92,0 & 0,89 & - \\
\hline 8 & PQ & 1,051 & $-27,1$ & - & - & 290,0 & $-92,0$ & 0,95 & - \\
\hline
\end{tabular}

$\mathrm{Na}$ Tabela 4.21 estão apresentados os valores de perdas do sistema e os valores de potência reativa gerados pelas barras de geração para os três testes realizados.

Tabela 4.21. Perdas e potência reativa gerada para os casos testados - sistema de 8 barras - Função Objetivo 2.

\begin{tabular}{|c|c|c|}
\hline Caso & Perdas sistêmicas (MW) & Q total gerado (MVAr) \\
\hline Base & 47,8 & 629,9 \\
\hline Sub Ótimo & 46,3 & 350,2 \\
\hline Super Ótimo & 46,0 & 4,8 \\
\hline
\end{tabular}


A partir da Tabela 4.21 é possível observar que:

- As perdas e os reativos gerados no sistema foram menores no caso "Sub Ótimo" em relação ao caso "Base";

- Para o caso "Super Ótimo" as perdas e os reativos gerados foram menores em relação ao caso "Sub Ótimo".

Comparando os valores apresentados na Tabela 4.21 com os valores apresentados na Tabela 4.7, observa-se que a Função Objetivo 1 foi tão eficiente quanto a Função Objetivo 2.

\subsubsection{Sistema de 30 Barras - Função Objetivo 2}

A seguir serão apresentadas as soluções obtidas a partir do sistema de 30 Barras. A Tabela 4.22 apresenta o resultado para o caso definido como "Solução Base". Para este caso, as potências reativas das barras de carga ficaram limitadas a um fator de potência menor ou igual 0,95 (indutivo).

Tabela 4.22. Estado final resultante do Fluxo de Potência do teste "Solução Base" para o sistema de

\begin{tabular}{|c|c|c|c|c|c|c|c|c|c|}
\hline \multirow[t]{2}{*}{ Barra } & \multirow[t]{2}{*}{ Tipo } & \multicolumn{2}{|c|}{ Tensão } & \multicolumn{2}{|c|}{ Geração } & \multicolumn{4}{|c|}{ Carga } \\
\hline & & $\begin{array}{c}\mathrm{V} \\
\text { (p.u.) }\end{array}$ & $\begin{array}{c}\Theta \\
\text { (graus) }\end{array}$ & $\begin{array}{c}\mathrm{P} \\
(\mathrm{MW})\end{array}$ & $\begin{array}{c}\mathrm{Q} \\
\text { (MVAr) }\end{array}$ & $\begin{array}{c}\mathrm{P} \\
(\mathrm{MW})\end{array}$ & $\begin{array}{c}\mathrm{Q} \\
\text { (MVAr) }\end{array}$ & $\cos \varphi$ & $\mathrm{Q}_{\mathrm{sh}}(\mathrm{MVAr})$ \\
\hline 1 & VO & 1,050 & 0,0 & 261,5 & $-51,2$ & - & - & - & - \\
\hline 2 & PV & 1,050 & $-5,8$ & 0,0 & 94,7 & $-18,3$ & 12,7 & - & - \\
\hline 3 & PV & 1,010 & $-12,3$ & 0,0 & 35,1 & 30,0 & 30,0 & - & - \\
\hline 4 & PV & 1,050 & $\begin{array}{l}-14,9 \\
\end{array}$ & 0,0 & 15,9 & - & - & - & - \\
\hline 5 & PV & 1,010 & $-14,6$ & 0,0 & 39,0 & 94,2 & 19,0 & - & - \\
\hline 6 & PV & 1,050 & $-15,8$ & 0,0 & 19,3 & - & - & - & \\
\hline 7 & PQ & 0,998 & $-13,2$ & - & - & 22,8 & 21,8 & 0,72 & - \\
\hline 8 & PQ & 1,023 & $-8,2$ & - & - & 2,4 & 2,4 & 0,71 & - \\
\hline 9 & PQ & 1,018 & $-14,9$ & - & - & 0,0 & 0,0 & - & - \\
\hline 10 & PQ & 1,026 & $-16,6$ & - & - & 5,8 & 1,9 & 0,95 & 20,0 \\
\hline 11 & PQ & 1,018 & $-9,9$ & - & - & 7,6 & 2,5 & 0,95 & - \\
\hline 12 & PQ & 1,024 & $-15,8$ & - & - & 11,2 & 3,7 & 0,95 & - \\
\hline 13 & PQ & 1,012 & $-11,6$ & - & - & 0,0 & 0,0 & - & - \\
\hline 14 & PQ & 1,011 & $-16,7$ & - & - & 6,2 & 2,0 & 0,95 & - \\
\hline 15 & PQ & 1,010 & $-16,9$ & - & - & 8,2 & 2,7 & 0,95 & - \\
\hline 16 & PQ & 1,019 & $-16,5$ & - & - & 3,5 & 1,1 & 0,95 & - \\
\hline 17 & PQ & 1,020 & $-16,8$ & - & - & 9,0 & 3,0 & 0,95 & - \\
\hline 18 & PQ & 1,004 & $-17,5$ & - & - & 3,2 & 0,7 & 0,98 & - \\
\hline
\end{tabular}




\begin{tabular}{|c|c|c|c|c|c|c|c|c|c|}
\hline 19 & PQ & 1,003 & $-17,7$ & - & - & 9,5 & 3,1 & 0,95 & - \\
\hline 20 & PQ & 1,008 & $-17,5$ & - & - & 2,2 & 0,7 & 0,95 & - \\
\hline 21 & PQ & 1,018 & $-17,2$ & - & - & 17,5 & 5,7 & 0,95 & - \\
\hline 22 & PQ & 1,018 & $-17,1$ & - & - & 0,0 & 0,0 & - & - \\
\hline 23 & PQ & 1,007 & $-17,4$ & - & - & 3,2 & 1,0 & 0,95 & - \\
\hline 24 & PQ & 1,011 & $-17,6$ & - & - & 8,7 & 2,9 & 0,95 & 4,4 \\
\hline 25 & PQ & 1,016 & $-17,1$ & - & - & 0,0 & 0,0 & - & - \\
\hline 26 & PQ & 1,003 & $-17,7$ & - & - & 3,5 & 1,1 & 0,95 & - \\
\hline 27 & PQ & 1,025 & $-16,4$ & - & - & 0,0 & 0,0 & - & - \\
\hline 28 & PQ & 1,006 & $-12,2$ & - & - & 0,0 & 0,0 & - & - \\
\hline 29 & PQ & 1,002 & $-17,6$ & - & - & 2,4 & 0,8 & 0,95 & - \\
\hline 30 & PQ & 0,988 & $-18,3$ & - & - & 10,6 & 3,5 & 0,95 & - \\
\hline \multicolumn{7}{|l|}{ Potência Reativa Gerada = 152,9MVAr } \\
\hline
\end{tabular}

A Tabela 4.23 apresenta os resultados do processo de otimização para o ponto operacional definido como "Solução Sub Ótima". Para este teste as potências reativas das barras de carga foram limitadas a um fator de potência menor ou igual a 0,98 (indutivo).

Tabela 4.23. Estado final resultante do Fluxo de Potência do teste "Solução Sub Ótima" para o sistema de 30 barras - Função Objetivo 2.

\begin{tabular}{|c|c|c|c|c|c|c|c|c|c|}
\hline \multirow[t]{2}{*}{ Barra } & \multirow[t]{2}{*}{ Tipo } & \multicolumn{2}{|c|}{ Tensão } & \multicolumn{2}{|c|}{ Geração } & \multicolumn{4}{|c|}{ Carga } \\
\hline & & $\begin{array}{c}\mathrm{V} \\
\text { (p.u.) }\end{array}$ & $\begin{array}{c}\Theta \\
\text { (graus) }\end{array}$ & $\begin{array}{c}\mathrm{P} \\
(\mathrm{MW})\end{array}$ & $\begin{array}{c}\mathrm{Q} \\
\text { (MVAr) }\end{array}$ & $\begin{array}{c}\mathrm{P} \\
(\mathrm{MW})\end{array}$ & $\begin{array}{c}\mathrm{Q} \\
\text { (MVAr) }\end{array}$ & $\cos \varphi$ & $\mathrm{Q}_{\mathrm{sh}}(\mathrm{MVAr})$ \\
\hline 1 & VO & 1,050 & 0,0 & 261,4 & $-52,0$ & - & - & - & - \\
\hline 2 & PV & 1,050 & $-5,8$ & 0,0 & 92,8 & $-18,3$ & 12,7 & - & - \\
\hline 3 & $\mathrm{PV}$ & 1,010 & $-12,3$ & 0,0 & 30,5 & 30,0 & 30,0 & - & - \\
\hline 4 & PV & 1,050 & $-14,9$ & 0,0 & 13,6 & - & - & - & - \\
\hline 5 & PV & 1,010 & $-14,6$ & 0,0 & 38,2 & 94,2 & 19,0 & - & - \\
\hline 6 & $\mathrm{PV}$ & 1,050 & $-15,7$ & 0,0 & 15,0 & - & - & - & - \\
\hline 7 & PQ & 0,998 & $-13,2$ & - & - & 22,8 & 21,8 & 0,72 & - \\
\hline 8 & PQ & 1,024 & $-8,2$ & - & - & 2,4 & 2,4 & 0,71 & - \\
\hline 9 & PQ & 1,023 & $-14,9$ & - & - & 0,0 & 0,0 & - & - \\
\hline 10 & $\mathrm{PQ}$ & 1,035 & $-16,6$ & - & - & 5,8 & 1,2 & 0,98 & 20,4 \\
\hline 11 & PQ & 1,019 & $-9,9$ & - & - & 7,6 & 1,5 & 0,98 & - \\
\hline 12 & PQ & 1,030 & $-15,7$ & - & - & 11,2 & 2,3 & 0,98 & - \\
\hline 13 & PQ & 1,013 & $-11,6$ & - & - & 0,0 & 0,0 & - & - \\
\hline 14 & PQ & 1,020 & $-16,7$ & - & - & 6,2 & 1,3 & 0,98 & - \\
\hline 15 & PQ & 1,019 & $-16,9$ & - & - & 8,2 & 1,7 & 0,98 & - \\
\hline 16 & PQ & 1,027 & $-16,5$ & - & - & 3,5 & 0,7 & 0,98 & - \\
\hline 17 & PQ & 1,030 & $-16,8$ & - & - & 9,0 & 1,8 & 0,98 & - \\
\hline 18 & PQ & 1,014 & $-17,5$ & - & - & 3,2 & 0,6 & 0,98 & - \\
\hline 19 & $\mathrm{PQ}$ & 1,014 & $-17,7$ & - & - & 9,5 & 1,9 & 0,98 & - \\
\hline 20 & PQ & 1,019 & $-17,5$ & - & - & 2,2 & 0,4 & 0,98 & - \\
\hline 21 & $\mathrm{PQ}$ & 1,028 & $-17,2$ & - & - & 17,5 & 3,6 & 0,98 & - \\
\hline 22 & $\mathrm{PQ}$ & 1,028 & $-17,1$ & - & - & 0,0 & 0,0 & - & - \\
\hline 23 & PQ & 1,018 & $-17,4$ & - & - & 3,2 & 0,6 & 0,98 & - \\
\hline 24 & $\mathrm{PQ}$ & 1,023 & $-17,6$ & - & - & 8,7 & 1,8 & 0,98 & 4,5 \\
\hline 25 & $\mathrm{PQ}$ & 1,028 & $-17,1$ & - & - & 0,0 & 0,0 & - & - \\
\hline 26 & $\mathrm{PQ}$ & 1,016 & $-17,7$ & - & - & 3,5 & 0,7 & 0,98 & - \\
\hline 27 & PQ & 1,036 & $-16,4$ & - & - & 0,0 & 0,0 & - & - \\
\hline 28 & $\mathrm{PQ}$ & 1,008 & $-12,3$ & - & - & 0,0 & 0,0 & - & - \\
\hline 29 & PQ & 1,017 & $-17,6$ & - & - & 2,4 & 0,5 & 0,98 & - \\
\hline 30 & PQ & 1,005 & $-18,4$ & - & - & 10,6 & 2,1 & 0,98 & - \\
\hline
\end{tabular}


A Tabela 4.24 apresenta os resultados do processo de otimização para o caso denominado por "Super Ótimo".

Tabela 4.24. Estado final resultante do Fluxo de Potência do teste "Solução Super Ótima" para o sistema de 30 barras - Função Objetivo 2.

\begin{tabular}{|c|c|c|c|c|c|c|c|c|c|}
\hline \multirow[t]{2}{*}{ Barra } & \multirow[t]{2}{*}{ Tipo } & \multicolumn{2}{|c|}{ Tensão } & \multicolumn{2}{|c|}{ Geração } & \multicolumn{4}{|c|}{ Carga } \\
\hline & & $\begin{array}{c}\mathrm{V} \\
\text { (p.u.) }\end{array}$ & $\begin{array}{c}\Theta \\
\text { (graus) }\end{array}$ & $\begin{array}{c}\mathrm{P} \\
(\mathrm{MW})\end{array}$ & $\begin{array}{c}\mathrm{Q} \\
\text { (MVAr) }\end{array}$ & $\begin{array}{c}\mathrm{P} \\
(\mathrm{MW})\end{array}$ & $\begin{array}{c}\mathrm{Q} \\
\text { (MVAr) }\end{array}$ & $\cos \varphi$ & $\mathrm{Q}_{\text {sh }}(\mathrm{MVAr})$ \\
\hline 1 & $\mathrm{VO}$ & 1,050 & 0,0 & 261,4 & $-53,6$ & - & - & - & - \\
\hline 2 & PV & 1,050 & $-5,8$ & 0,0 & 88,9 & $-18,3$ & 12,7 & - & - \\
\hline 3 & PV & 1,010 & $-12,3$ & 0,0 & 21,5 & 30,0 & 30,0 & - & - \\
\hline 4 & PV & 1,050 & $-14,9$ & 0,0 & 8,1 & - & - & - & - \\
\hline 5 & PV & 1,010 & $-14,6$ & 0,0 & 37,6 & 94,2 & 19,0 & - & - \\
\hline 6 & PV & 1,050 & $-15,6$ & 0,0 & 49 & - & - & - & - \\
\hline 7 & PQ & 0,999 & $-13,2$ & - & - & 22,8 & 23,9 & 0,69 & - \\
\hline 8 & PQ & 1,027 & $-8,2$ & - & - & 2,4 & 2,6 & 0,71 & - \\
\hline 9 & PQ & 1,034 & $-14,9$ & - & - & 0,0 & 0,0 & - & - \\
\hline 10 & PQ & 1,051 & $-16,6$ & - & - & 5,8 & $-0,4$ & 0,99 & 21,2 \\
\hline 11 & PQ & 1,023 & $-9,9$ & - & - & 7,6 & $-0,3$ & 0,99 & - \\
\hline 12 & PQ & 1,043 & $-15,6$ & - & - & 11,2 & $-1,5$ & 0,99 & - \\
\hline 13 & PQ & 1,016 & $-11,6$ & - & - & 0,0 & 0,0 & - & - \\
\hline 14 & PQ & 1,039 & $-16,7$ & - & - & 6,2 & $-0,3$ & 0,99 & - \\
\hline 15 & PQ & 1,039 & $-16,9$ & - & - & 8,2 & $-0,5$ & 0,99 & - \\
\hline 16 & PQ & 1,046 & $-16,4$ & - & - & 3,5 & 0,4 & 0,99 & - \\
\hline 17 & PQ & 1,051 & $-16,8$ & - & - & 9,0 & $-1,2$ & 0,99 & - \\
\hline 18 & PQ & 1,032 & $-17,6$ & - & - & 3,2 & 0,0 & 1,0 & - \\
\hline 19 & PQ & 1,040 & $-17,8$ & - & - & 9,5 & $-1,0$ & 0,99 & - \\
\hline 20 & PQ & 1,044 & $-17,6$ & - & - & 2,2 & 0,0 & 1,0 & - \\
\hline 21 & PQ & 1,050 & $-17,2$ & - & - & 17,5 & $-2,2$ & 0,99 & - \\
\hline 22 & PQ & 1,051 & $-17,2$ & - & - & 0,0 & 0,0 & - & - \\
\hline 23 & PQ & 1,042 & $-17,5$ & - & - & 3,2 & 0,0 & 1,0 & - \\
\hline 24 & PQ & 1,050 & $-17,8$ & - & - & 8,7 & $-1,3$ & 0,98 & 4,7 \\
\hline 25 & PQ & 1,050 & $-17,1$ & - & - & 0,0 & 0,0 & - & - \\
\hline 26 & PQ & 1,045 & $-17,9$ & - & - & 3,5 & $-0,4$ & 0,99 & - \\
\hline 27 & PQ & 1,053 & $-16,3$ & - & - & 0,0 & 0,0 & - & - \\
\hline 28 & PQ & 1,012 & $-12,3$ & - & - & 0,0 & 0,0 & - & - \\
\hline 29 & PQ & 1,040 & $-17,6$ & - & - & 2,4 & 0,9 & 0,99 & - \\
\hline 30 & PQ & 1,033 & $-18,5$ & - & - & 10,6 & $-0,4$ & 0,99 & - \\
\hline
\end{tabular}

$\mathrm{Na}$ Tabela 4.25 estão apresentados os valores de perdas do sistema e os valores de potência reativa gerados para o sistema de 30 barras.

Tabela 4.25. Perdas e potência reativa gerada para os casos testados - sistema de 30 barras - Função Objetivo 2.

\begin{tabular}{|c|c|c|}
\hline Caso & Perdas sistêmicas (MW) & Q total gerado (MVAr) \\
\hline Base & 18,1 & 152,9 \\
\hline Sub Ótimo & 18,0 & 138,1 \\
\hline Super Ótimo & 18,0 & 107,5 \\
\hline
\end{tabular}

A partir da Tabela 4.25 é possível observar que: 
- As perdas ativas e os reativos gerados no caso "Sub Ótimo" são menores em relação ao caso "Base";

- Para o caso "Super Ótimo", as perdas no sistema foram iguais e os reativos gerados foram menores em relação ao caso "Sub Ótimo".

Comparando os valores apresentados na Tabela 4.25 com os valores apresentados na Tabela 4.12, observa-se que a Função Objetivo 2 foi um pouco mais eficiente que a Função Objetivo 1.

\subsubsection{Sistema de 53 Barras - Função Objetivo 2}

A seguir serão apresentadas as soluções obtidas a partir do sistema de 53 Barras.

A Tabela 4.26 apresenta os resultados do caso definido por "Solução Base".

Tabela 4.26. Estado final resultante do Fluxo de Potência do caso "Solução Base" para o sistema de 53 barras - Função Objetivo 2.

\begin{tabular}{|c|c|c|c|c|c|c|c|c|c|}
\hline \multirow[t]{2}{*}{ Barra } & \multirow[t]{2}{*}{ Tipo } & \multicolumn{2}{|c|}{ Tensão } & \multicolumn{2}{|c|}{ Geração } & \multicolumn{4}{|c|}{ Carga } \\
\hline & & $\begin{array}{c}\mathrm{V} \\
\text { (p.u.) }\end{array}$ & $\begin{array}{c}\Theta \\
\text { (graus) }\end{array}$ & $\begin{array}{c}\mathrm{P} \\
(\mathrm{MW})\end{array}$ & $\begin{array}{c}\mathrm{Q} \\
\text { (MVAr) }\end{array}$ & $\begin{array}{c}\mathrm{P} \\
(\mathrm{MW})\end{array}$ & $\begin{array}{c}\mathrm{Q} \\
\text { (MVAr) }\end{array}$ & $\cos \varphi$ & $\begin{array}{c}\mathrm{Q}_{\mathrm{sh}} \\
\text { (MVAr) }\end{array}$ \\
\hline 1 & VO & 1,020 & 12,0 & 2389,1 & $-359,5$ & - & - & - & - \\
\hline 2 & PV & 1,050 & 7,8 & 1068,0 & $-68,6$ & - & - & - & - \\
\hline 3 & PV & 1,040 & 8,6 & 513,0 & $-181,4$ & - & - & - & - \\
\hline 4 & $\mathrm{PV}$ & 1,000 & 4,0 & 254,0 & 34,5 & - & - & - & - \\
\hline 5 & PV & 1,050 & $-6,0$ & 101,0 & 35,4 & - & - & - & - \\
\hline 6 & $\mathrm{PV}$ & 1,050 & $-9,1$ & 105,0 & 39,9 & - & - & - & - \\
\hline 7 & $\mathrm{PV}$ & 1,035 & $-14,1$ & 114,0 & 15,3 & - & - & - & - \\
\hline 8 & $\mathrm{PV}$ & 1,025 & $-19,7$ & 46,0 & 16,7 & - & - & - & - \\
\hline 9 & $\mathrm{PV}$ & 1,010 & 0,3 & 216,0 & 43,4 & - & - & - & - \\
\hline 10 & $\mathrm{PV}$ & 1,035 & $-19,2$ & 78,0 & 17,8 & - & - & - & - \\
\hline 11 & $\mathrm{PV}$ & 1,036 & $-21,1$ & 23,0 & 9,4 & - & - & - & - \\
\hline 12 & $\mathrm{PV}$ & 1,030 & $-21,8$ & 614,0 & 224,0 & - & - & - & - \\
\hline 13 & $\mathrm{PV}$ & 1,004 & $-21,6$ & 235,0 & 162,0 & - & - & - & - \\
\hline 14 & PV & 1,050 & $-14,7$ & 239,0 & 160,6 & - & - & - & - \\
\hline 15 & $\mathrm{PV}$ & 1,050 & $-12,7$ & 232,0 & 598,5 & - & - & - & $-198,4$ \\
\hline 16 & PV & 1,009 & $-16,8$ & 629,0 & 66,0 & - & - & - & - \\
\hline 17 & PQ & 1,042 & $-3,5$ & - & - & 41,9 & 11,2 & 0,96 & - \\
\hline 18 & PQ & 1,052 & $-12,8$ & - & - & 0,0 & 0,0 & - & - \\
\hline 19 & PQ & 1,035 & $-8,9$ & - & - & 1795,0 & 365,0 & 0,97 & - \\
\hline 20 & PQ & 1,036 & $-13,0$ & - & - & 85,2 & 25,0 & 0,95 & - \\
\hline 21 & PQ & 1,031 & $-14,0$ & - & - & 82,5 & 22,4 & 0,95 & - \\
\hline 22 & PQ & 0,991 & $-23,3$ & - & - & 198,1 & 65,1 & 0,95 & - \\
\hline 23 & PQ & 1,031 & $-18,2$ & - & - & 295,9 & 85,0 & 0,96 & - \\
\hline 24 & PQ & 1,013 & $-21,8$ & - & - & 191,3 & 56,0 & 0,95 & - \\
\hline 25 & PQ & 0,986 & $-25,3$ & - & - & 119,8 & 30,3 & 0,96 & - \\
\hline 26 & PQ & 0,995 & $-10,6$ & - & - & 123,3 & 41,6 & 0,95 & 19,8 \\
\hline
\end{tabular}




\begin{tabular}{|c|c|c|c|c|c|c|c|c|c|}
\hline 27 & PQ & 1,028 & $-18,6$ & - & - & 114,8 & 44,0 & 0,93 & - \\
\hline 28 & PQ & 1,049 & $-19,6$ & - & - & 287,2 & 75,0 & 0,96 & - \\
\hline 29 & PQ & 1,008 & $-12,5$ & - & - & 78,4 & 23,5 & 0,95 & 20,3 \\
\hline 30 & PQ & 0,992 & $-25,9$ & - & - & 91,3 & 19,3 & 0,97 & - \\
\hline 31 & PQ & 0,981 & $-28,2$ & - & - & 210,8 & 33,4 & 0,98 & 57,8 \\
\hline 32 & PQ & 1,009 & $-25,3$ & - & - & 17,3 & 3,3 & 0,98 & - \\
\hline 33 & PQ & 1,002 & $-10,9$ & - & - & 126,3 & 41,5 & 0,95 & - \\
\hline 34 & PQ & 1,035 & $-22,8$ & - & - & 16,3 & 5,4 & 0,95 & - \\
\hline 35 & PQ & 1,048 & $-4,1$ & - & - & 0,0 & 0,0 & - & - \\
\hline 36 & PQ & 1,025 & $-23,5$ & - & - & 74,5 & 19,5 & 0,96 & - \\
\hline 37 & PQ & 1,024 & $-8,2$ & - & - & 50,5 & 16,6 & 0,95 & - \\
\hline 38 & PQ & 1,023 & $-23,6$ & - & - & 0,0 & 0,0 & - & - \\
\hline 39 & PQ & 0,999 & $-20,5$ & - & - & 44,7 & 25,0 & 0,87 & - \\
\hline 40 & PQ & 0,998 & $-27,4$ & - & - & 162,9 & 47,5 & 0,96 & - \\
\hline 41 & PQ & 0,985 & $-29,9$ & - & - & 174,4 & 38,6 & 0,97 & 17,5 \\
\hline 42 & PQ & 1,004 & $-21,2$ & - & - & 0,0 & 0,0 & - & - \\
\hline 43 & PQ & 1,009 & $-27,9$ & - & - & 612,0 & 124,3 & 0,97 & - \\
\hline 44 & PQ & 1,050 & $-10,7$ & - & - & 29,1 & 10,2 & 0,94 & - \\
\hline 45 & PQ & 1,015 & $-27,4$ & - & - & 136,0 & 41,0 & 0,95 & - \\
\hline 46 & PQ & 1,002 & $-29,1$ & - & - & 276,2 & 105,0 & 0,94 & 30,1 \\
\hline 47 & PQ & 0,997 & $-30,2$ & - & - & 80,3 & 26,4 & 0,95 & 29,8 \\
\hline 48 & PQ & 0,999 & $-29,6$ & - & - & 541,3 & 110,0 & 0,97 & - \\
\hline 49 & PQ & 0,975 & $-30,7$ & - & - & 85,1 & 28,0 & 0,95 & - \\
\hline 50 & PQ & 0,999 & $-29,5$ & - & - & 0,0 & 0,0 & - & - \\
\hline 51 & PQ & 1,041 & $-1,4$ & - & - & 49,9 & 16,4 & 0,95 & - \\
\hline 52 & PQ & 0,978 & $-29,6$ & - & - & 224,0 & 66,0 & 0,95 & - \\
\hline 53 & PQ & 1,036 & 7,3 & - & - & 269,9 & 98,0 & 0,94 & - \\
\hline \multicolumn{4}{|c|}{ Perdas $=169,7 \mathrm{MW}$} & \multicolumn{6}{|c|}{ Potência Reativa Gerada $=814,0 \mathrm{MVAr}$} \\
\hline
\end{tabular}

\section{A Tabela 4.27 apresenta os resultados do caso definido por "Solução Sub Ótima"} para o sistema de 53 barras.

Tabela 4.27. Estado final resultante do Fluxo de Potência do caso "Solução Sub Ótima" para o sistema de 53 barras - Função Objetivo 2.

\begin{tabular}{|c|c|c|c|c|c|c|c|c|c|}
\hline \multirow[t]{2}{*}{ Barra } & \multirow[t]{2}{*}{ Tipo } & \multicolumn{2}{|c|}{ Tensão } & \multicolumn{2}{|c|}{ Geração } & \multicolumn{4}{|c|}{ Carga } \\
\hline & & $\begin{array}{c}\mathrm{V} \\
\text { (p.u.) }\end{array}$ & $\begin{array}{c}\Theta \\
\text { (graus) }\end{array}$ & $\begin{array}{c}\mathrm{P} \\
(\mathrm{MW})\end{array}$ & $\begin{array}{c}\mathrm{Q} \\
\text { (MVAr) }\end{array}$ & $\begin{array}{c}\mathrm{P} \\
(\mathrm{MW})\end{array}$ & $\begin{array}{c}\mathrm{Q} \\
\text { (MVAr) }\end{array}$ & $\cos \varphi$ & $\begin{array}{c}\mathrm{Q}_{\mathrm{sh}} \\
\text { (MVAr) }\end{array}$ \\
\hline 1 & Ve & 1,020 & 12,0 & 2388,5 & $-359,9$ & - & - & - & - \\
\hline 2 & PV & 1,050 & 7,8 & 1068,0 & $-69,1$ & - & - & - & - \\
\hline 3 & $\mathrm{PV}$ & 1,040 & 8,6 & 513,0 & $-181,6$ & - & - & - & - \\
\hline 4 & $\mathrm{PV}$ & 1,000 & 3,8 & 254,0 & 23,0 & - & - & - & - \\
\hline 5 & $\mathrm{PV}$ & 1,050 & $-6,0$ & 101,0 & 32,1 & - & - & - & - \\
\hline 6 & $\mathrm{PV}$ & 1,050 & $-9,0$ & 105,0 & 41,9 & - & - & - & - \\
\hline 7 & PV & 1,005 & $-13,9$ & 114,0 & $-13,1$ & - & - & - & - \\
\hline 8 & PV & 1,025 & $-19,7$ & 46,0 & 14,9 & - & - & - & - \\
\hline 9 & PV & 1,010 & 0,1 & 216,0 & 31,1 & - & - & - & - \\
\hline 10 & PV & 1,035 & $-19,3$ & 78,0 & 15,7 & - & - & - & - \\
\hline 11 & $\mathrm{PV}$ & 1,036 & $-21,1$ & 23,0 & 8,4 & - & - & - & - \\
\hline 12 & $\mathrm{PV}$ & 1,030 & $-21,8$ & 614,0 & 213,5 & - & - & - & - \\
\hline 13 & $\mathrm{PV}$ & 1,004 & $-21,6$ & 235,0 & 153,3 & - & - & - & - \\
\hline 14 & $\mathrm{PV}$ & 1,050 & $-14,6$ & 239,0 & 171,2 & - & - & - & - \\
\hline 15 & $\mathrm{PV}$ & 1,050 & $-12,7$ & 232,0 & 588,6 & - & - & - & $-198,4$ \\
\hline 16 & $\mathrm{PV}$ & 1,009 & $-16,8$ & 629,0 & 53,0 & - & - & - & - \\
\hline 17 & PQ & 1,047 & $-3,7$ & - & - & 41,9 & 8,5 & 0,98 & - \\
\hline 18 & PQ & 1,050 & $-12,7$ & - & - & 0,0 & 0,0 & - & - \\
\hline 19 & PQ & 1,035 & $-8,9$ & - & - & 1795,0 & 365,0 & 0,98 & - \\
\hline 20 & PQ & 1,036 & $-13,0$ & - & - & 85,2 & 25,0 & 0,96 & - \\
\hline 21 & PQ & 1,032 & $-14,0$ & - & - & 82,5 & 16,8 & 0,98 & - \\
\hline 22 & PQ & 0,998 & $-23,4$ & - & - & 198,1 & 45,3 & 0,98 & - \\
\hline
\end{tabular}




\begin{tabular}{|c|c|c|c|c|c|c|c|c|c|}
\hline 23 & $\mathrm{PQ}$ & 1,032 & $-18,2$ & - & - & 295,9 & 85,0 & 0,96 & - \\
\hline 24 & PQ & 1,016 & $-21,8$ & - & - & 191,3 & 56,0 & 0,96 & - \\
\hline 25 & PQ & 0,985 & $-25,3$ & - & - & 119,8 & 30,3 & 0,97 & - \\
\hline 26 & PQ & 1,004 & $-10,6$ & - & - & 123,3 & 41,6 & 0,95 & 20,2 \\
\hline 27 & $\mathrm{PQ}$ & 1,017 & $-18,3$ & - & - & 114,8 & 44,0 & 0,93 & - \\
\hline 28 & $\begin{array}{l}\mathrm{PQ} \\
\end{array}$ & 1,045 & $-19,5$ & - & - & 287,2 & 75,0 & 0,97 & - \\
\hline 29 & PQ & 1,015 & $-12,6$ & - & - & 78,4 & 23,5 & 0,96 & 20,6 \\
\hline 30 & PQ & 0,992 & $-25,9$ & - & - & 91,3 & 19,3 & 0,98 & - \\
\hline 31 & $\begin{array}{l}\mathrm{PQ} \\
\end{array}$ & 0,979 & $-28,1$ & - & - & 210,8 & 33,4 & 0,98 & 57,5 \\
\hline 32 & PQ & 1,010 & $-25,3$ & - & - & 17,3 & 3,3 & 0,98 & - \\
\hline 33 & PQ & 1,012 & $-11,1$ & - & - & 126,3 & 25,7 & 0,98 & - \\
\hline 34 & $\begin{array}{l}\mathrm{PQ} \\
\end{array}$ & 1,037 & $-22,9$ & - & - & 16,3 & 3,3 & 0,98 & - \\
\hline 35 & PQ & 1,051 & $-4,2$ & - & - & 0,0 & 0,0 & - & - \\
\hline 36 & $\begin{array}{l}\mathrm{PQ} \\
\end{array}$ & 1,027 & $-23,5$ & - & - & 74,5 & 15,1 & 0,98 & - \\
\hline 37 & $\mathrm{PQ}$ & 1,031 & $-8,3$ & - & - & 50,5 & 10,2 & 0,98 & - \\
\hline 38 & $\mathrm{PQ}$ & 1,025 & $-23,6$ & - & - & 0,0 & 0,0 & - & - \\
\hline 39 & PQ & 1,000 & $-20,5$ & - & - & 44,7 & 25,0 & 0,87 & - \\
\hline 40 & PQ & 1,000 & $-27,4$ & - & - & 162,9 & 47,5 & 0,96 & - \\
\hline 41 & $\mathrm{PQ}$ & 0,987 & $-29,9$ & - & - & 174,4 & 38,6 & 0,98 & 17,5 \\
\hline 42 & PQ & 1,005 & $-21,2$ & - & - & 0,0 & 0,0 & - & - \\
\hline 43 & $\begin{array}{l}\mathrm{PQ} \\
\end{array}$ & 1,009 & $-27,9$ & - & - & 612,0 & 124,3 & 0,98 & - \\
\hline 44 & $\mathrm{PQ}$ & 1,051 & $-10,7$ & - & - & 29,1 & 10,2 & 0,94 & - \\
\hline 45 & PQ & 1,016 & $-27,4$ & - & - & 136,0 & 41,0 & 0,96 & - \\
\hline 46 & $\begin{array}{l}\mathrm{PQ} \\
\end{array}$ & 1,004 & $-29,1$ & - & - & 276,2 & 105,0 & 0,93 & 30,2 \\
\hline 47 & PQ & 1,001 & $-30,3$ & - & - & 80,3 & 16,3 & 0,98 & 30,0 \\
\hline 48 & PQ & 1,001 & $-29,6$ & - & - & 541,3 & 110,0 & 0,98 & - \\
\hline 49 & PQ & 0,980 & $-30,8$ & - & - & 85,1 & 17,3 & 0,98 & - \\
\hline 50 & PQ & 1,002 & $-29,5$ & - & - & 0,0 & 0,0 & - & - \\
\hline 51 & $\mathrm{PQ}$ & 1,046 & $-1,6$ & - & - & 49,9 & 10,1 & 0,98 & - \\
\hline 52 & PQ & 0,981 & $-29,6$ & - & - & 224,0 & 66,0 & 0,96 & - \\
\hline 53 & $\begin{array}{l}\mathrm{PQ} \\
\end{array}$ & 1,036 & 7,3 & - & - & 269,9 & 98,0 & 0,94 & - \\
\hline \multicolumn{4}{|c|}{ Perdas $=169,1 \mathrm{MW}$} & \multicolumn{6}{|c|}{ Potência Reativa Gerada $=722,9 \mathrm{MVAr}$} \\
\hline
\end{tabular}

\section{A Tabela 4.28 apresenta os resultados do caso definido por "Solução Super} Ótima" para o sistema de 53 barras.

Tabela 4.28. Estado final resultante do Fluxo de Potência do caso "Solução Super Ótima" para o sistema de 53 barras - Função Objetivo 2.

\begin{tabular}{|c|c|c|c|c|c|c|c|c|c|}
\hline \multirow[t]{2}{*}{ Barra } & \multirow[t]{2}{*}{ Tipo } & \multicolumn{2}{|c|}{ Tensão } & \multicolumn{2}{|c|}{ Geração } & \multicolumn{4}{|c|}{ Carga } \\
\hline & & $\begin{array}{c}\mathrm{V} \\
\text { (p.u.) }\end{array}$ & $\begin{array}{c}\Theta \\
\text { (graus) }\end{array}$ & $\begin{array}{c}\mathrm{P} \\
(\mathrm{MW})\end{array}$ & $\begin{array}{c}\mathrm{Q} \\
\text { (MVAr) }\end{array}$ & $\begin{array}{c}\mathrm{P} \\
(\mathrm{MW})\end{array}$ & $\begin{array}{c}\mathrm{Q} \\
\text { (MVAr) }\end{array}$ & $\cos \varphi$ & $\begin{array}{c}\mathrm{Q}_{\mathrm{sh}} \\
\text { (MVAr) }\end{array}$ \\
\hline 1 & VE & 1,020 & 12,0 & 2387,2 & $-362,2$ & - & - & - & - \\
\hline 2 & PV & 1,050 & 7,8 & 1068,0 & $-74,2$ & - & - & - & - \\
\hline 3 & $\mathrm{PV}$ & 1,040 & 8,6 & 513,0 & $-183,0$ & - & - & - & - \\
\hline 4 & PV & 1,000 & 3,5 & 254,0 & $-1,7$ & - & - & - & - \\
\hline 5 & $\mathrm{PV}$ & 1,050 & $-6,0$ & 101,0 & 21,6 & - & - & - & - \\
\hline 6 & $\mathrm{PV}$ & 1,050 & $-8,9$ & 105,0 & 34,4 & - & - & - & - \\
\hline 7 & $\mathrm{PV}$ & 1,005 & $-13,8$ & 114,0 & $-16,9$ & - & - & - & - \\
\hline 8 & $\mathrm{PV}$ & 1,025 & $-19,8$ & 46,0 & 8,8 & - & - & - & - \\
\hline 9 & $\mathrm{PV}$ & 1,010 & $-0,1$ & 216,0 & 3,7 & - & - & - & - \\
\hline 10 & PV & 1,035 & $-19,3$ & 78,0 & 6,9 & - & - & - & - \\
\hline 11 & $\mathrm{PV}$ & 1,036 & $-21,1$ & 23,0 & 4,4 & - & - & - & - \\
\hline 12 & $\mathrm{PV}$ & 1,030 & $-22,2$ & 614,0 & 98,3 & - & - & - & - \\
\hline 13 & PV & 1,004 & $-21,6$ & 235,0 & 113,6 & - & - & - & - \\
\hline 14 & $\mathrm{PV}$ & 1,050 & $-14,4$ & 239,0 & 166,1 & - & - & - & - \\
\hline 15 & PV & 1,050 & $-12,7$ & 232,0 & 543,4 & - & - & - & $-198,4$ \\
\hline 16 & $\mathrm{PV}$ & 1,009 & $-16,8$ & 629,0 & 25,5 & - & - & - & - \\
\hline 17 & PQ & 1,052 & $-3,9$ & - & - & 41,9 & $-1,2$ & 0,99 & - \\
\hline 18 & $\mathrm{PQ}$ & 1,052 & $-12,6$ & - & - & 0,0 & 0,0 & - & - \\
\hline
\end{tabular}




\begin{tabular}{|c|c|c|c|c|c|c|c|c|c|}
\hline 19 & PQ & 1,037 & $-8,9$ & - & - & 1795,0 & 365,0 & 0,98 & - \\
\hline 20 & PQ & 1,043 & $-12,9$ & - & - & 85,2 & 25,0 & 0,96 & - \\
\hline 21 & PQ & 1,042 & $-13,9$ & - & - & 82,5 & $-2,2$ & 0.99 & - \\
\hline 22 & PQ & 1,011 & $-23,4$ & - & - & 198,1 & 11,0 & 0,99 & - \\
\hline 23 & PQ & 1,034 & $-18,2$ & - & - & 295,9 & 85,0 & 0,96 & - \\
\hline 24 & PQ & 1,022 & $-21,8$ & - & - & 191,3 & 56,0 & 0,96 & - \\
\hline 25 & PQ & 0,990 & $-25,2$ & - & - & 119,8 & 30,3 & 0,97 & - \\
\hline 26 & PQ & 1,023 & $-10,8$ & - & - & 123,3 & 41,6 & 0,95 & 20,9 \\
\hline 27 & PQ & 1,019 & $-18,1$ & - & - & 114,8 & 44,0 & 0,93 & - \\
\hline 28 & PQ & 1,047 & $-19,2$ & - & - & 287,2 & 75,0 & 0,97 & - \\
\hline 29 & PQ & 1,030 & $-12,7$ & - & - & 78,4 & 23,5 & 0,96 & 21,2 \\
\hline 30 & PQ & 0,998 & $-25,8$ & - & - & 91,3 & 19,3 & 0,98 & - \\
\hline 31 & $\mathrm{PQ}$ & 0,983 & $-28,0$ & - & - & 210,8 & 33,4 & 0,99 & 58,0 \\
\hline 32 & PQ & 1,013 & $-25,2$ & - & - & 17,3 & 3,3 & 0,98 & - \\
\hline 33 & PQ & 1,035 & $-11,3$ & - & - & 126,3 & $-4,3$ & 0,99 & - \\
\hline 34 & PQ & 1,044 & $-22,9$ & - & - & 16,3 & 0,0 & 1,00 & - \\
\hline 35 & PQ & 1,053 & $-4,4$ & - & - & 0,0 & 0,0 & - & - \\
\hline 36 & PQ & 1,035 & $-23,5$ & - & - & 74,5 & $-2,0$ & 0,99 & - \\
\hline 37 & PQ & 1,048 & $-8,5$ & - & - & 50,5 & $-2,0$ & 0,99 & - \\
\hline 38 & PQ & 1,033 & $-23,6$ & - & - & 0,0 & 0,0 & - & - \\
\hline 39 & PQ & 1,005 & $-20,5$ & - & - & 44,7 & 25,0 & 0,87 & - \\
\hline 40 & PQ & 1,010 & $-27,4$ & - & - & 162,9 & 47,5 & 0,96 & - \\
\hline 41 & PQ & 0,993 & $-29,7$ & - & - & 174,4 & 38,6 & 0,98 & 17,7 \\
\hline 42 & PQ & 1,005 & $-21,2$ & - & - & 0,0 & 0,0 & - & - \\
\hline 43 & PQ & 1,013 & $-27,8$ & - & - & 612,0 & 124,3 & 0,98 & - \\
\hline 44 & PQ & 1,051 & $-10,7$ & - & - & 29,1 & 10,2 & 0,94 & - \\
\hline 45 & PQ & 1,022 & $-27,3$ & - & - & 136,0 & 41,0 & 0,96 & - \\
\hline 46 & PQ & 1,012 & $-29,0$ & - & - & 276,2 & 105,0 & 0,93 & 30,7 \\
\hline 47 & $\mathrm{PQ}$ & 1,019 & $-30,3$ & - & - & 80,3 & $-3,4$ & 0,99 & 31,2 \\
\hline 48 & PQ & 1,026 & $-29,8$ & - & - & 541,3 & $-11,0$ & 0,99 & - \\
\hline 49 & PQ & 1,005 & $-30,9$ & - & - & 85,1 & $-2,9$ & 0,99 & - \\
\hline 50 & PQ & 1,027 & $-29,8$ & - & - & 0,0 & 0,0 & - & - \\
\hline 51 & PQ & 1,051 & $-1,9$ & - & - & 49,9 & $-2,0$ & 0,99 & - \\
\hline 52 & PQ & 0,994 & $-29,5$ & - & - & 224,0 & 66,0 & 0,96 & - \\
\hline 53 & PQ & 1,037 & 7,3 & - & - & 269,9 & 98,0 & 0,94 & - \\
\hline \multicolumn{10}{|c|}{ Perdas $=167,80 \mathrm{MW}$} \\
\hline
\end{tabular}

A Tabela 4.29 apresenta os valores de perdas do sistema e os valores de potência reativa gerados para o sistema de 53 barras.

Tabela 4.29. Perdas e potência reativa gerada para os casos testados - sistema de 53 barras - Função Objetivo 2.

\begin{tabular}{|c|c|c|}
\hline Caso & Perdas sistêmicas (MW) & Q total gerado (MVAr) \\
\hline Base & 169,7 & 814,0 \\
\hline Sub Ótimo & 169,1 & 722,9 \\
\hline Super Ótimo & 167,8 & 387,6 \\
\hline
\end{tabular}

A partir da Tabela 4.29 é possível observar que:

- As perdas e os reativos gerados no sistema são menores no caso "Sub Ótimo" quando comparado ao caso "Base"; 
- No caso "Super Ótimo", as perdas e os reativos gerados no sistema também são menores quando comparados com o caso "Sub Ótimo".

Comparando os valores apresentados na Tabela 4.29 com os valores apresentados na Tabela 4.17, observa-se que a Função Objetivo 2 foi mais eficiente que a Função Objetivo 1 na minimização das perdas do sistema.

Apresentado os testes relacionados à minimização das perdas ativas do sistema, a seguir será proposta uma metodologia com o objetivo de: valorar o suporte de reativos fornecido pelas barras de geração; e alocar o custo de fornecimento do mesmo às barras responsáveis.

\subsection{Valoração do Suporte de Potência Reativa Fornecido}

Para a valoração do suporte de potência reativa provido pelas unidades geradoras será realizada uma avaliação do custo incremental, resultante do aumento das perdas ativas ocorridas no conjunto gerador/ transformador e na transmissão. Esse aumento de perdas é calculado a partir das soluções denominadas "Solução Base" e "Solução Sub Ótima", definidos para o processo de otimização que contemplou a minimização das perdas do sistema.

O custo incremental descrito será calculado a partir da Equação 4.28. A solução deste cálculo representará o valor monetário mínimo do MVArh adicional gerado a partir de unidades geradoras. Este valor será utilizado como base de remuneração do serviço prestado pelas unidades geradoras. 


$$
C_{s r}=\frac{\Delta P * P L D}{\Delta Q} \quad R \$ / M V A r h
$$

Sendo: $\Delta P$ o incremento das perdas ativas ocorridas no conjunto gerador/ transformador elevador mais metade do incremento das perdas ativas ocorridas na transmissão; e $\Delta Q$ o diferencial de potência reativa gerada, com relação aos casos "Base" e "Sub Ótimo". PLD representa o Preço de Liquidação de Diferenças dado por $\mathrm{R} \$ \mathrm{MWh}$ - aqui adotado igual a 118,00 R $\$ \mathrm{MWh}$ (valor médio aproximado para o período de julho a agosto de 2006). A Figura 4.6 representa um resumo da metodologia a ser empregada para atender o objetivo de valorar o suporte de reativos fornecido pelas barras de geração.

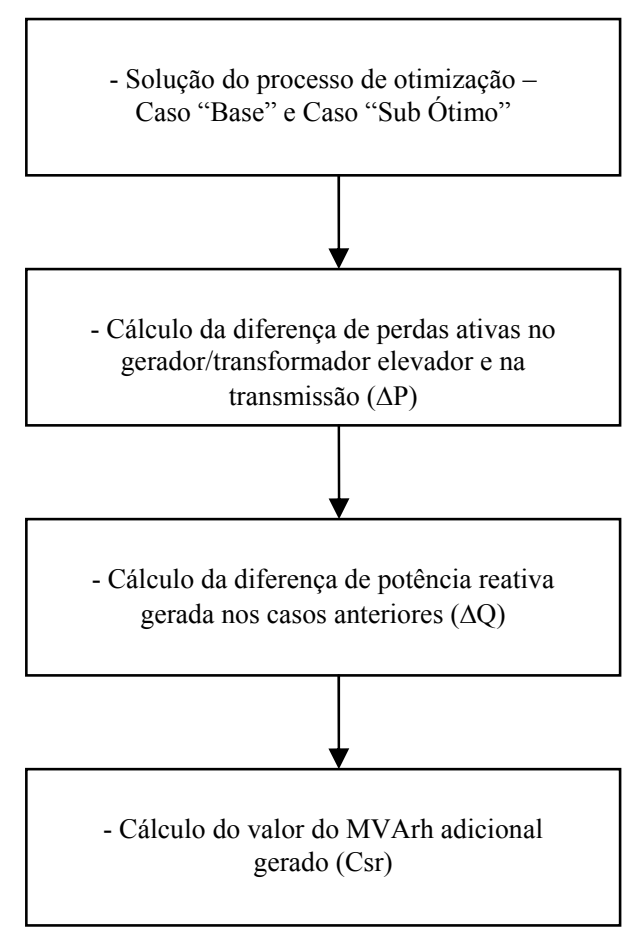

Figura 4.6. Fluxograma da metodologia de valoração e alocação dos custos resultantes do suporte de potência reativa. 
Com o objetivo de ilustrar a valoração do suporte de potência reativa fornecido a partir das unidades geradoras, os cálculos serão realizados a partir de um sistema equivalente ao Sistema de 53 barras, representado pela Figura 4.7, e partir das soluções "Base" e "Sub Ótima" obtidas a partir da minimização das perdas ativas do sistema.

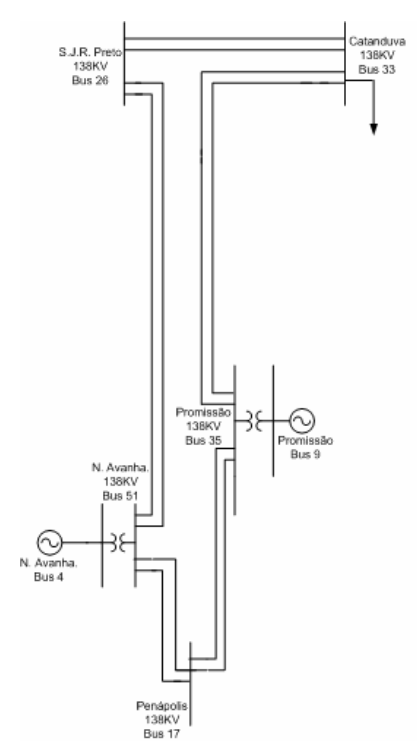

Figura 4.7. Equivalente utilizado na valoração do suporte de potência reativa.

Serão utilizadas as Figuras 4.8 e 4.9 com o objetivo de determinar as perdas no conjunto gerador/ transformador elevador das unidades geradoras apresentadas na Figura 4.7, JARDINI et al. (2002). 


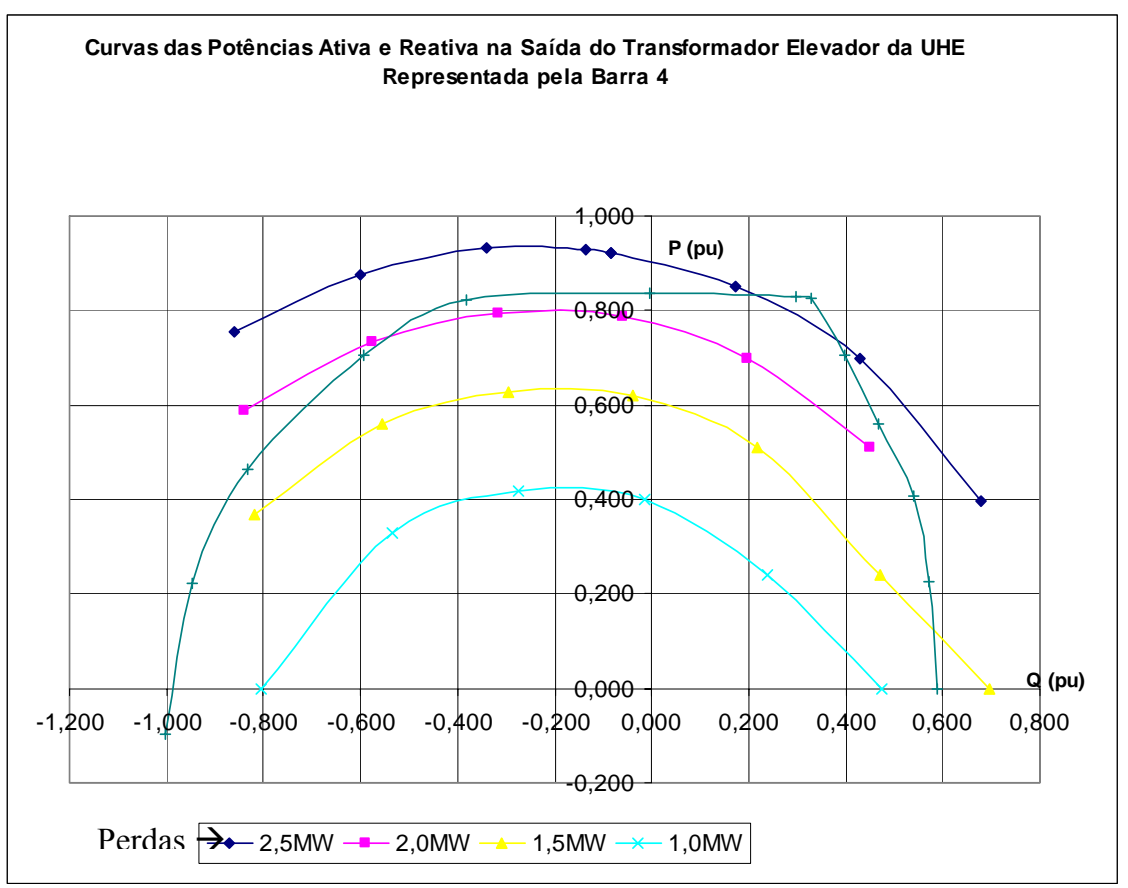

Figura 4.8. Figura representativa das perdas no conjunto gerador/transformador elevador.

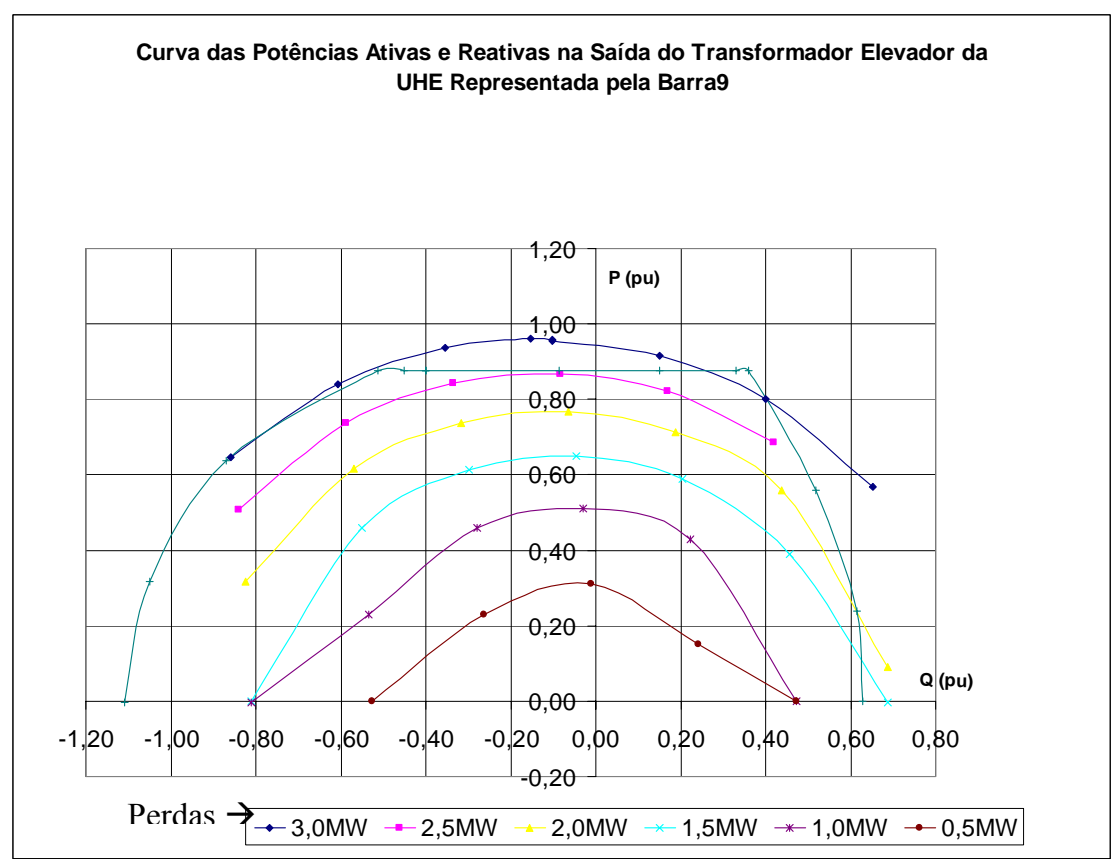

Figura 4.9. Figura representativa das perdas no conjunto gerador/transformador elevador.

A Tabela 4.30 apresenta os valores das perdas ativas no conjunto gerador/transformador elevador para as condições analisadas. 
Tabela 4.30. Valores das perdas ativas no conjunto gerador/transformador elevador.

\begin{tabular}{|c|c|c|c|c|c|c|c|}
\hline Usina & \multicolumn{7}{|c|}{ Fator de potência das barras de carga menor ou igual a 0,95} \\
\hline & $\mathrm{P}(\mathrm{MW})$ & $\mathrm{N}^{0}$ Máq. & $\begin{array}{l}\text { MW / } \\
\text { Máq. }\end{array}$ & Q (MVAr) & $\begin{array}{l}\text { MVAr / } \\
\text { Máq. }\end{array}$ & $\begin{array}{c}\Delta \mathrm{P} / \text { Máq. } \\
\text { (MW) }\end{array}$ & $\begin{array}{l}\Delta \mathrm{P} \text { Total } \\
(\mathrm{MW})\end{array}$ \\
\hline Barra 4 & 254,0 & 3 & 84,7 & 34,5 & 11,5 & 1,58 & 4,74 \\
\hline Barra 9 & 216,0 & 3 & 72,0 & 43,4 & 14,5 & 1,89 & 5,67 \\
\hline TOTAL & & & & 77,9 & & & 10,41 \\
\hline \multirow[t]{2}{*}{ Usina } & \multicolumn{7}{|c|}{ Fator de potência das barras de carga menor ou igual a 0,98} \\
\hline & $\mathrm{P}(\mathrm{MW})$ & Nº́a. & $\begin{array}{l}\text { MW / } \\
\text { Máq. }\end{array}$ & Q (MVAr) & $\begin{array}{l}\text { MVAr / } \\
\text { Máq. }\end{array}$ & $\begin{array}{c}\Delta \mathrm{P} / \text { Máq. } \\
(\mathrm{MW})\end{array}$ & $\begin{array}{l}\Delta \mathrm{P} \text { Total } \\
(\mathrm{MW})\end{array}$ \\
\hline Barra 4 & 254,0 & 3 & 84,7 & 23,0 & 7,7 & 1,32 & 3,96 \\
\hline Barra 9 & 216,0 & 3 & 72,0 & 31,1 & 10,4 & 1,66 & 4,98 \\
\hline TOTAL & & & & 54,1 & & & 8,94 \\
\hline
\end{tabular}

O diferencial de perdas no sistema de transmissão para os dois casos foi de 0,2MW, conforme resultado apresentado pela simulação do programa de Fluxo de Potência. Os encargos relacionados a estas perdas são divididos entre a geração e a carga em porcentagens iguais. $\mathrm{O}$ diferencial de perdas no gerador/transformador elevador para os dois casos foi de 1,47MW, conforme apresentado na Tabela 4.30.

Com base nos valores apresentados, a seguir é calculado o valor incremental de energia anual consumida, devido a não compensação total do reativo das cargas sob influência das usinas do sistema. O tempo assumido para representar esta condição será de 3 horas (período 18 - 21 h). Isto ocorre, pois, o Fluxo de Potência do sistema apresentado contempla a condição de carga pesada.

$$
\Delta \mathrm{E}_{\text {ativa }} \text { anual }=365 \times\{[1,47+(0,2 / 2)] \times 3\}=1719,15 \mathrm{MWh}
$$

Para o valor do custo marginal de energia igual a 118,00 R\$/ MWh, tem-se o seguinte valor do custo anual da energia, relativo ao incremento das perdas ativas:

$$
\Delta \mathrm{CE}_{\text {anual }}=202.859,70 \mathrm{R} \$
$$


A partir da Tabela 4.30, o incremento de energia reativa anual gerada pelas unidades é de:

$$
\Delta \mathrm{E}_{\text {reativa }} \text { anual }=365 \times(23,8 \times 3)=26.061,0 \mathrm{MVArh}
$$

Assim a partir da Equação 4.28, o custo do MVArh adicional gerado é dado por:

$$
C_{S R}=\frac{202.859,70}{26.061,0}=7,78 \frac{R \$}{M V A r h}
$$

O valor determinado para o custo da energia reativa adicional gerada resultou em um valor superior ao valor estabelecido para pagamento do suporte de reativos, providos por unidade geradora operando na situação de compensador síncrono. Este valor foi estabelecido em $\mathrm{R} \$ 3,53$ / MVArh, segundo Resolução Normativa $\mathrm{N}^{0}$ 195, de dezembro de 2005, publicada pela Agência Nacional de Energia Elétrica - ANEEL.

O valor obtido a partir da Equação 4.28 é definido como o valor mínimo de remuneração a ser empregado às unidades geradoras pelo fornecimento do suporte de potência reativa ao sistema.

\subsection{Alocação dos Custos Incrementais às Barras Responsáveis pelo Suporte de Potência Reativa}

A seguir será apresentado o método proposto para alocação do custo da energia reativa adicional gerada determinado no Item 4.8. O custo será alocado entre as barras responsáveis pela necessidade adicional de suporte de potência reativa. Para a realização da divisão deste custo será utilizada a Equação 4.29. 


$$
G_{R}(i)=\frac{|\Delta Q(i)|}{\sum_{i=1}^{N B C}|\Delta Q(i)|}
$$

Sendo $G_{R}(i)$ o grau de participação da barra de carga " $i$ " no fornecimento do suporte de potência reativa; NBC o número de barras de carga do sistema; e $\Delta Q(i)$ a variação de potência reativa nas barras de carga resultante do processo de otimização em relação aos casos analisados.

Para o sistema apresentado pela Figura 4.7, temos os seguintes valores de $G_{R}(i)$, Tabela 4.31.

Tabela 4.31. Valores de $G_{R}$ calculados a partir da Equação 4.29.

\begin{tabular}{|c|c|c|c|c|}
\hline & \multicolumn{3}{|c|}{ Potências Reativas (MVAr) } & \multirow[b]{2}{*}{$G_{R}$} \\
\hline Barra & $\begin{array}{l}\text { Caso } \\
\text { "Base" }\end{array}$ & $\begin{array}{c}\text { Caso } \\
\text { "Sub Ótimo" }\end{array}$ & Variação & \\
\hline 17 & 11,2 & 8,5 & 2,7 & 0,125 \\
\hline 26 & 41,6 & 41,6 & 0,0 & 0,000 \\
\hline 33 & $-15,6$ & $-8,2$ & 7,4 & 0,342 \\
\hline 35 & 5,0 & $-0,2$ & 5,2 & 0,241 \\
\hline 51 & 16,4 & 10,1 & 6,3 & 0,292 \\
\hline \multicolumn{3}{|c|}{$\overline{\mathrm{To}}$} & 21,6 & 1,000 \\
\hline
\end{tabular}

Com base nos valores de $G_{R}$ calculados é possível atribuir às barras de carga do sistema o custo da energia reativa adicional gerada, resultante do suporte de potência reativa.

\subsection{Função Objetivo}

O presente trabalho analisou duas diferentes funções objetivo, cujo objetivo final era a redução das perdas ativas do sistema. Ambas levaram à minimização das perdas e a redução da potência reativa gerada no sistema. 
Ao minimizar os reativos gerados são minimizadas, também, as perdas no conjunto gerador/transformador elevador. Esse processo de otimização contemplando a minimização das perdas no conjunto gerador/transformador elevador utilizado na metodologia proposta para a valoração do suporte de potência reativa pode vir a ser melhor, mesmo que não seja o melhor para a minimização das perdas do sistema de transmissão.

Desta forma, um terceiro método que inclua no arquivo de rede a resistência do gerador e do transformador elevador e utilize a Função Objetivo 2, minimizando as perdas do sistema (agora composto pelas linhas de transmissão, transformadores e gerador/transformador elevador) poderia trazer uma vantagem ainda maior em relação às formulações propostas.

\subsection{Conclusões Parciais}

O presente Capítulo apresentou uma metodologia com o objetivo de valorar o serviço de suporte de potência reativa realizado a partir de unidades geradoras.

Esta metodologia foi dividida em três etapas. A primeira etapa utilizou uma ferramenta de otimização de forma a possibilitar a definição de diferentes pontos de operação do sistema. Estes pontos de operação foram utilizados para medir a sensibilidade da potência reativa fornecida pelas unidades geradoras e das perdas ativas geradas no sistema em relação à potência reativa das barras de carga.

Os pontos de operação definidos mostraram que são possíveis de serem praticados e que parte do suporte de potência reativa tem como objetivo atender à segurança do sistema, principalmente em relação à correção dos fatores de potência e 
dos níveis de tensão praticados pelas barras de carga. Esse serviço prestado é definido como um Serviço Ancilar.

A partir dos testes de otimização realizados foi observado que as perdas do sistema, gerador/transformador elevador e transmissão, aumentam com o aumento do fornecimento de potência reativa a partir das unidades geradoras. Levando-se em conta que o fornecimento de potência reativa adicionado à geração de potência ativa é realizado dentro das curvas de capabilidade das unidades, a metodologia proposta utilizou o aumento das perdas do sistema como base para remuneração do suporte de potência reativa praticado pelas unidades geradoras.

A segunda etapa da metodologia proposta teve como objetivo quantificar a diferença de perdas do sistema e de geração de potência reativa em relação às soluções obtidas na primeira etapa. Quantificado estas diferenças foi proposta uma relação que definiu um valor financeiro atribuído à energia reativa (MVArh) adicional fornecida pelas unidades geradoras. Este valor foi definido como o valor mínimo de remuneração a ser empregado às unidades geradoras pelo fornecimento do suporte de potência reativa ao sistema. O valor máximo poderia ser definido como o custo que as barras de carga teriam para compensar cada MVArh necessários para ajustar seus fatores de potência e controlar seus níveis de tensão, de maneira a diminuir o suporte dado pelas unidades geradoras.

Definido o valor do MVArh adicional fornecido pelas unidades geradoras, a terceira etapa da metodologia proposta objetivou a alocação do custo desta energia fornecida proporcional as necessidades requeridas pelas barras do sistema, ou seja, o valor do MVArh é alocado apenas entre as barras que impactaram de maneira a 
aumentar a geração de potência reativa nas unidade geradoras, conforme apresentado na Tabela 4.31.

Como apresentado anteriormente, o valor obtido pela metodologia proposta resultou em um valor superior ao estabelecido para pagamento de suporte de reativos, providos por unidade geradora operando na situação de compensador síncrono. Embora tenha havido uma diferença, a metodologia proposta mostrou-se coerente com o que tem sido estabelecido, levando-nos a concluir que a mesma apresenta boas perspectivas para a melhora da remuneração dos Serviços Ancilares prestados pelos agentes pertencentes ao Sistema Elétrico Nacional. 


\section{Capítulo 5}

\section{Conclusões}

O presente trabalho abordou uma metodologia de valoração de Serviços Ancilares prestados a partir de plantas hidroelétricas. Os Serviços Ancilares abordados no trabalho foram: a reserva de potência ativa e o suporte de potência reativa.

Inicialmente foi apresentado um histórico sobre Serviços Ancilares com os seguintes objetivos: abranger as definições empregadas para estes serviços em diferentes mercados de energia; apresentar os agentes e/ ou equipamentos utilizados para prover estes serviços; apresentar os custos inerentes à provisão destes serviços; e apresentar como diferentes países têm tratado os Serviços Ancilares em seus mercados de energia. Foi apresentado um breve histórico que descreveu o que foi definido e regulamentado sobre Serviços Ancilares no Brasil.

O primeiro Serviço Ancilar abordado foi a provisão de reserva de potência ativa. O trabalho considerou a avaliação a partir de uma planta hidráulica (UHE de Água Vermelha). A metodologia adotada para a valoração do serviço de reserva de potência ativa seguiu a rotina descrita a seguir. Inicialmente foi realizada a mensuração da perda de eficiência resultante do fornecimento deste serviço para o 
período de um ano. Esta perda de eficiência é mensurada quando se leva em conta que o despacho realizado está gerando uma quantidade de potência com um número maior de máquinas que o necessário, trabalhando assim com as máquinas em pontos de operação de menor eficiência. Em seguida, a variação obtida das considerações aplicadas é então convertida em MWh e o resultado obtido é valorado considerando à perda de oportunidade, caso essa energia fosse comercializada no mercado de energia.

Os resultados alcançados a partir dos testes propostos mostraram que essa perda em eficiência, no final do período de um ano, torna-se significante (aproximadamente $0,77 \%$ da geração anual de uma usina de grande porte) e que uma compensação aos agentes geradores pela prestação deste serviço deveria ser provida.

No caso especifico da UHE de Água Vermelha, no ano de 2002, a economia alcançada com a otimização da reserva de potência ativa chegou a ordem de US\$ 400.000,00 no caso de se considerar o valor do MWh à US\$10,00 (Dez dólares).

Tais resultados mostraram a necessidade de se discutir uma forma de compensação aos agentes geradores pela prestação do serviço de reserva de potência ativa.

Ainda em relação à reserva de potência ativa, foi definida uma metodologia de despacho de máquinas com diferentes características, dentro de uma mesma usina. A metodologia proposta é semelhante à utilizada em usinas termoelétricas. Isto se torna possível a medida que os valores de eficiência das máquinas possam ser representados a partir de equações do segundo grau.

O segundo Serviço Ancilar abordado no presente trabalho foi o suporte de potência reativa. Para a valoração deste serviço foi utilizada a teoria de Fluxo de 
Potência Ótimo com objetivo de minimizar as perdas do sistema e relacionar essa minimização de perdas à redução do suporte de potência reativa dado pelos agentes geradores.

Assim, a metodologia proposta consiste em partir de um caso inicial de Fluxo de Potência Ótimo (FPO), onde as variáveis das barras do sistema estão livres (exceto os limites de tensões), buscando a minimização de uma função objetivo. Em seguida, outros casos (barras de carga com fator de potência menor ou igual a 0,95 ou menor ou igual a 0,98) são otimizados a partir do FPO proposto e o resultado da função objetivo é obtido. A diferença obtida a partir dos casos analisados é usada com o objetivo de gerar o valor a ser ressarcido pelas barras de carga que se distanciam do caso de referência.

A função objetivo a ser minimizada pode ser representada pela potência reativa gerada ou pelas perdas do sistema (gerador/transformador elevador/transmissão). Ambas foram utilizadas na formulação da metodologia de valoração do suporte de potência reativa.

Considerando que grande parte das perdas ocorre no transformador elevador e nos geradores, melhor seria representar os mesmos no arquivo de rede do sistema para que em seguida fosse aplicado o FPO com objetivo de minimizar as perdas ativas do sistema (que incluiria as linhas de transmissão, os transformadores e os geradores/transformadores elevadores).

Uma metodologia para valoração do custo do suporte de potência reativa foi proposta relacionando o aumento das perdas ativas do sistema com o aumento da potência reativa gerada, obtidos a partir do processo de otimização proposto. 
Os resultados alcançados a partir da metodologia proposta mostraram-se coerentes, levando-nos a concluir que a mesma apresenta boas perspectivas para a melhora da remuneração dos Serviços Ancilares.

Desta forma as principais contribuições do presente trabalho foram:

1. A apresentação da definição de Serviços Ancilares no SIN e também em sistemas elétricos de diferentes países;

2. A apresentação das regras de mercado utilizadas no SIN e em outros países para tratamento dos Serviços Ancilares;

3. A apresentação de ferramentas utilizadas, em diferentes mercados de diferentes países, que permitam a valoração dos Serviços Ancilares definidos;

4. A proposição de uma metodologia para a valoração de diferentes Serviços Ancilares. Para reserva de potência ativa utilizou-se a teoria de Custo de Oportunidade e para o suporte de potência reativa utilizou-se uma ferramenta baseada na teoria de Fluxo de Potência Ótimo;

5. A avaliação das metodologias propostas a partir de informações provenientes do SIN.

A partir das conclusões e das contribuições observadas, o trabalho desenvolvido leva-nos a uma seqüência de estudos/ desenvolvimentos futuros. São eles:

1. Para o cálculo da perda de eficiência utilizado na valoração da reserva de potência ativa foi considerado que todas as máquinas da planta hidroelétrica tinham rendimentos iguais. Isso pode não ocorrer. Desta forma, seria necessário determinar o valor correto destes rendimentos a fim de se 
empregar o modelo de otimização proposto, obtendo uma solução ainda mais otimizada;

2. Como as perdas ativas do conjunto, gerador/ transformador elevador, não são consideradas no programa de cálculo do Fluxo de Potência, seria necessário contemplar no arquivo de entrada deste cálculo os valores relativos a este conjunto, permitindo o cálculo das perdas ativas relacionadas ao mesmo;

3. Como as perdas ativas dos sistemas utilizados nos testes são de baixa grandeza, uma pequena variação nas variáveis de controle pode trazer uma variação maior em relação à solução obtida. Desta forma, seria necessário refinar a ferramenta de solução do problema de otimização proposto. 


\section{Bibliografia}

ABREU, R.L.; VILELA, L.C.T. (2001). Serviços Ancilares - Uma Proposta de Classificação e Precificação para o Setor Elétrico Brasileiro. XVI Seminário Nacional de Produção e Transmissão de Energia Elétrica, Campinas, Outubro.

AGANAGIC, M.; ABDUL-RAHMAN, K.H.; WAIGHT, J.G. (1998). Spot Pricing of Capacities for Generation and Transmission of Reserve in An Extended Poolco Model. IEEE Trans. on Power Systems, v.13, n.3, p. 1128-1135, August.

Agência Nacional de Energia Elétrica - ANEEL. Resolução nº 265, de 10 de Julho de 2003. Estabelece os Procedimentos para Prestação de Serviços Ancilares de Geração e Transmissão. Diário Oficial da União, Brasília, DF, 11 jun. 2003. Seção 1, p.65.

Agência Nacional de Energia Elétrica - ANEEL. Resolução n ${ }^{0}$ 133, de 23 de Dezembro de 2004. Estabelece o valor da Tarifa de Serviços Ancilares para pagamento do serviço de suporte de reativos, provido por unidade geradora operando na situação de compensador síncrono. Diário Oficial da União, Brasília, DF, 24 dez. 2004. Seção 1, p.72.

Agência Nacional de Energia Elétrica - ANEEL. Resolução $\mathrm{n}^{0}$ 195, de 19 de Dezembro de 2005. Estabelece o valor da Tarifa de Serviços Ancilares para pagamento do serviço de suporte de reativos, provido por unidade geradora operando na situação de compensador síncrono. Diário Oficial da União, Brasília, DF, 22 dez. 2004. Seção 1, p.85. 
ARCE, A.; SOARES, S. (2002). Optimal Dispatch of Generating Units of the Itaipú Hydroelectric Plant. IEEE Trans. on Power Systems, v.17, n.1, p. 154-158, February.

BHATTACHARYA, K.; ZHONG, J. (2001). Reactive Power as Ancillary Service. IEEE Transactions on Power Systems, vol.16, no. 2, p.294-300, May.

BILLINTON, R.; ABORESHAID, S.; FOTUHI-FIRUZABAD, M. (1996). Spinning Reserve Allocation Using Response Health Analysis. IEE ProceedingsGeneration, Transmission and Distribution, v.143, n.4, p. 337-343, July.

BOUFFARD, F.; GALIANA, F.D. (2004). An Electricity Market with a Probabilistic Spinning Reserve Criterion. IEEE Trans. on Power Systems, v.19, n.1, p. 300307, February.

BRASIL. Decreto $\mathrm{n}^{0}$ 2655, de 02 de Julho de 2002. Regulamenta o Mercado Atacadista de Energia Elétrica, define as regras de organização do Operador Nacional do Sistema Elétrico e dá outras providências. Diário Oficial da União, Brasília, DF, 03 jul. 1998. Seção 1, p.2.

CARPENTIER, J.L. (1962). Contribution a L'etude du Dispatching Economique. Bull-Soc. Fr. Elec. Ser. B3, p. 431-447.

CIGRÉ. (2001). Methods and Tools for Costing Ancillary Services. SC 38, Advisory Group 05, Task Force 38-05-07.

COSTA, A.L.; COSTA, A.S. (2004). Energy and Spinning Reserve Markets Through Dynamic Optimal Power Flow. IX Simpósio de Especialistas em Planejamento da Operação e Expansão Elétrica, Rio de Janeiro. 
DAI, Y.; LIU, X.D.; NI, Y.X.; WEN, F.S.; HAN, Z.X.; SHEN, C.M.; WU, F.F. (2003). A Cost Allocation Method for Reactive Power Service Based on Power Flow Tracing. Electric Power Systems Research, no.64, p. 59-65.

DANDACHI, N.H.; RAWLINS, M.J.; ALSAÇ, O.; PRAIS, M.; STOTT, B. (1996). OPF for Reactive Pricing Studies on the NGC System. IEEE Transactions on Power Systems, vol.11, no. 1, p.226-232, February.

DOÑA, V.M.; PAREDES, A.N. (2001). Reactive Power Pricing in Competitive Electric Markets Using the Transmission Losses Function. 2001 IEEE Porto Power Tech Conference, Portugal, September.

ELETROBRÁS (1994). Sistema de Informações do Potencial Hidroelétrico Brasileiro - SIPOT.

EL-KEIB, A.A.; MA, X. (1997). Calculating Short-Run Marginal Cost of Active and Reactive Power Production. IEEE Transactions on Power Systems, vol.12, no. 2, p.559-565, May.

ENCINA, A.S.A.; CICOGNA, M.A.; SOARES, S.; OHISHI, T. (2004). Despacho Ótimo de Unidades Geradoras em Usinas Hidroelétricas. IX Simpósio de Especialistas em Planejamento da Operação e Expansão Elétrica, Rio de Janeiro.

GJENGEDAL, T.; GJERDE, J.O.; FLOLO, R. (1998). Ancillary Services in Deregulated Power Systems; What are They; Who Need Them and Who Pays. ISSN 0-7803-4754-4/98, p. 704-709.

GJENGEDAL, T.; KVENNAS, O. (2000). Ancillary Services - To use for Whom? International Conference on Electric Utility Deregulation and Restructuring and Power Technologies, p. 493-498, April. 
GOMES, P.; LUZ, J.C.F.; SCHILLING, M.T.; FONTOURA, R.N.; SANTOS, M.G. (1997). Subsídios para a Determinação de Custos de Serviços Ancilares para a Gestão da Rede. XIV Seminário Nacional de Produção e Transmissão de Energia Elétrica, Belém.

GRANVILLE, S. (1994). Optimal Reactive Dispatch through Interior Point Method. IEEE Trans. on Power Systems, v.9, n.1, p. 136-146, February.

GROSS, G.; TAO, S.; BOMPARD, E.; CHICCO, G. (2002). Unbundled Reactive Support Service: Key Characteristics and Dominant Cost Component. IEEE Transactions on Power Systems, vol.17, no. 2, p.283-289, May.

HAO, S.; PAPALEXOPOULOS, A. (1997). Reactive Power Pricing and Management. IEEE Transactions on Power Systems, vol.12, no. 1, p.95-104, February.

IBA, K.; SUZUKI, H.; SUZUKI, KEN-ICHI.; SUZUKI, K. (1988). Practical Reactive Power Allocation/ Operation Planning Using Successive Linear Programming. . IEEE Transactions on Power Systems, vol.3, no. 2, p.558-566, February.

JARDINI, J.A.; CASOLARI, R.P.; HONDA, Y.; PELICER, J.C.; JUNIOR, M.R. (2002). Ancillary Services - Cost Benefit Evaluation as Related to Hydroelectric Power Plants Reactive Supply. 2002 IEEE PES T\&D Latin America, São Paulo.

KHIAT, M.; CHAKER, A.; GÓMEZ, E.A.; MARTÍNEZ, R.J.L. (2003). Reactive Power Optimization and Voltage Control in the Western Algerian Transmission System: a Hybrid Approach. Electric Power Systems Research, no.64, p. 3-10.

KISHORE, A.; HILL, E.F. (1970). Static Optimization of Reactive Power Sources by Use of Sensitivity Parameters. IEEE Power Group, p.1166-1173, April. 
LAMONT, J.W.; FU, J. (1999). Cost Analysis Reactive Power Support. IEEE Transactions on Power Systems, vol.14, no. 3, p.890-898, August.

LCG CONSULTING (2000a). Analyzing Multiple-Product Power Markets Introduction and Summary. Disponível em: http://www.energyonline.com/ reports/ reports.asp. Acesso em: 07 abr. 2005.

LCG CONSULTING (2000b). Regional Energy and Ancillary Services Market. Disponível em: http://www.energyonline.com/ reports/ reports.asp. Acesso em: 07 abr. 2005.

LIU, J.; KONG, P.; PAN, L.; HUANG, Y. (2004). Reactive Power Market Based on Consolidated Compensation. 2004 IEEE Conference on Electric Utility Deregulation, Restructuring, Power Technologies, p. 540-545, Hong-Kong, April.

MILLER, R. L. (1981). Microeconomia: Teoria, Questões e Aplicações. McgrawHill, São Paulo.

Ministério de Minas e Energia - MME (2006). Plano Decenal de Expansão de Energia Elétrica 2006-20015. Disponível em: <http://www.mme.gov.br.> Acesso em: 26 jul. 2006.

MONTICELli, A. (1983). Fluxo de Carga em Redes de Distribuição de Energia Elétrica. São Paulo, Edgard Blücher Ltda.

MUNSON, D.F.; Young \& OKIISHI, T.H. (1998). Fundamentals of Fluid Mechanics. 3rd ed., New York: Wiley, pp. xvii, 877.

ONGSAKUL, W.; CHAYAKULKHEEREE, K. (2003). Constrained Optimal Power Dispatch for Electricity and Ancillary Services Auctions. Electric Power System Research, n.66, p.p. 193-204. 
PAPADOGIANNIS, K.A.; HATZIARGYRIOU, N.D. (2004). Optimal Allocation of Primary Reserve Services in Energy Markets. IEEE Trans. on Power Systems, v.19, n.1, p. 652-659, February.

PETTIGREW, J. (2000). Trading in Ancillary Services. IEE Colloquium, March.

PRADA, R.B.; NOGUEIRA, G.A.S.; VIEIRA, M.A.M.; SOTO, J.O.; MARZANO, L.G.B.; MELO, A.C.G. (2003). Identificação dos Beneficiários e Alocação de Custos de Expansão do Suporte de Potência Reativa. XVII Seminário Nacional de Produção e Transmissão de Energia Elétrica, Uberlândia.

PRADA, R.B.; VELASCO, C.J.; SILVA, L.X.; MELO, A.C.G. (2002). Possible Design of the Brazilian Ancillary Service Market for Generation Reserve. Power System Management and Control, p. 414-419, April.

PUDJIANTO, D.; AHMED, S., STRBAC, G. (2002). Allocation of VAr Support Using LP and NLP Based Optimal Power Flows. IEE Proceedings-Generation, Transmission, Distribution, vol. 149, no. 4, p. 377- 383, July.

RAJARAMAN, R.; KIRSCH, L. (1998). Profiting from Operating Reserves. Electricity Journal. March.

RAMALHETE, M.; GUERREIRO, J.; MAGALHÃES, A. (1984). Programação Linear. McGRAW-HILL, vol.1.

RAU, N.S. (1999). Optimal Dispatch of a System Based on Offers and Bids - A Mixed Integer LP Formulation. IEEE Trans. on Power Systems, v.14, n.1, p. 274-279, February.

RIBAS, F.A.C. (2003). Otimização da Geração de Energia em Centrais Hidroelétricas. XVII Seminário Nacional de Produção e Transmissão de Energia Elétrica, Uberlândia. 
RIBEIRO, P.M.; MARZANO, L.G.B.; SOTO, J.R.O.; MELO, A.C.G. (2004). Methodology for Pricing the Generation Reserve and the Reactive Power Supply as Ancillary Services when Provided by Generators. IX Simpósio de Especialistas em Planejamento da Operação e Expansão Elétrica, Rio de Janeiro.

SALLÉ, C. (1996). Ancillary Services: An Overview. Colloquium IEE - Pricing of Ancillary Services: An International Perspective, June.

SCHMITT, A.; VERSTEGE, J.F. (2001). A Multi-Criteria Optimization of Ancillary Services with Pareto-based Evolution Strategies. IEEE Porto Power Tech Conference, September.

SCHULER, R.E. (2001). Electricity and Ancillary Services Markets in New York State: Market Power in Theory and Practice. $34^{\text {th }}$ Annual Hawaii Conference on Systems Sciences, January.

SILVA, E.L. (1998). Serviços Ancilares: Suporte à Tensão. Projeto Re-Seb, Working Paper 98/2/2-2-Anexo I, SEN/Eletrobrás, Outubro.

SILVA FILHO, D. (2003). Uma Nova Abordagem ao Dimensionamento EletroEnergético de Usinas Hidroelétricas para o Planejamento da Expansão da Geração. Tese de Doutorado, Escola de Engenharia de São Carlos, Universidade de São Paulo, São Carlos.

SINGH, H.; PAPALEXOPOULOS, A. (1999). Competitive Procurement of Ancillary Services by An Independent System Operator. IEEE Transaction On Power Systems, v.14, n.2, p. 498-504, May.

SOARES, N.H.M.; SOBRAL, S.C.; MORAND, S.R.; GOMES, P.; SARDINHA, S.; QUEIROZ, R. (2002). Proposta de Serviços Ancilares para o Sistema Interligado Nacional. VII Encontro para Debates de Assuntos de Operação, Foz do Iguaçu. 
SOUSA, T. (2003). Estudo de Planejamento de Reativos em Sistemas Elétricos de Potência. Dissertação de Mestrado, Escola de Engenharia de São Carlos, Universidade de São Paulo, São Carlos.

SOUSA, V. A. (2001). A Função Barreira Logarítmica Associada ao Método de Newton Modificado para a Resolução do Problema de Fluxo de Potência Ótimo. Dissertação (Mestrado) - Escola de Engenharia de São Carlos, Usp, São Carlos.

STASCHUS, K. (1996). Review of German Approaches to Ancillary Services Costing and Pricing. IEE WC2F, London.

STRBAC, G. (2001). Trading Electricity and Ancillary Services in the Reformed England and Wales Electricity Market. ISSN 0-7803-6672-7/01, p. 41-44.

VELASCO, C.J.; PRADA, R.B.; CALDAS, R.S. (2003). Análise da Interação entre os Procedimentos de Remuneração da Reserva de Potência Operativa e o Mecanismo de Realocação de Energia. XVII Seminário Nacional de Produção e Transmissão de Energia Elétrica, Uberlândia.

VERBIC, G.; GUBINA, F. (2004). Cost-Based Models for the Power Reserve Pricing of Frequency Control. IEEE Trans. on Power Systems, v.19, n.4, p. 1853-1858, November.

WOOD, A.J.; WOLlENBERG, B.F. (1983). Power Generation, Operation and Control. ISBN 0-471-09182-0.

WU, T.; ROTHLEDER, M.; ALAYWAN, Z.; PAPALEXOPOULOS, A.D. (2004). Pricing Energy and Ancillary Services in Integrated Market Systems by an Optimal Power Flow. IEEE Trans. on Power Systems, v.19, n.1, p. 339-347, February. 
XU, Z.; DONG, Z.Y.; WONG, K.P. (2003). Optimal Dispatch of Spinning Reserve in an Competitive Electricity Market Using Genetic Algorithms. ISSN 0-78037804-0/03.

YAMIN, H.Y. (2003). Review on Methods of Generation Scheduling in Electric Power Systems. Electric Power Systems Research, n.69, p. 227-248.

ZHU, J.Z.; XIONG, X.F. (2003). Optimal Reactive Power Control Using Modified Interior Point Method. Electric Power Systems Research, no.66, p. 187-192. 
Apêndice 1

\section{Custo de Oportunidade}

Sob o enfoque econômico, os seres humanos orientam suas decisões baseadas na premissa da otimização, suportadas pelas hipóteses da racionalidade objetiva e da liberdade de ação das pessoas. Ou seja, se elas são livres para agir, é lógico supor que procuram escolher coisas que lhes proporcionem a máxima satisfação. Este princípio é descrito por MILLER (1981) como modelo de comportamento racional, onde as alternativas de ação de uma decisão são avaliadas de forma sistemática e coerente, e a escolha da melhor opção tem como fronteiras as limitações do mundo real.

Nesta condição, o gestor executará uma análise racional das alternativas existentes e optará pela melhor alternativa no processo decisório, através de um comportamento intencional e sistemático. Portanto, para a teoria econômica, o custo de oportunidade ou custo alternativo surge quando o decisor opta por uma determinada alternativa de ação em detrimento de outras viáveis e mutuamente exclusivas, sendo assim, representa o benefício que foi desprezado ao escolher uma determinada alternativa em função de outras. Desta forma, o custo dos fatores de produção só pode ser mensurado através de seu custo de oportunidade. MILLER (1981) enfatiza dizendo que "o custo tem um significado muito especial em economia, significa apenas uma coisa - o custo de oportunidade.” 
No caso do fornecimento do serviço de reserva de potência ativa, qualquer unidade prestadora deste serviço deve satisfazer algumas condições. São elas:

- Deve ter a habilidade de aumentar sua potência de saída quando necessário. Unidades operando na sua máxima potência de saída são incapazes de fornecer reservas.

- Deve estar disponível e preparada para fornecer a potência dentro de um espaço de tempo para o qual a reserva é necessária.

Uma unidade hidráulica que está em operação e opera de forma síncrona é geralmente capaz de fornecer reservas rápidas, fornecendo-as em um tempo de resposta suficientemente baixo. Para uma unidade fornecer serviço de reserva de potência ativa deve-se escolher operar em um ponto menor que o ponto de máxima saída de potência. Se o preço que a unidade recebe por sua potência é maior que o custo marginal de operação da unidade, o custo de oportunidade para esta unidade fornecer reserva é o valor perdido da operação em relação ao recebido pela potência total. Para a unidade fornecer reservas lucrativas, o preço ou reserva deve exceder o custo de oportunidade da unidade, RAJARAMAN \& KIRSCH (1998). Isso é ilustrado pela Figura A1.1. 


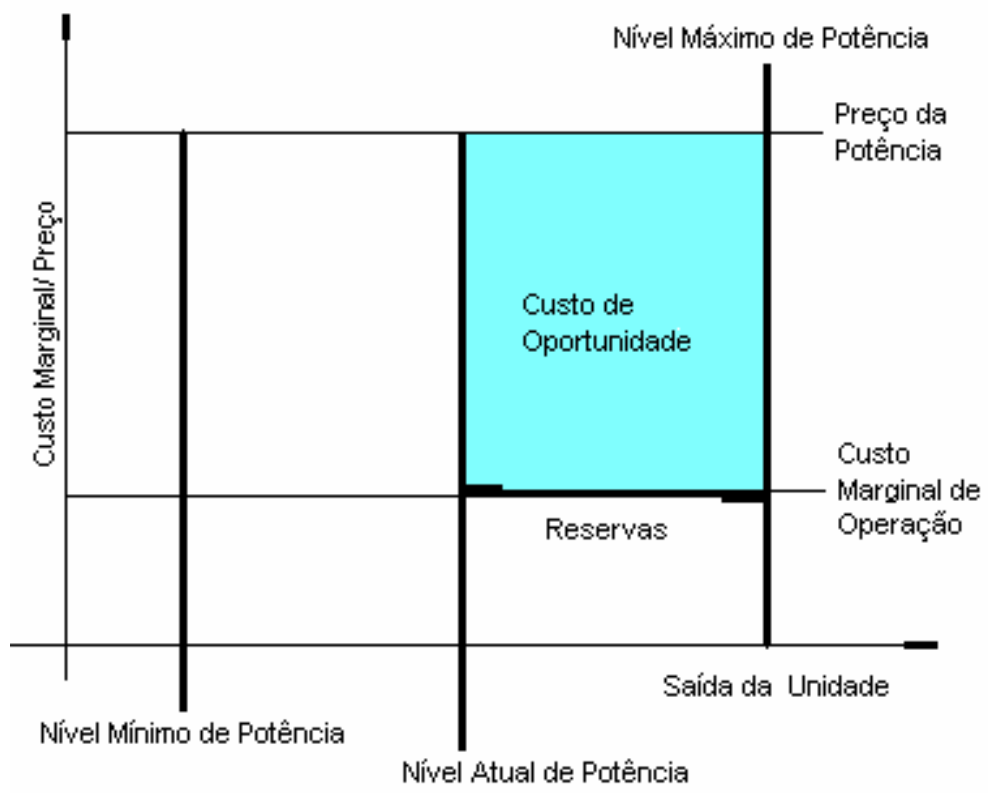

Figura A1.1. Custo de oportunidade de uma unidade com preço da potência maior que o custo marginal de operação.

A Figura A1 mostra o custo de oportunidade para uma unidade de fornecimento de serviço de reserva rápida quando o custo marginal da unidade é menor que o preço da potência no local onde a unidade está operando. A área em destaque ilustra o custo de oportunidade desta unidade. A linha identificada como reserva indica quanto está unidade é capaz de fornecer em reserva. 


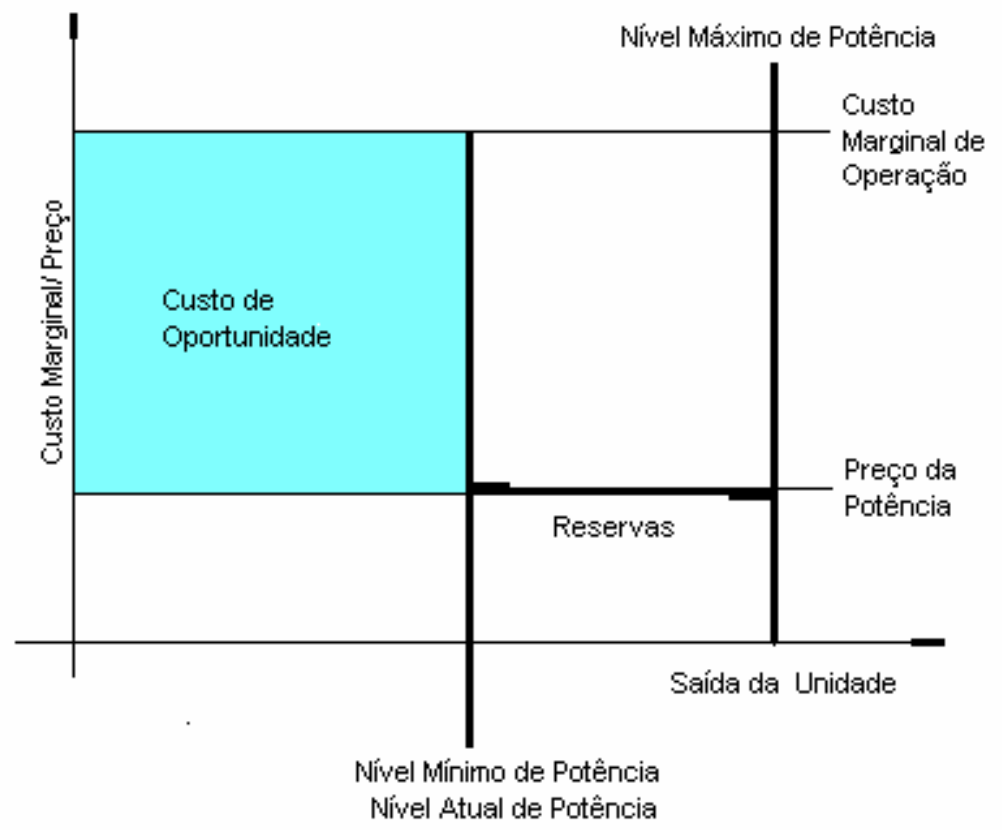

Figura A1.2. Custo de oportunidade de uma unidade com preço da potência menor que o custo marginal de operação.

A Figura A2 mostra o custo de oportunidade para uma unidade de fornecimento de serviço de reserva de potência ativa quando o custo marginal da unidade é maior que o preço da potência no local onde a unidade está operando. A área em destaque ilustra o custo de oportunidade desta unidade. A linha identificada como reserva indica quanto esta unidade é capaz de fornecer em reserva.

Uma análise similar pode ser feita para estabelecer o custo de oportunidade associado ao serviço de suporte de potência reativa. 
Apêndice 2

\section{Dados da Usina de Água Vermelha}

As Tabelas 1 e 2 a seguir foram originadas a partir do modelo reduzido da Usina

Hidroelétrica de Água Vermelha.

Tabrela 1 - Vazäo (Q) em relaçäo a altura de queda (H) e a Fotência Gerada ( $\mathrm{P})$

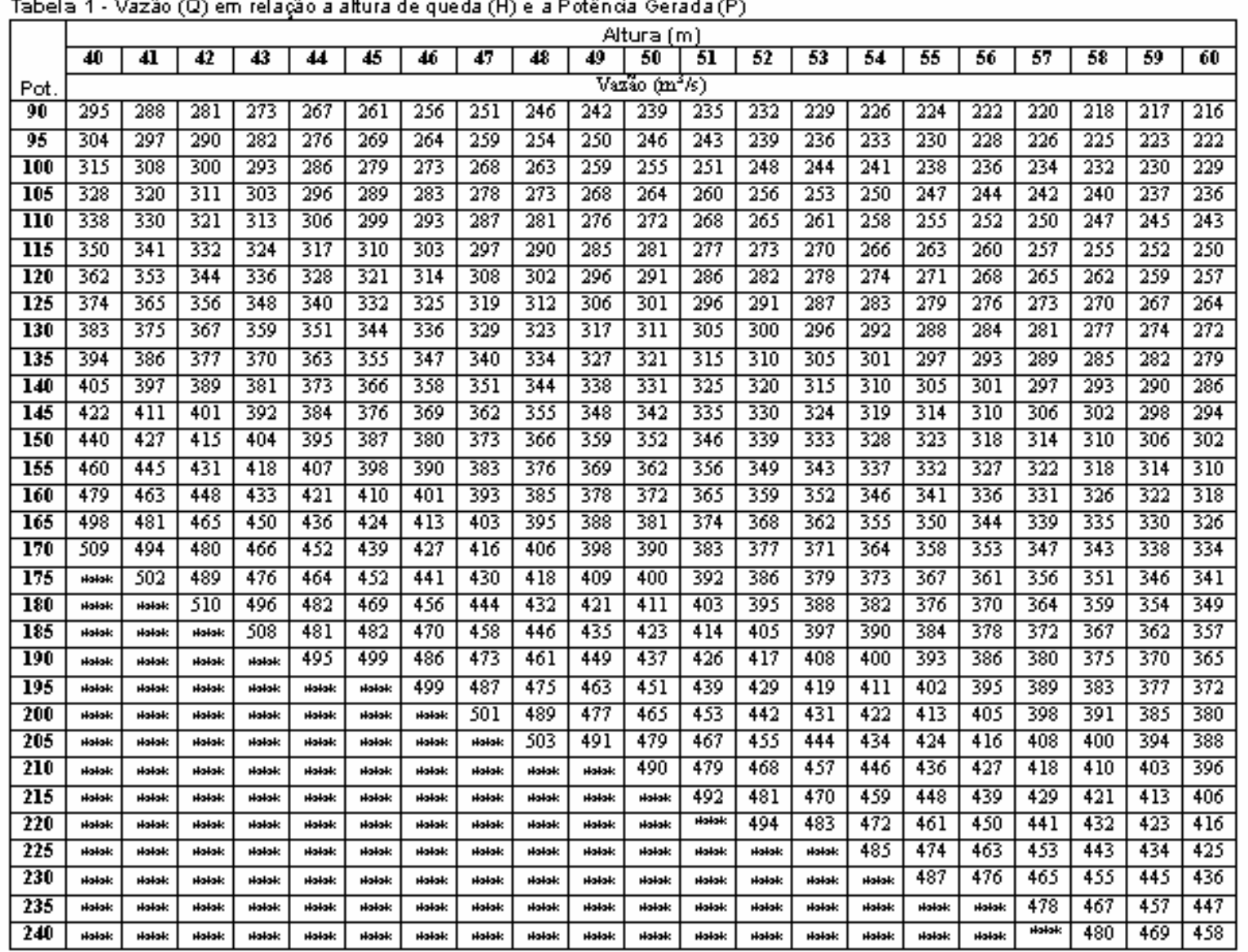


Tabela 2 - DyF em relaçäo a Fotência Gerada (P)

\begin{tabular}{|c|c|c|c|c|c|c|c|c|c|c|c|c|c|c|c|c|c|c|c|c|c|c|c|}
\hline \multirow[b]{3}{*}{ Pot. } & \multicolumn{23}{|c|}{ Ál一Ia (m) } \\
\hline & 40 & $\mathbf{4 1}$ & 42 & 4 & 44 & 45 & 46 & 47 & 46 & & 49 & 50 & 51 & 52 & 53 & & 54 & 55 & 56 & 57 & 56 & 59 & 6il \\
\hline & \multicolumn{23}{|c|}{ Relatao Q/P (mishW) } \\
\hline 90 & 3.28 & 3.20 & 3.12 & 3.00 & 2.97 & 2.90 & 2.84 & 2.7 & 2.7 & & 2.09 & 2.60 & $2 . \overline{101}$ & 2.5 & 2.5 & & 2.51 & 2.4 & $2.4 T$ & 2.44 & 2.42 & 2.41 & 2.40 \\
\hline 95 & 3.20 & 3.13 & 3.05 & 2.97 & 2.91 & 2.80 & 2.70 & 2.73 & 2.6 & & 2.69 & 2.89 & 2.56 & 2.5 & 2.4 & & 2.45 & 2.42 & 2.40 & 2.3 & 2.37 & 2.35 & 2.34 \\
\hline 100 & 15 & 08 & 00 & 2.90 & 2.60 & 2.79 & 2.73 & 2.60 & 2.6 & & 2.59 & 2.56 & 2.51 & 2.4 & 2.4 & & 2.41 & 2.30 & 2.30 & 2.34 & 2.32 & 2.30 & 2.29 \\
\hline 105 & 12 & .05 & 2.96 & 2.89 & 2.82 & 2.75 & 2.70 & 2.60 & 2.6 & & 256 & 2.51 & 2.48 & 2.4 & 2.4 & & 2.3 & 2.35 & 2.32 & 2.30 & 2.29 & 2.26 & 2.25 \\
\hline 110 & 3.07 & 300 & 2.92 & 2.85 & 2.78 & 2.72 & 2.60 & 2.61 & 2.5 & & 2.51 & $2.4 \pi$ & 2.44 & 2.4 & 2.3 & & 2.35 & 2.32 & 2.29 & 2.27 & 2.25 & 2.23 & 2.21 \\
\hline 115 & 3.04 & 2.97 & 2.89 & 2.82 & 2.76 & 2.70 & 2.68 & 2.58 & 2.5 & & 2.48 & 2.44 & 2.41 & 23 & $\overline{2.3}$ & & 2.31 & 2.29 & 2.26 & 2.23 & 2.22 & 2.19 & 2.17 \\
\hline 120 & 3.02 & 2.94 & 2.87 & 2.80 & 2.73 & 2.68 & 2.62 & 2.5 & 2.5 & & $2.4 \pi$ & 2.43 & 2.8 & 23 & 2. & & 2.28 & 2.26 & 2.23 & 2.21 & 2.18 & 2.16 & 2.14 \\
\hline 125 & 2.99 & 2.92 & 2.05 & 2.78 & 2.72 & 2.68 & 2.60 & 2.56 & 2.5 & & 2.45 & 2.41 & 2.37 & $2 x$ & 23 & & 2.28 & 2.23 & 2.21 & 2.18 & 2.16 & 2.14 & 2.11 \\
\hline 130 & 2.95 & 2.80 & 2.82 & 2.76 & 2.70 & 2.65 & 2.58 & 2.5 & 2.4 & & 2.44 & 2.39 & 2.35 & 2.3 & 2.2 & & 2.25 & 2.22 & 2.18 & 2.16 & 2.13 & 2.11 & 2.00 \\
\hline 135 & 2.92 & 2.80 & 2.79 & 2.74 & 2.69 & 2.60 & 2.5 & 2.52 & 2.4 & & 2.42 & 2.8 & 2.83 & 23 & 2. & & 2.23 & 2.20 & 2.17 & 2.14 & 2.11 & 2.00 & 2.07 \\
\hline 140 & 2.80 & 2.84 & 2.78 & 2.72 & 2.68 & 2.61 & 2.56 & 2.51 & $\overline{2.4}$ & & 2.41 & 2.36 & 2.32 & 2.2 & 2.2 & & 2.21 & 2.18 & 2.15 & 2.12 & 2.00 & 2.07 & 2.04 \\
\hline 145 & 2.91 & 2.80 & 2.7 & 2.70 & $2 . \bar{E}$ & 250 & 2.54 & 2.50 & 2.4 & & 2.40 & 2.66 & 2.31 & 2.2 & 2.2 & & 2.20 & 2.17 & 2.14 & 2.11 & 2.08 & $2.0 \overline{0}$ & 2.00 \\
\hline 150 & 2.90 & 2.85 & 2.7 & 2.69 & 2.60 & 2.58 & 2.58 & 2.4 & 2.4 & & 2.30 & $2 \%$ & 2.31 & 2.2 & 2.2 & & 2.19 & 2.15 & 2.12 & 2.09 & 2.07 & 2.04 & 2.01 \\
\hline 155 & 2.97 & 2.87 & 2.78 & 2.70 & 2.60 & 2.5 & 2.52 & 2.4 & 2.4 & & 2.30 & 2.34 & 2.30 & 2.2 & 2.2 & & 2.17 & 2.14 & 2.11 & 2.08 & 2.06 & 2.00 & 2.00 \\
\hline 160 & 2.99 & 2.89 & 2.80 & 2.71 & 2.63 & 2.56 & 2.51 & 2.45 & 2.4 & & 2.36 & 2.8 & 2.8 & 2.2 & 2.2 & & 2.16 & 2.13 & 2.10 & 2.07 & 2.04 & 2.01 & 1.90 \\
\hline 165 & 3.02 & 2.92 & 2.82 & 2.73 & 2.64 & 2.5 & 2.50 & 2.4 & 2.3 & & $2 . \$$ & 2.31 & 2.27 & 2.2 & 2. & & 2.15 & 2.12 & 2.08 & 2.05 & 2.00 & 2.00 & 1.98 \\
\hline 170 & 2.99 & 2.91 & 2.82 & 2.74 & 2.68 & 2.59 & 2.51 & 2.45 & 23 & & 2.34 & 2.29 & 2.25 & 2.2 & 2. & & 2.14 & 2.11 & 2.08 & 2.04 & 2.02 & 1.99 & 1.96 \\
\hline 175 & & 2.87 & 2.79 & 2.72 & 2.65 & 2.58 & 2.52 & 2.46 & 2.3 & & 2.34 & 2.29 & 2.24 & 2.2 & 2. & & 2.13 & 2.10 & 2.00 & 2.00 & 2.01 & 1.98 & 1.95 \\
\hline 180 & & & 2.80 & 2.76 & 2.68 & 2.81 & 2.53 & 2.4 & 2.4 & & 2.34 & 2.28 & 2.24 & 2.11 & 2. & & 2.12 & 2.09 & 2.06 & 2.02 & 1.99 & 1.97 & 1.94 \\
\hline 185 & & & & 2.75 & 2.60 & 2.61 & 2.54 & 2.49 & 2.4 & & 2.35 & 2.29 & 2.24 & 2.11 & 2. & & 2.11 & 2.08 & 2.04 & 2.01 & 1.99 & 1.96 & 1.90 \\
\hline 190 & & & & & 2.61 & 2.60 & 2.56 & 2.4 & 2.4 & & 2.60 & 2.30 & 2.24 & 2.10 & 2 & & 2.11 & 2.07 & 2.00 & 2.00 & 1.97 & 1.95 & 1.92 \\
\hline 195 & & & & & & & 2.56 & 2.50 & 2.4 & & 2.37 & 2.31 & 2.25 & 2.2 & 2 & & 2.11 & 2.06 & 2.00 & 1.99 & 1.90 & 1.90 & 1.91 \\
\hline 2010 & & & & & & & & 2.51 & 2.4 & & 2.39 & 2.30 & 2.27 & 2.2 & 2 & & 2.11 & 2.07 & 2.00 & 1.99 & 1.90 & 1.90 & 1.90 \\
\hline 205 & & & & & & & & & 2.4 & & 2.40 & 2.34 & 2.8 & 2.2 & 2. & & 2.12 & 2.07 & 2.00 & 1.99 & 1.95 & 1.92 & 1.80 \\
\hline 210 & & & & & & & & & & & & 2.8 & 2.28 & 2.2 & 2 & & 2.12 & 2.08 & 2.00 & 1.99 & 1.95 & 1.92 & 1.89 \\
\hline 215 & & & & & & & & & & & & & 2.20 & 2.2 & 2 & & 2.13 & 2.08 & 2.04 & 2.00 & 1.96 & 1.92 & 1.89 \\
\hline 270 & & & & & & & & & & & & & & 2.2 & 2 & & 2.15 & 2.10 & 2.05 & 2.00 & 1.90 & 1.92 & 1.89 \\
\hline 275 & & & & & & & & & & & & & & & & & 2.16 & 2.11 & 2.06 & 2.01 & 1.97 & 1.90 & 1.89 \\
\hline 230 & & & & & & & & & & & & & & & & & & 2.12 & 2.07 & 2.02 & 1.90 & 1.90 & 1.90 \\
\hline 235 & & & & & & & & & & & & & & & & & & & & 2.00 & 1.99 & 1.94 & 1.90 \\
\hline 240 & & & & & & & & & & & & & & & & & & & & & 2.00 & 1.95 & 1.91 \\
\hline
\end{tabular}


Tabeh 3: Mediröes realiaxdosmo din201 12002 na UHEde Agun Vermehn

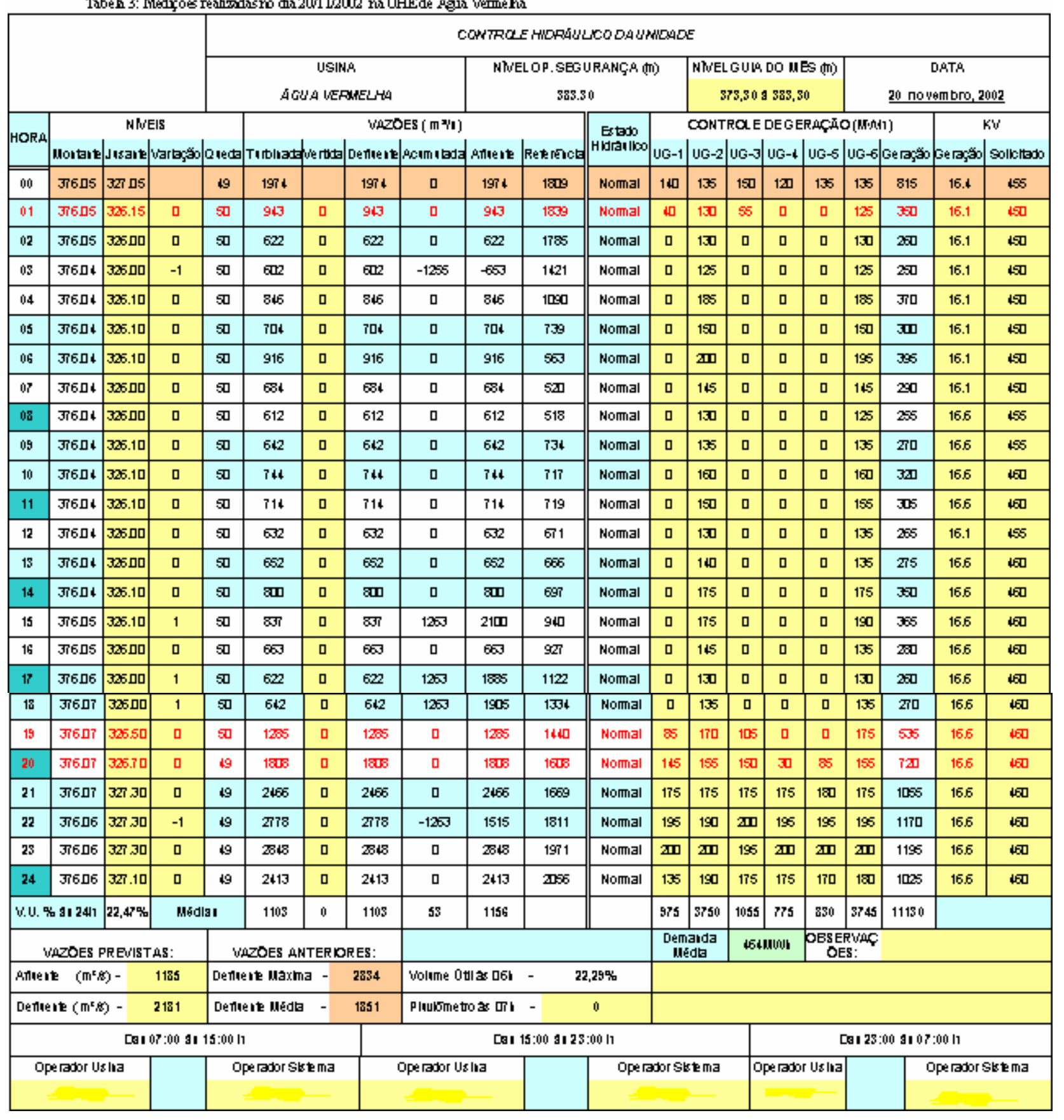


Tabeh 4: Modirõe realiadosro din 21/12002 na UHEde Agan Vomehn

\begin{tabular}{|c|c|c|c|c|c|c|c|c|c|c|c|c|c|c|c|c|c|c|c|c|}
\hline \multirow{4}{*}{\begin{tabular}{|l|}
\multicolumn{2}{|c|}{} \\
HORA \\
\end{tabular}} & \multirow{2}{*}{\multicolumn{2}{|c|}{ 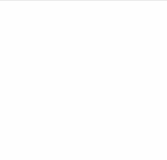 }} & & \multicolumn{17}{|c|}{ CONTROE MORÁULCO DAUMDUDE } \\
\hline & & & & \multicolumn{5}{|c|}{ AGUA VERAELUA } & \multicolumn{4}{|c|}{$\begin{array}{c}\text { NWEL OP.SEGURANÇA (T) } \\
385.30\end{array}$} & \multicolumn{4}{|c|}{$\begin{array}{l}\text { RTWELGULA DO MES } \\
\text { (ii) } \\
373,30 \text { a } 385,30\end{array}$} & \multicolumn{4}{|c|}{$\begin{array}{l}\text { DATA } \\
21 \text { novembro, } 2002 \\
\end{array}$} \\
\hline & NMEIS & & & & \multicolumn{6}{|c|}{ WAZOEES ( m $\left.{ }^{2} \mathbf{v}_{1}\right)$} & \multirow{2}{*}{$\begin{array}{l}\text { Extado } \\
\text { Hidral lico }\end{array}$} & \multicolumn{7}{|c|}{ CONTRQ E DEGERACFIO (M.ht1) } & \multicolumn{2}{|l|}{ KU } \\
\hline & $\underset{e}{\text { Mortat }}$ & dosant & varbogad & Qued & $\begin{array}{c}\text { Tutionad } \\
\mathbf{a}\end{array}$ & vertiotas & $\left|\begin{array}{c}\text { Dentoert } \\
\mathrm{e}\end{array}\right|$ & $\mid \begin{array}{c}a c a m i b a \\
a\end{array}$ & antiente & $\begin{array}{c}\text { Reternci } \\
a\end{array}$ & & UG-1 & UG-2 & , & & UG-5 & UG-6 & $\mid \begin{array}{c}\text { Gerogy } \\
0\end{array}$ & $\left|\begin{array}{c}\text { Ge } \sigma_{c}^{y} \\
0\end{array}\right|$ & Solleltado \\
\hline 00 & 36 66 & $32 \pi .10$ & & 49 & 2413 & & 2413 & $\square$ & 2413 & 2056 & Nomal & 135 & 190 & 175 & 175 & 170 & 180 & 1025 & 166 & 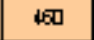 \\
\hline 01 & 36 66 & 325.50 & $\square$ & so & 1524 & $\square$ & 1524 & $\square$ & 1524 & $\pi 96$ & Nomal & $\square$ & 190 & 曰ा & 测 & 195 & SO & 605 & 16.4 & 455 \\
\hline 02 & ऊ6口6 & 32520 & $\square$ & s0 & 916 & $\square$ & 916 & 口 & 916 & 1947 & Nomal & 口 & 195 & 口 & 口 & III & 口 & 395 & 16.4 & 455 \\
\hline $0 \mathrm{~S}$ & उ6 66 & $325 \mathrm{DS}$ & 口 & so & 642 & व & 642 & 口 & 642 & 1643 & Nomial & 口 & 135 & 口 & 口 & 135 & 口 & $\pi 0$ & 16.4 & 455 \\
\hline 04 & 36म6 & 32505 & 口 & s & 612 & 口 & 612 & 口 & 612 & 1493 & Nomal & 口 & 125 & 口 & 口 & 130 & 口 & 255 & 16.4 & 455 \\
\hline 05 & ऊ6口6 & 32605 & 口 & s & 602 & 口 & 602 & 口 & 602 & 1118 & Nomal & 口 & 125 & 口 & 口 & 125 & 口 & $2 \pi 0$ & 16.4 & 455 \\
\hline 06 & उ 606 & 326.10 & 口 & so & 811 & 口 & 811 & 口 & 811 & 851 & Nomal & 口 & 180 & 口 & 口 & 175 & 口 & 355 & 16.4 & 455 \\
\hline 07 & 36 66 & 32680 & 口 & 19 & 1714 & 口 & 1714 & 口 & 1714 & 883 & Nomial & 180 & 190 & 口 & 175 & 185 & 口 & 730 & 16.4 & 455 \\
\hline 08 & ऊ6口6 & $32 \pi .15$ & 口 & 49 & 2581 & 口 & 2861 & 口 & 2581 & $112 \pi$ & Nomial & 185 & In & 170 & 180 & III & s & 965 & 16.4 & 455 \\
\hline 09 & ऊ6口5 & $32 \pi 50$ & -1 & 19 & 2595 & 口 & 2595 & -1263 & 1332 & $12 t 2$ & Nomal & III & 195 & 吅 & $\mathbf{D 5}$ & 195 & 205 & 1पाप & 16.4 & 455 \\
\hline 10 & 3604 & $32 \pi$ SD & -1 & 19 & 2005 & 口 & 2005 & -1255 & 1551 & 1399 & Nomal & 190 & 195 & III & 78s & 195 & 195 & 1180 & 16.4 & 155 \\
\hline 11 & ऊ6口i & $32 \pi 50$ & 口 & 49 & 2080 & 口 & 2000 & 口 & 2080 & 1780 & Nomial & II & III & III & 275 & 205 & III & 1210 & 16.4 & 455 \\
\hline 12 & 36 63 & $32 \pi 50$ & -1 & 19 & $20 \pi$ & 口 & $20 \pi$ & -1255 & 1565 & 1905 & Nombal & In & 2n & 20 & mo & 190 & 195 & 1185 & 16.4 & 455 \\
\hline 13 & उ $6 \mathrm{D2}$ & $32 \pi .50$ & -1 & 49 & 2848 & 口 & 2848 & -1255 & 1593 & 1805 & Nomial & II & In & II & m & 195 & III & 1195 & 168 & 100 \\
\hline 14 & 36D1 & $32 \pi 50$ & -1 & 49 & $2 \pi 78$ & 口 & $2 \pi 78$ & -1255 & 1523 & 1742 & Nomial & 185 & 195 & 195 & 20 & In & 195 & 1170 & 168 & 400 \\
\hline 15 & 3599 & $32 \pi 50$ & -2 & 48 & 2005 & 口 & 2005 & -2510 & 396 & 1586 & Nomal & II & 195 & III & In & 195 & III & 1190 & 168 & 400 \\
\hline 16 & ऊ598 & $32 \pi 50$ & -1 & 48 & 2849 & 口 & 2819 & -1255 & 1594 & 1594 & Nomial & 195 & 195 & 185 & II & 195 & III & 1170 & 168 & 100 \\
\hline 17 & 3597 & $32 \pi 50$ & -1 & 48 & 2751 & 口 & 2751 & -1255 & 1496 & 1361 & Nomal & 190 & 190 & 175 & 195 & 195 & 190 & 1135 & 168 & $4 \otimes 0$ \\
\hline 18 & 3596 & 32580 & -1 & 19 & 2131 & 口 & 2131 & -1255 & 876 & 1245 & Nomial & 195 & 145 & 130 & 140 & 140 & 135 & 85 & 168 & 400 \\
\hline 19 & 3595 & 325.70 & -1 & 19 & 1922 & 口 & 1902 & -1255 & 681 & $10 Q 2$ & Nomal & 135 & 130 & 130 & 130 & 130 & 135 & 790 & 16.4 & 455 \\
\hline 20 & 3593 & 32580 & -2 & 19 & 2131 & 口 & 2131 & -2494 & -363 & 778 & Nomal & 160 & 1 虹 & 140 & 180 & 190 & 190 & 890 & 16.4 & 455 \\
\hline 21 & 3592 & $32 \pi 50$ & -1 & 48 & 2622 & 口 & 2622 & -1247 & 155 & 974 & Nomal & 195 & 195 & 190 & 195 & 190 & 195 & $11 \otimes 0$ & 16.4 & 455 \\
\hline 22 & 3591 & 32750 & -1 & 48 & 2878 & 口 & 2878 & -1247 & 1031 & 960 & Nombal & 195 & III & 195 & $\pi$ & 195 & 195 & 1180 & 16.4 & 455 \\
\hline 23 & 3591 & $32 \pi 50$ & 口 & 48 & 2054 & 口 & 2054 & 口 & 2054 & 1258 & Nomal & 195 & In & 190 & 195 & III & 195 & 1175 & 16.4 & 455 \\
\hline 24 & 3591 & $32 \pi 30$ & 口 & 49 & 200 & 口 & 200 & 口 & 200 & 1447 & Nombal & 130 & 165 & 175 & 165 & 170 & 175 & 960 & 16.4 & 455 \\
\hline \multicolumn{2}{|c|}{ 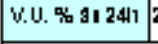 } & $21,16 \%$ & \multicolumn{2}{|c|}{ MédlaI } & 2146 & 0 & 2146 & 783 & 1368 & & & 3580 & 4280 & 3005 & 3410 & 4285 & 3100 & 21410 & & \\
\hline \multicolumn{4}{|c|}{ VAZOES PREVISTAS: } & \multicolumn{4}{|c|}{ WAZOES ANTERORES: } & & & & & \multicolumn{2}{|c|}{$\begin{array}{l}\text { Demanda } \\
\text { Méda }\end{array}$} & \multicolumn{7}{|c|}{ 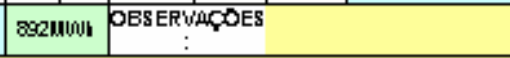 } \\
\hline \multicolumn{3}{|c|}{ Anteite $\left(m^{2} n\right)-$} & 1177 & & inteite Ma & $\operatorname{lng}$ & 2848 & volume & 0 ttlas 06 & $6 \mathbf{1}-$ & $22,4 \%$ & & & & & & & & & \\
\hline Dent & Aueve $\left(m^{\prime}\right.$ & $\left(x^{2}(x)-\right.$ & 2166 & & $\begin{array}{c}\text { Pentieite M } \\
-\end{array}$ & Edta & $110 \mathrm{~s}$ & Plaubme & etroas प & Th - & 0 & & & & & & & & & \\
\hline & & Cas of & : 15 & s:00 & & & & & CaI 15 & 5:00 31 25: & 1י & & & & & & S $28: 000$ & 1 & & \\
\hline & perador Ut & Is $1 \mathrm{sa}$ & & & erador Sts & tema & & erador Usit & & & Ope rad & br Ststen & & & Derador & r Usina & & & erador Sts & ma \\
\hline
\end{tabular}




\section{Programação Linear - Método Simplex}

A programação linear visa fundamentalmente encontrar a melhor solução para problemas que tenham seus modelos representados por expressões lineares. A tarefa da programação linear consiste na maximização ou minimização de uma função linear, sobre um conjunto poliédrico denominado de função objetivo, respeitando-se um sistema linear de igualdade ou desigualdade que recebem o nome de restrições do modelo ou região factível. As restrições representam normalmente limitações de recursos disponíveis ou, então, exigências e condições que devem ser cumpridas no problema. Essas restrições do modelo determinam uma região à qual dá-se o nome de conjunto das soluções viáveis ou admissíveis. O método é principalmente baseado na exploração dos pontos extremos do conjunto das soluções viáveis e nas direções do conjunto poliédrico definido no problema.

A melhor das soluções admissíveis, isto é, aquela que maximiza ou minimiza a função objetivo denomina-se solução ótima. O objetivo da programação linear consiste na determinação dessa solução ótima. Dois passos são fundamentais para a resolução de um problema de programação linear. O primeiro é a modelagem do problema, seguido do método de solução do modelo. 
O modelo matemático que representa a programação linear é freqüentemente apresentado na forma:

Maximizar(Minimizar) $z=c_{1} x_{1}+c_{2} x_{2}+\ldots+c_{N} x_{N}$

Sujeito a :

$$
\begin{array}{r}
a_{11} x_{1}+a_{12} x_{2}+\ldots+a_{1 N} x_{N} \leq b_{1} \\
a_{21} x_{1}+a_{22} x_{2}+\ldots+a_{2 N} x_{N} \leq b_{2} \\
\ldots \\
a_{M 1} x_{1}+a_{M 2} x_{2}+\ldots+a_{M N} x_{N} \leq b_{M} \\
x_{j} \geq 0, j=1,2, \ldots, N
\end{array}
$$

A função maximizar (minimizar), $z=c_{1} x_{1}+c_{2} x_{2}+\ldots+c_{N} x_{N}$, designa-se por função objetivo; as inequações (A3.2) designam-se por restrições funcionais ou simplesmente restrições; as desigualdades (A3.3) designam-se por condições de não negatividade. As variáveis $x_{j}$ são chamadas por variáveis principais, de decisão ou controláveis; as constantes $a_{i j}, b_{i} \mathrm{e} c_{j}$ são chamados de coeficientes técnicos, termos independentes e coeficientes da função objetivo, respectivamente, constituindo os parâmetros do modelo.

Uma forma de resolução de grande utilidade quando se inicia o estudo de programação linear é a representação gráfica dos problemas. O grande inconveniente destas representações é o fato de só serem possíveis quando não estão envolvidas mais de três variáveis, sendo incapazes de resolver problemas de maiores dimensões. Diante desse inconveniente, torna-se necessário utilizar um procedimento analítico suficientemente geral que não restrinja a dimensão do problema.

Como em geral é mais conveniente trabalhar com igualdades do que com desigualdades, o primeiro passo a cumprir com o objetivo de resolver um problema de programação linear consiste em converter as restrições funcionais de desigualdade em 
restrições equivalentes sob a forma de igualdade, obtendo-se assim um sistema de equações lineares. Esse processo é alcançado pela introdução no problema original de novas variáveis, igualmente não negativas, designadas por variáveis auxiliares. Diz-se então que se reduziu o problema original à forma estandardizada. Assim, a redução à forma estandardizada do problema de programação linear pode ser representada por:

$$
\begin{aligned}
& \text { Maximizar(Minimizar) } z=c_{1} x_{1}+c_{2} x_{2}+\ldots+c_{N} x_{N}+c_{N+1} x_{N+1}+\ldots+c_{N+M} x_{N+M} \\
& \text { Sujeito a: } \quad a_{11} x_{1}+a_{12} x_{2}+\ldots+a_{1 N} x_{N}+a_{1, N+1} x_{N+1}=b_{1} \\
& a_{21} x_{1}+a_{22} x_{2}+\ldots+a_{2 N} x_{N} \quad+x_{N+2}=b_{2} \\
& \text {... } \\
& a_{M 1} x_{1}+a_{M 2} x_{2}+\ldots+a_{M N} x_{N} \quad+a_{M, N+M} x_{N+M}=b_{M} \\
& x_{j} \geq 0, j=1,2, \ldots, N, N+1, \ldots, N+M
\end{aligned}
$$

O conjunto das soluções que satisfazem as restrições funcionais (A3.5) e as restrições de não negatividade (A3.6), $K$, de um problema de programação linear é um conjunto convexo fechado. Uma função linear sobre esse conjunto convexo, $K$, atinge o ótimo em um ponto extremo de $K$. O conjunto de pontos extremos de $K$ é finito e para este conjunto existe pelo menos um ponto extremo de $K$ que otimiza a função objetivo.

Um conjunto de $m$ variáveis tais que a matriz dos coeficientes respectivos no sistema de equações lineares (A3.5) seja não singular (isto é, cujo determinante seja não nulo) chama-se base do sistema (A3.5) e as $m$ variáveis por variáveis básicas. As restantes $n-m$ variáveis são designadas por variáveis não básicas. Atribuindo a estas variáveis o valor zero, as variáveis básicas serão então determinadas, designando-se a solução assim obtida por solução básica. Se as variáveis básicas forem não negativas, designa-se por solução básica admissível. 
O problema de programação linear, no caso de $K$ ser um poliedro convexo, é então teoricamente resolvido, pois a investigação exaustiva no conjunto das soluções básicas admissíveis é suficiente. Contudo, na generalidade dos casos de interesse prático, tal procedimento constitui tarefa impraticável. Além disso, no caso de $K$ ser não limitado, o exame exaustivo dos seus pontos extremos não detecta se o problema tem solução não limitada. Torna-se então necessário apresentar um procedimento que permita resolver qualquer problema de programação linear.

É natural que o processo de resolução mais generalizado seja um método iterativo que procura examinar o menor número possível de soluções básicas admissíveis. Um método que permite resolver este tipo de problema é designado por Método Simplex, proposto em 1947 por George B. Dantzig.

O Método Simplex é um procedimento sistemático para solucionar um problema de programação linear por mover de um ponto extremo a um ponto extremo com um melhor valor de função objetivo. Esse processo continua até que um ponto extremo ótimo é alcançado. Para um melhor entendimento do Método Simplex, um exemplo pode ser explorado em RAMALHETE (1984). 
Apêndice 4

\section{Programação Não Linear Aplicada ao Fluxo de Potência Ótimo}

A seguir será apresentado um método de solução do Problema de Fluxo de Potência Ótimo que utiliza técnicas não lineares de otimização.

O problema de Fluxo de Potência Ótimo é um problema de otimização e sua solução determina o melhor ponto de operação do sistema. O referido problema, em sua forma mais geral, pode ser representado matematicamente como:

$$
\begin{array}{ll}
\text { Min } & f(x) \\
\text { s.a.: } & g(x)=0 \\
& \underline{h} \leq h(x) \leq \bar{h} \\
& \underline{x} \leq x \leq \bar{x}
\end{array}
$$

O vetor das variáveis de estado $x$ pode ser representado pela magnitude de tensão $(V)$, pelo ângulo $(\theta)$ e pelo tap dos transformadores (t). A função objetivo $f(x)$ é uma função escalar e representa, para os estudos, as perdas de potência ativa na transmissão.

As restrições de igualdade $g(x)$ são as equações do fluxo de potência obtidas quando se impõe o princípio da conservação de potência em cada barra da rede. As restrições de desigualdade $h(x)$ representam as restrições funcionais, como a 
potência reativa nas barras de controle de reativos, os fluxos ativos e reativos nas linhas de transmissão, o fluxo de intercâmbio, as magnitudes de tensões, etc.

Ao rescrever (A4.1) utilizando as equações de fluxo de potência apresentadas por MONTICELLI (1983), tem-se o seguinte problema de fluxo de potência ótimo:

$$
\begin{array}{lll}
\text { Min } & \sum_{i=1}^{N L} g_{i}\left[V_{k}^{2}+V_{m}^{2}-2 V_{k} V_{m} \cos \theta_{k m}\right] & \\
\text { s.a.: } & P_{k}^{G}-P_{k}^{C}-V_{k} \sum_{m \in k} V_{m}\left(G_{k m} \cos \theta_{k m}+B_{k m} \operatorname{sen} \theta_{k m}\right)=0 & k=1, \ldots, N B C C R \\
& Q_{k}^{G}-Q_{k}^{C}-V_{k} \sum_{m \in k} V_{m}\left(G_{k m} \operatorname{sen} \theta_{k m}-B_{k m} \cos \theta_{k m}\right)=0 & k=1, \ldots, N B C \\
& \underline{Q}_{j} \leq V_{j} \sum_{m \in k} V_{m}\left(G_{k m} \operatorname{sen} \theta_{k m}-B_{k m} \cos \theta_{k m}\right) \leq \bar{Q}_{j} & j=1, \ldots, N B C R \\
& \underline{t}_{i} \leq t \leq \bar{t}_{i} & i=1, \ldots, N T \\
& \underline{V}_{k} \leq V_{k} \leq \bar{V}_{K} & k=1, \ldots, N B
\end{array}
$$

A função objetivo, apresentada pela equação (A4.2), representa as perdas ativas no sistema de transmissão.

Muitas técnicas de otimização para a solução do problema de Fluxo de Potência Ótimo são estudadas. Dentre estas, a técnica primal-dual barreira logarítmica, que utiliza pontos interiores, tem se mostrado uma boa alternativa na solução do problema de Fluxo de Potência Ótimo, GRANVILLE (1994).

\section{A4.1 O Método Primal-Dual Barreira Logarítmica associado ao problema de Fluxo de Potência Ótimo}

A seguir será apresentado o método primal-dual barreira logarítmica (PDBL), proposto por SOUSA (2001) e aplicado ao problema de Fluxo Potência Ótimo representado pela Equação (A4.1). Para a solução deste problema pelo método PDBL 
é necessário que as restrições de desigualdades se tornem igualdades através da adição de variáveis de folga ou excesso, positivas. O problema modificado pode ser rescrito como:

$$
\begin{array}{ll}
\text { Min } & f(x) \\
\text { s.a.: } & g(x)=0 \\
& h(x)+s_{1}=\bar{h} \\
& h(x)-s_{2}=\underline{h} \\
& x+s_{3}=\bar{x} \\
& x-s_{4}=\underline{x} \\
& s_{1}, s_{2}, s_{3}, s_{4} \geq 0
\end{array}
$$

Estas variáveis são incorporadas à função objetivo através da função barreira logarítmica. Assim, o problema (A4.3) passa a ser rescrito da seguinte forma:

$$
\begin{array}{ll}
\text { Min } & \left\{f(x)-\mu \sum_{i=1}^{N B C R} \ln \left(s_{1 i}\right)-\mu \sum_{i=1}^{N B C R} \ln \left(s_{2 i}\right)-\mu \sum_{i=1}^{N B} \ln \left(s_{3 i}\right)-\mu \sum_{i=1}^{N B} \ln \left(s_{4 i}\right)\right\} \\
\text { s.a.: } & g(x)=0 \\
& h(x)+s_{1}=\bar{h} \\
& h(x)-s_{2}=\underline{h} \\
& x+s_{3}=\bar{x} \\
& x-s_{4}=\underline{x}
\end{array}
$$

Sendo $\mu$ o parâmetro de barreira, positivo, que tende a zero durante o processo de otimização, isto é, $\mu_{0}>\mu_{1}>\mu_{2}>\ldots>\mu_{\infty}=0$.

A partir do problema restrito, representado por (A4.4), constrõe-se a função Lagrangiana, como mostrado a seguir:

$$
\begin{aligned}
L= & f(x)-\mu \sum_{i=1}^{N B C R} \ln \left(s_{1 i}\right)-\mu \sum_{i=1}^{N B C R} \ln \left(s_{2 i}\right)-\mu \sum_{i=1}^{N B} \ln \left(s_{3 i}\right)-\mu \sum_{i=1}^{N B} \ln \left(s_{4 i}\right)-\lambda^{t} g(x) \\
& -\pi_{1}\left(h(x)+s_{1}-\bar{h}\right)-\pi_{2}\left(h(x)-s_{2}-\underline{h}\right)-\pi_{3}\left(x+s_{3}-\bar{x}\right)-\pi_{4}\left(x-s_{4}-\underline{x}\right)
\end{aligned}
$$


Sendo $\lambda, \pi_{1}, \pi_{2}, \pi_{3}$ e $\pi_{4}$ vetores dos multiplicadores de Lagrange.

Aplicando as condições de ótimo em (A4.5), obtém-se o seguinte sistema de equações:

$$
\begin{aligned}
& \nabla_{x} L=\nabla_{x} f(x)-\nabla_{x} g(x)^{t} \lambda-\nabla_{x} h(x)^{t} \pi_{1}-\nabla_{x} h(x)^{t} \pi_{2}-\pi_{3}-\pi_{4} \\
& \nabla_{\lambda} L=-g(x)=0 \\
& \nabla_{\pi_{1}} L=-\left(h(x)+s_{1}-\bar{h}\right)=0 \\
& \nabla_{\pi_{2}} L=-\left(h(x)-s_{2}-\underline{h}\right)=0 \\
& \nabla_{\pi_{3}} L=-\left(x+s_{3}-\bar{x}\right)=0 \\
& \nabla_{\pi_{4}} L=-\left(x-s_{4}-\underline{x}\right)=0 \\
& \nabla_{s_{1}} L=-\mu S_{1}^{-1} e-\pi_{1}=0 \\
& \nabla_{s_{2}} L=-\mu S_{2}^{-1} e+\pi_{2}=0 \\
& \nabla_{s_{3}} L=-\mu S_{3}^{-1} e-\pi_{3}=0 \\
& \nabla_{s_{4}} L=-\mu S_{4}^{-1} e+\pi_{4}=0
\end{aligned}
$$

Sendo $e=(1,1, \ldots, 1)^{t}, \quad S_{1}, S_{2}, S_{3}, S_{4}$ matrizes diagonais, cujos elementos são $s_{1}, s_{2}, s_{3}, s_{4}$, respectivamente e $\nabla f(x)$ é o gradiente de $f(x)$.

\section{A4.1.1 O Método de Newton}

O método de Newton é utilizado com o intuito de solucionar o sistema de equações (A4.6) a (A4.15). Este método utiliza a expansão em série de Taylor até primeira ordem das equações do sistema, e gera as direções de busca $\left(\Delta x, \Delta \lambda, \Delta \pi_{1}, \Delta \pi_{2}, \Delta \pi_{3}, \Delta \pi_{4}, \Delta s_{1}, \Delta s_{2}, \Delta s_{3}, \Delta s_{4}\right) \quad$ que serão utilizadas para a atualização das variáveis do sistema. Desta forma, as equações de Newton para se obterem as direções são as seguintes: 


$$
\begin{aligned}
& W\left(x, \lambda, \pi_{1}, \pi_{2}\right) \Delta x-\nabla_{x} g(x)^{t} \Delta \lambda-\nabla_{x} h(x)^{t} \Delta \pi_{1}-\nabla_{\chi} h(x)^{t} \Delta \pi_{2}-\Delta \pi_{3}-\Delta \pi_{4}=-\nabla_{x} L \\
& -\left(\nabla_{x} g(x)\right) \Delta x=-\nabla_{\lambda} L \\
& -\left(\nabla_{x} h(x) \Delta x+\Delta s_{1}\right)=-\nabla_{\pi_{1}} L \\
& -\left(\nabla_{\chi} h(x) \Delta x-\Delta s_{2}\right)=-\nabla_{\pi_{2}} L \\
& -\left(\Delta x+\Delta s_{3}\right)=-\nabla_{\pi_{3}} L \\
& -\left(\Delta x-\Delta s_{4}\right)=-\nabla_{\pi_{4}} L \\
& \mu S_{1}^{-2} \Delta s_{1}-\Delta \pi_{1}=-\nabla_{s_{1}} L \\
& \mu S_{2}^{-2} \Delta s_{2}+\Delta \pi_{2}=-\nabla_{s_{2}} L \\
& \mu S_{3}^{-2} \Delta s_{3}-\Delta \pi_{3}=-\nabla_{s_{3}} L \\
& \mu S_{4}^{-2} \Delta s_{4}+\Delta \pi_{4}=-\nabla_{s_{4}} L
\end{aligned}
$$

Rescrevendo (A4.16) na forma matricial, tem-se:

$\left[\begin{array}{cccccccccc}W\left(x, \lambda, \pi_{1}, \pi_{2}\right) & -J(x)^{t} & -\nabla_{x} h(x)^{t} & -\nabla_{x} h(x)^{t} & -I & -I & 0 & 0 & 0 & 0 \\ -J(x) & 0 & 0 & 0 & 0 & 0 & 0 & 0 & 0 & 0 \\ -\nabla_{x} h(x) & 0 & 0 & 0 & 0 & 0 & -I & 0 & 0 & 0 \\ -\nabla_{x} h(x) & 0 & 0 & 0 & 0 & 0 & 0 & I & 0 & 0 \\ -I & 0 & 0 & 0 & 0 & 0 & 0 & 0 & -I & 0 \\ -I & 0 & 0 & 0 & 0 & 0 & 0 & 0 & 0 & I \\ 0 & 0 & -I & 0 & 0 & 0 & \mu S_{1}^{-2} & 0 & 0 & 0 \\ 0 & 0 & 0 & I & 0 & 0 & 0 & \mu S_{2}^{-2} & 0 & 0 \\ 0 & 0 & 0 & 0 & -I & 0 & 0 & 0 & \mu S_{3}^{-2} & 0 \\ 0 & 0 & 0 & 0 & 0 & I & 0 & 0 & 0 & \mu S_{4}^{-2}\end{array}\right]\left[\begin{array}{c}\Delta x \\ \Delta \lambda \\ \Delta \pi_{1} \\ \Delta \pi_{2} \\ \Delta \pi_{3} \\ \Delta \pi_{4} \\ \Delta s_{1} \\ \Delta s_{2} \\ \Delta s_{3} \\ \Delta s_{4}\end{array}\right]=-\left[\begin{array}{c}\nabla_{x} L \\ \nabla_{\lambda} L \\ \nabla_{\pi_{1}} L \\ \nabla_{\pi_{2}} L \\ \nabla_{\pi_{3}} L \\ \nabla_{\pi_{4}} L \\ \nabla_{s_{1}} L \\ \nabla_{s_{2}} L \\ \nabla_{s_{3}} L \\ \nabla_{s_{4}} L\end{array}\right]$

Sendo:

$W\left(x, \lambda, \pi_{1}, \pi_{2}\right)=\nabla^{2} f(x)-\sum_{i=1}^{2 \times N B} \lambda_{I} \nabla^{2} g_{i}(x)-\sum_{i=1}^{N B C R} \pi_{1 i} \nabla^{2} h(x)-\sum_{i=1}^{N B C R} \pi_{2 i} \nabla^{2} h(x) ;$

$J(x)=\nabla_{x} g(x)$, a matriz Jacobiana do fluxo de carga convencional;

I , a matriz identidade.

Pode-se escrever $W\left(x, \lambda, \pi_{1}, \pi_{2}\right)$ na forma matricial:

$$
W=\left[\begin{array}{lll}
\frac{\partial^{2} L}{\partial t^{2}} & \frac{\partial^{2} L}{\partial t \partial \theta} & \frac{\partial^{2} L}{\partial t \partial V} \\
\frac{\partial^{2} L}{\partial \theta \partial t} & \frac{\partial^{2} L}{\partial \theta^{2}} & \frac{\partial^{2} L}{\partial \theta \partial V} \\
\frac{\partial^{2} L}{\partial V \partial t} & \frac{\partial^{2} L}{\partial V \partial \theta} & \frac{\partial^{2} L}{\partial V^{2}}
\end{array}\right]
$$

O sistema matricial (A4.17) pode ser representado da seguinte maneira: 


$$
L a * \Delta d=-\nabla L
$$

Sendo $L a$ a matriz Lagrangiana; $\Delta d$ o vetor das direções de busca; e $\nabla L$ o vetor gradiente.

\section{A4.1.2 Matriz Lagrangiana}

A matriz Lagrangiana ( $L a)$, do sistema (A4.17), é esparsa, ou seja, possui muitos elementos nulos, e esta característica deve ser explorada no processo de solução do sistema. A dimensão da matriz Lagrangiana ( $L a)$, construída devido à aplicação do método primal-dual barreira logarítmica para a solução do problema (A4.1) é maior que a dimensão da matriz utilizada nos métodos de Penalidade de Newton, entre outros. Nestes métodos o sistema a ser resolvido é apenas uma parte do sistema dado em (A4.17), isto é:

$$
\left[\begin{array}{cc}
W(x, \lambda) & -J(X)^{t} \\
-J(X) & 0
\end{array}\right]\left[\begin{array}{l}
\Delta x \\
\Delta \lambda
\end{array}\right]=-\left[\begin{array}{c}
\nabla_{x} L \\
\nabla_{\lambda} L
\end{array}\right]
$$

A matriz Lagrangiana em (A4.17) tem dimensão total $(\mathrm{N})$ dada por:

$$
N=8 * N B+3 * N B C R+5 * N T-3
$$

Esta matriz possui elementos unitários e as submatrizes referentes às variáveis de folga são de fácil implementação. Assim, o esforço computacional necessário para a obtenção de (A4.17) não é muito elevado, quando comparado com os métodos que utilizam a expressão (A4.20). 


\section{A4.1.3 Tamanho do Passo e Atualização das Variáveis}

Conhecendo as direções de busca, a próxima etapa é calcular os passos $\alpha_{p} \mathrm{e} \alpha_{d}$, que serão usados na atualização das variáveis primais e duais respectivamente. Estes passos são calculados de maneira que cada componente das variáveis de folga ou excesso primais $\left(s_{i}, i=1,2,3,4\right)$ permaneçam estritamente positivas, e que os elementos do vetor $\left(\pi_{i}, i=1,2,3,4\right)$ permaneçam com os seus respectivos sinais, isto é, $\pi_{1}<0, \pi_{2}>0, \pi_{3}<0, \pi_{4}>0$.

Esse processo é feito encontrando-se o menor elemento entre o mínimo tamanho de passo de todos os componentes dos vetores. Em seguida este menor elemento é multiplicado por um fator $\sigma$, menor que “1”, que garante que o próximo ponto irá satisfazer as condições de positividade e, então, comparado com o valor “ 1 ”, o menor entre eles é escolhido como tamanho do passo primal ou dual.

Isso se traduz por:

$$
\begin{aligned}
& \alpha_{p}=\min \left\{\sigma\left(\min _{\Delta S_{1}<0} \frac{s_{1}}{\left|\Delta S_{1}\right|}, \min _{\Delta S_{2}<0} \frac{s_{2}}{\left|\Delta S_{2}\right|}, \min _{\Delta S_{3}<0} \frac{s_{3}}{\left|\Delta S_{3}\right|}, \min _{\Delta S_{4}<0} \frac{s_{4}}{\left|\Delta S_{4}\right|}\right), 1\right\} \\
& \alpha_{d}=\min \left\{\sigma\left(\min _{\Delta \pi_{1}>0} \frac{-\pi_{1}}{\left|\Delta \pi_{1}\right|}, \min _{\Delta \pi_{2}<0} \frac{\pi_{2}}{\left|\Delta \pi_{2}\right|}, \min _{\Delta \pi_{3}>0} \frac{-\pi_{3}}{\left|\Delta \pi_{3}\right|}, \min _{\Delta \pi_{4}<0} \frac{\pi_{4}}{\left|\Delta \pi_{4}\right|}\right), 1\right\}
\end{aligned}
$$

Sendo $\sigma=0,9995$ um valor determinado empiricamente.

Conhecendo as direções de busca e os passos primais e duais respectivamente, todas as variáveis do problema podem ser atualizadas por: 


$$
\begin{array}{ccrl}
x & =x+\alpha_{p} \Delta x & \lambda & =\lambda+\alpha_{d} \Delta \lambda \\
s_{1} & =s_{1}+\alpha_{p} \Delta s_{1} & \pi_{1}=\pi_{1}+\alpha_{d} \Delta \pi_{1} \\
s_{2}=s_{2}+\alpha_{p} \Delta s_{2} & \pi_{2}=\pi_{2}+\alpha_{d} \Delta \pi_{2} \\
s_{3}=s_{3}+\alpha_{p} \Delta s_{3} & \pi_{3}=\pi_{3}+\alpha_{d} \Delta \pi_{3} \\
s_{4}=s_{4}+\alpha_{p} \Delta s_{4} & \pi_{4}=\pi_{4}+\alpha_{d} \Delta \pi_{4}
\end{array}
$$

\section{A4.1.4 O Parâmetro de Barreira}

Uma etapa muito importante no algoritmo primal-dual barreira logarítmica é a escolha inicial do parâmetro de barreira. O valor do multiplicador $\mu$ para cada ponto é proporcional ao gap de dualidade. Este gap é a diferença entre o valor da função objetivo do problema primal e o valor da função objetivo do problema dual. A cada iteração o valor de $\mu$ deverá ser calculado de tal forma que o seu valor atual seja sempre inferior ao anterior e, desta forma, é proposto um cálculo para atualização de $\mu$, utilizando a equação (A4.25), na qual o numerador corresponde ao gap de dualidade:

$$
\mu=\frac{-\left(s_{1} \pi_{1}+s_{3} \pi_{3}\right)+\left(s_{2} \pi_{2}+s_{4} \pi_{4}\right)}{2^{*} N B^{*} \beta}
$$

Sendo $\beta>1$ e especificado pelo usuário.

Como visto em (A4.25) o parâmetro $\mu$ é reduzido a cada iteração de forma empírica, pois o valor de $\beta$ é determinado pelo usuário. Uma escolha inadequada do parâmetro $\beta$ poderá comprometer a convergência do método. Outra forma para atualizar o parâmetro $\mu$ é reduzi-lo a cada iteração de um valor $\beta^{\prime}$,GRANVILLE (1994), especificado pelo usuário, isto é: 


$$
\mu^{(k+1)}=\frac{\mu^{k}}{\beta}
$$

\section{A4.1.5 Inicialização das Variáveis}

Com respeito aos valores iniciais das variáveis, a única exigência que deve ser observada é que as variáveis do sistema, ou seja, as tensões, os taps e as injeções de reativos devem estar dentro de seus limites pré-estabelecidos. As equações de balanço do sistema e as inequações, que foram transformadas em equações através da inclusão das variáveis de folga ou excesso, não precisam ser satisfeitas na inicialização do problema. As variáveis de folga ou excesso $\left(s_{i}, i=1,2,3,4\right)$ podem ser inicializadas utilizando as equações (A4.8) a (A4.11) respectivamente.

Estas variáveis devem ser estritamente positivas. Isto é esperado desde que as variáveis do sistema estejam dentro de seus limites, porém, caso exista algum componente deste vetor, que seja nulo ou negativo, o mesmo poderá assumir o valor 0,02. Após terem sido inicializados os vetores referentes às variáveis de folga, os vetores dos multiplicadores de Lagrange $\left(\pi_{i}, i=1,2,3,4\right)$ podem ser inicializados utilizando-se as equações (A4.12) a (A4.15), respectivamente. E os vetores dos multiplicadores de Lagrange para as restrições de igualdades $(\lambda)$ são sempre inicializados em zero. O valor inicial do parâmetro de barreira e o multiplicador $\beta$ para atualização de $\mu$ são determinados pelo usuário, como mencionado anteriormente. 